\title{
Making sense of psychotic experiences
}

Citation for published version (APA):

Escher, A. D. M. A. C. (2005). Making sense of psychotic experiences. [Doctoral Thesis, Maastricht University]. s.n.]. https://doi.org/10.26481/dis.20050519ae

Document status and date:

Published: 01/01/2005

DOI:

10.26481/dis.20050519ae

Document Version:

Publisher's PDF, also known as Version of record

\section{Please check the document version of this publication:}

- A submitted manuscript is the version of the article upon submission and before peer-review. There can be important differences between the submitted version and the official published version of record.

People interested in the research are advised to contact the author for the final version of the publication, or visit the DOI to the publisher's website.

- The final author version and the galley proof are versions of the publication after peer review.

- The final published version features the final layout of the paper including the volume, issue and page numbers.

Link to publication

\footnotetext{
General rights rights.

- You may freely distribute the URL identifying the publication in the public portal. please follow below link for the End User Agreement:

www.umlib.nl/taverne-license

Take down policy

If you believe that this document breaches copyright please contact us at:

repository@maastrichtuniversity.nl

providing details and we will investigate your claim.
}

Copyright and moral rights for the publications made accessible in the public portal are retained by the authors and/or other copyright owners and it is a condition of accessing publications that users recognise and abide by the legal requirements associated with these

- Users may download and print one copy of any publication from the public portal for the purpose of private study or research.

- You may not further distribute the material or use it for any profit-making activity or commercial gain

If the publication is distributed under the terms of Article $25 \mathrm{fa}$ of the Dutch Copyright Act, indicated by the "Taverne" license above, 


\section{MAKING SENSE OF PSYCHOTIC EXPERIENCES}

\section{PROEFSCHRIFT}

ter verkrijging van de graad van doctor aan de universiteit Maastricht

op gezag van de Rector Magnificus,

Prof.mr.G.P.M.F.Mols

volgens het besluit van het college van Decanen

in het openbaar te verdedigen op

donderdag 19 mei 2005 om 14.00 uur

door

Alexandre, Dorothée, Marie, Adrienne, Charlotte Escher 
Promotoren

Prof. dr. J.J.van Os

Prof. dr. M.A.J. Romme

Co-promotor

Dr. Ph.A.E.G.Delespaul

Beoordelingscommissie

Prof. dr. M. de Vries (voorzitter)

Prof. dr. R.P. Bentall (University of Manchester)

Prof. dr. J. Jolles

Prof. dr. H. Katchnig (Universitätsklinik für Psychiatrie, Wien)

Prof. dr. M. M.W. Richartz

ISBN - 9056812181

M.C. Escher's "Relativity" 2005 The M.C. Escher Company - the Nethetherlands.

All rights reserved.

The studies described in this thesis were carried out at the department of Psychiatry and Neuropsychology, Maastricht University in cooperation with the RIAGG, Maastricht department of Social Psychiatric Services (SPD) . The first years they were funded by the Praevention fund, later by ZON. 
Aan Marius, Diederik en Rutger 



\section{Contents}

Introduction: The development of the hearing voices studies

Chapter 1: Hearing voices and its historical course

Chapter 2 : $\quad$ Hearing voices

Chapter 3: Coping with voices: an emancipatory approach

Chapter 4: Independent course of childhood auditory hallucinations:

a sequential 3-year follow-up study

Chapter 5: Formation of delusional ideation in adolescents hearing voices:

a prospective study

Chapter 6: $\quad$ Coping defence and depression in adolescents hearing voices. 79

Chapter 7: Determinants of outcome in the pathways through care for children hearing voices

Chapter 8: $\quad$ Maastricht Interview with a child hearing voices:

interview and frequencies

Chapter 9 : Stimmenhören bei Kindern

Chapter 10 : Trauma and hearing voices

Chapter 11: Epilogue

Chapter 12: Summary

Samenvatting

Chapter 13: Dankwoord

Curriculum vitae

Chapter 14: Publications 



\section{Introduction}

The development of the hearing voices studies 


\section{Introduction}

This study will give evidence that the experience of hearing voices must be seen in a broader context than individual psychopathology. The restricted view that hearing voices is a symptom of an illness has become disabling for all people with this experience, both for patients as well as for people who can cope well with their voices and use the experience positively. The generally accepted but restricted view of voices as symptoms creates a taboo that reduces the freedom of people to talk about their experience, because it is all too readily assumed to be a sign of mental illness.

This study is part of a programme that promotes the acceptance of voice hearing. The primary aim of this approach is to make explicit the relationship between individual history and the voices; to take the experience out of the realm of psychopathology and put it into the context of people's life-problems and their personal philosophy (Romme \& Escher, 1989, 1993, 1996; Romme, 1996; Pennings et al. 1996; Honig et al. 1998). In this thesis a research study is presented in which 80 children who hear voices were followed up over a period of 3 years. The experience itself was explored, alongside the relation with the life-history, factors influencing the continuity of this experience and the effectiveness of care.

\section{Evidence of the negative attitude towards voice hearing}

Hearing voices in West European societies is mostly associated with psychopathology, a belief that is specifically held by psychiatric professionals who interpret these experiences as a symptom of an illness. Also linked to this view is the belief that listening to the content of voices increases the hearer's undesirable fixation on this 'unreal' world, the voices being regarded as unreal because they cannot be heard by anyone other than the voice hearer. Thus the psychiatric assumptions about the individual with this experience cannot be very optimistic, and indeed hearing voices is mostly associated with the diagnosis of schizophrenia, a poor prognoses (cessation of the voice hearing experience), a life long experience of illness and not being fully in control of oneself. Blom (2003) describes how strong this believe is embedded.

'Schizophrenia is acknowledged to be one of the most serious and disabling disorders that plague humankind. According to the World health Organisation, it ranks among the ten leading causes of disability worldwide. It effects about one per cent of all human beings, most 
in the prime of life, interrupting their further development, breaking up families and marriages, ruining their careers, and causing one out of ten people with the diagnosis to commit suicide, It may be impossible to rank various kind of suffering, but schizophrenia is certainly one of the worst human afflictions' (Blom , 2003. p. 10)

This negative set of beliefs connected to voice hearing has become rooted not only in psychiatric practice but in public opinion as well, despite research such as Bleuler (1978), Huber et al. (1975), Harding (1986) and Ciompi (1980) and 'user' (of psychiatric services) literature (de Jong, 1997; Coleman, 1996; O’Hagan, 1993; Read \& Reynolds, 1996) contradicting this idea showing that people do recover from 'schizophrenia'). Recently psychiatric opinion has become more openly divided, with some expert opinion asserting that the disease 'schizophrenia' is of questionable scientific validity (van Praag,1993; Bentall,1990; Boyle,1990; Hoofdakker, 1995; Jenner et al., 1993; Ross \& Pam, 1995; Thomas, 1997; Blom, 2003; van Os \& McKenna, 2003). None of the implications of these challenging studies have so far been taken into account in the organisation of mainstream mental health services.

Public opinion parallels psychiatric belief, and this can be illustrated by looking at media reporting. Leudar and Thomas (2000) conducted research about the way newspapers report on hearing voices. They concluded that:

'The tie between hearing voices, mental illness and violence was a major recurrent theme in the British newspapers between 1993 and 1996.' (p.151).

It is not only the believed association with violence that is harmful, but the use of this kind of information is even more alarming.

'We have seen how Members of Parliament used cases of people with mental illness who committed violent deeds to justify their arguments and the need for legislative change, and these cases were composed by journalists using the phenomenon of hearing voices. In journalists' writing, hearing voices was typically (but not exclusively) presented as a symptom of mental illness and a concomitant of unreasoned violence'(Leudar and Thomas, 2000. p. 172). 
Acceptance of this general view about voices inevitably extends to popular literature, for example in general reference books and encyclopaedias such as Routledge (2000) and the Winkler Prince (2002), in which hearing voices is explained as evidence of either 'schizophrenia' or 'borderline' or a cantata (a medieval kind of singing).

There appears to be no room for normality despite many epidemiological studies (Sidgewick, 1898; Posey \& Losch, 1983-84; Bentall \& Slade, 1985; Posey, 1986; Tien, 1991; Eaton et al., 1991; Barret \& Etheridge, 1992; Bijl et al. 1998) showing that about two to four percent of the general population hear voices with the characteristics of auditory hallucinations. These studies suggest that about one third of these people take a course of action that leads to seeking help. Most voice hearers therefore do not take a course of action where their experience comes to be regarded formally as an illness. These relatively simple to understand research findings cannot be found in information that is available for the general public, including the media and popular art forms. There is no acceptance of any other view about voices than to regard them as abnormal, undesirable and unacceptable. Western European societies attitude toward voice hearing makes the open admission and discussion of such experiences taboo.

\section{Research setting}

The children's study developed as part of the programme of six studies into auditory hallucinations. The programme has been running since 1986 at the Department of Social Psychiatry at the University of Maastricht.

- The first study was an experiment in which people with auditory hallucinations were brought into contact with each other: Publications; Romme \& Escher (1987) Hearing voices Schizophrenia Bulletin, vol. 15 (2) 209-16;

Romme,M., Honig,A.,Noorthoorn,E.O.,Escher,A.D.M.A.C (1992).Coping with voices: an Emancipatory Approach . British Journal of Psychiatry, (161) 99-103.

- The second study consisted of intensive case studies of 26 patients and non-patients experiencing auditory hallucinations. Publications: Romme \& Escher (1989). the book 'Stemmen horen accepteren'. This book has been translated into English as 'Accepting Voices'(1993) London: Mind; into German (1997), Italian (1997), Portuguese (1997), 
Finish (1997), Russian (1998) and is in the process of translation into the Czech language.

- The third study was a systematic comparison of patients and non-patients experiencing auditory hallucinations. (Romme, 1996; Pennings et al. 1996; Romme,1996; Escher et all , 1996, Honig et al. 1998.).

- The fourth study was on the relationship between voices, trauma and life history, and also on adequate interventions for voice hearers. Publications: Romme \& Escher (1999). the book 'Omgaan met stemmenhoorders', translated and published into English 'Making sense of voices' (2000) by Mind, London. This book has been translated into Swedish (2003), Danish (2003) and is in the process of being translated into Spanish. At the University of Central England this book has been used since 2001 as part of an Honours.

- The fifth study is the subject of this thesis: a 3-year follow-up study of 80 children between 8 and 19 years of age. (Escher et al.,2002a; 2002b; 2003;2004)

- The sixth study, on recovery from voice hearing, is still running. This study will contain the anthologies of 50 voices hearers who learned to cope with their voices and are able to reflect on the process of coping and the relation with their life history.

The research setting is based within an intellectual environment that has its foundations in social psychiatry theory, practice and research (Romme et al., 1981). According to social psychiatry, mental illness is an expression of a person's inability to function in society. The illness behaviour (the symptoms and experiences) is regarded as a reaction to overwhelming social problems and personal interactions with which the person has not been able to cope. There are many reasons why people might be vulnerable to such stresses, but they vary enormously from individual to individual. People become ill because their 'symptoms', in combination with their unsolved problems, prevent them from leading a normal life. This relationship between environment and experience is well established in the various diagnostic categories subsumed under 'neurotic disorders', but less so in psychosis. 
Throughout the research it was hypothesised that hearing voices (defined as a psychotic phenomenon in clinical psychiatry) functions as a reaction pattern when someone is not coping with social and emotional problems, that makes them feel extremely powerless.

From this setting Marius Romme, Professor of Social Psychiatry at the Maastricht University and myself Sandra Escher, organised the first congress ever held for people hearing voices in Utrecht in 1987. I was at that time working as a science journalist and editor at the Department of Social Psychiatry at the Maastricht University and as a senior staff member of the Community Mental Health Centre in Maastricht. The interest in the experience of voice hearing had been stimulated by a patient of Marius Romme, who challenged him to accept her voices as real, something that at that moment, was not common in the daily practice of psychiatry. As a consequence of accepting her voices, he proposed that she should learn to cope with them. This was first tried out with a number of settings in which patients talked with each other about their voices, but non of them were able to cope with their voices. Romme therefore looked for ways to get in touch with other voice hearers who had learned to cope with their experiences and could talk about them. As an experienced journalist I suggested that appearing on a television talk show might present an opportunity to get in touch with such people. We approached the popular Dutch television presenter Sonja Barend to provide a timeslot on her programme to present our problem of how to cope with hearing voices. The patient who challenged Professor Romme to accept her voices as real told her story, and Romme explained that psychiatry had not much to offer to people like her. My role was to prepare the interviewer, interviewees and programme staff about the focus of the discussion, and we also announced that we would organise a congress strictly for people hearing voices.

The amount of people responding to this programme (about 700), patients as well as nonpatients (people who had never been received care because of the voices) was the start of the challenging Maastricht line of research in which non-patients were involved. Because of the great number of responses we sent out a questionnaire developed from the issues voice hearers told about when they telephoned after the television show. This questionnaire was sent to 450 addresses of those people who had explained over the telephone that they heard voices themselves. This included a question asking for an explanation of their voice experience. We had in mind to invite to the congress as speakers those people who were able to explain clearly their experience, and consequently a small group were invited for an interview and we helped them to prepare their talk. When we met with these people it was our 
first contact with voice hearers who had never been psychiatric patients, and who could cope with their voices and function well in their daily lives.

After the congress we developed a study protocol for comparing patients with non-patients in order to get homogeneous information about the differences and the similarities between the two groups. We planned to study one group of patients who had been diagnosed with 'schizophrenia', one group of patients diagnosed with 'dissociative disorder', and one groups of non-patients (people who did not look for help and could not be given a diagnoses with the psychiatric diagnostic instrument that was used. -- CIDI, Robins et al. ,1988). This psychiatric instrument measures symptoms and relates these to the DSM III illness categories.

The main research instrument for this study was the Maastricht interview for people hearing voices, that was developed following an analysis of the description of experiences and explanations offered by our initial sample. This Maastricht interview was used in the children's study as well.

Our accepting voices programme provided a means to inform patients as well as professionals about our approach, and to this end we organised 7 annual congresses during the course of the study. The contact with the many voice hearers made it possible to gain more knowledge about the experience. I was able to write anthologies, stories of people's experiences with voices; their ways of coping, their explanations for the voices, the meaning for the voices in their lives etc. I made 26 anthologies together with the voice hearers (published in Accepting Voices, Romme \& Escher, 1993).

Several researchers participated in the programme, with Professor Romme as the principle investigator. The other participants were Alex Buiks, M.A., psychologist; Dirk Corstens, M.A., psychiatrist, Bernadine Ensink, M.A.PhD, psychologist, Adrian Honig, M.D, PhD., psychiatrist; Eric Noordhoorn, M.D. PhD, psychiatrist, Monique Pennings,M.A., psychologist, and myself, Sandra Escher.MPhil.

Around the time of our first paper (Romme \& Escher, 1987), the first epidemiological study using a psychiatric diagnostic instrument had started that collected evidence about the prevalence of hearing voices in the normal population, identifying that between 2 to $4 \%$ of the 'normal' population heard voices and only one third of them were in need of psychiatric care (Tien, 1991; Eaton, 1991; chapter 3). 
Other researchers such as Bentall et al. (1994), Haddock and Slate (1996), Chadwick \& Birchwood (1996), Birchwood et al. (2000), Kingdon \& Turkington (1991, 2002) demonstrated that people could learn to cope with their voices, which complemented the findings of the Maastricht studies, suggesting that the psychiatric approach within a disease model conceptual framework was not helpful in stimulating people in the process of coping.

In the adult studies about $10 \%$ of the voice hearers started to hear voices in childhood and the onset of voice hearing was frequently related to trauma (about $70 \%$ ), often in childhood. As about $10 \%$ of the voice hearers indicated that their experience started in childhood, it raised questions about the natural development of voice hearing. To gain information about this question I was given resources to organise a congress for children who hear voices in Amsterdam in 1993. As with the adult congress the intention was to get in touch with children hearing voices. The significant response (about 150) led to an application for a research grant from a governmental research organization called 'The Prevention Fund', who awarded a full grant.

\section{Justification}

Auditory hallucinations are mostly seen as a symptom of an illness. This study is based on the assumption (supported by literature) that auditory hallucinations must not necessarily be understood as pathological, and therefore not necessarily approached as a psychiatric disorder as a starting point. However when voices cause distress and interfere with daily life, health care might be necessary in order to get control of the voices and relate them to the problems in the present and the past. In order to understand the contemporary view on hearing voices and the possibilities to changing of attitude, a review of the political and cultural changes in history that lead to the current ideas is needed. In Chapter 2 the history of the concept of auditory hallucinations is explained. Chapter 3 contains the first article on the hearing voices project from the described line of thinking. Hearing voices (Schizophrenia Bulletin, 1987; 15 (2). 209-216. p. 209-216) the experience of the experiment in which voice hearers were brought together.

Throughout our work it became more and evident that accepting voices and learning to cope with them required and emancipatory approach. Chapter 3 contains the article 'Coping with voices: an emancipatory approach (British Journal of Psychiatry. 1992.; 161. 99-103). As 
described above, the research and all the contacts with adults hearing voices were the reason for the children's research.

Chapters 4, 5,6,7 and 8 contain published articles on the children's research. Chapter 4 'Independent course of childhood auditory hallucinations: a sequential 3-year follow-up study (2002. British Journal of Psychiatry . 181 (suppl. 43), s10-s18). Chapter 5 'Formation of delusional ideation in adolescents hearing voices: a prospective study (2002. American Journal of Medical Genetics. 114:913-920). Chapter 6 'Coping defence and depression in adolescents hearing voices (2003. Journal of mental Health. 12,1,91-99).

In the research patients as well as non-patients participated. In chapter 7 'Determinants of outcome in the pathways through care for children hearing voices are described (International Journal of Social Welfare, 2004:13:208-222). Chapter 8 contains the translated Dutch article 'Het Maastrichtse Interview voor Kinderen en Jeugdigen (MIK)' published in Tijdschrift van de Vereniging voor Kinder- en jeugdpsychotherapie, jaargang 29, nr. 4, 2002. It gives an overview of the data of each of the items form the interview. The interview itself is in the appendix. Chapter 9 holds a chapter 'Stimmenhören bei Kindern' published in 'Anstösze Zu einer antropologischen Psychiatrie. Editors. Thomas Bock, Klaus Dörner and Dieter Naber (2004) p. 211-218. Psychiatrie Verlag, Bonn. Germany. In this chapter 3 children who participated in the research are described on case level. Chapter 10 contains the chapter 'Trauma and hearing voices' accepted for the book 'Understanding Trauma and Psychosis: New Horizons for Theory and Therapy'. Editors: Warren Larkin \& Tony Morrison Publisher: Brunner- Routledge, Hove (in press).

Chapter 11 holds the epilogue, chapter 12 contains the Summary and the Dutch translation Samenvatting. In chapter 13 are my Dankwoord, CV and chpater 14 contains the list of publications.

\section{References}

Barrett, T.R., and Etheridge, J.B. (1992) Verbal hallucinations in normals 1: People who hear 'voices'. Applied Cognitive Psychology, 6, 379-387

Bentall, R.P., Slade, P.D. (1985) Reality testing in auditory hallucinations: a signal detection analysis. British Journal of Clinical Psychology, 24, 159-169

Bentall, R.P. (ed) (1990) Reconstructing Schizophrenia (Routledge, London/New York).

Bentall, R.P., Haddock,G., Slade, P.D. (1996) Cognitive behavioural therapy for persistent auditory hallucinations. Behavioural Therapy 25: 51-66

Birchwood,M,Meaden,A.,Trower,P. et al. (2000). The power and omnipotence of voices: subordination and entrapment by voices and significant others. Psychological Medicine.30.337344.

Bleuler,M. (1978).The schizophrenic disorder-Long-term patient and family studies. New Haven and London:Yale University Press. 
Blom, J.D. (2003) Deconstructing schizophrenia; an analysis of the epistemic and nonepistemic values that govern the biomedical schizophrenia concept. Boom, Amsterdam.

Boyle, M. (1990) Schizophrenia - A.Scientific Delusion? London/New York: Routledge

Bijl, R.V., Ravelli, A., Van Zessen. G.,(1998) Prevalence of psychotic disorder in the general population: results from the Netherlands mental health survey and incidence study. Social Psychiatry Epidemiology, 33, 587-596

Chadwick,P.,and Birchwood,M. (1996). 'Cognitive therapy for voices'in Haddock,G.Slade,P. (eds). Cognitive Behavioral Interventions with Psychotic Disorders. Routledge, London/New York.

Ciompi, L. (1980) The natural history of schizophrenia in the long term. British Journal of Psychiatry 136: $413-20$

Coleman, R. (1996) Recovery - an alien concept. Gloucester: Handsell Publishing

Eaton, W.W., Romanonski, A., Anthony, J.C. (1991) Screening for psychosis in the

general population with a self-report interview. Journal of nervous and mental Disease 179, 689-693

Escher et all (1996) 'Maastricht Interview with a person who hears voices' (1996) in Romme,M. 'Understanding voices'. Handsell publications. Gloucester

Escher, A., Romme, M., Buiks, A., Delespaul, Ph., Van Os, J., (2002a) Independent course of childhood auditory hallucinations: a sequential 3-year follow-up study. British Journal of

Psychiatry . 181 (suppl. 43), s10-s18

Escher, A., Romme, M., Buiks, A., Delespaul, Ph., Van Os, J., (2002b) Formation of delusional ideation in adolescents hearing voices: a prospective study. American Journal of Medical Genetics. 114: 913-920

Escher, A., Delespaul, P., Romme, M., Buiks, A., Van Os. J. (2003) Coping defence and depression in adolescents hearing voices. Journal of Mental Health. 12,1,91-99

Escher, A., Morris, M., Buiks, A., Delespaul, Ph., Van Os, J., Romme, M. (2004) Determinants of outcome in the pathways through care for children hearing voices. International Journal of social Welfare. 13, 208-222

Escher,A.D.M. A.C., Romme, M.A.J. (2002) 'Het Maastrichtse Interview voor Kinderen en Jeugdigen (MIK)' published in Tijdschrift van de Vereniging voor Kinder- en jeugdpsychotherapie, jaargang 29, nr. 4, . p.22-45.

Escher,A.D.M.,Romme,M.A.J., (2004) 'Stimmenhören bei Kindern' in 'Anstősze'Zu einer antropologischen Psychiatrie. Editors. Thomas Bock, Klaus Dőrner and Dieter Naber. p. 211218. Psychiatrie Verlag, Bonn. Germany.

Haddock, G., Slade, P.D . (1996) Cognitive Behavioral Interventions with Psychotic Disorders.

London: Routledge

Harding,C.M. (1986). Speculations on the measurement of recovery from severe psychiatric disorder and the human condition. The Psychiatric Journal of the University of Ottawa, Vol. 11, No 4, p. 199-204.

Honig, A., Romme, M.A.J., Ensink, B. Escher, S., Pennings, M., de Vries,M. (1998) Auditory Hallucinations: a comparison between patients and nonpatients. Journal of Nervous and Mental disease 186: 646-651

Hoofdakker, R.H van den (1995) De mens als speelgoed. Bohn Stafleu van Loghum, Houten.

Huber,G.,Gross,G.,Schuttler,R.,Linz,M. (1980). Longitudinal studies of schizophrenic patients. Schizophrenia Bulletin, Vol. 6. NO. 4, p. 592-605. .

Jenner, A. Monteiro, A.C.D., Zargo-Cardoso, J.A., Cunhq-Olievera, J.A. (1993) Schizophrenia, a Disease or some ways of being human. Sheffield Academic Press, Sheffield

Jong, M.de (1997) 60 ways to drop your client Het anti-participatie boekje.Netwerk clientdeskundigen NP/CG, Utrecht

Kingdon, D., Turkington, D. (1991) A role for cognitive-behavioral strategies in Schizophrenia. Social Psychiatry and Psychiatric Epidemiology 26: 101-3

Kingdon, D., Turkington, D. (2002) ed. The case study guide to cognitive behavioural therapy of psychosis. John Wiley \& Sons: Hoboken, USA.

Leudar. I., Thomas, P. (2000). Voices of Reason, voices of insanity. Studies of verbal hallucinations. London and philadephia: Routledge

O’ Hagan, M. (1993) Stopovers on my way Home from Mars. London: Survivors Speak out 
Pennings, M., Romme,M. (1996) Stemmen horen bij schizofrene patienten, patienten met een dissociatieve stoornis en niet-patienten, in: Zin in waanzin. (eds. De hert,M.,Thys,E. Peusekens., Petry, D, van Raay,B. )Babylon-de Geus, Amsterdam. P. 127-140

Praag, H. M. van. (1993) Make-believes in Psychiatry or The Perils of Progress . Brunner/Mazel, New York

Posey, T.B., Losch, M.E. (1984) Auditory hallucinations of hearing voices in 375 normal subjects. Imagination, Cognition and Personality, 3 (2), 99-113

Posey, T.B. (1986) Verbal hallucinations also occur in normals. Behavioural and Brain

Sciences, 9, 530

Read, J., Reynolds, J. (1996) Speaking our minds. An Antopology of personal experiences and its consequences. The Open University/Mcmillan, London

Robins, L.N., Wing. J., Wittchen. H.U. Helzer.J.E.,babor. T.F., Burke. J., Farmer. A., Jablenski. A. Pickens.R., Regier. D.A., Satorius. N., Towle. L.H., (1988) The Composite International Diagnostic Interview: an epidemiologic instrument suitable for use in cogjuntion with different diagnostic systems and in different cultures. Arch Gen Psychiatry ; 45:1069-1077

Routledge (2000) Routledge Encyclopedia of Philosophy, London: Routledge.

Romme, M.A.J., Kraan.H., Rotteveel, R. (1981) Wat is sociale Psychiatrie ? (What is social psychiatry?). Samson Uitgeverij. Alphen aan den Rijn/Brussel.

Romme, M.A.J. \& Escher, A.D.M.A.C. (1989) Hearing voices. Schizophrenia Bulletin, 15, (2), 209-216.

Romme, M.A.J., Honig, A., Noorthoorn, O., Escher, A.D.M.A.C. (1992) Coping with voices: an emancipatory approach. British Journal of psychiatry 161, 99-103.

Romme, M.A.J., Escher, A.D.M.A.C (1993) Accepting voices. London: Mind.

Romme, M.A.J.,Escher , A.D.M.A.C (1996) Empowering people who hear voices. In Cognitive Behavioural Interventions with Psychotic Disorders'. Chapter 8, page 137-150.

Romme M.A.J. (1996) Understanding voices. Handsell publications. Gloucester

Romme, M.A.J., Escher, A.D.M.A.C (1997) Stimmen hören akzeptieren. Psychiatrie-Verlag. Bonn.

Romme, M.A.J., Escher, A.D.M.A.C (1997) Acceptare le voice. Giuffrè editore. Milano

Romme, M.A.J., Escher, A.D.M.A.C (1997) Na compananhia das voces. Editorial Estampa, Lda., Lisboa

Romme, M.A.J., Escher, A.D.M.A.C (1997) Moniääniset. Printway Oy, Vantaa

Romme, M.A.J.,Escher, A.D.M.A.C (1999). Stemmen horen accepteren (eds.) Tirion Uitgevers, Baarn.

Romme, M.A.J., Escher, A.D.M.A.C (2000). Making Sense of voices. London: Mind

Romme, M.A.J., Escher, A.D.M.A.C (2003) Förstå och hantera roster. RSMH. Riksförbundet för Social och Mental Hälsa.Stockholm

Romme, M.A.J., Escher, A.D.M.A.C (2003) Giv stemmerne mening. Systime Academic. Århus.

Romme \& Escher (2005). 'Trauma and hearing voices' in 'Understanding Trauma and Psychosis:

New Horizons for Theory and Therapy'. Editors: Warren Larkin \& Tony

Morrison Publisher: Brunner- Routledge, Hove.

Ross, C.A., Pam, A. (1995) Pseudo Science in Biological Psychiatry. Blaming the body London: Wiley

Sidgewick, H., Johnson, A, Myers, FWH et al (1894) Report on the census of hallucinations.

Proceedings of the Society for Psychical Research, 34, 25-394

Thomas, P. (1997) The Dialectics of Schizophrenia. London/ New York: Free Association Books

Tien, A.Y. (1991) Distributions of hallucination in the population. Social Psychiatry and Psychiatric Epidemiology 26, 287-292

Van Os, J., McKenna, J. (2003) Maudsley Discussion Paper (No.12). London: Maudsley Hospital

Winkler Prince (2002) Encyclopedia. Winkler Prince: Netherlands 
Chapter 1

Hearing voices and its historical course 


\section{Hearing voices and its historical course}

Understanding the phenomenon of hearing voices within the course of history is necessary to be able to understand why this experience must be seen within a broader context. It is relevant to understand the development of a culturally accepted and appreciated experience to the prominent position it currently has within the psychiatric framework. Without truly understanding how the experience slowly shifted into the medical model, with all the implication for the voice hearers, one is not able to be more open minded about voice hearing. In doing so, normalising the experience, one will help the voice hearer to develop and use his/her own resources. The importance of this change of attitude has been shown in our work in promoting the emancipatory approach for voice hearers.

This chapter does not attempt to provide a complete overview of the history of voice hearing. A whole book would be required to do it credit and several authors have already reviewed the relevant literature for different purposes and from different frames of reference (Slade \& Bentall, 1988; Thomas, 1997; Watson, 1998). On the other hand, neglecting this completely would not be helpful in understanding the background and rationale for the present study.

Hearing voices has been reported throughout history, from the ancient civilisations of Egypt, Rome, Babylon, Tibet and Greece until the modern day (Watson, 1998). In these earliest societies positive voices were commonly reported. It was believed that, at certain sacred sites, it was possible to obtain advice and guidance for important decisions from the voice of a God. In later times it was more common that these divine messages were mediated through appointed priests or priestesses. The earliest well-known voice hearer was Socrates (469-399 $\mathrm{BC}$ ). Although he reported hearing the voice of a demon, he valued the voice positively.

The first hypothesis about hallucinations came from Aristotle (384-322 BC), who did not relate them to his own experience. According to Aristotle, voices were produced by the same mechanisms that normally produce hallucinations during sleep, the mechanism of dreaming (Feinberg, 1970).

Experiences of voice hearing are often mentioned in a religious context. Significantly, people identified as founders of religious movements reported hearing voices: Jesus (Christianity); Mohammed (Islam); George Fox (Quakers) and Joseph Smith (Mormons). Both in the old 
and new testament; Moses, Jesus, the apostle Paul and Maria were all described as hearing voices. It is known that the abbess Hildegard von Bingen, the saints Teresa of Avila and Fransiscus of Assise, and the protestant Luther heard voices (Watson, 1998). Probably the best known voice-hearer is Jeanne d'Arc (1412-1431) who perhaps gives the earliest example of a voice hearer where political events had a great influence in the way people looked at her experiences. She was openly known by her troops to be guided by voices when she took them into battle to free France from the English. However, when she was captured she was then accused of witchcraft because of her voices. In fact her trial was a political debate about who would own the French crown.

The first noticeable change toward hearing voices might be seen in relation to the development of individualisation as part of the evolving European cultural movement of the 'Renaissance'. It was a time widely regarded as involving the emancipation of mankind in respect to the powers that dominated their existence: the clergy and the state. Across much of Europe during the middle ages, political power was in the hands of the Roman Catholic Church as church and state operated as one body. The church functioned as the prime controller of knowledge, and the development of independent thought represented by individualism threatened the power of the church.

As early as the fourteenth century one can find the first traces of the Renaissance and individualisation in the work of Dante (1265-1321) who was a poet, statesman and a philosopher. In his text, 'Monarchia' (Winkler Prince, 2002; Perler in Routledge 2000) Dante proposed that the aim of civilisation was the bundling of human potentials to obtain peace and freedom. Dante held revolutionary ideas and proposed that the individual, state and church should have separate roles, where the role of state and church provided guidance rather than control. In the fifteenth and sixteenth century the developing influence of the renaissance was so strong that it influenced all facets of daily life, including all kinds of art such as architecture, painting, sculpturing, music, copper-plating, tapestry, glass blowing and also beliefs about the treatment of ill people (Thomas, 1997)

Until the early renaissance, theories of disease were still grounded in astrology and alchemy (Thomas, 1997). Medical changes were a consequence of an apparently harmless revival and interest in classical Greece. This interest was stimulated by an interest in the human body, exemplified by the work of the artist Leonardo da Vinci, who published a series of anatomical 
sketches, which in turn influenced the Belgian anatomist Vesalius, who studied medicine in Paris. Vesalius was taught in the traditions of anatomy unchanged since Galen (around the second century BC.), who in his work extended the theories of Hypocrates. To learn more about anatomy, Vesalius undertook dissection, a very risky business as the church had forbidden to do this, the Roman Catholic Church regarding the structure and function of the human body as God-given, sacred and not for men's eyes (Thomas, 1997). Vesalius' actions and observations thus challenged ideas sacred to organized Christianity, for example the belief that women had one more rib than men and that the heart was the centre of the mind.

Many others challenged the established views of the church. Copernicus calculated that the sun, not the earth, lay at the centre of the solar system, a view at that time that was seen as heretical. The invention of the telescope, thermometer, barometer and microscope provided the means by which the early scientist philosophers could delve ever more deeply into material properties of the natural world. (Thomas, 1997, p.153). The church perceived the development of science as a threat, as the acquiring of knowledge through scientific exploration effectively made God and the church redundant. Therefore the church sought means to retain control, and across Europe it greatly expanded the system of inquisition to detect heretics. The inquisition started around 1184 in Rome when it was legislated by Pope Lucius III and it finally stopped in 1772 in France:

'In order to defend Christendom against Satanic influences, Pope Innocent VIII ordered in 1489 the publication of the book 'Malleus malefircarum (The hammer of the witches). This book set the conditions for the burning of people who were suspected of witchcraft or possession by demons. '(Slade en Bentall, 1988 p. 6)

It was a brutal system run by monks who were given wide-ranging powers, such that their actions were unaccountable to the local bishops. When heretics were detected they were brought to trial according to the Roman laws. The inquisition was thus much feared and at this time reporting hallucinations was clearly a danger to ones life.

Theresa of Avila (1515-1582), who was an abbess, was able to save a number of visionary nuns from the machinations of the Inquisition by introducing concepts of 'sickness' and 'lack of responsibility'. She explained that certain 'natural causes' were capable of explaining visitations, namely (a) melancholy, (b) a weak imagination, or (c) drowsiness, sleep, or sleeplike states (Slade \& Bentall, 1988, p.6). Thus it was Avila who developed the first medical conceptualisation of hallucinations, born out of a political need. Positive reports of voices thus 
disappeared, but whilst this did not mean that these experiences no longer occurred, a strong cultural taboo was created.

The second historical influence on the contemporary attitude towards hearing voices is the cultural development in the period of 'Enlightenment'. This movement started around the sixteenth century, where it is related to the era of British 'Glorious Revolution' and the end of the French Revolution (Winkler Prince, 2002). This period is also sometimes called the 'the period of philosophy', a time when people were challenged to use their minds, challenging beliefs that a human being could not use his reason as he was bound by superstition, prejudices and the powers that maintained these. The new optimistic view was that through reason one could separate what is natural and what is unnatural. (Thomas, 1997)

Influential to the Enlightenment movement was the French philosopher Descartes (15961650), with his 'Cartesian' system of thought, regarded as the foundations for the science of psychology (Thomas, 1997). His famous phrase 'I think and therefore I am' introduced 'dualism', the doctrine that conceptualised the separation of body and mind.

\begin{abstract}
'Our understanding of the world is located in internal experiences, in the mind of the individual. The twin peaks of Cartesian thought, mind/body, that opened the way for the materialistic study of human behaviour, and the belief in the foundation of knowledge through the experience of the individual, has had a potent effect in shaping psychological thought. In particular, it has stimulated scientific approaches aimed at understanding the internal mechanisms of minds, and their relationship to brain. The problem is that it has led to neglect of the relationship between the individual and other(s), for as Russell observed, morals and ethics, those aspects of philosophy that understand the values that govern our individual and social relationships, had little or no place in Cartesian thought. '(Thomas, 1997 p. 157/158)
\end{abstract}

In the centuries to follow, this scientific approach became the dominant culture with many consequences. The tools of science are objectivity assured by the condition that what is accepted as knowledge must be produced by methods and thus results that are replicable. By separating the body and mind, Descartes created the possibility of studying the mind as an object, separate from the body and from the environment, as if there is no interaction, no relation what so ever. (Thomas, 1997, 2003)

With the development of science, terminology developed as well. In relation to such experiences as hearing voices, the term hallucinations was for the first time introduced by Lavater in 1572 (Slade \& Bentall, 1988), based on a translation of Galen's conception of madness as 'a disturbance of bodily humours'. 
'The word 'hallucinations' is an anglicised version of the latin allucinatio (wandering of the mind, idle talk). The term was used to refer to a variety of strange noises, omens and apparitions. '(Slade\& Bentall, 1988 p. 7).

The French physician Esquirol (1832) conceptualised hallucinations in an attempt to distinguish between 'insane' and 'sane' hallucinations. He differentiated these extra-ordinary experiences into illusions and hallucinations.

'People who suffer from hallucinations are dreamers while they are awake. Hallucinations are "memory recalls without the intervention of senses. '(Slade\& Bentall, 1988 p. 8).

The insane were mistaken about the nature and cause of their present sensation. Illusions, on the other hand, were seen as situations where:

'...the sensibility of the nervous extremities are excited; the senses are active, the present impressions call into action the reaction of the brain'. (Slade\& Bentall, 1988 p. 8).

The distinction between 'insane' and 'sane' was strongly debated. Esquirol described the insane as 'mistaken about the cause of the present sensation', while in 1855 the French Société Medico-Psychologique distinguished insanity in relation to the inability to control experience. Both arguments still play a role in the contemporary debates.

However insanity did not restrict itself to an individual illness but within a social context.

'It was Esquirol and his teacher Pinel who rejected the view of mental illness as a self-acting entity, independent and alienated from the community of people that produced it. To the contrary, they argued, how much the mental patient and the normal had in common. In attempting to refute the notion that the mental patient was globally disturbed, possessed, they attempted to differentiate precise symptom pictures. In what they called 'folie raisonnante' as patient might at times have a different perception of reality than his examiner, but in many other aspects he might be reasonable. It is by some lamentable misinterpretation of history that Esquirol is now reported in the textbooks to deserve credit for the modern mystifying use of the term hallucinations. '(Rabkin, 1970, p. 115.)

According to Rabkin (1970) it was not Esquirol's idea to diagnose a person as an individual that is without reason.

'By defining the two terms, Esquirol's main purpose was to point to the rest of the patients behaviour and circumstances, behaviour which was rational. This is usually not mentioned. (R. Rabkin, 1970, p.116) 


\section{Categorisation into illness entities and the consequences}

In the second half of the nineteenth century and in the first half of the twentieth century mental illness was mostly still considered in terms of an interaction between environment and individual. Under the influence of Freud's philosophy, Adolf Meyer even attempted to integrate Freudian theory into the practice of clinical psychiatry:

\footnotetext{
'Meyer's approach to understanding mental illness was normalising, in that he regarded it as an understandable reaction to a set of life experiences. His approach was significant in the importance that it attached to the person in understanding mental illness. His approach focused on persons not patients.'(Thomas, 1997, p. 148)
}

At the same time a small but powerful group in Germany criticized this social approach (Kraepelin,1883 Bleuler,1911). They found working with the psychosocial model unscientific, believing that it would fail to generate any meaningful research in the field of mental illness. They instead wanted to refine the pathological concept that attempted to explain mental illnesses from within a biological or genetic frame of reference. It was step a forwards in trying to refine pathological concepts.

'Kraepelin (1856-1915) developed a classification system for mental illnesses. His first modest overview was published in 1883 as 'Compendium der Psychiatrie', followed in 1887 by a second edition 'ein kurzes Lerchbuch fur studerende und Arzte' (Blom, 2003.p.53)

'Chronicity' and 'deterioration' were the essence of Kraeplins concept of 'dementia praecox', which, as can be shown today, was biased due to the more severly ill patients Kraepelin saw in the mental hospitals of his time. While Bleuler (1911) corrected this consept of chronicity by pointing out that several subtypes exist and that the defining criterion should be psychopathology and not the course, he unwittingly created another misunderstanding by introducing the term of schizophrenais. (Katchnig, 2002).

In his early work Bleuler, in contrast to the European psychiatric establishment, acknowledged Freud's more dynamic and reconstructing access to psychopathological phenomenon. It must have been the setting again that influenced his idea. Bleuler lived and worked in close contact with his patients. Later under the pressure of the German-speaking psychiatry to confirm to their idea, Bleuler stripped the schizophrenia concept from all psycho-analytical influences (Richartz, 1985) Under the influence of Eugen Bleuler psychiatry in the United States has diagnosed nearly all psychotic experiences with a clear conscious involving hallucinations and/or delusions with the label of schizophrenia (Richartz, 1985) 
So with the development of classification system, expressions of mental illness were no longer seen as an understandable reactions to a set of life experiences, but as expressions of an illness entity, an underlying illness of the functioning of the brain. The influence of this line of understanding is predominant in medical faculties nowadays. Textbooks structure the first medical ideas of medical students - the doctor's to be. This kind of thinking is the first step toward learning to use diagnosis on the basis of symptoms, categorised into illness entities without aetiological knowledge of these symptoms.

With this approach, Kreapelin and others working in clinical psychiatry had little regard for what the symptoms (of the illness) the patients alleged to be suffering from, might mean for them (Zilborg \& Henry, 1941). Nonetheless, Kraepelinplin's system became a great success.

Slade and Bentall formulated their critism:

\begin{abstract}
'The development of specified illnesses has all kind of consequences which might be considered negative.

Firstly the medical model has led to the study of syndromes rather than symptom. Most research into abnormal behaviour over the last 50 years or more has taken diagnostic categories such as 'schizophrenia' or 'depression as independent variables.

Secondly the view that hallucinations are medical phenomena has led to a relative lack of interest in them by psychologists. (Slade and Bentall, 1988, p.9)
\end{abstract}

Slade and Bentall are right in their criticism, but in the first half of the last century psychiatrists felt in need of a diagnostic system to establish whether certain symptoms were pathognomonic for certain illnesses. Therefore, the psychiatrist Kurt Schneider (1956) developed criteria for identifying verbal hallucinations which he thought were specific to schizophrenia. He distinguished: 'hearing voices that speak your thoughts aloud; hearing two or more voices talking about you (in the third person, referring to you as 'he' or 'she'); hearing one or more voices carrying on a running discussion in which your actions or thoughts are commented on'. Schneider suggested that any one of these characteristics could be indicative of the presence of the illness of schizophrenia.

However the existence of this kind of reality is hypothetical. As Mary Boyle (1990) states:

'What is perhaps most remarkable about their work (Kraepelin, Bleuler, Schneider) is that in spite of aligning themselves to a scientific framework, not one of them presented a single piece of data relevant to their assumption that they were justified in introducing and using the concept of dementia praecox and schizophrenia'(Boyle, 1990. p. 75) 
In our own study (Romme, 1996, Honig, 1998, Pennings, 1996) no clear differentiation between characteristics of verbal hallucinations were found, experienced in patients diagnosed with schizophrenia, with dissociative disorder or in the non-patients (people with no psychiatric illness when assessed with the CIDI, Robins et al., 1988).

Whilst it is clear that criticism can be levelled at diagnostic systems, the recognition of disease entities had much to offer clinicians, encapsulating a desire to work scientifically, culminating in the development of the Diagnostic and Statistical Manual (DSM) of the American Psychiatric Association.

'It was a victory for biological psychiatry over the psychosocial movement and psychoanalysis in particular. Its detailed prescription of criteria for the diagnosis of mental illness has had international implications. It proved a firm basis for diagnosis which generated a new impetus in biological research'. (Thomas, 1997 p.149).

The American Psychiatric Association Committee on Nomenclature and Statistics published in 1952 the first edition of the Diagnostic and Statistical Manual: Mental Disorders (DSM-I). Since 1952 the DSM has been upgraded several times.

'DSM-I contained a glossary of descriptions of the diagnostic categories and was the first official manual of mental disorders to focus on clinical utility. The use of the term 'reaction' throughout DSM-I reflects the influence of Adolf Meyer's psychobiological view that mental disorders represented reactions of the personality to psychological, social and biological factors'.'(DSM-IV.1994. p. xvii)

In 1980 the DSM-III was published.

'DSM-III introduced a number of important methodological innovations, including explicit diagnostic criteria, a multiaxial system, and a descriptive approach that attempted to be neutral with respect to theories of etiology. '(DSM-IV. 1994. p. xvii/xviii)

In 1994 the DSM-IV was published.

However with all the efforts of refining the DSM the influence of social circumstances as refered to in the first DSM was not taken in again. Aetiological factors are not longer taken into account in the DSM classification system, with one exeption: the Post Traumatic Stress Disorder.

Criticism on this classification system started more openly at the end of 1980's, resulting amongst others in the publication of a number of seminal texts: Richard Bentall's (1990) 
'Reconstructing Schizophrenia', Mary Boyle's (1990) 'Schizophrenia: a scientific delusion', Phil Thomas' (1997) 'The dialectics of Schizophrenia' and Dirk-Jan Blom's (2003) 'Deconstructing Schizophrenia'.

Criticism has also grown out of daily practice, leading clinicians to question the utility of the diagnosis of schizophrenia, so that today it is enormously diminished in credibility amongst many practitioners (van Os \& McKenna, 2003). In the Maudsley Discussion Paper (No.12) Jim van Os express the following concern;

'The DSM definition is severely biased towards non-affective symptomatology. The reason for this discrepancy is likely to be related to the need of medical practitioners to convince of illnesses as clearly separable disease entities, based on the old Kreapelinian distinction between poor-outcome schizophrenia and good-outcome affective illness. '(van Os \& McKenna, 2003).

There is also clearly an argument about why this DSM classification system is inadequate for voice hearers, as it does not incorporate the significance of the social context. In the Maastricht research, that looks for a relationship between the voices and the life history, great care was taken to clarify the onset of the voices and any traumatic events at that specific time. About $70 \%$ of the voices hearing in adults began after stressful events, including death of a family member, divorce, moving houses, losing a job, sexual abuse (Romme \& Escher, 1989). The events occurred in social circumstances, and happened to people beyond their control. The voices often tell about circumstances that created an overwhelming experience of powerlessness. Voices are messengers of the problem or problems of the voice hearer. In any diagnostic system including the DSM, the social context and the content of the voices needs to be included instead of exluded, in order to understand the experience and the need of the voice hearer. Instead of moving forwards the medical profession seems to have lost this social context, something that was still taken on board in the beginning of the last century. In search of scientific objectivity, psychiatry seems to have lost the patient and has not found what it aimed at.

As the clinician Rabkin (1970) formulates it:

'It is my contention that Esquirol's worst fears have been realized, that his term has achieved the opposite of his intention: namely that the psychiatrist as alienist, as he used to be called, has created a set of alienating ideas or ideologies, prominent among which is hallucinations, which he mistakes for the real world of behaviour as one can mistake the image in the mirror for the veridical perception. By using these myths to alienate his patients in space he has alienated himself in a much more profound fashion. '(Rabkin, 1970, p.116). 


\section{Modern diagnoses in relation to hallucinations}

The attitudes towards hallucinations of modern psychiatrists have been shaped by widely accepted assumptions about the diagnosis of psychiatric disorders. Following the work of Emil Kraepelin and others in the $19^{\text {th }}$ and early $20^{\text {th }}$ centuries, attempts were made to develop standardised criteria for classifying different conditions (Bentall, 2003). These efforts, which culminated in the creation of the American Psychiatric Association's DSM system, placed great effort in determining the presence or absence of particular symptoms such as hallucinations, but have led to an almost total neglect of their meaning.

The DSM is a categorical system with no proven scientific validity (Bentall, 2003). It is a classification system not a diagnostic system because it does not include aetiological factors. In the DSM manual psychosis is described as:

\footnotetext{
'The term psychotic has historically received a number of different definitions, none of which has achieved universal acceptance. The narrowest definition of psychotic is restricted to delusions or prominent hallucinations, with the hallucinations occurring in the absence of insight into their pathological nature. A slightly less restrictive definition would include prominent hallucinations that the individual realizes are hallucinatory experiences. Broader still is a definition that also includes other positive symptoms of schizophrenia (i.e., disorganised speech, grossly disorganised or catatonic behaviour). '(DSM-IV. p.273)
}

This reduces the scope on hallucinations and it is not open for the reality which we observed in our research that hallucinations are also a signal of social, emotional problems and should not be alienated from the person.

\section{Children}

The discussion so far has followed the history of voice hearing and the development of the categorisation and diagnosis of psychiatric disorders in adults. Whilst the beginning of contemporary psychiatry can be situated in the middle of the $18^{\text {th }}$ Century, child psychiatry did not develop until the beginning of the twentieth century. There are two influential factors that stimulated it's origin cited by Hart de Ruyter et al., (1973), and Timimi (2002), both generated from socio-cultural developments. At the end of the nineteenth/beginning of the twentieth century juridical authorities no longer wanted to judge deviant and criminal behaviour of children only as punishable cases, instead seeking psychological causes in the development of the child, and looking for causal influences in the environment. The reason for this change of policy was that it created a possibility to educate and treat those children, and provided a context for prevention. In this way one might create preventive measures to 
avert asocial behaviour developing into delinquent behaviour. The second factor in the development of child psychiatry was the rise of the child guidance clinics in during the 1920's and 1930's, founded in the United States and later promoted in Europe.

In the beginning, child psychiatry mainly was the domain of neurologists. With the development of child guidance clinics, responsibility for care extended to the multidisciplinary team. It thus took political power from within the medical profession to establish the specialism of child psychiatry (Hart de Ruyter, 1973).

There is relatively little know about children and hallucinations. There is some literature including Freud and Bleuler (Kemph, 1987) relating auditory hallucinations to childhood. However their observations were based on research with children. One of the earliest studies undertaken with children with hallucinations was by Bender (1940), who stated that it was difficult to distinguish between normal and pathological experiences in young people. However Despert (1948) had a different opinion, asserting that a 3 year old child is able to distinguish reality from fantasy and thus does not have genuine hallucinations. According to Despert, genuine hallucinations are in Freud's concept, formulated as regression to gratify infantile wishes, passing beyond the testing of reality. She therefore concluded that they are simply not present in very young healthy children, stating that children from 10 years of age have similar hallucinations to those in psychotic adults.

Kemph (1987) argued that the only difference between adult and child hallucinations is that they are simpler and lack organisation and systematisation. Kemph studied 331 psychotic children between 6 and 15 years of age and found no hallucination in children under 8 years of age. The group from 8 to 11 years of age had a significantly higher incidence $(68 \%)$ of hallucinations than the older children. He suggests that this might be because young children have more primitive defences and less firmly developed ego functions such as reality testing' and a tendency to think in terms of concrete objects and actions.

Other researchers like Bender, Jaffe, Lucianowicz and Esman (in Rothstein, 1981) gave more attention to the role that psychodynamics might play in cases of childhood hallucinations. They tried to find a relation between hallucinations and social cultural variables. Specific background variables which seemed to affect vulnerability to the experience included low social class, race, gender, deprivation, poverty, and isolation from prime carers. Bender (1970) 
'At whatever age children's hallucinations occur, they are always a window to the inner life of the child and reveal the child's psychodynamic problems to the observer and may serve the function of substitute interpersonal relationships in deprived children' (Bender, in Origin and mechanism of hallucinations. P. 100).

In the past and present literature there are different and contradictory opinions about the age children are able to experience hallucinations and about their cause. In the last fifteen years children have become more the focus of attention or one could say, became more popular in research. In clinical studies of children and adolescents' auditory, hallucinations are reported as occurring in the context of a variety of psychiatric states such as schizophrenia (Bettes, 1987; Green, 1992; Galdos, 1995; Galdos, 1993), anxiety and depression (Garralda, 1984; Ryan, 1987; Chambers, 1982), migraine (Schreier, 1998), trauma, dissociation processes and reactive psychoses (Altman, 1997; Famularo, 1992; Putnam, 1994) as well as in deprivation (Bender, 1970).

Nearly all studies concern selected clinical samples, and a small number of children. Longterm follow-ups of such groups suggest variable outcomes, reflecting the heterogeneity of the subject selection procedures in the different studies (Garralda, 1984; Del Beccaro et al., 1988).

Slowly, interest is developing in the experience of hallucinations in non-clinical settings. The first study of non-patients was that of Yeates \& Bannard who, in a study of three subjects, described hallucinations as a reaction to grieving (Yeates \& Bannard, 1988). Altman et al. (1997) and Schreier (1998) report on 'not treated' children as well; however they still relate to them in medical model terminology using the word 'non-psychotic' children. No short-term sequential follow-ups of children with hallucinations have been conducted to study the course of these experiences, and the possible factors that influence their course. Little is known about the course of hearing voices and their outcome in relation to the pathways through care. This children's study is aimed at plugging this gap in knowledge.

Although research shows that hearing voices is present in patients and non-patients, contemporary daily practice of child psychiatrists mostly follows the general psychiatric approach in adults. The key word is diagnosis. Hearing voices might be an early symptom of psychosis and those children are seen at the risk of developing schizophrenia later in life. As clinicians work with diagnoses or are expected to use diagnoses for organisational reasons, 
this might force a more medical approach than is helpful (Timimi, 2002). Child psychiatry research has come to rely too heavily on medical model inspired methods as the gold standard.

One consequence is that medication, for example Ritalin, has become ever more popular and is promoted as the best treatment (Timimi, 2002) for instance in ADHD. This approach might make the child dependent on the medical system and does not stimulate and activate the selfhealing capacities of the child. Rather, it takes power away; as some children and parents reported in this research, they were told either by their GP or psychiatrist "you are ill, you might have schizophrenia". This first reaction within an illness model is not the best start to overcoming problems and obtaining support.

However it is not only the medication that can be problematic, but also the rules set by the therapist. Children and parents may be forbidden to talk about the voices as, in line with the clinical opinion, talking about the voices is thought to reinforce engagement with the hallucinations. Timimi (2002) warns about this medicalisation of childhood, and thus the outcome of this children's study is directly relevant to Timimi's conclusions. As child psychiatry is a relatively young profession, the outcomes of the study can provide a significant contribution to existing ideas and practices, with the potential to develop the discipline in a new direction. Professional input should not be the only option the child is given. In adult psychiatry the influence of the user perspective has become more important (Kleinman, 1988; Coleman, 1996, Read \& Renoulds, 1996). Child psychiatry has to engage in these debates about cultural, political and social contexts (Timimi, 2002).

\section{Summary}

The evidence from the literature clearly shows that the same medical view applied to adults is brought to understand the experience of children, with all its concomitant therapeutic and social consequences. As with adults, we are in the situation of simply not knowing enough about the development and course of voice hearing in children, particularly amongst nonpatients. Neither the bio-medical psychiatric model nor various psychological models developed from a pathological perspective, provide an adequate framework from which to explore the contextual issues that are connected to the origine of, bring meaning to, and influence the development of the experience. This study thus seeks to explore the experiences 
of non-patients and patients together over time, to better understand the nature of that experience, and whether and in what way there is a difference between these two groups.

\section{References}

Altman, H. Collins, M., Mundy,P. (1997) Subclinical hallucinations and delusions in non psychotic adolescents. Journal of Child Psychology and Psychiatry 38,(4),413-420.

American Psychiatric Association (1980). Diagnostic and Statistical Manual of mental Disorders (3th edn). Washington D.C.: A.P.A.

Bentall, R.P. (1990) Reconstructing Schizophrenia (Routledge, London/New York).

Bentall, R.P.(2003) Madness explained: psychosis and human nature. London. Penguin.

Bender,L., Lipkowitz, H.H. (1940) Hallucinations in children. American Journal of Orthopsychiatry. New York: Plenum.

Bender, L. (1970). The maturation process and hallucinations in children. Origin and mechanism of hallucinations. Ed. W. Kemp. New York: Plenum

Bettes, B.A., Walker, E. (1987) Positive and negative symptoms in psychotic and other psychiatrically disturbed children. Journal of Child Psychology and psychiatry 28 (4), 555-568.

Bleuler, E. (1911) Dementia Preacox or the Group of Schizophrenias (trans. J. Zinkin, international University Press, New York, 1950) Leipzig: Deuticke.

Boevink, W., Escher, S. eds. (2001) Zelfverwonding begrijpelijk maken. St. Positieve Gezondheidzorg. Bemelen: Netherlands

Boyle, M (1990) Schizophrenia- A.Scientific Delusion? (Routledge, London/New York)

Blom, J.D. (2003) Deconstructing schizophrenia; an analysis of the epistemic and nonepistemic values that govern the biomedical schizophrenia concept. Boom, Amsterdam.

Chambers, W.J., Puig-Antich, J. Tabrizi, M.A., Davies, M. (1982) Psychotic symptoms in prepuberal depressive disorder. Archieves of General Psychiatry 39 (8), 921-927.

Coleman, R. (1996) Recovery- an alien concept. Handsell Publishing, Gloucester

Despert,J.L. (1948) Delusional and hallucinatory experiences in children. The American Journal of Psychiatry, 104, (8), 528-537.

Del Beccaro, M.A., Burke, P and McCauley, E. (1988) Hallucinations in children: a followup study. Journal of the American Academy of Child and Adolescent Psychiatry, 27. 462-465.

Encyclopedia, Winkler Price (2002)

Famularo, R. Kinscherff, R. Fenton, T. (1992) Psychiatric diagnoses of maltreated children: preliminary findings. Journal of American Academic Child Adolescents Psychiatry 31, 863-867.

Feinberg, 1. (1970) Hallucinations, dreaming and rem sleep. In; Origins and mechanism of hallucinations'.W. Kemp ed. Plenum Press, New York/London. 125-132

Galdos, P.M., Van Os, J.J., Murray, R.M. (1993). Puberty and the onset of psychosis.

Schizophrenia Res 10 (1), 7-14.

Galdos, P., Van Os, J. ( 1995). Gender, psychopathology and development from puberty to early childhood. Schizofrenia RES 14 (2) 105-112.

Garralda, M.E. (1984) Psychotic children with hallucinations. British Journal of Psychiatry, $145,74-77$

Garralda, M.E.(1984) Hallucinations in children with conduct and emotional disorder: In: The clinical phenomena. Psychological Medicine, 14, 589-596.

Green, W.H., Padron-Gayol, M. Hardesty, A.S., Bassiri, M. (1992). Schizophrenia with 
childhood onset, a phenomenological study of 38 cases. Journal of American Academic Child and Adolescent Psychiatry 31 (5), 968-976.

Hart de Ruyter, Th., Kamp, L.N.J. (1973) Hoofdlijnen van de kinderpsychiatrie. Van Lochem Slaterus, Deventer.

Honig, A., Romme, M.A.J., B., Ensink, S. Escher., M. Pennings, M., de Vries.M. (1998) Auditory Hallucinations: a comparison between patients and nonpatients. Journal of Nervous and Mental disease 186: 646-651.

Katchnig, H,(2002). Stigmarelevante historiche Wurzeln des Schizophreniekonzepts in Kraeplins, Bleulers and Schneiders Werk. Neuropsychiatrie, Band 16,nr.1 und 2 ,S.1119

Kleinman (!988) Rethinking Psychiatry from cultural Category to Personal experience. The Free Press, New York.

Kemph, J.P.(1987) Hallucinations in psychotic children. Journal of American Academic Child and Adolescence Psychiatry, 26,4:556-559.

Kreapelin, E. (1883) Compendium der Psychiatrie. Zum Gebrauche fur Studirende and Arzte. Leipzig: Verlag von Johann Ambrosius Abel.

Van Os, J., McKenna, J. (2003) Maudsley Discussion Paper (No.12). London: Maudsley Hospital

Pennings, M.,\& Romme,M. (1996) Stemmen horen bij schizofrene patienten, patienten met een dissociatieve stoornis en niet-patienten, in: Zin in waanzin. (eds. De hert,M.,Thys,E. Peusekens., Petry, D, van Raay,B. )Babylon-de Geus, Amsterdam. P. 127-140.

Putman, F.W., Peterson, G. (1994) Further validation of the child dissociative checklist. Dissociation (7) 204-220.

Rabkin, R. (1970) Do You see things that aren't there? Construct Validity of the concept of 'hallucinations' in Origins and mechanisms of hallucinations' W. Kemp ed.:Plenum Press New York, London. 112-124

Read, J., Reynolds,J. (1996) Speaking our minds. An Antopology of personal experiences and its consequences. The Open University/Mcmillan, London.

Richartz, M. (1985). Schizofrenie,-een onmogelijk begrip of een moeilijk peilbare uitdaging? COBO Bulletin.1985.-2.p.4-13.

Romme, M.A.J. \& Escher, A.D.M.A.C. (1989) Hearing voices. Schizophrenia Bulletin, 15, (2), 209-216.

Romme (1996) Understanding voices. Handsell publications. Gloucester

Robins, L.N., Wing. J., Wittchen. H.U. Helzer.J.E.,babor. T.F., Burke. J., Farmer. A., Jablenski. A. Pickens.R., Regier. D.A., Satorius. N., Towle. L.H., (1988) The Composite International Diagnostic Interview: an epidemiologic instrument suitable for use in cogjuntion with different diagnostic systems and in different cultures. Arch Gen Psychiatry ; 45:1069-1077.

Rothstein, A (1981) Hallucinatory phenomena in childhood. Journal of the American Academy of child psychiatry, 20,623-625. Routledge (2000) Routledge Encyclopedia of Philosophy, London Routledge.

Ryan, N.D., Puig-Antich,J., Ambrosini. H., Robbinson, D., Nelson, B., Lyengar, S., Twomey, J. (1987) The clinical picture of major depression in children and adolescents. Archives of General Psychiatry 44 (10), 854-861.

Schreier, H.A., (1998) Auditory hallucinations in nonpsychotic children with affective syndroms and migraines: report of 13 cases (see comments). Journal of Child Neurology $13(8), 377382$.

Slade, P.D. Bentall,R.P., (1988) Sensory deception, A scientific analysis of hallucinations. Croom Helm Ltd, London. 
Timimi, s (2002) Pathological child Psychiatry and Medicalisation of Childhood. BrunnerRoutledge, Taylor \& Francis group.

Thomas, P. (1997) The Dialectics of Schizophrenia. Free Association Books, London/New York.

Watson,J. (1998) Hearing Voices. A Common Human Experience. Hill of Content Publishing Co. Melbourne.

Yeates, T.T.,\& Bernnard, J.R. (1988) The 'haunted'child: Grief, hallucinations and family dynamics. Journal of the American Academy of Child and Adolescent Psychiatry, 27, (5), 573-581.

Zilboorg, G., Henry, G.W. (1941) A history of medical Psychology. Norton, New York. 


\section{Chapter 2}

\section{Hearing voices.}

Schizophrenia Bulletin, 15, (2), 209-216.

Romme, M.A.J. \& Escher, A.D.M.A.C. (1987) 
U.S. Department of Health

and Human Services

Public Health Service

Alcohol, Drug Abuse

and Mental Health

Administration

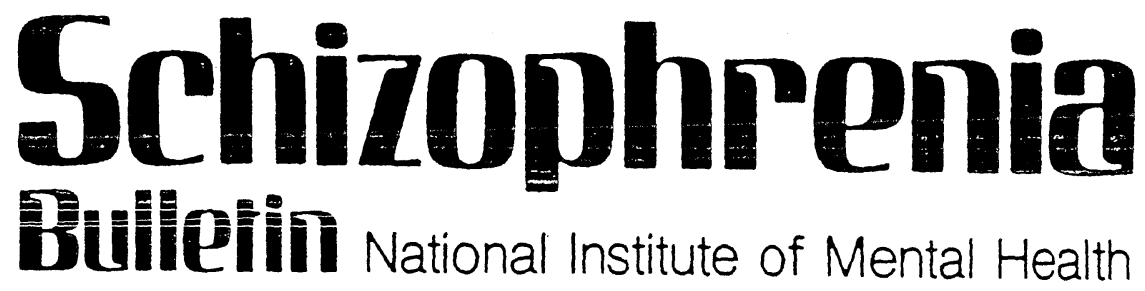

Issue Theme: Subjective Experiences of Schizophrenia and

Related Disorders

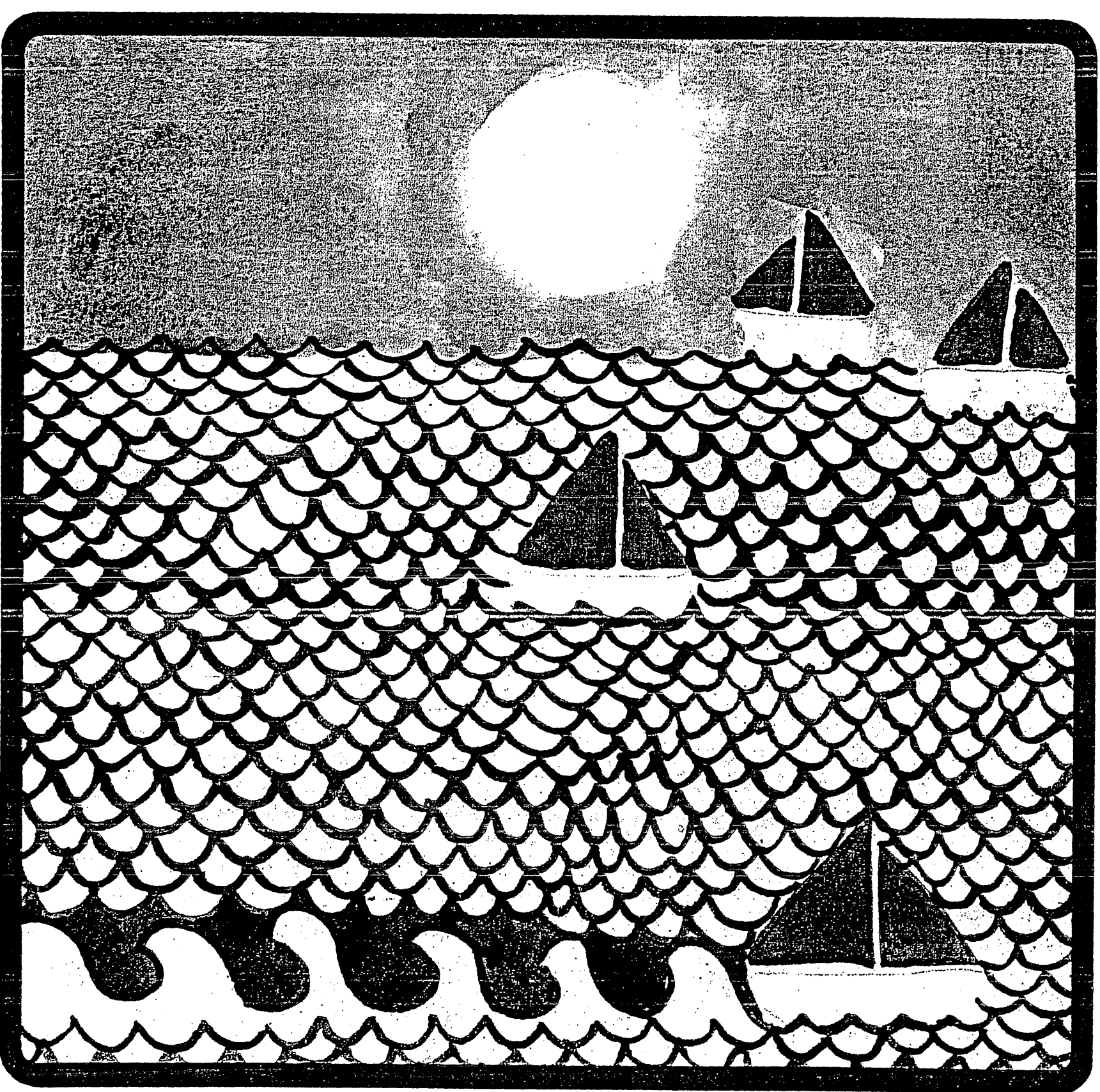




\section{Abstract}

An experiment is described in which people with auditory hallucinations were brought into contact with each other. On an evening television talk show, a patientdiagnosed several times as having schizophrenia-talked about her voices. Four hundred and fifty people who also were hearing voices reacted to the program by telephone. A questionnaire was sent to those who responded to the television program in order to get more information about their way of coping with the voices. From those who filled out the questionnaire, 20 people were selected who explained their experiences in a clear way. A meeting for people hearing voices was organized, and the 20 persons were invited to become the speakers. In this article the experiences described by the participants are reported as well as the many ways in which they coped with these experiences.

For some years, one of my patients, a 30-year-old woman, has heard voices in her mind. These voices give her orders or forbid her to do things. They dominate her completely. She has been hospitalized several times and diagnosed as having schizophrenia. Neuroleptics do not have any effect on the voices, although they reduce the anxiety provoked by them. But the medication also reduces her mental alertness. For that reason, in order to stay alert, my patient does not take medication over long periods and does not remain an inpatient long when she is hospitalized. Nevertheless, the voices have isolated her more and more by forbidding her to do things she has always loved to do.

Last year she started to talk increasingly about suicide. I felt she was taking a road with no turning point. The only positive topic in our communication then was the theory she developed about the phenomenon of the voices. The theory was based on a book written by the American psychologist Julian Jaynes (1976), The Origin of Consciousness in the Breakdown of the Bicameral Mind. It was reassuring for her that the author described hearing voices as having been a normal way of making decisions until about 1300 B.C. According to Jaynes, hearing voices has disappeared and been replaced by what we now call "consciousness."

I began to wonder if she could communicate especially effectively with others who also heard voices, and whether her theory would be accepted by other people who had these experiences. This might have a positive effect on her isolation, her suicidal tendency, and her feeling dependent on the voices. She and I began to plan together how she might share some of her experiences and views.

From this point, things progressed rapidly. Speaking on a popular Dutch television program, my patient and I invited people to contact us. After the television program, 700 persons responded to our appeal; 450 of them heard voices. Of these 450, 300 reported not being able to cope with the voices

Reprint requests should be sent to Dr. M.A.J. Romme, Professor of Social Psychiatry, University of Limburg, Maastricht, The Netherlands. 
and 150 said they were able to handle them. Hearing from this last group was especially important in encouraging me to organize a congress for people who heard voices and who wanted to exchange ideas about their experiences.

We sent out a questionnaire to those who responded to the television program in order to get more information from them. From those who returned the questionnaire, we selected a number of people who could cope with the voices and invited them for an interview about their way of coping. We selected 20 persons who we thought were able to explain their experiences in a clear way and who would like to tell their experiences to others who could not handle their voices. These 20 became the speakers at a congress attended by 300 people who heard voices, a congress that took place on October 13, 1987.

The congress itself was held in a large labor union meeting building not connected physically or administratively to any psychiatric or even medical institution. Although members of the psychiatry department were active in organizing and guiding the meeting, the plenary speakers were all people who had responded to the television program and heard voices. Following the morning plenary session, there was a series of 1-hour smaller group workshops with facilitators from the department of psychiatry who did not lead the discussions but rather guided them or helped out as necessary.

The general atmosphere of the entire congress was of a meeting of a group of people with common interests and experiences. Although medical aspects of these experiences were discussed, there was no sense that this was a medical meeting or a meeting of medical patients. The participants freely shared their experiences, their many interpretations of these experiences including religious views or a range of other human reactions, and their approaches to coping. Some people were obviously troubled by their voices and saw them as part of a mental illness, but many had very different ways of understanding these experiences and appeared to be competent, not disabled, and depending on one's view of the nature of voices, not in any way "ill."

The considerable range of experiences described by the participants and the many wavs they dealt with these experiences, successfully or unsuccessfully, can be viewed from many perspectives. It seems most useful to divide the reports into three possible phases they reflected relevant to coping with the voices:

- The startling phase: the usually sudden onset, primarily as a frightening experience.

- The phase of organization: the process of selection and communication with the voices.

- The stabilization phase: the period in which a more continuous way of handling the voices is acquired.

Many participants described phases of roughly this type. For example, one of the speakers distinguished the following phases in the process of learning to cope with the voices: (1) fear, anxiety, and escape; (2) investigation of what the voices mean and accepting the voices as independent beings; and (3) accepting myself, exploring what I try to escape from, reversing the confrontation with the voices, and not trying to escape any more.

In this report, we illustrate the three phases found among people who learned to handle their voices. We also present information from the questionnaire about the frequency of experiences and coping mechanisms described.

\section{The Startling Phase}

Most people who heard voices said that it began quite suddenly, at a moment they well remembered. This was usually a startling and anxiety-provoking experience:

On a Sunday morning at 10 o'clock, it suddenly was as if I received a totally unexpected enormous blow on my head. I was alone and there was a message-a message at which even the dogs would turn up their noses. I instantly panicked and couldn't prevent terrible events from happening. My first reaction was: What on earth is happening? The second was: I'm probably just imagining things. Then I thought: No, you're not imagining it; you have to take this seriously.

The age of onset for the initial experience of voices varied widely. Many of the respondents stated that their voices had started in childhood. For 6 percent of the questionnaire respondents, onset occurred before age 6; for 10 percent, onset was between ages 10 and 20 . One of the speakers told about her first experience as a child.

As long as I remember I have had one, and later more voices inside myself. My earliest memories about voices go back to kindergarten. Perhaps it sounds funny but I had two "egos." A normal child-ego, fitting with my age, and an adult-ego. The voice adapted itself to the ego. It spoke a child-language to the child and an adult-language to the other ego. The adult-ego gradually disappeared in primary school. As a child, I didn't experience these two egos as strange. In fact, for a child, nothing is strange. 
A representative of those who started hearing the voices in their adolescence, in a period of developing personal independence, told us:

In 1977, after high school, I decided to move into lodgings. I must say student life was fascinating, but I didn't sleep enough; I didn't eat regularly. After 4 months, I wanted to paint the large white wall in my room. That wall was challenging me. Painting is like bringing something from your head to your hands. I started to paint a dark forest on the wall, with a reptile on the foreground. I have always been able to hear colors. They transmit vibrations. I can hear black, red, and deep brown. During the painting it was deathly quiet in the room. The radio wasn't on. In this silence, something frightening was slowly growing. Something threatening was coming up. I had the feeling I wasn't alone in the room any more. Then I heard a monotonous sound in my ears that didn't come from myself and which I couldn't explain. It was a bit like the squeaking you hear when your ears are closed, only this sound was lower and more monotonous. It was like an emotion, but deeper. I had the feeling something was looking for me.

Antecedents to the Voices' Initial Occurrence. To the question whether the onset of the voices was due to a certain event, 70 percent of the respondents answered that the voices began after a traumatic (traumatic = emotional) event, such as an accident (4 percent), divorce or death (1.4 percent), a psychotherapy session (12 percent), spiritism (4 percent), and other events like illness, being in love, moving, or pregnancy (36 percent).

Impact of the Voices. People who began to hear voices after a trauma desciibed two general impacts. The first was that the voices were helpful, the beginning of an integrative coping process. They evoked a feeling of recognition or marked a period of rest after a miserable time. Afterwards, these people felt the purpose of the voices was to strengthen them, for example, or to raise their self-esteem. The voices were viewed positively, and as understandable aspects of their internal selves.

For other respondents, the voices were considered as aggressive and negative from the beginning. One woman said: "The positive voices were suddenly accompanied by what I call real crooks, who could become very nasty." and "They came from everywhere: in my head, behind me, in front of me. It seemed as if telephone lines operated from inside my chest." Among these individuals, the voices were hostile, and were not generally accepted as parts of the self or as internally generated phenomena.

People who considered the voices as negative often perceived them to be causing chaos in their minds, and demanding so much attention that the people could hardly communicate with the outside world anymore. One man reported:

In no time (through the voices) I made contact with family members, friends, neighbors, colleagues, the psychiatrist, the police, secret service, criminals, politicians, members of the royal family, and other well-known people. I got in touch with plants, animals, and things. I even discovered "robot people." Once, my brother came to visit me and his eyes were a bit glassy; his skin was smooth. I thought he had been replaced by a robot. I had to take care, because robots are awfully strong. I talked to him in a superficial way and got rid of him as soon as possible.
The Phase of Organization: Coping With the Voices

Many people who heard voices got confused by them and wanted to escape. For some of these people, the period of hearing voices only lasted weeks or months. For others, this period lasted many years. From the interviews, it emerged that after the panic and the feeling of powerlessness, there was a period of great anger toward the voices. This anger, however, did not seem to be a fruitful coping strategy. $\mathrm{Mr}$. R. told us:

Every time I thought I had telepathic contact with people, I went to visit them. If those people denied having telepathic contact with me, then I argued with the voices. So we scolded each other; there was a lot of negative communication. This only made the voices stronger and more aggressive.

Ignoring the voices was another strategy employed by those with unfriendly voices. From the questionnaire it appeared that only 33 percent of the respondents were able to ignore the voices successfully. This strategy did not always seem a good solution. The effort spent on ignoring often led to a curtailment in the scope of activities, as noted in the following description:

Finally I decided to ignore the voices and asked them to leave me alone. In all my ignorance I handled this in a totally wrong way. You can't just put aside something that is existing in yourself and manifesting itself in such a strong way. Moreover, the result of such a decision would be that the voices would lose their right to exist because of a lack of attention and energy, and of course this was not what they wanted. Until then the voices had always been polite and friendly, 
but it changed in the opposite way: they said all kinds of strange things and they made the things that were important to me look ridiculous. It was a fullblown civil war, but I was determined to win and I continued to ignore everything. And I did so by keeping myself busy the entire day. In that period, I solved a lot of crossword puzzles, my house had never been cleaner, and the allotment garden was never taken care of better. The result was that life became more peaceful, but in a constrained way; I almost couldn't relax anymore.

The most fruitful strategies, described by people who heard voices, was to select the positive voices and listen and talk only to them, trying to understand them.

The woman who had talked about ignoring the voices said:

In this period of ignoring the voices, to my surprise there were two voices that wanted to help me. My first reaction was to send them away, because this whole story was getting on my nerves, but they insisted that I needed them and to be honest, I realized this was true. The voices taught me how to watch, hear, and feel. For example, they asked me: "How do you hear us and in what way do we talk to you?" And I, very smart, answered:

"Well, I just hear you with my ears, and you talk with your mouth." "Oh, really," was the answer, "then where is our larynx and in the same time we would like you to notice how you answer us." I was very much amused by this last remark. At first I took everything literally which didn't improve the already strained relation with the voices.

We then agreed to say everything twice, at least the important things: once as we always did, and the second time in symbols in an expressive way. The receiver would repeat briefly the essence of what was expressed.

At first we jerked along. I wasn't used to thinking in symbols at all, but I could immediately apply what they taught me and as a result I began to feel better.

Accepting the voices seemed to be related to a process of growth toward taking responsibility for one's own decisions. Others cannot always be blamed for problems. Or as some people described it, you have to learn to think in a positive way about yourself, the voices, and your own problems.

Another strategy that was frequently mentioned was "drawing limits" or "structuring the contact," whether or not accompanied by ritual or repeated acts. An example was given by someone who heard negative voices and interpreted them as follows:

I must mention that I was attacked by the evil. With my ego-will, I choose not to be identified with the evil. The evil in myself, the evil in others, the evil in things surrounding $\mathrm{me}-\mathrm{I}$ don't want it to be there. That's why I make gestures. You can also do that in your mind. I think you really turn your back to the voices, only by making a physical gesture. "This doesn't fit me, I throw the message away." That gives me a feeling of relief, and then I think: "There, good riddance to bad rubbish." Next, I send away the messenger, and I say aloud or in my mind "You just go to your friends, don't bother me with this." That is the first step. The second step is choosing with my own will to make contact-to associdte with the light in me, the mos beautiful thing there is. I havela source of heat and a healthy core, consisting of pure healthy energy. I know such a thing is present in each human being and that we can choose whether to make contact or not.

In the preceding section, two dimensions of relating to voices emerge: (1) The friendliness or hostility felt, and (2) the relationship or location of the voice relative to the "host" or person hearing the voice. Some respondents integrated the voices as accepted, hostile foes. There is, however, no simple association between internality, friendliness, and acceptance or hostility, externality, and attempts to reject, ignore, or control the voices. In the next section, we learn more about coping modes that worked for the respondents and congress attendees.

\section{Phase of Stabilization}

People who learned to cope with the voices developed a kind of balance. In this stabilization, the individuals saw the voices as a part of themselves. The voices are part of life and self, and they can have a positive influence. In this phase, the individual is able to choose between following the advice of the voices of his or her own ideas. These people are able to say: "I hear voices, and I'm happy for that." One woman told us:

They show me the things I do wrong and teach me how to do them otherwise. But they leave the choice to me if I really waint to change it or rather leave it as it was. They think the way I listen to music isn't right. I lose myself in music, and they think I shouldn't. I tried the way they think I should listen to music, but I didn't want to make the effort. I don't see the use of it. Such a decision is taken in mutual consideration, but I have the final choice and the voices always resign to it.

\section{Another speaker said}

Later on, it seemed as if life was slowing down a little. I was in calmer waters and I could concentrate on my own life again.

A third woman described: 
When you fall with your bicycle, you don't throw it away, but you continue in the right relation to each other. You create a beautiful bicycle trip just as it can go in your inner self. Finally, I have the feeling to be neither the winner nor the loser, but it is as if a dimension is added to my life, a dimension that you dare to handle and which can be useful in the end.

Comparisons of People Who Coped Well With the Voices and Those Who Did Not. The frequency of different types of response to hearing voices and coping in this group of people is illustrated by tabulations of the responses to the questionnaire that had been completed before the congress. We arranged these data by the differences between those persons who could cope with the voices (group A) and those who could not (group B). In table 1 only the variables that appeared to distinguish the two groups are listed. Maily people (33.8 percent) reported that they were able to manage their voices well, but 66.2 percent said they could not. People who could not handle the voices generally experienced them as negative and aggressive, whereas people who could cope with their voices often experienced them as positive and friendly.

The process of coping is complex and entails many variations in this preliminary sample. The common dimensions include: the attributed meaning of the voice; the hostility or friendliness seen in the voice and its messages; the degree of interference or rejection of the voice as internal and part of self or external and alien; the nature of the voice as psychological, medical, spiritual, or the personification of someone else. Coping success, as discussed in the next section, appears to entail reaching some sort of peaceful accommodation and acceptance of the voice as "part of me." Those strategies that focused on ignoring a hostile, "not-part-of-me" voice were less adaptive. At this early juncture in the study of voices from the individual's perspective, we can only suggest further scrutiny of these dimensions and their efficacy in coping strategies.

\section{Coping Success, Frames of Refer-} ence, and Coping Strategies. In the introduction we noted that the 30 year-old woman (one of our patients) who heard voices was somewhat reassured by adopting a specific frame of reference (Jaynes 1976). We wondered whether others would share her theory. This was a naive expectation, because it became clear that there are a great many frames of reference used by the people who heard voices. These frames of reference included psychodynamic, mystical, parapsychological, and medical perspectives. Each of these perspectives has examples in writings of many authors the congress participants had read Jung 1961; Ehrenwald 1978; Pierrakos 1979; Roberts 1979; Atkinson 1985). In an attempt to classify the frames of reference somewhat, we used two main categories: (1) viewing the voices as a psychological phenomenon arising from within the individual (e.g., coming from mystical, psychodynamic, or parapsychologic origins), and (2) viewing the voices as a phenomenon the causes of which lie primarily outside the psychological characteristics of the person.

Viewing voices as a phenomenon related to "not me" psychological characteristics within the person. This perspective, which was described by many participants, has origins in many scholarly sources. Carl Jung (1961), for example, had a psychodynamically based view that impulses from the unconscious speak to humans in visions or voices. Jung's work appealed to many "voice hearers." By reading his books, they felt they developed a better understanding of their voices and what those voices were trying to tell them.

Another relevant psychodynamic theory focuses more on psychodynamic mechanisms for dealing with emotions. It is assumed that a human being may react to an extremely traumatic experience such as incest, sadistic rearing patterns, life-threatening accidents, hostageship, and acts of war by isolating these memories from the consciousness. The trauma then returns in forms of flashbacks, feeling pursued, aggressive voices, or terrifying images (Putnam 1987). Some speakers seemed to be using this strategy of interpreting their voices as coping mechanisms to deal with the emotions provoked by life events.

Mystics have an explanation for hearing voices that is not based on fear but on development (Roberts 1979). They often assume that people have the capacity to expand their consciousness by developing spirituality. Voices may be viewed as part of that expansion. By training themselves, people are able to overstep their limits in a spiritually creative, divine, and/or cosmic ego.

A third "psychological" explanation is given by parapsychology. From this perspective, voices may be viewed as originating from a special gift or sensitivity. It is even possible that a person can be a medium for others. Voices thus are understood as occurring at a more subtle level of consciousness. The 
Table 1. Differences between "good coping" and "bad coping" individuals

\begin{tabular}{|c|c|c|c|}
\hline & & $\begin{array}{c}\text { Group A } \\
\text { good coping (\%) }\end{array}$ & $\begin{array}{c}\text { Group B } \\
\text { bad coping }(\%)\end{array}$ \\
\hline \multicolumn{4}{|l|}{ Nature of the voices } \\
\hline Mostly friendly & & 24 & 18 \\
\hline \multicolumn{4}{|l|}{ Friendly, aggressive, or } \\
\hline giving commands & & 25 & 17 \\
\hline Mostly negative & & 39 & 15 \\
\hline \multicolumn{4}{|l|}{ Who is stronger? } \\
\hline $\mathrm{He}$ & & 85 & 50 \\
\hline The voices & & 15 & 50 \\
\hline \multicolumn{4}{|l|}{ How do you cope with the voices? } \\
\hline \multirow[t]{2}{*}{ Selecting } & Yes & 50 & 15 \\
\hline & No & 50 & 85 \\
\hline \multirow[t]{2}{*}{ Draw limits } & Yes & 50 & 33 \\
\hline & No & 50 & 67 \\
\hline \multirow[t]{2}{*}{ Distraction } & Yes & 25 & 40 \\
\hline & No & 75 & 60 \\
\hline \multirow[t]{2}{*}{ Do you have to obey the voices? } & Yes or sometimes & 40 & 75 \\
\hline & No & 60 & 25 \\
\hline \multirow[t]{3}{*}{ Can you ignore the voices? } & Yes $\cdots$ & 58 & 28 \\
\hline & Sometimes & 6 & 34 \\
\hline & No & 35 & 37 \\
\hline \multicolumn{4}{|l|}{ Are the voices disturbing } \\
\hline \multirow[t]{2}{*}{ the contact with others? } & Yes & 32 & 75 \\
\hline & No & 68 & 25 \\
\hline \multicolumn{4}{|l|}{ Do the voices take over } \\
\hline \multirow[t]{2}{*}{ your thoughts? } & Yes & 33 & 47 \\
\hline & No & 67 & 53 \\
\hline \multicolumn{4}{|l|}{ Did you learn to cope with } \\
\hline \multirow[t]{2}{*}{ them on your own strength? } & Yes & 80 & 30 \\
\hline & No & 20 & 70 \\
\hline \multicolumn{4}{|l|}{$\begin{array}{l}\text { How do you interpret the } \\
\text { voices? }\end{array}$} \\
\hline \multirow[t]{2}{*}{ As gods or spirits } & Yes & 50 & 40 \\
\hline & No & 50 & 60 \\
\hline \multirow[t]{2}{*}{ As a good guide } & Yes & 25 & 14 \\
\hline & No & 75 & 86 \\
\hline \multirow[t]{2}{*}{ As people you know } & Yes & 15 & 35 \\
\hline & No & 85 & 65 \\
\hline \multirow[t]{2}{*}{ As a special gift } & Yes & 46 & 22 \\
\hline & No & 54 & 78 \\
\hline
\end{tabular}

purpose of parapsychology is to handle this sensitivity, for the benefit of oneself or for others. From this perspective, one does not want to lose such a sensitivity, but rather wants to cope with it. It is important to draw limits, to learn to handle the sensitivity instead of being overrun.

Views about voices as caused by factors not primarily psychological 
in origin or external to the person. One group of other than psychological explanations described by participants is founded in biologically oriented psychiatry. Voices are viewed as a symptom of an illness, believed to be anchored in the biological functioning of the brain. Several participants at the congress held this view. For example, one person said:

I never experienced the voices as something from outside myself, I know they are inside of me and I can do something about it. I take medication on a daily basis, and I know I will have to do so for the rest of my life. However, this doesn't bother me. I have been working for 10 years as a secretary and I feel good.

Another very different group of nonpsychological explanations is presented more broadly by the Society for Natural Medicine, a group interpreting voices as spirits of wandering deceased. Some religious groups, such as Jehovah's Witnesses, consider voices as demons. For example, one person said:

I heard three to five different voices. They were sexless and they were always threatening. I had to do exactly what they said. One day they even commanded me to tell my stepfather and at the last moment I came back to myself. Shortly after I admitted myself to a psychiatric hospital. I got medication, but the voices remained. By means of my hobby, which is art and history of the Middle Ages, I started reading the bible. In my opinion in the bible Jesus heals people like myself. It is the story of the possessed man. Matthew VIII, verses

1-5 and Mark V, verses 2-20.

Both frames of reference described above lead to certain coping strategies logically associated with the theoretical explanations.
Group 1 includes the following:

- Psychodynamics-psychotherapy focusing on archetypes and split off emotions.

- Mysticism-mystical training (e.g., through meditation and transcendent experiences).

- Parapsychology-learning how to deal with different levels of consciousness, keeping one's sensitivity under control.

Group 2 includes the following:

- Biological psychiatry-medication.

- Natural medicine-escort of the wandering deceased.

- Religion-faith healing.

If coping attempts are to be made, it seems very important for individuals to adopt a frame of reference, to attribute some meaning to the voices; otherwise it is very difficult to start the phase of organizing one's relationship to the voices to reduce anxiety. Interestingly, at least in terms of coping efforts, it seems unfortunate when individuals adopt a frame of reference discouraging them from attempting to master the voices. Viewing the voices as linked to electronic influences is one such example. The explanation offered by biological psychiatry may also not be very helpful in coping with the voices because it, too, places the phenomenon beyond one's grasp.

\section{The Psychiatric Paradigm and Treatment}

One hypothesis that might be generated from this congress is that the reduction of "hearing voices" to being viewed merely as a pathological phenomenon is not very fruitful in helping patients to deal with these experiences. It may also be inaccurate. Outside the world of psychiatry (Ehrenwald 1978), many people hear voices and are quite able to handle them, even experiencing the voices as enriching their lives. Thus, in the mental health professions, it may be worthwhile to explore in greater detail which frames of reference and coping strategies are best for patients who hear voices so that we can help them more effectively in learning to deal with these experiences.

The main steps in this process are the following:

- To accept the patient's experience of the voices. Those voices are often more penetrating than sensory perceptions.

- To try to understand the different language patients use to describe their frame of reference as well as the different language the voices use for communication. Often a world of symbols and feelings is involved. For example, the voices might speak about light and dark when expressing love and aggression.

- To consider helping the individual communicate with the voices. Issues of differentiating good and bad voices and accepting the person's own negative emotions may be involved. Such acceptance may be assisted when support is given to promote self-esteem.

- To stimulate the patient to meet other people with similar experiences and to read about hearing voices in order to diminish the taboo and the isolation.

For most psychiatrists, these steps will require an enlargement of one's perspective in addition to broadening the generally accepted theories within the profession. We are very interested in hearing from others about the experiences they 
have encountered that might relate to the suggestions we received from the congress participants described above.

\section{References}

Atkinson, J.M. Schizophrenia: A Guide for Sufferers and Their Families. Wellingborough: Turnstone Press, 1985.

Ehrenwald, J. The ESP Experience. New York: Basic Books, 1978.

Jaynes, J. The Origin of Consciousness in the Breakdown of the Bicameral Mind. Boston: Houghton Mifflin, 1976.
Jung, C. Memories, Dreams, Reflections. New York: Pantheon Books, Random House, 1961.

Pierrakos, E. The Path. New York: Phoenicia, 1979.

Putnam, F. "Dissociation as a Response to Extreme Trauma." Presented at a diagnostic workshop, Free University, Armsterdam, 1987. Roberts, J. Seth Speaks: The Eternal Validity of the Soul. Englewood Cliffs, NJ: Prentice Hall, 1979.

\section{Acknowledgments}

We thank Professor S. de Batselier from Leuven, Belgium; Professor J.
Strauss from New Haven, CT; and Professor M. deVries from Maastricht for their stimulation in developing the approach to the phenomenon "hearing voices" as described in this article.

\section{The Authors}

Marius A.J. Romme, M.D., is Professor of Social Psychiatry,

University of Limburg, Maastricht, The Netherlands. Alexandre D.M.A.C. Escher, M.A., is Science Journalist, Community Mental Health Center, Maastricht, The Netherlands. 


\section{Chapter 3}

\section{Coping with voices: an emancipatory approach.}

British Journal of psychiatry 161, 99-103.

Romme, M.A.J., Honig, A., Noorthoorn, O., Escher, A.D.M.A.C. (1992). 


\title{
Coping with Hearing Voices: An Emancipatory Approach
}

\author{
M. A. J. ROMME, A. HONIG, E. O. NOORTHOORN and A. D. M. A. C. ESCHER
}

\begin{abstract}
A questionnaire comprising 30 open-ended questions was sent to 450 people with chronic hallucinations of hearing voices who had responded to a request on television. Of the 254 replies, 186 could be used for analysis. It was doubtful whether 13 of these respondents were experiencing true hallucinations. Of the remaining 173 subjects, 115 reported an inability to cope with the voices. Ninety-seven respondents were in psychiatric care, and copers were significantly less often in psychiatric care $(24 \%)$ than non-copers $(49 \%)$. Four coping strategies were apparent: distraction, ignoring the voices, selective listening to them, and setting limits on their influence.
\end{abstract}

Verbal auditory experiences or perceptions in clear consciousness without corresponding external stimuli are common symptoms of mental illness. Although schizophrenia is generally amenable to pharmacotherapy and social therapies, many chronic schizophrenic patients continue to hear voices (Falloon \& Talbot, 1981). These persistent voices may be of a threatening or obscene nature, representing some outside evil power over which the patients feel they have no control. At other times the same voices may be regarded as good and pleasant companions. Some patients are so preoccupied with and reactive to the voices that social reintegration is hampered.

Hearing voices is considered to be a common sign of psychosis (i.e. insanity) by all leading psychiatric textbooks. We are used to interpreting hallucinations within a psychodynamic, biological, or psychopharmacological frame of reference (Kaplan \& Sadock, 1985). Hence hearing voices is supposed to be accompanied by other psychiatric signs or symptoms. It is perceived as a sign of mental illness by the psychiatric profession and is accepted as such by both patients and lay people. However, it is questionable whether hearing voices is an unequivocal sign of mental illness. Many people know that hearing voices is considered to be pathological, and so are not likely to discuss their hallucinations openly, as they do not want to be perceived as a psychiatric patient.

In general, the aim of psychiatric treatment is to bring the patient back into our reality with antipsychotic medication, social therapies, and sometimes psychodynamic therapy. Acceptance of patients' reality is avoided, as this might confuse them even further and increase their internal chaos. Thus, discussion of the subjective experiences of hearing voices is not encouraged, even though these auditory experiences sometimes represent a large part of the patient's daily life.
This paper explores the phenomenon of hearing voices and the way in which hallucinators discuss and cope with their voices.

\section{Method}

After an evening television talkshow in which a schizophrenic patient talked about her voices, viewers who heard voices were asked to telephone the Correlation Foundation (a non-profit organisation with a staff of trained therapists which acts as an intermediary after 'emotional' television programmes). Seven hundred individuals responded, 450 of whom heard voices. The Foundation reported this to be an extremely high response rate (Langelaan, 1987).

A questionnaire was designed consisting of 30 open-ended questions. The questions were partly based around the accounts and themes mentioned by those who contacted the Correlation Foundation. The questionnaire was posted to the 450 persons who heard voices, and 254 replies (56\%) were received, of which only $186(41 \%)$ could be used for a complete analysis. The other 68 were mostly extended letters about experiences which could not unequivocally be categorised. The questions were open ended as we were interested in people's own descriptions of their experiences and the effect of the voices on their lives.

The following are examples of the type of questions asked: "How many voices do you hear? Are the voices friendly, aggressive, advising, or otherwise? How do you interpret the voices? Who is stronger, the voices or yourself? Do the voices intrude in your daily contact with others? Do others know of your voices? Did you receive help in coping with the voices (e.g. psychiatrist, psychologist, clairvoyant, mesmerist)?"

\section{Results}

Of the 186 respondents only $13(7 \%)$ reported that they did not experience disruption of social contacts by the voices nor any other formal psychiatric symptoms. These 13 respondents said of their voices: "They stimulate me. They are friends. It is my guide and tutor". In this group seven felt themselves to be paranormally gifted and described 


\section{ROMME ET AL}

Table 1

Respondents with additional psychiatric symptoms or who were distressed by hallucinations

\begin{tabular}{|c|c|c|c|}
\hline & $\begin{array}{c}\text { No. }(\%) \text { of } \\
\text { subjects } \\
(n=164)\end{array}$ & $\begin{array}{c}\text { No. }(\%) \text { of } \\
\text { men } \\
(n=49)\end{array}$ & $\begin{array}{c}\text { No. }(\%) \text { of } \\
\text { women } \\
(n=115)\end{array}$ \\
\hline $\begin{array}{l}15-30 \\
30-40 \\
40-65 \\
65+\end{array}$ & $\begin{array}{rr}29 & (18 \%) \\
56 & (34 \%) \\
73 & (45 \%) \\
6 & (4 \%)\end{array}$ & $\begin{array}{rr}8 & (16 \%) \\
19 & (39 \%) \\
19 & (38 \%) \\
3 & (6 \%)\end{array}$ & $\begin{array}{rr}21 & (18 \%) \\
37 & (32 \%) \\
54 & (47 \%) \\
3 & (3 \%)\end{array}$ \\
\hline $\begin{array}{l}\text { Marital status } \\
\text { unmarried } \\
\text { married } \\
\text { divorced } \\
\text { other } \\
\text { data missing }\end{array}$ & $\begin{array}{rr}41 & (25 \%) \\
60 & (37 \%) \\
26 & (16 \%) \\
4 & (2 \%) \\
33 & (20 \%)\end{array}$ & $\begin{array}{rr}9 & (18 \%) \\
20 & (41 \%) \\
6 & (12 \%) \\
1 & (2 \%) \\
13 & (27 \%)\end{array}$ & $\begin{array}{rr}32 & (28 \%) \\
40 & (35 \%) \\
20 & (17 \%) \\
3 & (3 \%) \\
20 & (17 \%)\end{array}$ \\
\hline $\begin{array}{l}\text { Employment } \\
\text { paid } \\
\text { not paid } \\
\text { household } \\
\text { vocational training } \\
\text { no occupation } \\
\text { data missing }\end{array}$ & $\begin{array}{rr}64 & (39 \%) \\
33 & (20 \%) \\
31 & (19 \%) \\
18 & (11 \%) \\
8 & (5 \%) \\
10 & (6 \%)\end{array}$ & $\begin{array}{rr}22 & (45 \%) \\
9 & (19 \%) \\
1 & (2 \%) \\
14 & (29 \%) \\
0 & (0 \%) \\
3 & (5 \%)\end{array}$ & $\begin{array}{rr}42 & (37 \%) \\
24 & (21 \%) \\
30 & (26 \%) \\
4 & (3 \%) \\
8 & (7 \%) \\
7 & (6 \%)\end{array}$ \\
\hline
\end{tabular}

themselves as 'clairaudient'. These subjects were excluded from further evaluation as one might question whether these experiences were true hallucinations. We defined a hallucination as a disorder of perception which people describe as being located in the external world (ego-dystonic) and which has the same qualities as normal perceptions, that is, is vivid and solid, in the absence of any actual sensory stimulus. The data reported below refer to the remaining 173 respondents who fulfilled this definition of a hallucination.

Nine patients did not indicate their sex. More than twothirds of the respondents were women. The majority were 30 years or over, and the respondents were predominantly married. Only a small proportion did not have an occupation (5\%) (Table 1). The age and sex of respondents were similar to those of all the people who contacted the Correlation Foundation in 1987, although twice as many respondents were divorced, and the proportion of respondents who were married was slightly less than half that of others who contacted the Foundation in 1987.

The data were analysed with reference to ability to cope with voices. We divided the sample into a coping and a non-coping group, according to their own statements in answer to the question, "Are you able to cope with the voices or not?"' Of the 173 respondents, $115(66 \%)$ reported an inability to cope with the voices. Table 2 shows some characteristics of the voices experienced by both groups. Most respondents had been hearing voices for five years or more, with the onset peaking between 15 and 30 years of age. Demographic data did not differ significantly between copers and non-copers. The non-copers felt significantly less in control of their voices and experienced the voices more negatively. Imperative hallucinations were significantly more common among the non-copers.
Table 2

Characteristics of hallucinations in copers and non-copers

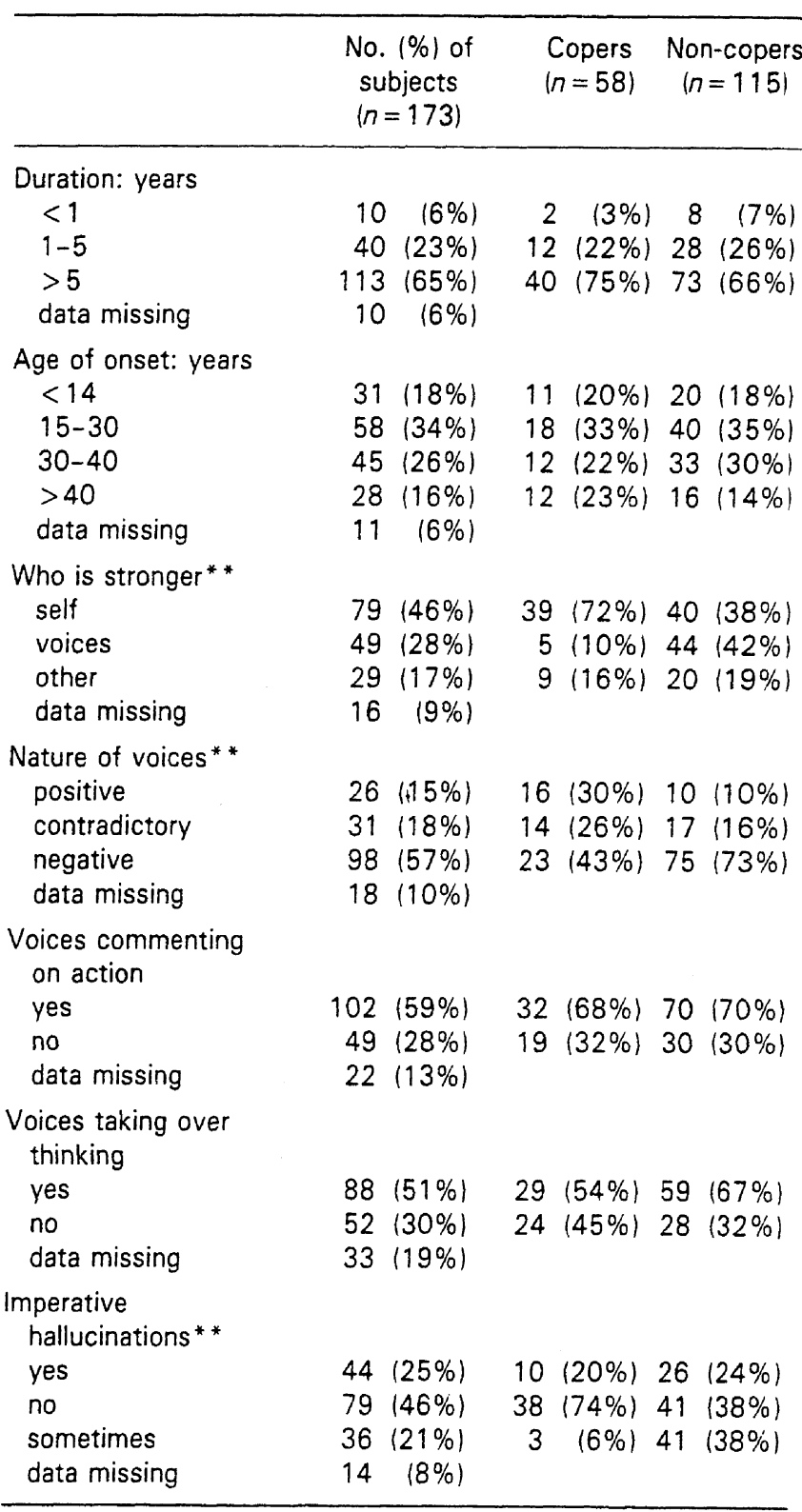

$* * P<0.001$, for distribution between copers and non-copers.

The coping strategies described by the respondents were categorised into four groups. Of these distraction was the only strategy used significantly more often by the noncopers, while selective listening and setting limits was only used by a few non-copers (Table 3) compared with copers.

Responses to the questions "Do others know about your voices? Do you talk about your voices with others? What is the reaction of others when you talk about your voices with them?", did not differ significantly between copers and non-copers.

Respondents in psychiatric care (patients) compared with others (non-patients) perceived significantly less support from others. They also reported significantly more often that others did not know about their voices. 


\section{COPING WITH HEARING VOICES}

Table 3

Coping strategies of copers and non-copers

\begin{tabular}{|c|c|c|c|}
\hline & $\begin{array}{c}\text { No. }(\%) \text { of } \\
\text { subjects }\end{array}$ & $\begin{array}{c}\text { No. }(\%) \text { of } \\
\text { copers }\end{array}$ & $\begin{array}{l}\text { No. }\langle \%\rangle \text { of } \\
\text { non-copers }\end{array}$ \\
\hline \multicolumn{4}{|l|}{ Distraction* } \\
\hline $\begin{array}{l}\text { yes } \\
\text { no } \\
\text { data missing }\end{array}$ & $\begin{array}{ll}42 & (24 \%) \\
72 & (42 \%) \\
59 & (34 \%)\end{array}$ & $\begin{array}{ll}10 & (26 \%) \\
29 & (74 \%)\end{array}$ & $\begin{array}{ll}32 & (43 \%) \\
43 & (57 \%)\end{array}$ \\
\hline \multicolumn{4}{|l|}{ Ignoring ** } \\
\hline $\begin{array}{l}\text { yes } \\
\text { no } \\
\text { sometimes } \\
\text { data missing }\end{array}$ & $\begin{array}{ll}54 & (31 \%) \\
57 & (33 \%) \\
37 & (21 \%) \\
25 & (14 \%)\end{array}$ & $\begin{array}{rr}31 & (56 \%) \\
21 & (37 \%) \\
4 & (7 \%)\end{array}$ & $\begin{array}{ll}23 & (25 \%) \\
36 & (39 \%) \\
33 & (36 \%)\end{array}$ \\
\hline \multicolumn{4}{|c|}{ Selective listening ** } \\
\hline $\begin{array}{l}\text { yes } \\
\text { no } \\
\text { data missing }\end{array}$ & $\begin{array}{ll}30 & (17 \%) \\
87 & (50 \%) \\
56 & (33 \%)\end{array}$ & $\begin{array}{ll}19 & (46 \%) \\
22 & (53 \%)\end{array}$ & $\begin{array}{ll}11 & (14 \%) \\
65 & (85 \%)\end{array}$ \\
\hline \multicolumn{4}{|l|}{ Setting limits** } \\
\hline $\begin{array}{l}\text { yes } \\
\text { no } \\
\text { data missing }\end{array}$ & $\begin{array}{ll}45 & (26 \%) \\
79 & (46 \%) \\
49 & (28 \%)\end{array}$ & $\begin{array}{ll}19 & (48 \%) \\
20 & (51 \%)\end{array}$ & $\begin{array}{ll}26 & (30 \%) \\
59 & (70 \%)\end{array}$ \\
\hline
\end{tabular}

$* P<0.05, * *<<0.001$, for distribution between copers and non-copers.

The patients were older and were more frequently unmarried than the non-patients (Table 4). Copers were significantly less often in psychiatric care $(24 \%)$ than noncopers $(49 \%)(P<0.001)$.

\section{Successful coping strategies}

Twenty copers who gave a clear description of their problems and coping strategies were selected for further interview. Ten of these copers had never received any psychiatric care. Of these, two cases could be interpreted as pathological bereavement reactions, as the onset of their voices coincided with the death of a child. Three copers had heard voices from childhood onwards. In the other five cases the onset of hearing voices started at different ages and in various circumstances. In none of these ten individuals could a definite psychiatric diagnosis be made. Four of the other ten individuals who were known to have a psychiatric history had been diagnosed with schizophrenia and four others with a dissociative disorder. In the other two cases we could not trace a formal psychiatric diagnosis.

The stages leading up to the acceptance of the voices, which precede the actual development of coping strategies, have been described by Romme \& Escher (1989) and are not discussed here. Four main groups of coping strategies - distraction, ignoring, selective listening, and setting limits - were apparent.

\section{Distraction}

Two main forms were described: (a) distraction by physical means (taking a shower, jogging, breathing exercises, watching a pleasant video) and (b) distraction by more abstract means (drawing a cloak around yourself in your mind, meditation, yoga).
Table 4

Perceived support and discussion on voices between patients in psychiatric care and non-patients

\begin{tabular}{|c|c|c|}
\hline & $\begin{array}{c}\text { No. }(\%) \text { of } \\
\text { non-patients } \\
(n=67)\end{array}$ & $\begin{array}{l}\text { No. }(\%) \text { of } \\
\text { patients } \\
(n=97)\end{array}$ \\
\hline $\begin{array}{l}\text { Sex } \\
\text { male } \\
\text { female }\end{array}$ & $\begin{array}{ll}16 & (24 \%) \\
51 & (76 \%)\end{array}$ & $\begin{array}{l}33(34 \%) \\
64(66 \%)\end{array}$ \\
\hline Mean (s.d.) age: years* & $37(10.6)$ & $43(12.6)$ \\
\hline $\begin{array}{l}\text { Age of onset: years } \\
<15 \\
15-30 \\
30-40 \\
40-65 \\
>65\end{array}$ & $\begin{array}{rr}12 & (18 \%) \\
30 & (45 \%) \\
17 & (25 \%) \\
8 & (12 \%) \\
0 & (0 \%)\end{array}$ & $\begin{array}{rr}19 & (20 \%) \\
28 & (29 \%) \\
28 & (29 \%) \\
20 & (21 \%) \\
1 & (1 \%)\end{array}$ \\
\hline $\begin{array}{l}\text { Employment } \\
\text { paid } \\
\text { not paid } \\
\text { household } \\
\text { vocational training } \\
\text { no occupation }\end{array}$ & $\begin{array}{rr}28 & (42 \%) \\
17 & (25 \%) \\
9 & (13 \%) \\
3 & (5 \%) \\
10 & (15 \%)\end{array}$ & $\begin{array}{rr}41 & (43 \%) \\
18 & (19 \%) \\
22 & (23 \%) \\
5 & (5 \%) \\
9 & (10 \%)\end{array}$ \\
\hline $\begin{array}{l}\text { Marital status* } \\
\text { single } \\
\text { married } \\
\text { divorced } \\
\text { widowed }\end{array}$ & $\begin{array}{rr}11 & (19 \%) \\
35 & (60 \%) \\
11 & (19 \%) \\
1 & (2 \%)\end{array}$ & $\begin{array}{rr}30 & (38 \%) \\
31 & (39 \%) \\
15 & (19 \%) \\
3 & (4 \%)\end{array}$ \\
\hline $\begin{array}{l}\text { Duration: years } \\
\qquad 1 \\
\qquad \begin{array}{l}1-5 \\
>5\end{array}\end{array}$ & $\begin{array}{rr}4 & (6 \%) \\
18 & (27 \%) \\
45 & (67 \%)\end{array}$ & $\begin{array}{rr}6 & (6 \%) \\
22 & (23 \%) \\
68 & (71 \%)\end{array}$ \\
\hline $\begin{array}{l}\text { Perceived support }{ }^{* *} \\
\text { no } \\
\text { yes }\end{array}$ & $\begin{array}{rr}1 & (2 \%) \\
69 & (98 \%)\end{array}$ & $\begin{array}{ll}47 & (49 \%) \\
49 & (51 \%)\end{array}$ \\
\hline $\begin{array}{l}\text { Do others know about } \mathrm{m} \\
\text { no } \\
\text { yes }\end{array}$ & $\begin{array}{rr}2 & (2 \%) \\
69 & (98 \%)\end{array}$ & $\begin{array}{l}15(14 \%) \\
86(86 \%)\end{array}$ \\
\hline $\begin{array}{l}\text { Discussion with others ab } \\
\text { no } \\
\text { yes }\end{array}$ & $\begin{array}{l}35(50 \%) \\
34(50 \%)\end{array}$ & $\begin{array}{ll}46 & (48 \%) \\
50 & (52 \%)\end{array}$ \\
\hline $\begin{array}{l}\text { What reaction do people } \\
\text { positive interest } \\
\text { negative interest } \\
\text { no interest } \\
\text { other }\end{array}$ & $\begin{array}{rr}11 & (19 \%) \\
23 & (40 \%) \\
1 & (1 \%) \\
23 & (40 \%)\end{array}$ & $\begin{array}{rr}24 & (29 \%) \\
29 & (35 \%) \\
4 & (5 \%) \\
26 & (32 \%)\end{array}$ \\
\hline
\end{tabular}

Numbers do not add up to column totals as not all respondents gave the relevant information.

${ }^{*} P<0.05,{ }^{*} P<0.01$, patients $v$. non-patients.

\section{Ignoring}

A 42-year-old housewife had been hearing one voice for five years. She had been diagnosed as suffering from schizophrenia and had been admitted four times following suicide attempts ordered by her voice. Eventually she discussed the voice with her husband. He compared the voice with that of a nagging neighbour and asked her if she would harm herself if this neighbour ordered her to do so. Since then, whenever the voice gives these orders, she ignores them. For instance, when she is peeling potatoes 
and is ordered to stab herself with the knife, she stabs a potato instead. Her control over the voice has increased dramatically and she has not been readmitted since.

\section{Selective listening}

A 53-year-old divorcee had over the last ten years been in contact with various psychotherapists and lay people in connection with her voices. She described voices which periodically predicted disaster which she could not prevent. At one stage she tried to eradicate the voice by 'getting hold of it', lifting it in the air and throwing it as far as possible, while saying "Go back to your own friends, there is no place for you here". This ritual proved useful and enabled her to select the positive from the negative voices, and control them.

\section{Setting limits}

A 28-year-old woman had been in hospital several times and still saw her psychiatrist on an out-patient basis. She said: "I made a deal with the voices. After eight o'clock it is their time. I don't answer telephone calls and I don't meet other people from eight o'clock onwards. During the day they hardly bother me now and I am able to function much better in daily life."

\section{Discussion}

This sample of auditory hallucinators is unique, as we were able to contact people who were not patients who coped well with often potentially disabling hallucinations. Our results are not of an epidemiological nature, as the population was self-selected, not random, and the attrition rate was too high. However, this does not impair the clinical importance of the description of the variations in coping styles. The questionnaire was not studied for reliability or validity, and as yet no objective criteria have been applied to determine how many of the respondents actually were mentally ill according to formal standards such as the Present State Examination (Wing et al, 1974). Some of the demographic data reflect the general response trend of the Correlation Foundation rather than a specific trait of this research sample. All of these aspects of the method should be taken into account in the discussion of the data.

Because of the way we recruited our respondents, they included those who reported experiences which could hardly be described as auditory hallucinations, as well as chronic psychiatric patients and those whose hearing of voices did not lead to psychiatric treatment. The first group was excluded from further analysis. The second group was divided into copers and non-copers. The copers experienced the voices more often as a positive phenomenon. They were able to keep the voices under control by communicating with them in a selective manner. This group sought less psychiatric help than the non-copers. These data give some indication that hearing voices does not always lead to a psychosocial handicap or to seeking psychiatric help. The voices commenting on action and taking over thinking were equally represented in the two groups, but imperative hallucinations were more common among non-copers.

Coping styles were more diverse in the copers. Distraction was used significantly more often by the non-copers. A similar proportion in each group discussed hearing voices with others, which does not support our hypothesis that the professional attitude to hearing voices limits wider discussion of them, although the perceived support from such a discussion was significantly less in the patient group.

In October 1987 we organised a meeting for the people who responded to the television programme (Romme \& Escher, 1989). As a result of this congress some participants founded a self-help association. which they called "RESONANCE". So far the association has organised an emergency telephone service, workshops for people who hear voices, and regular lectures and discussion sessions for psychiatric nurses. The network has started to expand, with MIND in the UK setting up a national working group on hearing voices. Contacts within the association and the publicity following the congress have encouraged people who hear voices to accept them.

Exchanging information on hearing voices and enabling sufferers to organise themselves can help them to cope with chronic auditory hallucinations and experiences, which are not always sufficiently alleviated by traditional psychiatric treatment. Help of a more practical nature to master the voices, as in the examples above, should be encouraged. That hearing voices does not seem to be limited to psychiatric patients might prove helpful in the acceptance of hearing voices and the development of coping mechanisms.

One problem that needs further research is the differentiation between true and pseudo-hallucinations. When we defined true hallucinations as hearing voices coming from outside the mind and through the ears, none out of 20 were experiencing true hallucinations. This was also the case for the schizophrenic patients. When we defined true hallucinations as hallucinations that are clearly experienced as coming from somebody else, 18 (8 who had had psychiatric care and 10 who had not had psychiatric care) were experiencing voices as ego-dystonic. Most schizophrenic patients hear voices inside their head, but are not able to have a dialogue with them and do not feel they can cope with them. 


\section{COPING WITH HEARING VOICES}

In our experience hallucinators describe hearing voices initially as perceived through their ears. However, as time passes, this develops into a perception of these voices as inside their head or body.

Many chronic hallucinators who are not able to cope with their voices or show signs of mental illness end up in psychiatric care. Helping the patient to accept the voices and actively developing effective coping strategies with the patient may well prove an effective adjunct to psychiatric rehabilitation, as has been reported earlier (Falloon \& Talbot, 1981; Strauss, 1989). We cannot assume that all hallucinations and hallucinators are the same. There are many more possible coping strategies than the four described by our respondents (McInnis \& Marks, 1990). 'Coping with hearing voices' should be included in psycho-education programmes for relatives of people with schizophrenia. Another approach would be to help the hallucinators to share their experiences, as demonstrated in Holland by the television programme and the subsequent congress.

This report justifies further and more formal psychiatric research, to gather epidemiological data on hearing voices in the general population, and to develop more diverse coping strategies. Communication between the families of patients who chronically hear voices and psychiatric staff should also be stimulated.

\section{References}

Falloon, I. R. H. \& Talbot, R. E. (1981) Persistent auditory hallucinations: coping mechanics and implications for management. Psychological Medicine, 11, 329-339.

KAPLAN, H. I. \& SADOCK, B. J. V. (eds) (1985) Comprehensive Textbook of Psychiatry (4th edn). Baltimore: Williams and Wilkins.

LANGELAAN, M. (1987) Correlation Foundation hears more than 700 voices. Maandblad Geestelijke Volksgezondheid, 718, 822-828.

MCINNIS, M. \& MARKS, I. (1990) Audiotape therapy for persistent auditory hallucinations. British Journal of Psychiatry, 157, 913-914.

Romme, M. A. J. \& Escher, A. D. M. A. C. (1989) Hearing voices. Schizophrenia Bulletin, 15, 209-216.

Strauss, J. S. (1989) Subjective experiences of schizophrenia: towards a new dynamic psychiatry II. Schizophrenia Bulletin, $15,179-187$.

Wing, J. K., Cooper, J. E. \& Sartorius, N. (1974) The Measurement and Classification of Psychiatric Symptoms. Cambridge: Cambridge University Press.

*M. A. J. Romme, MD, PhD, Professor of Social Psychiatry, University of Limburg; A. Honig, MD, PhD, MRCPsych, Consultant in Social Psychiatry, Community Mental Health Center, Maastricht, Lecturer, Department of Social Psychiatry, University of Limburg; E. O Noorthoorn, MD, Research Fellow, Department of Social Psychiatry, University of Limburg; A. D. M. A. C. Escher, MA, Science Journalist, Community Mental Health Center, Maastricht, The Netherlands

*Correspondence: Rijksuniversiteit Limburg, Vakgroep Sociale Psychiatrie, Postbus 616, 6200 MD Maastricht, The Netherlands 
Chapter 4

\section{Independent course of childhood}

\section{auditory hallucinations:}

\section{a sequential 3-year follow-up study.}

British Journal of Psychiatry. 181 (suppl. 43), s10-s18

Escher, A., Romme, M., Buiks, A., Delespaul, Ph., Van Os, J., (2002) 


\title{
Independent course of childhood auditory
}

\section{hallucinations: a sequential 3-year follow-up study*}

\author{
SANDRA ESCHER, MARIUS ROMME, ALEX BUIKS, PHILIPPE DELESPAUL \\ and JIM VAN OS
}

\begin{abstract}
Background Childhoodhallucinations of voices occur in a variety of contexts and have variable long-term outcomes.
\end{abstract}

\begin{abstract}
Aim To study the course of experience of voices sequentially over a 3-year period in those with and those without a need for mental health care (patient status).
\end{abstract}

\begin{abstract}
Method In a group of 80 children of mean age 12.9 years (s.d. $=3.1$ ), of which around $50 \%$ were not receiving mental health care, baseline measurement of voice characteristics, voice attributions, psychopathology, stressful life events, coping mechanisms and receipt of professional care were used to predict 3-year course and patient status.
\end{abstract}

Results The rate of voice discontinuation over the 3-year period was $60 \%$. Patient status was associated with more perceived influence on behaviour and feelings and more negative affective appraisals in relation to the voices. Predictors of persistence of voices were severity and frequency of the voices, associated anxiety/depression and lack of clear triggers in time and place.

\section{Conclusions Need for care in the context of experience of voices is associated with appraisal of the voices in terms of intrusiveness and 'omnipotence'. Persistence of voices is related to voice appraisals, suggesting that experience of voices by children should be the target of specific interventions.}

\section{Declaration of interest None.}

Supported by the Dutch Prevention Fund.
Hallucinations of hearing voices by children and adolescents can occur in the context of a variety of psychiatric states, such as schizophrenia (Bettes \& Walker, 1987; Green et al, 1992; Galdos et al, 1993; Galdos \& van Os, 1995), symptoms of anxiety and depression (Chambers et al, 1982; Garralda, 1984a; Ryan et al, 1987), migraine (Schreier, 1998), trauma, dissociation processes and reactive psychoses (Famularo et al, 1992; Putnam \& Peterson, 1994; Altman et al, 1997). All these studies concern selected clinical samples, and small numbers of long-term follow-ups of such groups suggest variable outcomes, reflecting the heterogeneity of the subject selection procedures in the different studies (Garralda, 1984b; Del Beccaro et al, 1988). A recent population-based epidemiological study found that the prevalence of at least sometimes experiencing hallucinatory phenomena in children was $8 \%$, of which only a third had a DSM-III (American Psychiatric Association, 1980) diagnosis, about twice the diagnostic rate for children in the nonhallucinatory group (McGee et al, 2000). For the majority of children experiencing hallucinations in the general population, therefore, these experiences appear to be non-pathological. A small group, however, may develop persistent symptoms and subsequent psychotic disorder in adult life. In a recent follow-up of 761 children, selfreported psychotic symptoms at age 11 years increased the odds for psychotic illness at age 26 years by 16.4 times, but the actual number of children that developed a psychotic disorder was very small. In this study, childhood psychotic experiences had predictive value independent of childhood psychiatric diagnosis (Poulton et al, 2000). Other work also suggests that childhood hallucinations (especially persisting hallucinatory experiences) may increase the risk

*Presented in part at the European First Episode Schizophrenia Network Meeting,Whistler BC, Canada, 27 April 200I. for later psychotic disorder (Fennig et al, 1997).

There is thus an extreme diversity of possible outcomes in children with pathological and non-pathological hallucinatory experiences, and although the risk is increased, only a very small number of children develop psychosis. Although there have been a number of prospective and retrospective long-term follow-up studies (Garralda, 1984b; Poulton et al, 2000), no shorter-term sequential follow-ups of children with hallucinations have been conducted to study the course of these experiences themselves and the possible factors that influence their short-term course. In this study, a group of children who were hearing voices were followed sequentially over a period of 3 years to establish the rate of discontinuation of voices in the short term. In addition, we wished to establish the predictive value of attributions associated with the voices, life events and social adversity, coping, professional help received, concurrent psychopathology and dissociation. We wished to recruit not only individuals who were in contact with mental health professionals but also children who had never sought professional help, in order to examine to what extent differences between 'patients' and 'non-patients' would influence the course of hallucinatory experiences (Romme \& Escher, 1989, 1994; Romme et al, 1992).

\section{METHOD}

\section{Sample}

Power calculations suggested that around 80 children were required at conventional alpha, given an effect size of 2 and a $40 \%$ overall rate of voice discontinuation over 3 years. In order to recruit children and adolescents who were hearing voices, we proceeded in two stages. First, extensive media contacts, formed in the course of a prior investigation (Romme et al, 1992), were used in an attempt to create awareness and reduce stigmatisation at the national level. For example, two of the research team (M.R. and S.E.) made an appearance on a popular TV talk show, where the experience of a child hearing voices, as well as the view of its parents, were discussed. At the end of the programme, viewers were invited to attend a special conference on the subject. This conference was attended by 40 children and their parents and received 
media coverage. In the second stage, the actual recruitment started. Press releases were sent out and several TV and radio appearances were made in which help in contacting the target population was requested. The local community paediatric health service in Maastricht was contacted, where all children aged 0-14 years are screened periodically, as well as several child and adolescent psychiatric services in the country. Over a period of approximately 1 year 80 children were recruited. The children were seen at baseline, and subsequently at 1-year intervals over a period of 3 years; each child was therefore interviewed four times. Whenever a child had indicated at the first follow-up that the voices had disappeared, no attempts were made to re-interview at the second followup, in order to avoid unnecessary focus on a past, and often upsetting, experience. However, in order to have an estimate of the rate of recurrence of voices after earlier discontinuation, an attempt was made to again interview all 80 children at the third follow-up, regardless of whether they heard voices or not. Thus, a total of 31 person-years of follow-up were available of children who on an earlier occasion had indicated that they had stopped hearing voices.

\section{Research instruments and procedures}

The research team consisted of two field workers who had extensive prior experience in interviewing individuals with hallucinations, using a similar format as the one in the present study. They also had prior experience in administrating the other instruments used. Nearly all children were interviewed at home. The baseline interview was conducted in the presence of at least one parent or grandparent (with a few exceptions where adolescents had specifically asked that the parent not be present). All subjects and their parents, where appropriate, provided written informed consent, conforming to the local ethics committee guidelines. At each interview the same instruments were used. The main instrument was the Maastricht Voices Interview for Children. The interview consisted of the Maastricht Voices Interview for adults that we adapted for children with the help of a clinical child psychologist. It contains several items in relation to the experience of hearing voices which were included on the basis of extensive qualitative research involving many individuals hearing voices over a period of at least 10 years, including children (Romme, 1996; Romme \& Escher, 1996).

The number of voices was coded as 1 , $2-5,6-10,>10$ and 'variable'. The frequency of the voices was coded as 'continuous', 'hourly', 'daily', 'weekly', 'monthly' and 'variable'. The emotional tone of the voice was coded as 'mainly positive', 'mainly negative' and 'variable'. Triggers of the voices were coded as 'present' or 'absent' in the analyses, and assessed in terms of time, place, and emotional trigger events (angry, scared, sad, tired, jealous, doubtful, guilty, insecure, in love, unhappy, lonely, happy).

The degree of coping mobilised by the voices was assessed by constructing a total score of 18 possible coping mechanisms that were enquired about in a structured way and could be scored as 'present', or 'absent'. In addition, different dimensions of coping were constructed based on a previous classification (Bak et al, 2001a,b) by calculating the sum of the items divided by the number of items. We thus distinguished the coping styles: passive illness behaviour (using medication, using alcohol or drugs), passive problem-solving (ignoring voice, listening selectively to voice, doing something), active problem-solving (making a deal with voice, swearing at voice, seeking distraction, making a drawing of the voice, sending voice away, writing something about the voice), active problem-avoiding (thinking of something else, running away from the voice, calling someone over the telephone, visiting someone), symptomatic coping (listening carefully to voice, performing a ritual against the voice) and other coping (other way of coping).

Attributions were assessed as follows. A secondary explanation was coded as 'present' if the child had indicated explanations of the voice being caused by a spirit or ghost, by a special gift, by a disease, coming from a different world, or another explanation. Attribution of perceived power of the voices in terms of negative influence on emotions and behaviour was expressed as the total score of the 'yes'/'no' coded items: 'voice is scaring me'; 'voice makes me confused'; 'voice interferes with paying attention at school'; 'voice interferes with homework'; 'I am getting into arguments because of the voice'; 'I am getting punished because of voice'; 'voice makes me run away'; 'voice makes me do things I don't want'. A total score of life events in the past year was constructed by asking, in a structured way, about 22 common childhood events scored 'present' or 'absent' (e.g. death, illness, accidents, friends moving away, changing school, first menstruation, pregnancy, unanswered love, arguments, parental divorce, repeating school year, other life events). A total childhood adversity score was constructed by adding the scores of the items that were assessed in a structured way (scored 'present' or 'absent'): childhood not pleasant; not feeling safe at home; not feeling safe on the street; not feeling safe at school; being punished in strange ways; being beaten regularly; being scolded regularly; feeling unwanted; witness of physical abuse; witness of sexual abuse; molested or abused sexually. In addition, the child was asked specifically whether it thought the voice was related to some past stressful life event or trauma.

Receipt of professional help and helpseeking behaviour were assessed by asking whether professional help was being received in relation to the voices, and/or whether a hospital admission had ever occurred in relation to the voices. In addition, after assessing the size of the child's social network in a structured way, the proportion of the total network to which the child had revealed the voices was assessed.

General and specific psychopathology were assessed using the extended Brief Psychiatric Rating Scale (BPRS; Overall \& Gorham, 1962; Lukoff et al, 1986), yielding scores for the dimensions anxiety/ depression (anxiety, depressive mood, guilt feelings, suicidality), positive psychotic symptoms (suspiciousness, unusual thought content, hallucinations) negative psychotic symptoms (motor retardation, blunted affect, emotional withdrawal, self-neglect), disorganisation (disorientation, conceptual disorganisation, bizarre behaviour) and mania (excitement, euphoria, hyperactivity, distractibility) to rate psychiatric symptoms, and the Youth Self-Report/11-18 (YSR) to measure general problem behaviour expressed as the total score (Verhulst et al, 1996). Although the YSR and related Child Behaviour Checklist (CBCL; Verhulst et al, 1996) scales allow for the calculation of separate scores corresponding to several behavioural dimensions based on exploratory factor analysis, confirmatory factor analytic studies have shown inadequate empirical support for these syndromes and their differentiation (Greenbaum \& Dedrick, 1998; Hartman et al, 1999). Instead, a general problem behaviour factor 
appears to underlie $\mathrm{CBCL}$ and related scales data across different age groups (Greenbaum \& Dedrick, 1998; Hartman et al, 1999). We therefore examined the total amount of psychopathology, as measured by the total problem score. The Dissociative Experience Scale (DES; Bernstein \& Putnam, 1986) is a 28 -item self-report instrument measuring dissociative experiences. The respondent is asked to indicate agreement with a statement on a scale between 1 and 10 . The sum of the amount of agreement, divided by the number of items constitutes the DES score. A score exceeding 30 is considered deviant. Items of the DES were reworded to match the cognitive level of children, and all items were read aloud to the children, followed by assessment of whether they had understood the question.

Global level of functioning was assessed using the Children's Global Assessment Scale (CGAS; Shaffer et al, 1983). This scale was administered on the occasion of the first and last measurement (the last measurement being the last time the child was seen for follow-up).

During the interviews, care was taken to elicit and record the child's experiences rather than those of the parents. Researchers did not make therapeutic statements or suggestions (although they would, of course, answer any questions to the best of their ability), and did not comment on ongoing mental health care, if present. At the end of each interview, research staff made a report covering all the data collected. This was subsequently discussed with the research team (M.R., S.E. \& A.B.) in order to identify problems and ambiguities and to create continuing consensus on how to conduct the interview and rate answers in a standardised way.

\section{Analyses}

The 3 years were divided into three equal time-bands. During each of the three timebands (baseline to year 1, year 1-2, and year 2-3) person-time was allocated to each patient. Person-time was the number of years between baseline and the interview at which the child indicated that the voices had disappeared, or between baseline and the last interview if the voices did not disappear. If a child who was eligible for interview missed an interview on a given occasion, but was seen on the next occasion, the most recently updated status was used to assess the presence of auditory hallucinations and person-time was assigned accordingly. For example, a child who was not interviewed at year 2, but was seen at year 3 was retained in the data-set on the basis of the year 3 interview outcome.

Incidence rates (of discontinuation of hallucinations) were calculated for each time-band by dividing the number of incident discontinuations by the person-time of follow-up. Incidence rates were expressed as number of cases per 100 persons per year. Cumulative incidence was expressed as the number of discontinuations during the 3 years divided by the total baseline sample. Children who ceased to hear voices at one screening point were excluded for incidence rate analyses at the next screening points. The STCOX command in STATA (version 6; STATA Corporation, 1999) was used to estimate Cox maximumlikelihood proportional hazard models of discontinuation of hallucinations (Clayton \& Hills, 1993). Children who had ceased to hear voices at one screening point were excluded for the Cox proportional hazard analyses at the next screening points (i.e. were 'censored' in statistical terms). Associations were expressed as the hazard ratio, a measure of relative risk (Kendler et al, 1994), with $95 \%$ confidence intervals. Tests were performed two-tailed with $\alpha$ of 0.05 .

To examine whether the effect of predictors of voice discontinuation varied as a function of receipt of mental health care or being a case in terms of high levels of psychopathology, problem behaviour, or low levels of social functioning, we fitted interactions between predictors on the one hand, and receipt of mental health care, case level of psychopathology (defined as score greater than 90th percentile on BPRS sum score), case level of problem behaviour (score greater than 90th percentile on the YSR) and case level of poor social functioning (score greater than 90th percentile on

Table I Rate of change of auditory hallucinations in 80 children over a 3-year period

\begin{tabular}{lccccc}
\hline Time & With voices & Without voices & $\begin{array}{c}\text { Eligible children } \\
\text { not seen }(n)\end{array}$ & $\begin{array}{c}\text { Person-years } \\
\text { Rate/100 person-years } \\
(95 \% \mathrm{Cl})\end{array}$ \\
\hline Baseline & 80 & 0 & - & - & \\
Year I & 56 & 19 & 5 & 75 & $25.3(16.2-39.7)$ \\
Year 2 & 34 & 13 & 14 & 501 & $26.0(15.1-44.8)$ \\
Year 3 & 19 & 16 & 13 & 35 & $45.7(28.0-74.6)$ \\
\multicolumn{2}{l}{ Cumulative incidence of discontinuation of voices: $48 / 80=60 \%}$.
\end{tabular}

I. Including 3 person-years for children who were not seen in year 2 but who were interviewed at year 3 . the CGAS) on the other. Interactions were assessed by likelihood ratio tests (LRS).

\section{Rate of voice discontinuation}

The mean age was 12.9 years (s.d. 3.1; range $8-19$ years). Around half of the children $(53.8 \%)$ were female. Taking into account that children who ceased to hear voices were 'censored' in the analyses, a total of $80,75,47$ and 35 children were available for analysis at baseline, year 1, year 2 and year 3 , respectively, and the rate of voice discontinuation (or censoring in survival analytical terms) was $25.3 \%$, $26.0 \%$ and $47.7 \%$ at the year 1 , year 2 and year 3 interviews, respectively (Table 1 ). A total of 31 person-years of follow-up were available for children who on an earlier occasion had indicated that their voices had gone away. The rate of recurrence in these children was $13 \%$ (four children).

\section{Patients v. non-patients}

Children who received professional help generally had higher scores of social and psychopathological dysfunction than nonpatients (Table 2). Thus, at baseline they had a higher rating on the BPRS hallucinations item, higher YSR problem behaviour scores, lower CGAS scores and symptoms. Children who were receiving mental health care more often reported the presence of emotional triggers to the voices and more often reported childhood adversity. Emotional appraisals of the voices in this group were more often negative and they more often perceived an influence of the voices on emotions and behaviour. Finally, children receiving mental health care more often made use of passive problem-solving coping strategies.

\section{RESULTS} more BPRS anxiety/depression and negative 
Table 2 Baseline differences between children who did and who did not receive professional help

\begin{tabular}{|c|c|c|c|c|}
\hline Variables (range) & $\begin{array}{l}\text { Help. Mean } \\
\text { (s.d.) or \% }\end{array}$ & $\begin{array}{l}\text { No help. Mean } \\
\text { (s.d.) or \% }\end{array}$ & $\begin{array}{c}t \text {-test or } \\
\chi^{2} \text { test }\end{array}$ & $P$ \\
\hline \multicolumn{5}{|l|}{ Demographics } \\
\hline Age (years: 8-19) & I3.5 (0.5) & $12.2(0.4)$ & $\mathrm{t}_{78}=-1.9$ & 0.059 \\
\hline \multicolumn{5}{|l|}{ Gender } \\
\hline Boys & 47.5 & 45.0 & & \\
\hline Girls & 52.5 & 55.0 & $\chi^{2}{ }_{1}=0.05$ & 0.82 \\
\hline \multicolumn{5}{|l|}{ Voice characteristics } \\
\hline \multicolumn{5}{|l|}{ Number of voices } \\
\hline I & 12.8 & 27.5 & & \\
\hline $2-5$ & 43.6 & 32.5 & & \\
\hline $6-10$ & 18.0 & 15.0 & & \\
\hline$>10$ & 25.6 & 20.0 & & \\
\hline Variable & 0.0 & 5.0 & $\chi_{4}^{2}=5.1$ & 0.28 \\
\hline \multicolumn{5}{|l|}{ BPRS hallucinations rating } \\
\hline Lowest & 27.5 & 50.0 & & \\
\hline Middle & 32.5 & 27.5 & & \\
\hline Highest & 40.0 & 22.5 & $\chi_{\text {trend }}^{2}=4.7$ & 0.033 \\
\hline \multicolumn{5}{|l|}{ Frequency of voices } \\
\hline Continuous & 12.5 & 7.5 & & \\
\hline Hourly & 20.0 & 7.5 & & \\
\hline Daily & 35.0 & 32.5 & & \\
\hline Weekly & 17.5 & 22.5 & & \\
\hline Monthly & 2.5 & 7.5 & & \\
\hline Variable & 12.5 & 22.5 & $\chi_{5}^{2}=5.2$ & 0.39 \\
\hline \multicolumn{5}{|l|}{ Psychopathology and dissociation } \\
\hline Sees things & 57.5 & 67.1 & $\chi_{1}^{2}=1.6$ & 0.21 \\
\hline Total YSR problem behaviour (42-138) & $92.3(23.9)$ & $74.2(20.7)$ & $t_{72}=-3.5$ & 0.0009 \\
\hline Total DES score (2-76) & $23.4(15.9)$ & $19.6(13.7)$ & $t_{78}=-I .1$ & 0.26 \\
\hline BPRS anxiety/depression (4-23) & $10.0(5.2)$ & $6.4(2.3)$ & $t_{78}=-4.1$ & 0.0001 \\
\hline BPRS positive symptoms (5-I5) & $9.9(2.5)$ & $9.6(2.4)$ & $\mathrm{t}_{78}=-0.5$ & 0.65 \\
\hline BPRS disorganisation (3-7) & $3.2(0.7)$ & $3.1 \quad(0.5)$ & $t_{78}=-0.7$ & 0.47 \\
\hline BPRS negative symptoms (4-8) & $4.3(0.9)$ & $4.0(0.0)$ & $t_{78}=-2.2$ & 0.035 \\
\hline BPRS mania (4-10) & $5.2(1.5)$ & $5.2(1.6)$ & $\mathrm{t}_{78}=0.1$ & 0.89 \\
\hline \multicolumn{5}{|l|}{ Triggers and adversity } \\
\hline Emotional trigger present & 95.0 & 77.5 & $\chi_{1}^{2}=5.2$ & 0.023 \\
\hline Place trigger present & 42.5 & 62.5 & $\chi_{1}^{2}=3.2$ & 0.073 \\
\hline Time trigger present & 42.5 & 35.0 & $\chi_{1}^{2}=0.5$ & 0.49 \\
\hline Sleep related & 27.9 & 23.2 & $\chi_{1}^{2}=0.5$ & 0.50 \\
\hline Total life event score (0-3.2) & $0.9(0.8)$ & $0.7(0.8)$ & $\mathrm{t}_{77}=-0.9$ & 0.37 \\
\hline Childhood adversity score $(0-8)$ & $2.0(1.9)$ & I.I (I.3) & $t_{78}=-2.5$ & 0.016 \\
\hline Attributions & & & & \\
\hline Secondary explanation & 57.5 & 65.0 & $\chi_{1}^{2}=0.5$ & 0.49 \\
\hline Attribution past adversity & 25.0 & 26.3 & $\chi_{1}^{2}=0.02$ & 0.89 \\
\hline Affective appraisal & & & & \\
\hline Mainly positive & 7.5 & 27.5 & & \\
\hline Mainly negative & 75.0 & 47.5 & & \\
\hline Variable & 17.5 & 25.0 & $\chi_{2}^{2}=7.6$ & 0.023 \\
\hline Perceived influence on emotions/behaviour (0-8) & $4.7(2.2)$ & $3.0(1.9)$ & $\mathrm{t}_{78}=-3.7$ & 0.0004 \\
\hline Coping & & & & \\
\hline Total coping score (0-9) & $4.1 \quad(2.3)$ & $4.7(2.6)$ & $t_{78}=I . I$ & 0.26 \\
\hline Passive illness behaviour & $0.088(0.22)$ & $0.064(0.17)$ & $\mathrm{t}_{77}=-0.5$ & 0.60 \\
\hline Active problem-solving & $0.26(0.20)$ & $0.33(0.26)$ & $\mathrm{t}_{78}=\mathrm{I} .5$ & 0.13 \\
\hline Passive problem-solving & $0.29(0.26)$ & $0.44(0.36)$ & $\mathrm{t}_{78}=2.2$ & 0.035 \\
\hline Active problem avoidance & $0.21 \quad(0.25)$ & $0.19 \quad(0.20)$ & $\mathrm{t}_{78}=-0.4$ & 0.69 \\
\hline Symptomatic & $0.25(0.36)$ & $0.29(0.34)$ & $\mathrm{t}_{78}=0.5$ & 0.63 \\
\hline Other & $0.28(0.45)$ & $0.23(0.42)$ & $\mathrm{t}_{78}=-0.5$ & 0.61 \\
\hline Global functioning & & & & \\
\hline Baseline CGAS & $57.0(17.1)$ & $67.7(11.2)$ & $\mathrm{t}_{77}=3.3$ & 0.0015 \\
\hline Last follow-up CGAS & $67.8(18.2)$ & $76.9(16.0)$ & $\mathrm{t}_{72}=2.3$ & 0.025 \\
\hline CGAS improvement: baseline to last follow-up 10. & $0.1(11.1)$ & $8.7(11.5)$ & $\mathrm{t}_{72}=-0.5$ & 0.60 \\
\hline Help sought/received & & & & \\
\hline Proportion of network revealed to $(0-100)$ & $40.3(24.0)$ & $35.2(23.6)$ & $\mathrm{t}_{78}=-1.0$ & 0.34 \\
\hline Was admitted to hospital & 0.0 & 15.0 & $\chi_{1}^{2}=6.5$ & 0.011 \\
\hline
\end{tabular}

BPRS, extended Brief Psychiatric Rating Scale; YSR, Youth Self-Report; DES, Dissociative Experience Scale; CGAS, Children's Global Assessment Scale.

\section{Predictors of voice discontinuation}

Higher severity ratings on the BPRS hallucinations item and higher frequency predicted voice persistence (Tables 3-5). Voice persistence was also associated with older age and lack of clear triggers of time and place. The greater the proportion of individuals in the social network to whom children had revealed their voices, the greater the risk of voice persistence. This association remained when an adjustment was made for the number of people in the network (hazard ratio, $\mathrm{HR}=0.18,95 \%$ CI $0.04-0.81$ ). Adjustment for the case variables changed the parameters only minutely and did not change the pattern of results. Having mental health care in itself did not influence the probability of voice discontinuation.

\section{Predictors and care status}

To examine whether the effect of predictors of voice discontinuation varied as a function of being a case or not, we fitted interactions between predictors on the one hand, and receipt of mental health care, case level of psychopathology, case level of problem behaviour and case level of social functioning (all as defined above) on the other. There was no clear or suggestive evidence to suggest that the effect of predictors varied between those who were and those who were not a case by any of the variables used.

\section{DISCUSSION}

In a group of 80 children hearing voices, the cumulative rate of discontinuation over a 3 -year period was $60 \%$. In 31 years of follow-up for children whose voices disappeared on one occasion, the experience recurred on another in four cases. Children hearing voices who received professional help differed from children who did not, in that they had a higher rating on the BPRS hallucinations item, higher YSR problem behaviour scores, lower CGAS scores and more BPRS anxiety/depression and negative symptoms. These children also reported more perceived influence on behaviour and feelings and more negative affective appraisals in relation to the voice. This combination of results suggests that need for care is to a large part associated with the child's (and parents') appraisal of the voices rather than the perception itself. 
Table 3 Descriptive statistics of predictors of voice discontinuation

\begin{tabular}{|c|c|c|}
\hline Predictor variables (range) & $\begin{array}{l}\text { Discontinuation. } \\
\text { Mean (s.d.) or \% }\end{array}$ & $\begin{array}{l}\text { Persistence. } \\
\text { Mean (s.d.) or \% }\end{array}$ \\
\hline \multicolumn{3}{|l|}{ Demographics } \\
\hline Age (years: 8-19) & 12.2 & 13.6 \\
\hline \multicolumn{3}{|l|}{ Gender } \\
\hline Boys & 50.0 & 40.6 \\
\hline Girls & 50.0 & 59.4 \\
\hline \multicolumn{3}{|l|}{ Voice characteristics } \\
\hline \multicolumn{3}{|l|}{ Number of voices } \\
\hline 1 & 18.8 & 22.6 \\
\hline $2-5$ & 43.8 & 29.0 \\
\hline $6-10$ & 18.7 & 16.1 \\
\hline$>10$ & 18.8 & 29.0 \\
\hline Variable & 2.1 & 3.2 \\
\hline \multicolumn{3}{|l|}{ BPRS hallucinations rating } \\
\hline Lowest & 50.0 & 21.9 \\
\hline Middle & 33.3 & 25.0 \\
\hline Highest & 16.7 & 53.1 \\
\hline \multicolumn{3}{|l|}{ Frequency of voices } \\
\hline Continuous & 4.2 & 18.8 \\
\hline Hourly & 10.4 & 18.8 \\
\hline Daily & 33.3 & 34.4 \\
\hline Weekly & 22.9 & 15.6 \\
\hline Monthly & 8.3 & 0.0 \\
\hline Variable & 20.8 & 12.5 \\
\hline \multicolumn{3}{|l|}{ Psychopathology and dissociation } \\
\hline Sees things & 60.4 & 71.9 \\
\hline Total YSR problem behaviour (42-138) & $82.0(24.6)$ & $86.3(23.6)$ \\
\hline Total DES score (2-76) & $18.0(12.3)$ & $26.8(17.1)$ \\
\hline BPRS anxiety/depression (4-23) & $7.0(3.7)$ & $10.0(4.8)$ \\
\hline BPRS positive symptoms (5-15) & $9.1 \quad(2.1)$ & $10.7(2.5)$ \\
\hline BPRS disorganisation (3-7) & $3.1 \quad(0.6)$ & $3.2(0.7)$ \\
\hline BPRS negative symptoms (4-8) & $4.2(0.8)$ & $4.0(0.2)$ \\
\hline BPRS mania (4-10) & $5.4(1.5)$ & $5.0(1.6)$ \\
\hline \multicolumn{3}{|l|}{ Triggers and adversity } \\
\hline Emotional trigger present & 87.5 & 84.4 \\
\hline Place trigger present & 60.4 & 40.6 \\
\hline Time trigger present & 50.0 & 21.9 \\
\hline Sleep related & 34.0 & 19.4 \\
\hline Total life event score (0-3.2) & $0.6(0.7)$ & I.I $(0.9)$ \\
\hline Childhood adversity score (0-8) & $1.3(1.4)$ & $1.9(2.1)$ \\
\hline \multicolumn{3}{|l|}{ Attributions } \\
\hline Secondary explanation & 56.3 & 68.8 \\
\hline Attribution past adversity & 26.1 & 25.0 \\
\hline \multicolumn{3}{|l|}{ Affective appraisal } \\
\hline Mainly positive & 14.6 & 21.9 \\
\hline Mainly negative & 66.7 & 53.1 \\
\hline Variable & 18.7 & 25.0 \\
\hline Perceived influence on emotions/behaviour (0-8) & $3.7(2.1)$ & $4.1 \quad(2.4)$ \\
\hline \multicolumn{3}{|l|}{ Coping } \\
\hline Total coping score $(0-9)$ & $4.1 \quad(2.6)$ & $4.9(2.3)$ \\
\hline Passive illness behaviour & $0.031(0.12)$ & $0.15(0.26)$ \\
\hline Active problem-solving & $0.25(0.22)$ & $0.36(0.24)$ \\
\hline Passive problem-solving & $0.38 \quad(0.32)$ & $0.35(0.33)$ \\
\hline Active problem avoidance & $0.19(0.23)$ & $0.21(0.22)$ \\
\hline Symptomatic & $0.25(0.34)$ & $0.30(0.36)$ \\
\hline Other & $0.21(0.4 I)$ & $0.31 \quad(0.47)$ \\
\hline Global functioning & & \\
\hline Baseline CGAS & $63.5(15.2)$ & $60.7(15.6)$ \\
\hline Help sought/received & & \\
\hline Proportion of network revealed to $(0-100)$ & $32.5(23.2)$ & $45.4(22.9)$ \\
\hline Had professional help & 50.0 & 50.0 \\
\hline Was admitted to hospital & 8.3 & 6.3 \\
\hline
\end{tabular}

BPRS, extended Brief Psychiatric Rating Scale; YSR, Youth Self-Report; DES, Dissociative Experience Scale; CGAS, Children's Global Assessment Scale.
Predictors of persistence of voices, independent of receipt of mental health care, severity of psychopathology, severity of problem behaviour or level of impairment of social functioning, were severity and frequency of the voices, as well as associated anxiety/depression, lack of clear triggers of time and place and having told more people in the child's network about the voices. However, being in receipt of mental health care did not influence voice persistence.

\section{Methodological issues}

In order to examine the influence of possible misclassification of children whose voices recurred after earlier discontinuation, the four children whose voices recurred were reclassified as voice persistence on all earlier measurement occasions. This did not affect the overall pattern of results. The effect of age was reduced $(\mathrm{HR}=0.94,95 \%$ CI 0.85 1.04; $P=0.20$ ) and the effect of a place trigger became statistically more imprecise $(\mathrm{HR}=1.70,95 \%$ CI $0.93-3.11 ; P=0.085)$. The effect of sleep-related occurrence of voices became more marked $(\mathrm{HR}=1.99$, 95\% CI 1.07-3.70; $P=0.029)$, as did the effect of life events $(\mathrm{HR}=0.56,95 \% \mathrm{CI}$ $0.34-0.94 ; P=0.027$ ), indicating that the higher the number of reported life events, the higher the risk of voice persistence.

We did not conduct detailed diagnostic interviews yielding ICD or DSM diagnoses. Instead, we collected dimensional measures of problem behaviour, psychopathology and social functioning. This was carried out for several reasons. First, the variable of interest in this study was experience of voices, and the psychopathological and social functioning context of these experiences is arguably better described by global dimensional measures than diagnostic constructs of uncertain validity. Second, many of our subjects would not have met the distress/dysfunction criteria for disorder and therefore remained 'undiagnosable' using traditional measurements.

Some of the subjects were quite young and the age range was quite large. It is possible that the older children were better able to understand questions about, for example, coping and childhood trauma. Care was taken, however, that all questions were understood by the children during interview, and to the extent that this bias operated it is unlikely to have produced the current results. 
Table 4 Non-psychopathological factors influencing discontinuation of voices

\begin{tabular}{|c|c|c|}
\hline Baseline variable & Hazard ratio $(95 \% \mathrm{Cl})$ & $P$ \\
\hline \multicolumn{3}{|l|}{ Demographics } \\
\hline Age (years) & $0.90(0.8 \mathrm{I}-0.99)$ & 0.046 \\
\hline Age at onset (years) & $1.00(0.94-1.08)$ & 0.82 \\
\hline Gender & $0.93(0.53-1.64)$ & 0.80 \\
\hline \multicolumn{3}{|l|}{ Voice characteristics } \\
\hline \multicolumn{3}{|l|}{ Number of voices } \\
\hline I & II & - \\
\hline $2-5$ & I.77 (0.8I-3.88) & 0.15 \\
\hline $6-10$ & $1.46(0.56-3.80)$ & 0.44 \\
\hline$>10$ & I.II (0.44-2.80) & 0.83 \\
\hline Variable & $0.67(0.09-5.28)$ & 0.70 \\
\hline \multicolumn{3}{|l|}{ BPRS hallucinations rating } \\
\hline Lowest & $I^{\prime}$ & - \\
\hline Middle & $0.77(0.4 \mathrm{I}-\mathrm{I} .46)$ & 0.43 \\
\hline Highest & $0.31(0.14-0.68)$ & 0.004 \\
\hline Linear trend ${ }^{2}$ & $0.85(0.75-0.96)$ & 0.009 \\
\hline \multicolumn{3}{|l|}{ Frequency of voices } \\
\hline Continuous & $I^{\prime}$ & - \\
\hline Hourly & $2.11(0.4 I-10.88)$ & 0.37 \\
\hline Daily & $3.48(0.80-15.15)$ & 0.097 \\
\hline Weekly & $4.39(0.97-19.83)$ & 0.055 \\
\hline Monthly & $7.57(1.38-41.66)$ & 0.020 \\
\hline Variable & $3.44(0.75-\mid 5.7 I)$ & 0.11 \\
\hline \multicolumn{3}{|l|}{ Triggers and adversity } \\
\hline Emotional trigger present & $\mathrm{I} .07(0.46-2.53)$ & 0.87 \\
\hline Place trigger present & $1.93(1.08-3.46)$ & 0.027 \\
\hline Time trigger present & $2.14(1.22-3.78)$ & 0.008 \\
\hline Sleep related & $1.71(0.93-3.13)$ & 0.084 \\
\hline Total life event score & $0.69(0.44-1.09)$ & 0.11 \\
\hline Childhood adversity score & $0.88(0.73-1.05)$ & 0.17 \\
\hline \multicolumn{3}{|l|}{ Attributions } \\
\hline Secondary explanation & $0.82(0.47-1.46)$ & 0.50 \\
\hline Attribution past adversity & $0.98(0.5 \mathrm{I}-\mathrm{I} .90)$ & 0.96 \\
\hline \multicolumn{3}{|l|}{ Affective appraisal } \\
\hline Mainly positive & I & - \\
\hline Mainly negative & $\mathrm{I} .64(0.72-3.74)$ & 0.24 \\
\hline Variable & $1.28(0.48-3.44)$ & 0.62 \\
\hline Perceived influence on emotions/behaviour & $0.96(0.84-1.09)$ & 0.52 \\
\hline \multicolumn{3}{|l|}{ Coping } \\
\hline Coping score & $0.92(0.82-1.04)$ & 0.18 \\
\hline Passive illness behaviour & $0.14(0.02-1.39)$ & 0.094 \\
\hline Active problem-solving & $0.45(0.10-1.99)$ & 0.30 \\
\hline Passive problem-solving & I.3I (0.46-3.72) & 0.61 \\
\hline Active problem avoidance & $0.93(0.25-3.48)$ & 0.91 \\
\hline Symptomatic & $0.92(0.35-2.4 I)$ & 0.87 \\
\hline Other & $0.69(0.34-\mathrm{I} .42)$ & 0.32 \\
\hline \multicolumn{3}{|l|}{ Global functioning } \\
\hline Baseline CGAS & I.0I (0.99-I.03) & 0.42 \\
\hline \multicolumn{3}{|l|}{ Help sought/received } \\
\hline \multicolumn{3}{|l|}{ Proportion of network revealed to } \\
\hline Lowest quartile group & I & - \\
\hline Second lowest & $0.77(0.37-1.62)$ & 0.50 \\
\hline Second highest & $0.50(0.23-1.07)$ & 0.073 \\
\hline Highest & $0.42(0.18-1.02)$ & 0.056 \\
\hline Linear trend ${ }^{2}$ & $0.73(0.56-0.96)$ & 0.024 \\
\hline Had professional help & $\mathrm{I} .14(0.60-2.00)$ & 0.66 \\
\hline Was admitted to hospital & $0.95(0.34-2.65)$ & 0.92 \\
\hline
\end{tabular}

BPRS, extended Brief Psychiatric Rating Scale; CGAS, Children's Global Assessment Scale.

I. Reference category.

2. The summary increase in risk with one unit change in the exposure variable.

\section{Receipt of professional help}

Although receipt of professional help cannot be equated with need for care, and absence of professional help with absence of need, the mean level of need for care, given the fact that mental health services are freely available for all in The Netherlands, can be safely assumed to be much higher in the receipt-of-care group. The result suggests that need for care in the context of experience of voices was associated not only with higher levels of problem behaviour and related negative symptoms of psychosis, but also with characteristics of the voices themselves and associated attributions.

Children who were in care not only had more severe ratings of the BPRS hallucinations item and more severe ratings of anxiety/depression, negative symptoms and problem behaviour, but also had more negative affective appraisals and felt that the voices had more influence on emotions and behaviour. These children also reported more frequent experience of earlier traumatic experiences and precipitation by emotional triggers. It has been suggested that appraisal of characteristics such as volume, tone and frequency of the voices are the result of appraisals of the voices' ranking and power, and that the distress associated with the voices is linked to the underlying social and interpersonal cognitive processes that drive these appraisals (Birchwood et al, 2000). Dysfunctional cognitions could thus contribute to the development of need for mental health care and increased likelihood of voice persistence. The fact that the perceived influence of the voice over emotions and behaviour and negative affective appraisals were also associated with need for care similarly points to the importance of underlying beliefs and appraisal processes. The higher frequency of reports of feeling traumatised by early events and recent triggers may also be interpreted in the tendency to feel 'overpowered' by events, and/or may represent repeated exposures to trauma with the reduced capability to assert oneself in the face of intrusive experiences or events. Some individuals may develop a need for care as a result of a 'power imbalance' between the individual and 'intruders' or intruding events, the origin of which may lie in the cognitive processes that regulate adaptation to the voices. There may be an association between early childhood trauma and psychotic experiences (Greenfield 
Table 5 Psychopathological factors influencing voice discontinuation

\begin{tabular}{|c|c|c|}
\hline Baseline variable & Hazard ratio $(95 \% \mathrm{Cl})$ & $P$ \\
\hline \multicolumn{3}{|l|}{ Psychopathology and dissociation } \\
\hline Sees things & $0.95(0.54-1.73)$ & 0.91 \\
\hline Total YSR problem behaviour & $\mathrm{I} .00(0.98-1.0 \mathrm{I})$ & 0.53 \\
\hline \multicolumn{3}{|l|}{ Total DES score } \\
\hline Lowest quartile group & $I^{\prime}$ & - \\
\hline Second lowest & $0.85(0.4|-| .78)$ & 0.67 \\
\hline Second highest & $0.54(0.25-1.16)$ & 0.12 \\
\hline Highest & $0.42(0.18-0.97)$ & 0.042 \\
\hline Linear trend ${ }^{2}$ & $0.74(0.57-0.96)$ & 0.022 \\
\hline \multicolumn{3}{|l|}{ BPRS anxiety/depression } \\
\hline Lowest quartile group & $I^{\prime}$ & - \\
\hline Second lowest & I.2I (0.60-2.42) & 0.60 \\
\hline Second highest & $0.47(0.22-1.0 I)$ & 0.054 \\
\hline Highest & $0.30(0.11-0.80)$ & 0.017 \\
\hline Linear trend ${ }^{2}$ & $0.67(0.51-0.87)$ & 0.003 \\
\hline \multicolumn{3}{|l|}{ BPRS positive symptoms } \\
\hline Lowest quartile group & $I^{\prime}$ & \\
\hline Second lowest & $0.94(0.49-1.83)$ & 0.87 \\
\hline Second highest & $0.74(0.35-1.57)$ & 0.43 \\
\hline Highest & $0.21(0.05-0.90)$ & 0.035 \\
\hline Linear trend ${ }^{2}$ & $0.73(0.55-0.97)$ & 0.033 \\
\hline BPRS disorganisation & $0.79(0.45-1.38)$ & 0.40 \\
\hline BPRS negative symptoms & $\mathrm{I} .12(0.79-\mathrm{I} .57)$ & 0.54 \\
\hline BPRS mania & $\mathrm{I} .03(0.87-\mathrm{I} .22)$ & 0.73 \\
\hline
\end{tabular}

YSR, Youth Self-Report; DES, Dissociative Experience Scale; BPRS, extended Brief Psychiatric Rating Scale. I. Reference category.

2. The summary increase in risk with one unit change in the exposure variable.

et al, 1994; Ross et al, 1994; Berenbaum, 1999), also according to investigations using modern epidemiological approaches (Window et al, 2000).

There was no difference between those with and without mental health care in terms of total coping score. However, those with mental health care less often displayed passive problem-solving (ignoring voice, listening selectively to voice, doing something), which agrees with the view that need for care is related to the way the person interacts with their experience of voices, rather than just the experience by itself (Romme \& Escher, 1994; Claridge, 1997).

\section{Predictors of voice persistence}

Predictors of voice persistence only concurred partially with those that discriminate between those who did and those who did not receive mental health care. However, severity of voices assessed by the BPRS, as well as associated anxiety and depression, influenced both receipt of care and voice persistence, confirming the possible role of cognitive processes regulating appraisals of volume and frequency of experience of voices and the ensuing affective response. The favourable course associated with the child being able to identify triggers of time and place (for example, only hearing voices at school or when alone in one's bedroom at night) suggests that individuals whose voices are not omnipresent (and therefore not 'omnipotent') but instead limited to a circumscribed situation are more likely to overcome the experience.

Higher scores on the DES were associated with an increased likelihood of voice persistence. High levels of dissociation measured with the DES are associated with higher levels of proneness to psychosis, and the current findings suggest that the DES could be identifying those individuals who are most liable to develop enduring psychotic symptoms (Allen \& Coyne, 1995; Spitzer et al, 1997; Pope \& Kwapil, 2000). High scores on the DES in the context of psychosis may be associated with childhood adversity (Goff et al,
1991), and although reported childhood adversity did not predict voice persistence, it could be that part of the effect of the DES is mediated through its association with childhood adversity, individuals with high DES scores representing the group most prone to enduring experiences of voices given exposure to early adversity.

The greater the proportion of people in the network that the child had revealed the experience of voices to, the greater the likelihood that the voices would persist, independent of the number of people in the network. One explanation of this finding is that the more severe and the more stressful the experience of voices is, the more likely it becomes that the child will reveal the experience to significant others in his or her network.

Being in receipt of mental health care did not influence voice persistence, possibly because, at the time of this investigation, most care appeared to be directed towards suppressing voices rather than coping with them.

\section{Influence of caseness variables on course of voices}

A remarkable finding was that voice persistence or discontinuation was independent of the various caseness variables used. Thus, the predictive effect of severity, anxiety/depression, triggers of time and place and other variables was the same in cases and non-cases, regardless of whether caseness was defined in terms of need for mental health care, problem behaviour, psychopathology or social functioning. This suggests that the longitudinal course of voices is a relatively autonomous process, influenced by a range of factors that are independent of the presence of diagnosis and, if a diagnosis is present, severity of psychopathology and problem behaviour. Thus, the cognitive processes underlying volume and frequency of the voices and the associated distress could be more important in predicting longitudinal course than caseness context. This suggests that therapeutic interventions for the experience of voices should be targeted specifically at the experience itself, rather than the presence of diagnosis.

\section{REFERENCES}

Allen, J. G. \& Coyne, L. (1995) Dissociation and vulnerability to psychotic experience. The Dissociative Experiences Scale and the MMPI-2. Journal of Nervous and Mental Disease, 183, 615-622. 
Altman, H., Collins, M. \& Mundy, P. (1997) Subclinical hallucinations and delusions in nonpsychotic adolescents. Journal of Childhood Psychology and Psychiatry, 38 $413-420$

American Psychiatric Association (1980) Diagnostic and Statistical Manual of Mental Disorders (3rd edn) (DSM-III).Washington, DC: APA

Bak, M., Van der Spil, F., Gunther, N., et al (200la) Macs II. Does coping enhance subjective control over symptoms? Acta Psychiatrica Scandinavica, 103, 460-464.

_, _, , et al (200lb) Macs I. Maastricht Assessment of Coping Strategies: A brief instrument to assess coping with psychotic symptoms. Acta Psychiatrica Scandinavica, 103, 453-459.

Berenbaum, H. (1999) Peculiarity and reported childhood maltreatment. Psychiatry, 62, 21-35.

\section{Bernstein, E. M. \& Putnam, F. W. (1986)}

Development, reliability, and validity of a dissociation scale. Journal of Nervous and Mental Disease, 174 727-735.

Bettes B. A. \& Walker, E. (1987) Positive and negative symptoms in psychotic and other psychiatrically disturbed children. Journal of Childhood Psychology and Psychiatry, 28, 555-568.

Birchwood, M., Meaden, A., Trower, P., et al (2000) The power and omnipotence of voices: subordination and entrapment by voices and significant others. Psychological Medicine, 30, 337-344.

Chambers, W. J., Puig-Antich, J., Tabrizi, M. A., et al (1982) Psychotic symptoms in prepubertal major depressive disorder. Archives of General Psychiatry, 39. 921-927.

Claridge, G. (1997) Final remarks and future directions In Schizotypy. Implications for Illness and Health (ed. G. Claridge), pp. 301-317. Oxford: Oxford University Press.

Clayton, D. \& Hills, M. (1993) Cox's regression models. In Statistical Methods in Epidemiology, pp. 298-306. Oxford: Oxford University Press.

Del Beccaro, M. A., Burke, P. \& McCauley, E. (1988) Hallucinations in children: a follow-up study. Journal of the American Academy of Child and Adolescent Psychiatry, 27, 462-465.

Famularo, R., Kinscherff, R. \& Fenton, T. (1992) Psychiatric diagnoses of maltreated children: preliminary findings. Journal of the American Academy of Child and Adolescent Psychiatry, 3I, 863-867.

Fennig, S., Susser, E. S., Pilowsky, D. J., et al (1997) Childhood hallucinations preceding the first psychotic episode. Journal of Nervous and Mental Disease, I85, 115-117.

Galdos, P. \& van Os, J. (1995) Gender, psychopathology, and development: from puberty to early adulthood. Schizophrenia Research, 14, 105-112.

_, \& Murray, R. M. (1993) Puberty and the onset of psychosis. Schizophrenia Research, 10, 7-14.

Garralda, M. E. (1984a) Hallucinations in children with conduct and emotional disorders: I. The clinical phenomena. Psychological Medicine, 14, 589-596.

- (1984b) Hallucinations in children with conduct and emotional disorders: II. The follow-up study. Psychological Medicine, 14, 597-604.

Goff, D. C., Brotman, A. W., Kindlon, D., et al (1991) Self-reports of childhood abuse in chronically psychotic patients. Psychiatry Research, 37, 73-80.

Green, W. H., Padron-Gayol, M., Hardesty, A. S., et al (1992) Schizophrenia with childhood onset: a phenomenological study of 38 cases. Journal of the

\section{CLINICAL IMPLICATIONS}

- The majority of children hearing voices stop reporting the experience over the course of 3 years.

- The children hearing voices who need professional help are more likely to feel overpowered by the voices.

- Voice appraisals and associated anxiety and depression are better predictors of voice persistence than 'traditional' measures of psychotic symptomatology, problem behaviour and global functioning.

\section{LIMITATIONS}

- Lack of detailed information.

- The age range was quite wide, introducing a large degree of sample heterogeneity.

- The use of self-reports of life events and early trauma.

SANDRA ESCHER, MA, Department of Psychiatry and Neuropsychology, University of Maastricht and Intervoice, Bemelen, The Netherlands; MARIUS ROMME, MD, PhD, Intervoice, Bemelen, The Netherlands; ALEX BUIKS, MA, PHILIPPE DELESPAUL, Department of Psychiatry and Neuropsychology, Maastricht University, The Netherlands; JIM VAN OS, MD, PhD, Department of Psychiatry and Neuropsychology, Maastricht University, The Netherlands and Division of Psychological Medicine, Institute of Psychiatry, London, UK

Correspondence: Professor Jim van Os, Department of Psychiatry and Neuropsychology, Maastricht University, European Graduate School of Neuroscience, PO Box 616, 6200 MD Maastricht, The Netherlands. Tel: +31 43 3299773; e-mail: j.vanos@sp.unimaas.nl

American Academy of Child and Adolescent Psychiatry, 31, 968-976.

Greenbaum, P. E. \& Dedrick, R. F. (1998) Hierarchical confirmatory factor analysis of the child behaviour checklist 4-18. Psychological Assessment, 10, 149-155.

Greenfield, S. F., Strakowski, S. M., Tohen, M., et al (1994) Childhood abuse in first-episode psychosis. British Journal of Psychiatry, 164, 83I-834.

Hartman, C. A., Hox, J., Auerbach, J., et al (1999) Syndrome dimensions of the child behavior checklist and the teacher report form: a critical empirical evaluation. Journal of Child Psychology and Psychiatry and Allied Disciplines, 40, I095-1116.

Kendler, K. S., McGuire, M., Gruenberg, A. M., et a (1994) Clinical heterogeneity in schizophrenia and the pattern of psychopathology in relatives: results from an epidemiologically based family study. Acta Psychiatrica Scandinavica, 89, 294-300.

Lukoff, D., Nuechterlein, K. H. \& Ventura, J. (1986) Manual for the expanded brief psychiatric rating scale. Schizophrenia Bulletin, 12, 594-602.

McGee, R., Williams, S. \& Poulton, R. (2000)

Hallucinations in nonpsychotic children (letter). Journal of the American Academy of Child and Adolescent Psychiatry, 39, $12-13$

Overall, J. E. \& Gorham, D. R. (1962) The brief psychiatric rating scale. Psychological Report, 10 799-812
Pope, C. A. \& Kwapil, T. R. (2000) Dissociative experience in hypothetically psychosis-prone college students. Journal of Nervous and Mental Disease, $\mathbf{1 8 8}$ 530-536.

Poulton, R., Caspi, A., Moffitt, T. E., et al (2000) Children's self-reported psychotic symptoms and adult schizophreniform disorder: A 15-year longitudinal study. Archives of General Psychiatry, 57, 1053-1058.

Putnam, F.W. \& Peterson, G. (1994) Further validation of the child dissociative checklist. Dissociation, 7 204-2II.

Romme, M. (ed.) (1996) Understanding Voices. Coping with auditory hallucinations and confusing realities. Clouchester: Handheld Publications.

\& Escher, A. D. (1989) Hearing voices. Schizophrenia Bulletin, 15, 209-216.

— \& Escher, S. (1994) Hearing voices. British Medical Journal, 309, 670

_ \& - (1996) Empowering people who hear voices. In Understanding Voices. Coping with Auditory Hallucinations and Confusing Realities (ed. M. A. J. Romme), pp. 23-38. Maastricht: University of Maastricht.

_ , Honig, A., Noorthoorn, E. O., et al (1992)

Coping with hearing voices: an emancipatory approach. British Journal of Psychiatry, 161, 99-103.

Ross, C. A., Anderson, G. \& Clark, P. (1994)

Childhood abuse and the positive symptoms of schizophrenia. Hospital and Community Psychiatry, 45, 489-491. 
Ryan, N. D., Puig-Antich, J., Ambrosini, P., et al (1987) The clinical picture of major depression in children and adolescents. Archives of General Psychiatry, 44, 854-86I.

Schreier, H. A. (1998) Auditory hallucinations in nonpsychotic children with affective syndromes and migraines: report of 13 cases. Journal of Childhood Neurology, I3, 377-382.
Shaffer, D., Gould, M. S., Brasic, J., et al (1983) A children's global assessment scale (CGAS). Archives of General Psychiatry, 40, 1228-1231.

Spitzer, C., Haug, H. J. \& Freyberger, H. J. (1997) Dissociative symptoms in schizophrenic patients with positive and negative symptoms. Psychopathology, 30 , 67-75.

STATA Corporation (1999) STATA Statistical Software Release 6.0. College Station, TX: STATA Corporation.
Verhulst, F. C., Van der Ende, J. \& Koot, H. M. H et al (1996) Handleiding voor de CBCL/4-18: Sophia Kinderziekenhuis/Academisch Ziekenhuis, Erasmus Universiteit.

Window, S. J., Boot, D., Williams, P., et al (2000) Gender, voice hallucinations and recalled childhood adversity. Schizophrenia Research, 4I, 60. 


\section{Chapter 5}

\section{Formation of delusional ideation in adolescents hearing voices: a prospective study.}

American Journal of Medical Genetics. 114:913-920

Escher, A., Romme, M., Buiks, A., Delespaul, Ph., Van Os, J., (2002). 


\title{
Invited Paper
}

\section{Formation of Delusional Ideation in Adolescents Hearing Voices: A Prospective Study}

\author{
Sandra Escher, ${ }^{1,2,3}$ Marius Romme, ${ }^{2,3}$ Alex Buiks, ${ }^{1}$ Philippe Delespaul, ${ }^{1}$ and Jim van Os ${ }^{1,4 *}$ \\ ${ }^{1}$ Department of Psychiatry and Neuropsychology, Maastricht University, European Graduate School of Neuroscience, \\ Maastricht, The Netherlands \\ ${ }^{2}$ Mental Health Policy Centre, University of Central England, Birmingham, United Kingdom \\ ${ }^{3}$ Intervoice, Bemelen, The Netherlands \\ ${ }^{4}$ Division of Psychological Medicine, Institute of Psychiatry, London, United Kingdom
}

Previous work suggests that auditory hallucinations in children and adolescents occur frequently in the absence of psychotic illness, although a number of such children go on to develop more severe psychotic symptomatology and need for care. We examined prospectively what factors are associated with formation of delusions in adolescents who are hearing voices. Eighty adolescents (mean age 12.9 years, $\mathrm{SD}=3.1$ ) who reported hearing voices were examined at baseline and followed-up three times over a period of 3 years. Fifty percent were receiving professional care, but $50 \%$ were not in need of care. Baseline measurement of voice appraisals, attributions, psychopathology, global functioning, dissociation, stressful life events, coping mechanisms, and receipt of professional care were used as predictors of delusion formation, measured as a score of 6 or greater on the extended BPRS items: "suspiciousness," "unusual thought content" and "grandiosity." Thirteen children (16\%) displayed evidence of delusional ideation over at least one of the three follow-up periods, of which seven (9\%) de novo. Adjusting for presence of baseline delusional ideation, delusion formation over the follow-up period was associated with baseline voice appraisals and attributions such as tone of

\footnotetext{
Grant sponsor: Dutch Prevention Fund.

*Correspondence to: Prof. Jim van Os, Department of Psychiatry and Neuropsychology, Maastricht University, European Graduate School of Neuroscience, PO Box 616 (PAR 45), 6200 MD Maastricht, The Netherlands. E-mail: j.vanos@sp.unimaas.nl Received 27 July 2001; Accepted 17 October 2001

DOI 10.1002/ajmg.10203
}

the voice (hazard ratio voice "variably friendly and hostile" compared to "always friendly": $H R=6.8,95 \%$ CI: $1.1,41.0$ ), perceived location of the voice (outside vs. inside head: $H R=2.9,95 \%$ CI: $1.0,8.7$ ), and whether the voice resembled that of a parent $(\mathrm{HR}=3.5,95 \%$ CI: 1.0, 12.0); baseline BPRS anxiety/depression $(\mathrm{HR}=6.4,95 \% \mathrm{CI}$ : 1.9, 21.4), baseline BPRS disorganization $(\mathbf{H R}=5.0,95 \%$ CI: $0.98,26.1)$ and the baseline amount of reported recent stressful life events (HR continuous life events score: 1.8, 95\% CI: 1.0, 3.3). In addition, in older children, the perceived influence of the voices on emotions and behavior was strongly associated with delusion formation $(\mathbf{H R}=5.1,95 \%$ CI: 1.0, 25.9). Delusion formation in children hearing voices may be responsive to triggering events and facilitated by feelings of anxiety/depression. The results also highlight the role of attributions associated with external sources, authority figures, perceived influence or "power" over the person, as well as emotional appraisal processes and cognitive disorganization.

(c) 2002 Wiley-Liss, Inc.

\section{INTRODUCTION}

Recent population-based work suggests that among children the prevalence of hallucinatory phenomena is around 8\% [McGee et al., 2000]. Around a third of such children present with a DSM-III diagnosis, which, although representing twice the diagnostic rate of children in the non-hallucinatory group [McGee et al., 2000], is low enough to suggest that for the majority of hallucinating children in the general population these experiences are non-pathological. A small group, however, is at risk of subsequent psychotic disorder in adult life. In a recent follow-up of 761 children, self-reported

(c) 2002 Wiley-Liss, Inc. 


\section{Escher et al.}

psychotic symptoms at age 11 years increased the odds for psychotic illness at age 26 years 16.4 times. The actual number of children that developed a psychotic disorder, however, was very small. These childhood self-reported psychotic experiences had predictive value independent of childhood psychiatric diagnosis [Poulton et al., 2000]. Other work also suggests that childhood hallucinations may increase the risk for later psychotic disorder [Fennig et al., 1997].

In patients with psychotic disorder, the positive symptoms of hallucinations and delusions typically occur together [Bilder et al., 1985; Liddle, 1987; Peralta et al., 1992]. Observational studies suggest that also in non-clinical samples experience of hallucinations is strongly associated with delusional ideation [Van Os et al., 2000]. This clinical observation is compatible with theories that some delusions arise secondarily in an attempt to explain abnormal perceptual experiences [De Clérambault, 1942; Maher, 1974, 1988] and that biased conscious appraisal processes are critical in judging that these confusing experiences are in fact externally caused [Garety et al., 2001].

Although it is known that experience of hallucinations and delusional ideation are strongly associated in clinical and non-clinical samples, there is not much empirical work on possible factors mediating this relationship. We wished to study, using a longitudinal design in a sample of adolescents with experiences of hearing voices, the factors that may influence delusion formation given the presence of a hallucinatory experience.

\section{MATERIALS AND METHODS}

\section{Sample}

To recruit sufficient children and adolescents who were hearing voices, we proceeded in two stages. First, two of the research team (M.R. and S.E.) made extensive use of media contacts, formed in the course of a prior investigation [Romme et al., 1992] to create awareness about hearing voices and reduce stigmatization at the national level. They appeared on a popular TV talk show, where the experience of a child hearing voices, as well as the view of its parents, were discussed. At the end of the program, viewers were invited to attend a special conference on the subject in the Dutch capital. This conference was attended by 40 children and their parents, and received media coverage. In the second stage, the actual recruitment started. Press releases were sent out and several TV and radio appearances were made in which help was asked to get in touch with the target population. The local community pediatric health service in Maastricht was contacted, where all children aged $0-14$ are periodically screened, as well as several child and adolescent psychiatric services in the country. Over a period of approximately 1 year, 80 children who were hearing voices were thus recruited. The children were seen at baseline, and subsequently at 1-year intervals over a period of 3 years. Each child was thus interviewed four times. Whenever a child had indicated at the first follow-up that the voices had disappeared, no attempts were made to re-interview at the second follow-up, to avoid unnecessary focus on a past, and often upsetting, experience. To have an estimate of the rate of recurrence of voices after earlier discontinuation, however, an attempt was made to again interview all 80 children at the third follow-up, regardless of whether they heard voices or not. Thus, a total of 31 person-years of followup were available of children who on an earlier occasion had indicated that they had stopped hearing voices. Recurrence occurred in four instances, representing a rate of $13 \%$.

\section{Research Instruments and Procedures}

The research team consisted of two field workers who had extensive prior experience in interviewing individuals with hallucinations, using a similar format as the one in the present study. They also had prior experience in administrating the other instruments used. Nearly all children were interviewed at home. The baseline interview was conducted in the presence of at least one parent or grandparent (with a few exceptions where adolescents had specifically asked that the parent not be present). All subjects and their parents, where appropriate, provided written informed consent conform the local ethics committee guidelines. At each interview occasion, the same instruments were used. The main instrument was the Maastricht Voices Interview for Children. This interview was derived from the Maastricht Voices Interview for adults and adapted for children with the aid of a clinical child psychologist. It contains several items in relation to the experience of hearing voices, that were included on the basis of extensive qualitative research involving many individuals with voices over a period of at least 10 years, including children [Romme, 1996; Romme and Escher, 1996].

The number of voices was coded as $1,2-5,6-10,>10$ and "variable." The frequency of the voices was coded as "continuous," "hourly," "daily," "weekly," "monthly," and "variable." The emotional tone of the voice was coded as "friendly," "hostile," "neutral," "variably friendly and hostile," and "other." Triggers of the voices were coded as "present" or "absent" in the analyses, and assessed in terms of time, place, and emotional trigger events (angry, scared, sad, tired, jealous, doubt, guilty, insecure, in love, unhappy, lonely, happy).

The degree of coping mobilized by the voices was assessed by constructing a total score of 18 possible coping mechanisms that were enquired about in a structured way and could be scored as "present," or "absent." In addition, different dimensions of coping were constructed based on a previous classification [Bak et al., 2001a,b], by calculating the sum of the items divided by the number of items. We thus distinguished the coping styles passive illness behavior (using medication, using alcohol or drugs), passive problem solving (ignoring voice, listening selectively to voice, doing something), active problem solving (making a deal with voice, swearing against voice, seeking distraction, making a drawing of the voice, sending voice away, writing something about the voice), active problem avoiding 


\section{Delusional Ideation in Adolescents Hearing Voices}

(thinking of something else, running away from the voice, calling someone over the telephone, visiting someone), symptomatic coping (listening carefully to the voice, performing a ritual against the voice) and other coping (other way of coping).

Attributions were assessed as follows. Presence of a secondary explanation was coded "present" if the child had indicated explanations of the voice being caused by a spirit or ghost, by a special gift, by a disease, coming from a different world, or another explanation. Attribution of perceived power of the voices in terms of negative influence on emotions and behavior was expressed as the total score of the "yes"| "no" coded items: "voice is scaring me," "voice makes me confused," "voice interferes with paying attention at school," "voice interferes with homework," "I am getting into arguments because of voice," "I am getting punished because of voice," "voice makes me run away," "voice makes me do things I don't want." This approximately normally distributed score was divided by the median value to create a dichotomous exposure. A total score of life events in the past year was constructed by asking, in a structured way, about 22 common childhood events scored "present" or "absent" (e.g., death, illness, accidents, friends moving away, changing school, first menstruation, pregnancy, unanswered love, arguments, parental divorce, repeating school year, other life events, etc.). A total childhood adversity score was constructed by adding the scores of the items that were assessed in a structured way (scored "present" or "absent"): childhood not pleasant, not feeling safe at home, not feeling safe on the street, not feeling safe at school, being punished in strange ways, being beaten regularly, being scolded regularly, feeling unwanted, witness of physical abuse, witness of sexual abuse, molested or abused sexually. In addition, the child was specifically asked whether it thought the voice was related to some past stressful life event or trauma.

Receipt of professional help and help-seeking behavior was assessed by asking whether professional help was being received in relation to the voices, or whether a hospital admission had ever occurred in relation to the voices. In addition, after assessing the size of the child's social network in a structured way, the proportion of the total network that the child had discussed the voices with was assessed.

Psychopathology was assessed using the Extended Brief Psychiatric Rating Scale (BPRS; [Overall and Gorham, 1962; Lukoff et al., 1986]), yielding scores for the dimensions anxiety/depression (anxiety, depressive mood, guilt feelings, suicidality), positive psychotic symptoms (suspiciousness, unusual thought content, hallucinations) negative psychotic symptoms (motor retardation, blunted affect, emotional withdrawal, selfneglect), disorganization (disorientation, conceptual disorganization, bizarre behavior), and mania (excitement, euphoria, hyperactivity, distractibility). These variables were expressed as dichotomous "case" level variables by using the 90th percentile as the cut-off.

Evidence of delusional thinking was considered whenever a child had a score of " 6 ," or " 7 " (on a 17 scale) on any of the three delusion items of the
BPRS: "suspiciousness," "unusual thought content," and "grandiosity." Any evidence of delusional ideation, regardless of the type of delusion, is rated under the item "unusual thought content," so that the measure should cover all instances of delusional experience.

Item 105 of the Youth Self Report/11-18 (YSR) [Verhulst et al., 1996] was used to measure use of drugs and alcohol. Children indicated whether they used drugs or alcohol (item: "I use drugs or alcohol") on a three-point scale. The categories "a little/sometimes" and "a lot/often" were joined together in a single category. Nineteen children had a positive rating on this measure of drug/alcohol use ("a little/sometimes: $n=13$; "a lot/often": $n=6$ ).

Global level of functioning was assessed using the Children's Global Assessment Scale (CGAS) [Shaffer et al., 1983]. This scale was administered at the first and last measurement occasion (the last measurement being the last time the child was seen for follow-up). In the analyses, a "case" level poor social functioning variable was used, defined as a score greater than the 90th percentile of the CGAS.

The Dissociative Experience Scale (DES) [Bernstein and Putnam, 1986], is a 28-item self-report instrument measuring dissociative experiences. The respondent is asked to indicate agreement with a statement on a scale between 1 and 10 . The sum of the amount of agreement, divided by the number of items constitutes the DES score. A score exceeding 30 is considered deviant. Items of the DES were reworded to match the cognitive level of children, and all items were read aloud to the children, followed by assessment of whether they had understood the question.

During the interviews, care was taken to elicit and record the child's experiences, rather than those of their parents. Researchers did not make therapeutic statements or suggestions (although they would, of course, answer any questions to the best of their ability), and did not comment on ongoing mental health care, if present. At the end of each interview, research staff made a report covering all the data collected. This was subsequently discussed with the research team (M.R., S.E., and A.B.), to discuss problems and ambiguities, and to create continuing consensus on how to conduct the interview and rate answers in a standard way.

\section{Analyses}

The 3 years were divided in three equal timebands. During each of the three timebands (baseline-Year 1, Year 1-Year 2, and Year 2-Year 3) person-time was allocated to each patient. Person-time was the number of years between baseline and the follow-up interview at which the child indicated that delusional ideation was present. If a child who was eligible for interview missed an interview at a given occasion, but was seen again on the next, the most recently updated status was used to assess the presence of delusions and persontime was assigned accordingly. For example, a child who was not interviewed at Year 2, but was seen at Year 3 was retained in the data set on the basis of the Year 3 interview outcome. 


\section{Escher et al.}

The STCOX command in STATA (version 6) [STATA, 1999] was used to estimate Cox maximumlikelihood proportional hazard models of delusional ideation [Clayton and Hills, 1993]. Children who developed delusional ideation at one screening point were excluded from the Cox proportional hazard analyses at the next screening points (i.e., were "censored" in statistical terms). Associations were expressed as the hazard ratio, a measure of relative risk [Kendler et al., 1994], with $95 \%$ confidence intervals. Tests were performed two-tailed with alpha of 0.05 .

The age range of the sample was quite wide, and assessment of some of the predictors used would be dependent on general cognitive level of the subject. It could be argued that spurious results might arise because younger children would not understand the questions (for example, on dissociations or voice attributions) or would answer them in a "delusional" way because of greater levels of childhood magical thinking. To test for such spurious results, analyses were also conducted in the sample of the oldest children, using the median age (age 13 years) as the cut-off.

\section{RESULTS \\ Sample}

The mean age was 12.9 years $(\mathrm{SD}=3.1$; range $8-$ 19 years). Around half (53.8\%) were female. Taking into account censoring (when children had indicated they had delusional ideation on one occasion and therefore were excluded from the rest of the follow-ups), respectively $80,75,43$, and 60 children were seen at baseline, Year 1, Year 2, and Year 3. A total of 13 children had displayed evidence of delusional ideation at Year 1, Year 2, or Year 3. Of these, six also had displayed evidence of delusional ideation at baseline.

\section{Predictors of Delusional Ideation}

There was, predictably, a strong effect of baseline presence of delusional ideation on follow-up delusional ideation $(\mathrm{HR}=4.36,95 \% \mathrm{CI}: 1.46,13.08 ; P=0.009)$. All the analyses hereafter were controlled for baseline delusional ideation. The BPRS dimensions depression and disorganization displayed the strongest associations with delusional ideation (Tables I, II). Delusional ideation was also associated with higher level of reported life events, reports that the voices were heard outside the head, and that the voices resembled those of the parents. Children that had indicated that voices were variably friendly and hostile or had another emotional tone had a higher probability to display delusional ideation. A coping style characterized by passive illness behavior predicted delusional ideation, and receiving mental health care at baseline was also associated with delusional ideation at follow-up.

\section{Predictors in Older Children}

Analyses, adjusted for baseline delusional ideation, restricted to the group of children aged over 13 years ( $n=33$, of which nine had displayed delusional idea- tion) revealed that the pattern of results remained largely unchanged. Significant predictors remained significant or were not reduced by more than $30 \%$. The effect of two predictors, however, were reduced substantially: a passive illness behavior coping style, which was reduced by nearly $80 \%$, and receipt of professional care, which was reduced by close to $60 \%$. The effect of perceived influence of the voices on emotions and behavior increased by nearly $75 \%$, and was statistically significant.

\section{DISCUSSION}

In a group of 80 children with voices, 13 children (16\%) displayed evidence of delusional ideation over at least one of three follow-up periods. In seven cases (9\%) the delusions appeared de novo. Delusion formation over the follow-up period was associated with baseline voice appraisals and attributions such as tone of the voice, perceived location of the voice and whether the voice resembled that of a parent. Other predictors were baseline BPRS anxiety/depression, baseline BPRS disorganization and the baseline amount of reported recent stressful life events. In addition, in older children, the perceived influence of the voices on emotions and behavior was strongly associated with delusion formation.

\section{Methodological Issues}

We did not conduct detailed diagnostic interviews yielding ICD or DSM diagnoses. Instead, we collected general measures of psychopathology and social functioning. This was done for several reasons. First, the variable of interest in this study was experience of voices, and the psychopathological and social functioning context of these experiences is arguably better described by global measures than diagnostic constructs of uncertain validity. Second, many of our subjects would not have met the distress/dysfunction criteria for disorder and therefore would have remained "undiagnosable" using traditional measurements.

Some of the subjects were quite young, and the age range was quite large. It is possible that the older children were better able to understand questions about, for example, coping and childhood trauma. Care was taken, however, that all questions were understood by the children during interview and to the extent that this bias operated it is unlikely to have produced the current results. In addition, analyses restricted to the oldest group of children largely confirmed the pattern of results.

It could be argued that the reported associations are the result of circular reasoning, in that certain attributions themselves, used as predictors in the analyses, in fact constituted part of the delusional ideation itself. This, however, is not the case, as all analyses were adjusted for baseline delusional ideation as assessed by the BPRS. Thus, in as much as any attribution could be rated as a delusion at baseline, its effect would have been controlled for. This would explain why attributions that came closest to overt delusional explanations, such as attributions of the voice being caused by a spirit 


\section{Delusional Ideation in Adolescents Hearing Voices}

TABLE I. Descriptive Statistics of Predictors of Delusional Ideation

\begin{tabular}{|c|c|c|}
\hline $\begin{array}{l}\text { Group } \\
\quad \text { Predictor variables (range) }\end{array}$ & $\begin{array}{l}\text { Delusional ideation Mean } \\
\text { (SD) or percentage }\end{array}$ & $\begin{array}{l}\text { No delusional } \\
\text { ideation Mean } \\
\text { (SD) or percentage }\end{array}$ \\
\hline \multicolumn{3}{|l|}{ Demographic } \\
\hline Age (years: 8,19 ) & $14.2(3.5)$ & $12.6(3.0)$ \\
\hline \multicolumn{3}{|l|}{ Gender } \\
\hline Boys & 38.5 & 47.8 \\
\hline Girls & 61.5 & 52.2 \\
\hline \multicolumn{3}{|l|}{ Voice characteristics } \\
\hline \multicolumn{3}{|l|}{ Number of Voices: } \\
\hline 1 & 23.1 & 19.7 \\
\hline $2-5$ & 30.8 & 39.4 \\
\hline $6-10$ & 23.1 & 15.2 \\
\hline$>10$ & 23.1 & 22.7 \\
\hline Variable & 0.0 & 3.0 \\
\hline \multicolumn{3}{|l|}{ BPRS severity rating hallucinations } \\
\hline Lowest & 38.5 & 38.8 \\
\hline Middle & 0.0 & 35.8 \\
\hline Highest & 61.5 & 25.4 \\
\hline \multicolumn{3}{|l|}{ Frequency of voices } \\
\hline Continuous & 15.4 & 9.0 \\
\hline Hourly & 15.4 & 13.4 \\
\hline Daily & 46.2 & 31.3 \\
\hline Weekly & 15.4 & 20.9 \\
\hline Monthly & 0.0 & 6.0 \\
\hline Variable & 7.7 & 19.4 \\
\hline \multicolumn{3}{|l|}{ Psychopathology and dissociation } \\
\hline Sees things & 92.3 & 59.7 \\
\hline Total DES score $(2,76)$ & $26.6(21.1)$ & $20.5(13.5)$ \\
\hline BPRS "case" level anxiety/depression & 38.5 & 4.5 \\
\hline BPRS "case" level positive symptoms & 30.8 & 10.5 \\
\hline BPRS "case" level disorganisation & 15.4 & 6.0 \\
\hline BPRS "case" level negative symptoms & 15.4 & 4.5 \\
\hline BPRS “case" level mania & 7.7 & 13.4 \\
\hline \multicolumn{3}{|l|}{ Triggers and adversity } \\
\hline Presence emotional trigger & 84.6 & 86.6 \\
\hline Presence trigger in place & 23.1 & 58.2 \\
\hline Presence trigger in time & 7.7 & 44.8 \\
\hline Sleep related & 9.1 & 31.3 \\
\hline Total life event score $(0,3.2)$ & $1.4(1.0)$ & $0.7(0.7)$ \\
\hline Childhood adversity score $(0,8)$ & $2.5(2.5)$ & $1.3(1.5)$ \\
\hline Use of drugs or alcohol & 15.4 & 25.8 \\
\hline \multicolumn{3}{|l|}{ Appraisals/attributions } \\
\hline Secondary explanation & 61.5 & 61.2 \\
\hline Attribution past adversity & 38.5 & 23.1 \\
\hline Voice outside head & 53.9 & 30.3 \\
\hline Voices resembles parents & 66.7 & 28.4 \\
\hline \multicolumn{3}{|l|}{ Affective appraisal } \\
\hline Friendly & 15.4 & 26.9 \\
\hline Hostile & 38.5 & 47.8 \\
\hline Neutral & 7.7 & 11.9 \\
\hline Variable & 30.8 & 11.9 \\
\hline Other & 7.7 & 1.5 \\
\hline Perceived influence on emotions/behaviour & 61.5 & 34.3 \\
\hline \multicolumn{3}{|l|}{ Coping } \\
\hline Total coping score $(0,9)$ & $4.9(1.9)$ & $4.3(2.6)$ \\
\hline Passive illness behaviour & $0.17(0.25)$ & $0.06(0.19)$ \\
\hline Active problem solving & $0.40(0.30)$ & $0.28(0.22)$ \\
\hline Passive problem solving & $0.44(0.37)$ & $0.35(0.31)$ \\
\hline Active problem avoidant & $0.10(0.20)$ & $0.21(0.23)$ \\
\hline Symptomatic & $0.35(0.47)$ & $0.25(0.32)$ \\
\hline Other & $0.39(0.51)$ & $0.22(0.42)$ \\
\hline \multicolumn{3}{|l|}{ Global functioning } \\
\hline Baseline "case" level CGAS social functioning & 7.7 & 6.1 \\
\hline \multicolumn{3}{|l|}{ Help sought/received } \\
\hline Proportion in network discussed with $(0,100)$ & $49.4(25.1)$ & $35.5(23.0)$ \\
\hline Had professional help & 61.5 & 47.8 \\
\hline Was admitted to hospital & 23.1 & 4.5 \\
\hline
\end{tabular}




\section{Escher et al.}

TABLE II. Non-Psychopathological Factors Influencing Discontinuation of Voices, Adjusted for Baseline Delusional Ideation

\begin{tabular}{|c|c|c|c|c|}
\hline \multirow{2}{*}{$\begin{array}{l}\text { Group } \\
\text { Baseline variable }\end{array}$} & \multicolumn{2}{|c|}{ Whole group } & \multicolumn{2}{|c|}{ Oldest children only $^{\mathrm{b}}$} \\
\hline & Hazard ratio $(95 \% \mathrm{CI})$ & $P$ & Hazard ratio $(95 \% \mathrm{CI})$ & $P$ \\
\hline \multicolumn{5}{|l|}{ Demographic } \\
\hline Age (years) & $1.16(0.96,1.39)$ & 0.1 & $1.07(0.68,1.70)$ & 0.8 \\
\hline Age at onset (years) & $0.93(0.80,1.09)$ & 0.4 & $0.86(0.72,1.03)$ & 0.1 \\
\hline Sex & $1.35(0.44,4.16)$ & 0.6 & $1.03(0.28,3.88)$ & 0.1 \\
\hline \multicolumn{5}{|l|}{ Voice characteristics } \\
\hline \multicolumn{5}{|l|}{ Number of voices: } \\
\hline 1 & $1^{\mathrm{a}}$ & - & $1^{\mathrm{a}}$ & - \\
\hline $2-5$ & $0.87(0.19,3.91)$ & 0.2 & $0.24(0.02,2.61)$ & 0.2 \\
\hline $6-10$ & $1.22(0.25,6.13)$ & 0.4 & $2.57(0.42,15.80)$ & 0.3 \\
\hline$>10$ & $1.41(0.27,7.19)$ & 0.8 & $1.45(0.23,8.95)$ & 0.7 \\
\hline Variable & $0^{c}$ & - & $0^{c}$ & - \\
\hline BPRS severity rating hallucinations & $1.06(0.83,1.36)$ & 0.6 & $1.13(0.83,1.54)$ & 0.4 \\
\hline Frequency of voices & & & & \\
\hline Continuous & $1^{\mathrm{a}}$ & - & $1^{\mathrm{a}}$ & - \\
\hline Hourly & $1.40(0.18,10.86)$ & 0.8 & $2.00(0.15,26.67)$ & 0.6 \\
\hline Daily & $1.30(0.26,6.55)$ & 0.8 & $1.60(0.16,16.08)$ & 0.7 \\
\hline Weekly & $0.75(0.11,5.40)$ & 0.8 & $1.25(0.05,29.53)$ & 0.9 \\
\hline Monthly & $0^{\mathrm{c}}$ & - & $0^{\mathrm{c}}$ & - \\
\hline Variable & $0.60(0.05,7.67)$ & 0.7 & $0^{\mathrm{c}}$ & - \\
\hline \multicolumn{5}{|l|}{ Triggers and adversity } \\
\hline Presence emotional trigger & $0.88(0.20,3.96)$ & 0.9 & $0.76(0.15,3.91)$ & 0.7 \\
\hline Presence trigger in place & $0.31(0.09,1.15)$ & 0.08 & $0.27(0.03,2.20)$ & 0.2 \\
\hline Presence trigger in time & $0.17(0.02,1.37)$ & 0.10 & $0.36(0.04,3.23)$ & 0.4 \\
\hline Sleep related & $0.34(0.05,2.85)$ & 0.3 & $0.49(0.06,4.05)$ & 0.5 \\
\hline Total life event score & $1.80(1.00,3.26)$ & 0.05 & $2.17(1.10,4.29)$ & 0.03 \\
\hline Childhood adversity score & $1.25(0.93,1.69)$ & 0.1 & $1.31(0.99,1.75)$ & 0.06 \\
\hline Use of drugs or alcohol & $0.54(0.12,2.43)$ & 0.4 & $0.25(0.05,1.26)$ & 0.09 \\
\hline \multicolumn{5}{|l|}{ Appraisals/attributions } \\
\hline Secondary explanation & $0.84(0.27,2.66)$ & 0.8 & $0.59(0.12,2.88)$ & 0.5 \\
\hline Attribution past adversity & $1.43(0.46,4.47)$ & 0.5 & $1.38(0.36,5.20)$ & 0.6 \\
\hline Voice outside head & $2.91(0.97,8.73)$ & 0.06 & $5.94(1.20,29.54)$ & 0.03 \\
\hline Voices resembles parents & $3.45(1.00,12.04)$ & 0.05 & $2.89(0.64,13.05)$ & 0.2 \\
\hline \multicolumn{5}{|l|}{ Affective appraisal } \\
\hline Friendly & $1^{\mathrm{a}}$ & - & $1^{\mathrm{a}}$ & - \\
\hline Hostile & $1.81(0.35,9.34)$ & 0.5 & $2.47(0.25,24.74)$ & 0.4 \\
\hline Neutral & $2.91(0.22,38.54)$ & 0.4 & $5.12(0.24,110.48)$ & 0.3 \\
\hline Variable & $6.80(1.13,41.0)$ & 0.04 & $7.03(0.66,75.06)$ & 0.1 \\
\hline Other & $15.89(1.19,212.3)$ & 0.04 & $11.46(0.52,250.47)$ & 0.1 \\
\hline Perceived influence on emotions/behaviour & $2.08(0.64,6.77)$ & 0.2 & $5.13(1.01,25.94)$ & 0.05 \\
\hline \multicolumn{5}{|l|}{ Coping } \\
\hline Coping score & $0.96(0.74,1.23)$ & 0.7 & $0.98(0.68,1.40)$ & 0.9 \\
\hline Passive illness behaviour & $12.09(1.23,118.4)$ & 0.03 & $3.29(0.60,18.00)$ & 0.2 \\
\hline Active problem solving & $0.83(0.04,16.23)$ & 0.9 & $1.25(0.02,88.63)$ & 0.9 \\
\hline Passive problem solving & $1.07(0.16,7.31)$ & 0.9 & $2.92(0.20,43.10)$ & 0.4 \\
\hline Active problem avoidant & $0.04(0.00,2.32)$ & 0.1 & $0.08(0.00,19.06)$ & 0.4 \\
\hline Symptomatic & $1.88(0.32,10.93)$ & 0.5 & $0.91(0.09,9.20)$ & 0.9 \\
\hline Other & $2.45(0.62,9.64)$ & 0.2 & $4.07(0.80,20.70)$ & 0.09 \\
\hline \multicolumn{5}{|l|}{ Global functioning } \\
\hline Baseline "case" level CGAS poor social functioning & $1.34(0.17,10.35)$ & 0.8 & $1.35(0.17,10.81)$ & 0.8 \\
\hline \multicolumn{5}{|l|}{ Help sought/received } \\
\hline Proportion in network discussed with & $3.28(0.43,24.84)$ & 0.3 & $2.88(0.22,37.27)$ & 0.4 \\
\hline Has professional help & $3.53(1.00,12.48)$ & 0.05 & $2.12(0.49,9.12)$ & 0.3 \\
\hline Was admitted to hospital & $3.20(0.87,11.81)$ & 0.08 & $2.32(0.57,9.49)$ & 0.2 \\
\hline \multicolumn{5}{|l|}{ Psychopathology and dissociation } \\
\hline Sees things & $6.67(0.86,51.79)$ & 0.07 & $-^{\mathrm{d}}$ & \\
\hline Total DES score & $1.16(0.70,1.95)$ & 0.6 & $1.22(0.67,2.15)$ & 0.5 \\
\hline BPRS "case" level anxiety/depression & $6.41(1.93,21.35)$ & 0.002 & $4.63(1.14,18.72)$ & 0.032 \\
\hline BPRS "case" level positive symptoms & $1.51(0.39,5.81)$ & 0.6 & $1.34(0.27,6.75)$ & 0.7 \\
\hline BPRS “case" level disorgańisation & $5.04(0.98,26.07)$ & 0.05 & $5.70(0.94,34.69)$ & 0.06 \\
\hline BPRS "case" level negative symptoms & $2.94(0.65,13.38)$ & 0.2 & $2.51(0.26,24.73)$ & 0.4 \\
\hline BPRS "case" level mania & $0.67(0.09,5.26)$ & 0.7 & $0^{\mathrm{c}}$ & - \\
\hline
\end{tabular}

${ }^{\text {a}}$ Reference category.

${ }^{\mathrm{b}}$ Over 13 years of age.

cEstimate unstable.

${ }^{\mathrm{d}}$ Model did not converge. 


\section{Delusional Ideation in Adolescents Hearing Voices}

or a ghost, by a special gift, or coming from a different world, did not increase the risk for delusional ideation. Other attributions such as perception of the voices being perceived outside the head, resemblance to parental voices and perceived influence on behavior and emotions can be readily understood as individualspecific attempts to explain and appraise abnormal perceptual experiences. Even to the extent to which these attributions may be understood formally as the early stages of delusional experience, their effects remain very important as they can be seen as risk factors for adverse outcome of the experience of hearing voices, secondary delusion formation contributing to risk of persistence of psychosis and eventually patient status.

\section{Appraisals, Attributions, and Risk of Psychosis}

It is well known that many individuals in the general population display psychotic experiences in the absence of social dysfunction or distress associated with clinical psychosis [Romme and Escher, 1989; Romme et al., 1992; Honig et al., 1998; Verdoux et al., 1998; Peters et al., 1999; Van Os et al., 2001]. There is now a growing literature on the role of emotions and attributions in relation to not only experience of psychosis itself, such as auditory hallucinations, but also in relation to associated depression and adverse outcome of the experience, for example in the form of secondary delusion formation and ensuing patient status [Romme and Escher, 1989, 1994, 2000; Romme et al., 1992; Garety and Freeman, 1999; Birchwood et al., 2000; Blackwood et al., 2001; Garety et al., 2001].

An important bias facilitating onset of delusions in association with experience of voices is the individual's conscious appraisal of the experience being externally caused [Garety and Freeman, 1999]. The results of the current study are in agreement with this theory, as evidenced by appraisal of external location of the voices.

Another factor that has been proposed is the individual's underlying schema of social subordination, fuelling "powerful" voices and delusional ideation [Chadwick and Birchwood, 1994; Romme and Escher, 1989, 2000; Birchwood et al., 2000]. The current results agree, in that children who felt more controlled by voices in terms of behavior and emotions had a higher risk of delusion formation. The fact that this finding was especially evident in the older children may be due the fact that expression of such an influence requires a certain level of cognitive ability. The equivalence of this finding in younger children may be reports that the voices resembled those of authority figures such as the parents.

The role of emotions and worry in relation to psychotic symptoms has been highlighted by a number of authors [Maher, 1988; Romme and Escher, 1989, 1996, 2000; Freeman and Garety, 1999; Garety and Freeman, 2001]. Negative emotions may feed back into experiences of voices and influence the content of associated beliefs, facilitating delusion formation. Emotions may also make hallucinatory experiences personally signifi- cant or more intrusive, prompting the individual to search for explanations. Similarly, negative appraisal of the tone of the voices may influence delusion formation. Although all ratings other than "friendly" increased the risk of delusional ideation, only voices that were alternating friendly or hostile, or that had another affective connotation, were statistically significantly associated with delusion formation. It may be that the variability of emotional tone reflects an underlying subjective perception of uncontrollability of the experience.

A number of ways in which the role of triggering events might contribute to psychotic symptoms has been considered. First, a triggering event may give rise in a predisposed individual to the basic disruption of cognitive processes that leads to a breakdown in "willed intention," facilitating the emergence of psychotic symptoms [Garety and Hemsley, 1994]. Triggering events may also cause significant anxiety/depression, influencing the content of appraisal processes of the voices as described above. Another possibility is that subjective experience of intrusive life events is reflective of a general tendency to feel easily overwhelmed by events, and develop feelings of uncontrollability contributing to maintenance of psychotic beliefs, or facilitating submission to "powerful" voices [Romme and Escher, 1989, 1996, 2000; Romme et al., 1992; Romme, 1996; Honig et al., 1998; Birchwood et al., 2000; Garety et al., 2001].

\section{REFERENCES}

Bak M, Van der Spil F, Gunther N, Radstake S, Delespaul P, Van Os J. 2001a. Macs-I. Maastricht Assessment of coping strategies: a brief instrument to assess coping with psychotic symptoms. Acta Psychiatr Scand 103:453-459.

Bak M, Van der Spil F, Gunther N, Radstake S, Delespaul P, Van Os J. 2001b. Macs II. Does coping enhance subjective control over symptoms? Acta Psychiatr Scand 103:460-464.

Bernstein EM, Putnam FW. 1986. Development, reliability, and validity of a dissociation scale. J Nerv Ment Dis 174:727-735

Bilder RM, Mukherjee S, Rieder RO, Pandurangi AK. 1985. Symptomatic and neuropsychological components of defect states. Schizophr Bull 11:409-419.

Birchwood M, Meaden A, Trower P, Gilbert P, Plaistow J. 2000. The power and omnipotence of voices: subordination and entrapment by voices and significant others. Psychol Med 30:337-344.

Blackwood NJ, Howard RJ, Bentall RP, Murray RM. 2001. Cognitive neuropsychiatric models of persecutory delusions. Am J Psychiatry 158:527-539.

Chadwick P, Birchwood M. 1994. The omnipotence of voices. A cognitive approach to auditory hallucinations. Br J Psychiatry 164:190201.

Clayton D, Hills M. 1993. Cox regression models. In: Statistical methods in epidemiology. Oxford: Oxford University Press. p 298-306.

De Clérambault GG. 1942. Oeuvre psychiatrique. In: PUF. p 457-467.

Fennig S, Susser ES, Pilowsky DJ, Bromet EJ. 1997. Childhood hallucinations preceding the first psychotic episode. J Nerv Ment Dis 185: 115-117.

Freeman D, Garety PA. 1999. Worry, worry processes and dimensions of delusions: an exploratory investigation of a role for anxiety processes in the maintenance of delusional distress. Behav Cogn Psychother 27: 47-62.

Garety PA, Freeman D. 1999. Cognitive approaches to delusions: a critical review of theories and evidence. Br J Clin Psychol 38:113-154.

Garety PA, Hemsley DR. 1994. Delusions: investigations into the psychology of delusional reasoning. Oxford: Oxford University Press. 


\section{Escher et al.}

Garety PA, Kuipers E, Fowler D, Freeman D, Bebbington PE. 2001. A cognitive model of the positive symptoms of psychosis. Psychol Med 31:189-195

Honig A, Romme MAJ, Ensink B, Escher ADMAC, Pennings MHA, deVrie MW. 1998. Auditory hallucinations: a comparison between patients and non-patients. J Nerv Ment Dis 186:646-651.

Kendler KS, McGuire M, Gruenberg AM, Walsh D. 1994. Clinical heterogeneity in schizophrenia and the pattern of psychopathology in relatives: results from an epidemiologically based family study. Acta Psychiatr Scand 89:294-300.

Liddle PF. 1987. The symptoms of chronic schizophrenia. A re-examination of the positive-negative dichotomy [see comments]. Br J Psychiatry 151:145-151.

Lukoff D, Nuechterlein KH, Ventura J. 1986. Manual for the expanded brief psychiatric rating scale. Schizophr Bull 12:594-602.

Maher BA. 1974. Delusional thinking and perceptual disorder. J Ind Psychol 30:98-113.

Maher BA. 1988. Anomalous experience and delusional thinking: the logic of explanations. In: Oltmanns TF, Maher BA, editors. Delusional beliefs. New York: Wiley. p 15-33.

McGee R, Williams S, Poulton R. 2000. Hallucinations in nonpsychotic children [letter; comment]. J Am Acad Child Adolesc Psychiatry 39: $12-13$

Overall JE, Gorham DR. 1962. The Brief Psychiatric Rating Scale. Psychol Rep 10:799-812.

Peralta V, de Leon J, Cuesta MJ. 1992. Are there more than two syndromes in schizophrenia? A critique of the positive-negative dichotomy. $\mathrm{Br} \mathrm{J}$ Psychiatry 161:335-343.

Peters ER, Joseph SA, Garety PA. 1999. Measurement of delusiona ideation in the normal population: introducing the PDI. Schizophr Bull 25:553-576.

Poulton R, Caspi A, Moffitt TE, Cannon M, Murray R, Harrington H 2000. Children's self-reported psychotic symptoms and adult schizophreniform disorder: a 15-year longitudinal study [in process citation]. Arch Gen Psychiatry 57:1053-1058.

Romme MAJ. 1996. Understanding voices. Coping with auditory hallucinations and confusing realities. Clouchester: Handheld Publications.

Romme MA, Escher AD. 1989. Hearing voices. Schizophr Bull 15:209-216.

Romme MA, Escher AD. 1994. Hearing voices. BMJ 309:670.

Romme MAJ, Escher AD. 1996. Empowering people who hear voices. In: Romme MAJ, editor. Understanding voices. Coping with auditory hallucinations and confusing realities. Maastricht: University of Maastricht. p 23-38.

Romme MA, Escher AD. 2000. Making sense of voices London: Mind.

Romme MAJ, Honig A, Noorthoorn E, Escher AD. 1992. Coping with hearing voices: an emancipatory approach. Br J Psychiatry 161:99_ 103.

Shaffer D, Gould MS, Brasic J, Ambrosini P, Fisher P, Bird H, et al. 1983. A children's global assessment scale (CGAS). Arch Gen Psychiatry 40:1228-1231.

STATA C, 1999. STATA Statistical Software: Release 6.0. Texas: College Station.

Van Os J, Hanssen M, Bijl RV, Ravelli A. 2000. Strauss (1969) revisited: a psychosis continuum in the general population? Schizophr Res 45: $11-20$.

Van Os J, Hanssen M, Bijl RV, Vollebergh W. 2001. Prevalence of psychotic disorder and community level of psychotic symptoms: an urban-rural comparison. Arch Gen Psychiatry 58:663-668.

Verdoux H, Maurice-Tison S, Gay B, Van Os J, Salamon R, Bourgeois ML. 1998. A survey of delusional ideation in primary-care patients. Psychol Med 28:127-134.

Verhulst FC, Van der Ende J, HMHvdC-Rak-ej Koot. 1996. Sophia Kinderziekenhuis/Academisch Ziekenhuis Rotterdam, Erasmus Universiteit Rotterdam, 1996. Handleiding voor de CBCL/4-18. In Afdeling kinder-en jeugdpsychiatrie SKAZR, Erasmus Universiteit, editor. Rotterdam. 
Chapter 6

\section{Coping defence and depression in adolescents hearing voices.}

Journal of mental Health. 12,1,91-99.

Escher,Sandra., Delespaul, Philippe., Romme,Marius.,Buiks,Alex., Van Os,Jim (2003). 


\title{
Coping defence and depression in adolescents hearing voices
}

\author{
SANDRA ESCHER ${ }^{1,2,3}$, PHILIPPE DELESPAUL ${ }^{1}$, MARIUS ROMME $^{2,3}$, ALEX $^{2}$ \\ BUIKS $^{1}$, JIM VAN OS ${ }^{1,4}$
}

${ }^{1}$ Department of Psychiatry and Neuropsychology, Maastricht University, European Graduate School of Neuroscience, Maastricht, The Netherlands, ${ }^{2}$ Mental Health Policy Centre, University of Central England, Birmingham, ${ }^{3}$ Intervoice, Bosweg bij 2, 6268NH, Bemelen, The Netherlands \& ${ }^{4}$ Division of Psychological Medicine, Institute of Psychiatry, London, UK

\begin{abstract}
Background. The level of self-initiated coping defences in the face of auditory hallucinations reflects the degree to which the psychotic experiences are exceeding the person's resources. As it has been suggested that individuals who feel overwhelmed by their psychotic experiences are also more likely to develop depression, greater levels of self-initiated coping defences should predict onset of depression in the context of auditory hallucinations. Method. Eighty adolescents (mean age 12.9 years, $\mathrm{SD}=3.1$ ) who reported hearing voices were examined at baseline and followed-up three times over a period of 3 years. Fifty per cent were receiving professional care, but $50 \%$ were not in need of care. Baseline measurement of self-initiated coping defences and psychopathology were used as predictors of depression at follow-up. Results. Baseline level of self-initiated coping was strongly associated with baseline severity of positive psychotic symptoms. Coping at baseline, with the exception of active problem solving, predicted an increase in the level of depression over the followup period $(\mathrm{OR}=3.0,95 \% \mathrm{CI}: 1.4,6.4)$, independent of baseline psychopathology, demographic characteristics, receipt of professional care and appraisals and attributions related to the voices. Conclusions. The results suggest that individuals who have a tendency to feel overwhelmed by the experience of voices, as evidenced by a more defensive style of response, are more likely to develop depression.
\end{abstract}

Declaration of interest: Funded by the Dutch Prevention Fund.

Key words: coping, psychosis, adolescence, depression, hallucinations

\section{Introduction}

Coping is defined as 'the person's cognitive and behavioural efforts to manage the internal and external demands of the personenvironment transaction that is appraised as taxing or exceeding the person's resources' (Lazarus \& Folkman, 1984). Self-initiated 
coping is common in psychosis (Boker et al., 1984; Brenner et al., 1987; Carter et al., 1996; Falloon \& Talbot, 1981; Mueser et al., 1997; M. A. Romme et al., 1992), indicating that individuals who feel overwhelmed by their psychotic experiences mobilise coping defences. It has been shown that the degree of coping mobilised by the person is associated with severity of the psychotic experience and the level of distress, and is aimed at improving subjective control over the experience (Bak et al., 2002; Bak et al., 2001a, 2001b). The presence of coping, therefore, may be conceived as an indicator of the response by a person who feels overwhelmed by the experience of psychosis.

Individuals with psychotic experiences such as auditory hallucinations commonly experience depressive symptoms (Barnes et al., 1989; Berrios \& Bulbena, 1987; Van Os et al., 1999; van-Os et al., 2000; Verdoux et al., 1999). Key beliefs about the voices' power and omnipotence may lead to feelings of powerlessness and helplessness (Chadwick \& Birchwood, 1994) that contribute to the onset of depression, particularly in those who attribute power to and feel overwhelmed by their voices (Birchwood \& Chadwick, 1997).

Given the fact that the level of self-initiated coping defences in the face of auditory hallucinations reflects the degree to which the psychotic experiences are exceeding the person's resources, and given the fact that individuals who feel overwhelmed by their psychotic experiences are also more likely to develop depression, greater levels of selfinitiated coping defences should predict onset of depression in the context of auditory hallucinations. We hypothesised that in individuals with experience of voices at baseline, greater level of self-initiated coping defence at baseline would predict onset of depression over the follow-up period. We examined this hypothesis prospectively in a cohort of adolescents who reported hearing voices.

\section{Methods}

\section{Sample}

In order to recruit adolescents who were hearing voices, we proceeded in two stages. First, two of the research team (MR and SE) made extensive use of media contacts, formed in the course of a prior investigation (Romme et al., 1992) to create awareness about hearing voices and reduce stigmatisation at the national level. They appeared on a popular TV talk show, where the experience of a child hearing voices, as well as the view of its parents, were discussed. At the end of the programme, viewers were invited to attend a special conference on the subject in the Dutch capital. This conference was attended by 40 children and their parents, and received media coverage. In the second stage, the actual recruitment started. Press releases were sent out and several TV and radio appearances were made in which help was asked to get in touch with the target population. The local community paediatric health service in Maastricht, where all children aged 0-14 are periodically screened, was contacted, as well as several child and adolescent psychiatric services in the country. Over a period of approximately one year, 80 children who were hearing voices were thus recruited. The children were seen at baseline, and subsequently at 1-year intervals over a period of 3 years. Each child was thus interviewed four times. Whenever a child had indicated at the first follow-up that the voices had disappeared, no attempts were made to re-interview at the second follow-up, in order to avoid unnecessary focus on a past, and often upsetting, experience. However, an attempt was made to again interview all 80 children at 
the third follow-up, regardless of whether they heard voices or not.

\section{Research instruments and procedures}

The research team consisted of two field workers who had extensive prior experience in interviewing individuals with hallucinations, using a similar format as the one in the present study. They also had prior experience in administrating the other instruments used. Nearly all children were interviewed at home. The baseline interview was conducted in the presence of at least one parent or grandparent (with a few exceptions where adolescents had specifically asked that the parent not be present). All participants and their parents, where appropriate, provided written informed consent to conform to the local ethics committee guidelines. At each interview occasion, the same instruments were used. The main instrument was the Maastricht Voices Interview for Children. This interview was derived from the Maastricht Voices Interview for adults and adapted for children with the aid of a clinical child psychologist. It contains several items in relation to the experience of hearing voices, that were included on the basis of extensive qualitative research involving many individuals, including children, with voices over a period of at least 10 years (Romme, 1996; Romme \& Escher, 1996).

The frequency of the voices was coded as 'continuous', 'hourly', 'daily', 'weekly', 'monthly' and 'variable'. The emotional appraisal of the voice was coded as 'friendly', 'hostile', 'neutral', 'variably friendly and hostile' and 'other'. Attributions were assessed by coding a perceived origin of the voices as 'present' if the child had indicated explanations of the voice being caused by a spirit or ghost, by a special gift, by a disease, coming from a different world, or another explanation.
The degree of coping mobilised by the voices was assessed by constructing a total score of 18 possible coping mechanisms that were enquired about in a structured way and could be scored as 'present', (score 1) or 'absent' (score 0). A total score - weighted for different coping domains - was derived by i) calculating, for each coping domain (see below), the sum of the items divided by the number of items, and ii) adding the weighted scores of the six coping domains (maximum =6). The following coping mechanisms were assessed: passive illness behaviour (using medication, using alcohol or drugs), passive problem solving (ignoring voice, listening selectively to voice, doing something), active problem solving (making a deal with voice, swearing against voice, seeking distraction, making a drawing of the voice, sending voice away, writing something about the voice), active problem avoiding (thinking of something else, running away from the voice, calling someone over the telephone, visiting someone), symptomatic coping (listening carefully to the voice, performing a ritual against the voice) and other coping (other way of coping).

Receipt of professional help and help-seeking behaviour was assessed by asking whether professional help was being received in relation to the voices. Global level of functioning was assessed using the Children's Global Assessment Scale, administered at baseline (CGAS) (Shaffer et al., 1983).

Psychopathology was assessed using the Extended Brief Psychiatric Rating Scale (BPRS; (Lukoff et al., 1986; Overall \& Gorham, 1962)), yielding continuous scores for the dimensions anxiety/depression (anxiety, depressive mood, guilt feelings, suicidality), positive psychotic symptoms (suspiciousness, unusual thought content, hallucinations) negative psychotic symptoms (motor retardation, blunted affect, emotional 
withdrawal, self-neglect), disorganisation (disorientation, conceptual disorganisation, bizarre behaviour), and mania (excitement, euphoria, hyperactivity, distractibility). In addition, the Youth Self Report/11-18 (YSR) was used to measure general problem behaviour expressed as the total score (Verhulst $e t$ al., 1996)(Achenbach, 1991). Although the YSR and related CBCL scales allow for the calculation of separate scores corresponding to several behavioural dimensions based on exploratory factor analysis, confirmatory factor analytic studies have shown inadequate empirical support for these syndromes and their differentiation (Hartman, 1999 \#2445; Greenbaum, 1998 \#2447). Instead, a general problem behaviour factor appears to underlie CBCL and related scales data across different age groups (Hartman, 1999 \#2445; Greenbaum, 1998 \#2447). We therefore, used the total score as a general measure of problem behaviour.

During the interviews, care was taken to elicit and record the child's experiences, rather than those of the parents. Researchers did not make therapeutic statements or suggestions (although they would, of course, answer any questions to the best of their ability), and did not comment on ongoing mental health care, if present. At the end of each interview, research staff made a report covering all the data collected. This was subsequently discussed with the research team (MR, SE \& $\mathrm{AB}$ ), in order to discuss problems and ambiguities, and to create continuing consensus on how to conduct the interview and rate answers in a standard way.

\section{Analyses}

In order to validate self-initiated coping as a response to overwhelming experience of psychosis, correlations between coping level and severity of psychopathology were assessed, in particular with positive symptoms of psychosis. In order to test the specificity of this association, similar correlations were calculated with YSR problem behaviour and CGAF global functioning scale. Follow-up depression was defined dichotomously using the sample 90th percentile cut-off of the continuous BPRS depression score at the three follow-ups. Logistic regression in STATA(StataCorp, 2001), yielding odds ratios with $95 \%$ confidence intervals, was performed with follow-up depression as the response variable and baseline coping score and other variables as the exposure variables. Baseline depression was controlled for, using the baseline continuous BPRS depression score to avoid residual confounding. The adjustment for baseline depression means that an odds ratio greater than unity for a given exposure can be interpreted as indicating that the exposure predicts onset of new depression or worsening of depression that already existed at baseline. Otherconfounders selected $a$ priori were age, sex, receipt of professional help, YSR problem behaviour, CGAF global functioning and appraisals and attributions relating to the voices as described in the methods section. These confounders were selected on the a priori likelihood that they were associated with both coping and the onset depression (Clayton \& Hills, 1993a, 1993b).

In order to assess whether any effect of coping varied as a function of type of coping, we also examined a model in which the weighted scores of the six coping domains were entered simultaneously, so as to examine their independent effects on depression.

As there were three follow-ups with three observations per person in the data file, observations were clustered within individuals, compromising statistical independence of the observations. The CLUSTER and ROBUST options were therefore used in the STATA logistic regression analyses. The CLUSTER 
option combined with the ROBUST option allows for the use of observations which are not independent within clusters (in this case: within individuals) and obtains the Huber/ White/Sandwich estimator of variance instead of the traditional variance estimator. These procedures result in standard errors that are adjusted for clustering within persons. Tests were performed two-tailed with alpha of 0.05 .

\section{Results}

\section{Sample}

The mean age was 12.9 years $(\mathrm{SD}=3.1$; range $8-19$ years). Around half $(53.8 \%)$ were female. Respectively 80, 75, 51 and 64 children were seen at baseline, year 1 , year 2 and year 3. A total of 21 children met the criteria for dichotomously defined depression as defined above at one of the three follow-ups. The mean BPRS depression sum score at baseline was 8.2 ( $\mathrm{SD}=4.4$, range 423), and the mean BPRS score over the three follow-ups was somewhat lower at 5.9 ( $\mathrm{SD}=3.2$, range 4-22).

\section{Coping score and severity of positive psychotic symptoms}

The weighted coping score at baseline was $1.4(\mathrm{SD}=0.8$, range: $0-3.2)$; the mean number of self-initiated coping defenses was 4.4 ( $\mathrm{SD}=2.5$, range: $0-9$ ). The weighted coping score was correlated with total BPRS score at baseline (Pearson's $r=0.28, p=0.013$ ), in particular with severity of positive psychotic symptoms ( $r$ BPRS positive psychotic symptoms score $=0.41, p=0.0002$ ). No significant associations were apparent between coping and YSR problem behaviour $(r=0.19, p=0.10)$, or between coping and CGAF global functioning $(r=-0.04, p=0.73)$.

\section{Baseline coping and follow-up depression}

Baseline level of coping defences strongly predicted follow-updepression ( $\mathrm{OR}=3.0,95 \%$ CI: $1.4,6.4, p=0.005)$. This association further increased after adjustment for baseline dimensions of psychopathology, including baseline depression, and again after additional adjustment for sex, age, YSR level of problem behaviour, CGAF global functioning and voice characteristics such as frequency, emotional tone and attributions about the origin of the voices (Table 1). Analyses by coping domain suggested that passive and problem avoiding styles were most likely to be associated with depression. The only coping style that was negatively associated with depression, although statistically inconclusive, was active problem solving (Table 2).

\section{Discussion}

First, it was found that baseline level of self-initiated coping was strongly and specifically associated with baseline severity of positive symptoms of psychosis, suggesting that coping is indeed a valid measure for the degree to which individuals attempt to 'defend' themselves against the experience of being overwhelmed by their psychotic experiences. Second, it was found that higher levels of coping defences at baseline were strongly predictive of depression at followup, and that this association was independent of severity of baseline global functioning, problem behaviour and psychopathology dimensions, including depression, and independent of demographic characteristics, helpseeking and voice characteristics such as frequency, emotional tone and attributions about their origin. The findings therefore suggest that the pathway from coping defence to depression is one related to a charac- 


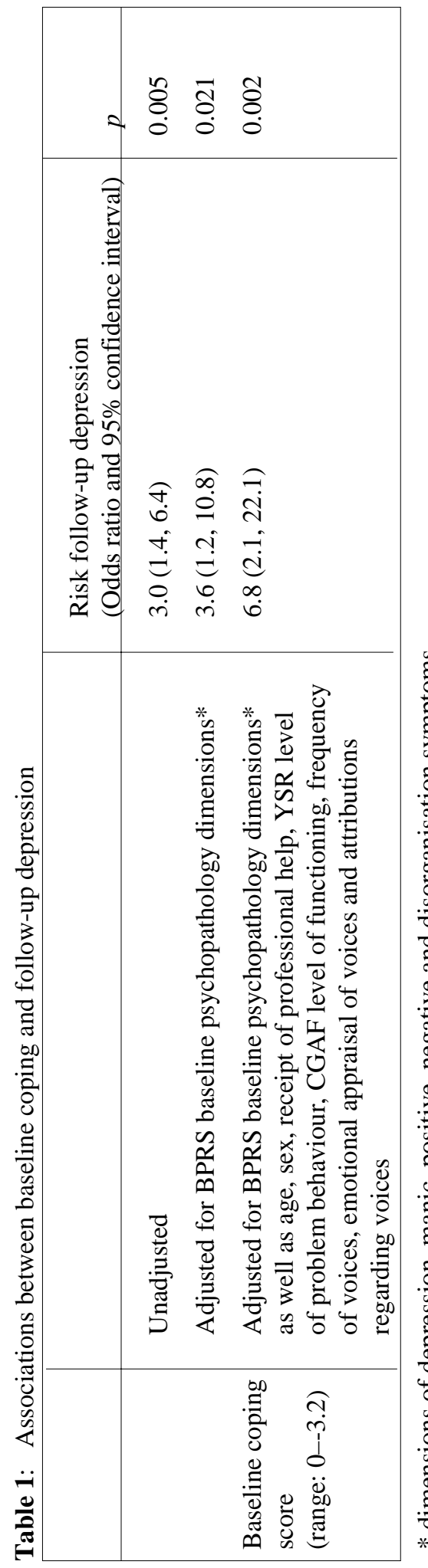

Table 2: Effect of coping on onset of depression, by coping domain, entered together in the model

\begin{tabular}{|l|c|}
\hline Coping domain & OR $(95 \% \mathrm{CI})$ \\
Passive illness behaviour & $12.9(1.9,88.0)$ \\
Passive problem solving & $5.6(0.6,55.3)$ \\
Active problem solving & $0.03(0.0,3.9)$ \\
Active problem avoiding & $30.2(1.4,640.1)$ \\
Symptomatic coping & $3.6(0.6,22.4)$ \\
Other coping & $4.5(1.3,16.1)$ \\
\hline
\end{tabular}

teristic of the person rather than a characteristic of the psychotic experience itself. It has been proposed that the individual's underlying schema of social subordination and, by implication, the tendency to feel overwhelmed by the psychotic experiences, fuels feelings of distress associated with the experiences (Birchwood et al., 2000; Romme \& Escher, 1989, 2000). The current results therefore agree with these theories. The fact that active problem solving was the only coping style negatively associated with depression, albeit statistically imprecise, whereas passive and avoidant styles had the strongest effect sizes, is also compatible with this line of reasoning. In a previous study, we showed that active problem solving was associated with more experience of control over the psychotic experience than other coping styles (Bak et al., 2002). This suggests that some coping strategies may be more useful than others and that not only quantity, but also quality of coping is important.

\section{Methodological issues}

The finding should be viewed in the context of several possible limitations. First, the level of self-initiated coping strategies was used as an indicator of the person's sense of being overwhelmed by severity of the psy- 
chotic experience. However, it could be argued that our measure was liable to false positive (individuals who feel overwhelmed and do not report coping responses) and false negative (individuals who feel in control over their experience but report a large amount of coping) classification. Although some degree of misclassification cannot be ruled out, the fact that the amount of self-initiated coping was associated with BPRS severity of psychotic experiences in this and previous work (Bak et al., 2002; Bak et al., 2001a, 2001b) strongly suggests that the amount of self-initiated coping increases linearly with appraised severity of symptoms, on which the BPRS rating is based. Since both false positive and false negative results would drive the correlation between self-initiated coping and appraised severity towards the null, it is unlikely that the data contain substantial misclassification. Second, the assessment of coping strategies was not based on a structured interview with clear anchor points. The questions on coping nevertheless had face validity, and although imprecise measurement may have introduced more random error, it is difficult to conceive how onset of depressive symptoms at follow-up could have biased baseline assessment of coping, resulting in spurious associations. Third, data on coping were assessed in a sample of children of varying ages. However, correction for age did not reduce the associations. Fourth, the sample collected was a not community-based and cannot therefore be considered representative for the group of children hearing voices. Similarly, this sample is per definition one in which self-initiated coping was not effective in terms of making the voices disappear altogether. Many individuals may cease to have hallucinatory experiences through self-initiated coping, but these would not have been included in our sample ini- tially. Fifth, our adjustment for baseline psychopathology may have been incomplete, because the measure of psychopathology was cross-sectional and did not include later fluctuation in symptoms. However, even if the measure was incomplete, adjustment for this possible confounder further increased the association, making it very unlikely that confounding by psychopathology caused spurious results. Sixth, our use of the concept of 'coping' as a response to severity of psychopathology suggests that all self-initiated coping is merely passive and is not successful in reducing symptom burden. This is in part an artificial function of our selection criteria of children who per definition had not been successful to reduce their experiences by self-initiated coping as they had persistent voices. Finally, we did not conducting detailed diagnostic interviews yielding ICD or DSM diagnoses. Instead, we collected dimensional measures of YSR problem behaviour, BPRS psychopathology and CGAF social functioning. This was done for several reasons. First, the variable of interest in this study was experience of voices, and the psychopathological and social functioning context of these experiences is arguably better described by global dimensional measures than diagnostic constructs of uncertain validity. Second, many of our participants would not have met the distress/dysfunction criteria for disorder and therefore remained 'undiagnosable' using traditional measurements.

\section{References}

Achenbach, T.M. (1991). Manual for the Youth SelfReport and 1991 Profile, with Dutch translation. Burlington, VT: University of Vermont.

Bak, M., Hanssen, M., Bijl, R.V., Vollebergh, W., Delespaul, P. \& Van Os, J. (2002). When does experience of psychosis result in need for care? A 
prospective general population study. Schizophrenia Bulletin, in press.

Bak, M., Van der Spil, F., Gunther, N., Radstake, S., Delespaul, P. \& Van Os, J. (2001a). Macs II. Does coping enhance subjective control over symptoms? Acta Psychiatrica Scandinavica, 103, 460-464.

Bak, M., Van der Spil, F., Gunther, N., Radstake, S., Delespaul, P. \& Van Os, J. (2001b). Macs-I. Maastricht Assessment of coping strategies: A brief instrument to assess coping with psychotic symptoms. Acta Psychiatrica Scandinavica, 103, 453459.

Barnes, T.R., Curson, D. A., Liddle, P.F. \& Patel, M.. (1989). The nature and prevalence of depression in chronic schizophrenic in-patients. British Journal of Psychiatry, 154, 486-491.

Berrios, G.E. \& Bulbena, A. (1987). Post psychotic depression: the Fulbourn cohort. Acta Psychiatrica Scandinavica, 76, 89-93.

Birchwood, M., \& Chadwick, P. (1997). The omnipotence of voices: testing the validity of a cognitive model. Psychological Medicine, 27, 1345-1353.

Birchwood, M., Meaden, A., Trower, P., Gilbert, P. \& Plaistow, J. (2000). The power and omnipotence of voices: Subordination and entrapment by voices and significant others. Psychological Medicine, 30, 337-344.

Boker, W., Brenner, H.D., Gerstner, G., Keller, F., Muller, J. \& Spichtig, L. (1984). Self-healing strategies among schizophrenics: attempts at compensation for basic disorders. Acta Psychiatrica Scandinavica, 69, 373-378.

Brenner, H.D., Boker, W., Muller, J., Spichtig, L. \& Wurgler, S. (1987). On autoprotective efforts of schizophrenics, neurotics and controls. Acta Psychiatrica Scandinavica, 75, 405-414.

Carter, D.M., Mackinnon, A. \& Copolov, D.L. (1996). Patients' strategies for coping with auditory hallucinations. Journal of Nervous and Mental Disease, 184, 159-164.

Chadwick, P., \& Birchwood, M. (1994). The omnipotence of voices. A cognitive approach to auditory hallucinations. British Journal of Psychiatry, 164, 190-201.

Clayton, D., \& Hills, M. (1993a). Choice and interpretation of models. In D. Clayton \& M. Hills (Eds.), Statistical Models in Epidemiology (pp. 271-282). Oxford: Oxford Science Publications.

Clayton, D. \& Hills, M. (1993b). Testing Hypotheses. In D. Clayton \& M. Hills (Eds.), Statistical Models in Epidemiology (pp. 237-249). Oxford: Oxford Science Publications.
Falloon, I. R. \& Talbot, R. E. (1981). Persistent auditory hallucinations: coping mechanisms and implications for management. Psychological Medicine, 11, 329-339.

Lazarus, R.S. \& Folkman, S. (1984). Stress, Appraisal and Coping. New York: Springer Verlag.

Lukoff, D., Nuechterlein, K.H.,\& Ventura, J. (1986). Manual for the Expanded Brief Psychiatric Rating Scale. Schizophrenia Bulletin, 12, 594-602.

Mueser, K.T., Valentiner, D.P. \& Agresta, J. (1997). Coping with negative symptoms of schizophrenia: patient and family perspectives. Schizophrenia Bulletin, 23, 329-339.

Overall, J.E., \& Gorham, D.R. (1962). The Brief Psychiatric Rating Scale. Psychological Report, 10, 799-812.

Romme, M.A. \& Escher, A.D. (1989). Hearing voices. Schizophrenia Bulletin, 15, 209-216.

Romme, M.A. \& Escher, A.D. (2000). Making Sense of Voices. London: Mind.

Romme, M.A., Honig, A., Noorthoorn, E.O. \& Escher, A.D. (1992). Coping with hearing voices: An emancipatory approach. British Journal of Psychiatry, 161, 99-103.

Romme, M.A.J. (1996). Understanding Voices. Coping with auditory hallucinations and confusing realities. Clouchester: Handheld Publications.

Romme, M.A.J. \& Escher, A.D. (1996). Empowering people who hear voices. In M.A.J. Romme (Ed.), Understanding Voices. Coping with auditory hallucinations and confusing realities (pp. 23-38). Maastricht: University of Maastricht.

Romme, M.A.J., Honig, A., Noorthoorn, E. \& Escher, A.D. (1992). Coping with hearing voices: An emancipatory approach. British Journal of Psychiatry, 161, 99-103.

Shaffer, D., Gould, M.S., Brasic, J., Ambrosini, P., Fisher, P., Bird, H. \& Aluwahlia, S. (1983). A children's global assessment scale (CGAS). Archives of General Psychiatry, 40, 1228-1231.

StataCorp. (2001). STATA Statistical Software: Release 7.0. Texas: College Station.

Van Os, J., Verdoux, H., Maurice-Tison, S., Gay, B., Liraud, F., Salamon, R. \& Bourgeois, M. (1999). Self-reported psychosis-like symptoms and the continuum of psychosis. Social Psychiatry Psychiatric Epidemiology, 34, 459-463.

van-Os, J., Hanssen, M., Bijl, R.-V. \& Ravelli, A. (2000). Straus (1969) revisited: A psychosis continuum in the general population? Schizophrenia Research, 45, 11-20. 
Verdoux, H., Van Os, J., Maurice-Tison, S., Gay, B., Salamon, R. \& Bourgeois, M.L. (1999). Increased occurrence of depression in psychosis-prone subjects: a follow-up study in primary care settings. Comprehensive Psychiatry, 40, 462-468.
Verhulst, F.C., Van der Ende, J. \& Koot, H.M. (1996). Handleiding voor de CBCL/4-18. Rotterdam: Afdeling kinder- en jeugdpsychiatrie, Sophia Kinderziekenhuis/ Academisch Ziekenhuis Rotterdam. 


\section{Chapter 7}

\section{Determinants of outcome in the pathways through care for children hearing voices.}

International Journal of Social Welfare.

Escher, A., Morris, M., Buiks, A., Delespaul, Ph., Van Os, J., Romme, M. (2004) 


\section{Determinants of outcome in the pathways through care for children hearing voices}

Escher S, Morris M, Buiks A, Delespaul P, Van Os J, Romme M. Determinants of outcome in the pathways through care for children hearing voices

Int J Soc Wefare 2004: 13: 208-222 C Blackwell Publishing, 2004.

Auditory hallucination, or hearing voices, is generally associated with psychopathology. In psychiatry it is interpreted as a symptom of an illness, with no connection to the individual's life history. Voice hallucinations in childhood occur in a variety of contexts and have variable long-term outcomes. Little is known about the course of the experience. In this study, 80 children and youngsters hearing voices were interviewed on four occasions over a period of three years about the content of the voices and their overall experience of voices, focusing on the determinants for a promising outcome in the pathways through care. The results indicate that the need for care in the context of the experience of voices is associated not only with high levels of problem behaviour and associated negative symptoms of psychosis, but also, independently, with an appraisal of the voices in terms of anxiety, depression, dissociation and frequency of occurrence. In 60 per cent of the participants the voices disappeared during the three-year research period. The relationship between the disappearance of voices and the course of mental health treatment is, however, ambiguous.

\section{Sandra Escher1,2, Mervyn Morris², Alex Buiks1, Philippe Delespaul1, Jim Van Os1, 2, Marius Romme1,2,3}

1 Maastricht University, Maastricht, The Netherlands

2 University of Central England, Birmingham, UK

3 Chair Intervoice, Bemelen, The Netherlands

Key words: auditory hallucinations in children and adolescence, patients versus non-patients, effective mental health care

A Escher, Department of Psychiatry and Neuropsychology, Maastricht University, PO BOX 616, 6200 MD Maastricht, The Netherlands

Email: escherromme@skynet.be

Accepted for publication December 3, 2003
Over the last 15 years we have been studying the hearing of voices with the characteristics of auditory hallucinations in adults and children. In this article we report on treatment-related aspects of outcome in a three-year follow-up study of 80 children and youngsters between eight and nineteen years of age, who hear voices. The cohort included both children who were receiving treatment and others who were not, and they were interviewed on four occasions during this period. We analysed the effect of different kinds of treatment on voice-hearing as well as on the youngsters' development. The treatment issues are reported in this article.

There are a number of population surveys on the prevalence of hearing voices with the characteristics of auditory hallucinations. In all of these studies adults were found who experienced auditory hallucinations but could cope well with these experiences and were not in need of mental health care. These studies were conducted in student populations (Barrett \& Etheridge, 1992; Bentall \& Slade, 1985; Leuder \& Thomas, 2000; Posey, 1986; Posey \& Losch, 1983) as well as in the general population (Bijl, Ravelli \& Van Zessen, 1998; Eaton, Romanoski \& Anthony, 1991; Sidgwick, 1894;
Tien, 1991; Van Os, Hanssen, Bijl \& Vollebergh, 2001; West, 1948).

Tien (1991) and Eaton (1991) were the first to use a psychiatric diagnostic instrument, the Composite International Diagnostic Instrument (CIDI) - developed by Robins, Wing, Wittchen, Helzer and Babor in 1988 - to determine whether or not such experiences could be interpreted as psychopathology. The CIDI can also be used to categorise findings in accordance with the DSM psychiatric diagnostic system. Tien (1991), using trained lay people, found that amongst 18,572 subjects, 3 per cent experienced auditory hallucinations, a third of which could be categorised as pathological hallucinations and two thirds as non-pathological.

Eaton (1991) replicated the Tien study using a smaller number of adults (800) and where the participating psychiatrists used the CIDI to make their assessments. The psychiatrists found that 4 per cent of the subjects experienced auditory hallucination; they also found, however, a higher prevalence of psychopathology (45 per cent). Of these, a relative small number (16 per cent) could be diagnosed as schizophrenic. 
Eaton's findings show that in more than half (55 per cent) of the subjects, the experience of auditory hallucination could not be related to a psychiatric diagnosis.

It is therefore of interest to study the phenomenon of hearing voices with the characteristics of auditory hallucinations in both patients and non-patients. We use the term 'non-patients' to mean individuals who do not meet the criteria for a psychiatric diagnosis and who are not in need of care because they are able to cope well with their voices. To compare these two groups, we could study the influences that provoke a level of distress which in psychiatry is interpreted as a sign of psychopathology, or we could look for influences that might provide protection from distress. We conducted several studies of adults on the basis of these two perspectives (Romme \& Escher, 1989, 1996, 2000; Romme, Honig, Noorthoorn \& Escher, 1992) and found that hearing voices in both patients and non-patients was related to a traumatic experience in 70 per cent of the cases. However, the non-patients were able to integrate their trauma, compensate for it or find a solution to the trauma, whereas those who were patients had remained powerless in the face of the trauma. In adults, the history of hearing voices and the influence of the voices on daily life often become more complex with time. For this reason we chose to study children, because we expected their personal histories to be less complicated. We hoped that in children we would be able to detect not only the factors that influence the distress itself, but also the factors that influence the continuation or discontinuation of the voices and which might be related to the distress.

In preparing our research we were interested in epidemiological surveys and studies in clinical settings of children who heard voices with the characteristics of auditory hallucination. The first epidemiological study on children hearing voices was conducted by Green (1973). He did not use a diagnostic instrument, but instead interviewed 1,000 mothers about a child in the family who was presenting a problem, such as bedwetting, aggression etc.; the study also included children with auditory hallucinations. The children were between 6 and 18 years of age. Green found a 2 per cent point-prevalence of auditory hallucinations in all age groups. He found more pathology in the older children and concluded that auditory hallucinations might lead to greater impairment as the child grew older.

In a recent population-based epidemiological study in which a psychiatric diagnostic instrument was used, a prevalence of auditory hallucinations of around 8 per cent was found (McGee, Williams \& Poulton, 2000). Around a third of such children presented with a DSMIII diagnosis; this suggests that for the majority of hallucinating children in the general population, such experiences are non-pathological (McGee et al., 2000).
A small group of children may, however, develop persistent symptoms and subsequent psychotic disorder in adult life. In a recent follow-up study of 761 children, self-reported psychotic symptoms at age 11 increased the odds for psychotic illness at age 26 by a factor of 16.4 , but the actual number of children who developed a psychotic disorder was very small. In this study, childhood psychotic experiences had predictive value, independent of childhood psychiatric diagnosis (Poulton et al., 2000).

So much for epidemiological studies about the prevalence and number of children who are at risk. In clinical studies, auditory hallucinations or hearing voices in children and adolescents may occur in the context of a variety of psychiatric states such as schizophrenia (Bettes \& Walker, 1987; Galdos, Van Os \& Murray, 1993; Galdos \& Van Os, 1995; Green, Padron-Gayol, Hardesty \& Bassiri, 1992), anxiety and depression (Chambers, Puig-Antich, Tabrizi \& Davies, 1982; Garralda, 1984; Ryan et al., 1987), migraine (Schreier, 1998), trauma, dissociation processes and reactive psychoses (Altman, Collins \& Mundy, 1997; Famularo, Kinscherff \& Fenton, 1992; Putnam \& Peterson, 1994), as well in deprivation (Bender, 1970) and as a reaction to grieving (Yates \& Bernnard, 1988). All these studies concern selected clinical samples and a small number of participants. Long-term follow-up of such groups suggests variable outcomes, reflecting the heterogeneity of the subject selection procedures in the different studies (Del Beccaro, Burke \& McCauley, 1988; Garralda, 1984).

Thus, there is a wide range of possible outcomes in children with pathological and non-pathological hallucinatory experiences, and although there is an increased risk, only a very small number of children develop psychosis. Although there have been a number of prospective and retrospective long-term follow-up studies (Garralda, 1984; Poulton et al., 2000), no short-term sequential follow-ups of children with hallucinations have been conducted to study the course of these experiences in the short-term and the possible factors that might influence that course. Furthermore, little is known about the course of hearing voices and the outcome in relation to the pathways through care.

As an influence on care, attitudes towards the experience of hearing voices must be taken into account. In clinical settings using a pathological model, hearing voices is defined as a symptom of an individual illness, with little attention given to the fact that voices might not be related to a DSM illness category, but might be seen as a reaction to problems the child is confronting but is unable to solve.

In epidemiological studies it is clear that auditory hallucinations are apparent in a number of adults and children for whom an illness diagnosis would be inappropriate. However, in our Western culture, hearing 


\section{Escher et al.}

voices is still usually identified with illness. In encyclopaedias (Winkler Prince, 2002) hearing voices is associated with schizophrenia and borderline personality. A common view among the general public is that hearing voices is associated with schizophrenia, aggression and life-long illness. When we first met the parents in our research studies on children, they also expressed their concern about the presence of a serious mental illness.

This attitude has not always been present; it has shifted over time with cultural and social changes. In a historical context, reports of hearing voices were present in ancient Egypt, Rome, Babylon, Tibet and Greece. In earlier times it was believed that at certain sacred sites it was possible to receive advice and guidance about important decisions from the voice of a deity. In later times it was more common that the divine messages were mediated through appointed priests or priestesses (Watson, 1998). In a religious context, there are a number of well-known hearers of voices such as Jesus, Moses, Maria, Hildegard von Bingen, Teresa von Avilla, Francis of Assisi, as well as founders of religions such as Mohammed (Islam), George Fox (Quakers), Joseph Smith (Mormons) and Marten Luther. Another well-known hearer of voices was Joan of Arc (Romme \& Escher, 1996; Watson, 1998).

In non-Western, less rational cultures, there is yet another attitude. Individuals are encouraged to experience hallucinations and fantasies and to share these experiences with others (Al-Issa, 1977). In these cultures, hallucinations are socially accepted, appreciated and related to cognitions and actions shared by individuals, groups and professions (Bourguignon, 1970). The voices might begin as a spontaneous experience, but the duration and subsequent discontinuation of this experience might eventually be integrated through the control of social stimuli by means of rituals (Bourguignon, 1970).

In academic settings, reflection based on 'objective' truth is encouraged; in the case of auditory hallucinations, 'objective' truth refers to the diagnosis of illness. Objectivity seems to encourage looking at the perceptions only and, as a consequence, neglecting what the voices say and regarding the content as lacking meaning.

In research studies in biological psychiatry, the cause of hearing voices is sought in the brain, where deformations in several parts of its structure have been found (Barta, Pearlson \& Powers, 1990, Culberg \& Nybäck, 1992; Foster \& Caplan, 1994), as well as a number of dysfunctional areas (Cleghorn, Franco \& Szechtman, 1992; Green \& Preston, 1981; Musalek, Podreka \& Walter, 1989). However, these results are unsatisfactory in explaining the course of the voicehearing experience. It should be borne in mind that these studies are based on the assumption that the presence of voices is pathological in origin. They therefore looked only for the presence of the voices and not at the content, which is mostly accorded little value.
The content is neither appreciated, nor regarded as meaningful, nor as metaphoric messages related to the individual's life history. The content is regarded as meaningless to the diagnostic process and is thus discounted in terms of treatment.

In developmental approaches the content is given some attention but is not fully appreciated. In the cognitive model voices are regarded as being related to an absence of reality testing; in psychoanalytic theory voices are regarded as being related either to the underdevelopment of the ego (Wenar, 1994) or to regression to an earlier stage of development. The social-psychodynamic approach is nearest to Bourguignon's (1970) observations that voices might be seen as a form of coping with life events (Heilbrun, Blum \& Haas, 1983; Romme \& Escher, 1989) or as a defence mechanism developed as a reaction to trauma (Pruett, 1984; Romme \& Escher, 1989, 1996).

In this study we explored the determinants of outcome in the pathways through care for children hearing voices. We studied the level of pathology (BPRS) as well as the need for care.

\section{Methods}

\section{Sample}

This study concerns the characteristics that influence the continuity or discontinuity of hearing voices in children. Power calculations indicated that some 80 of the children in the study were at conventional alpha, given an effect size of two and a 40 per cent overall rate of voice discontinuation, over three years (Escher, Romme, Buiks, Delespaul \& Van Os, 2002a). In order to recruit children and adolescents who were hearing voices, we proceeded in two stages. First, extensive media contacts, formed in the course of a prior investigation (Romme \& Escher, 1989; Romme et al., 1992) were used in an attempt to create awareness and reduce stigmatisation at the national level. For example, a member of the research team (MR) made an appearance on a popular TV chat show where the experience of a child hearing voices and the view of the child's parents were discussed. At the end of the programme, viewers were invited to attend a special conference on the subject. This conference was attended by 40 children and their parents, and also received media coverage. The second stage marked the start of the actual recruitment process. We sent out 20 press releases and made several TV and radio appearances in which we asked for help to get in touch with the target population. We also contacted several community paediatric health services in The Netherlands, where all children aged $0-14$ are periodically screened.

Over a period of about a year, 80 children were thus recruited from all over The Netherlands. The mean age 
Table 1. Rate of change of auditory hallucinations in 80 children over a three-year period.

\begin{tabular}{|c|c|c|c|c|c|}
\hline Time & With voices & Without voices & $\begin{array}{l}\text { Eligible children } \\
\text { not seen }(n)\end{array}$ & Person-years & $\begin{array}{l}\text { Rate/100 person- } \\
\text { years }(95 \% \mathrm{Cl})\end{array}$ \\
\hline Baseline & 80 & 0 & - & - & \\
\hline Year 1 & 56 & 19 & 5 & 75 & $25.3(16.2-39.7)$ \\
\hline Year 2 & 34 & 13 & 14 & $50^{*}$ & $26.0(15.1-44.8)$ \\
\hline Year 3 & 19 & 16 & 13 & 35 & $45.7(28.0-74.6)$ \\
\hline
\end{tabular}

Notes: Including three person-years for children who were not seen in Year 2 but who were interviewed at Year 3.

Columns 1 and 2 give the total in column 4 . Year 2 is 47 plus 3 is the total of 50 . These three are not dropouts, but children who began to hear voices again.

was 12.9 years $(\mathrm{SD}=3.1$; range $8-19$ years $)$ and around half (53.8 per cent) were girls. With respect to care, about half of the children were receiving mental health care on a regular basis. Thirteen children (16.5 per cent) dropped out during the course of the study. There was an age difference between those who stayed in the study and those who withdrew. Most of the dropout children were older than 13 years. A few more girls than boys dropped out. At baseline 53.8 per cent of girls participated, after a 49.2 per cent dropout. There was hardly any difference in relation to care modalities.

Respectively 80, 75, 50 and 35 (See Table 1) children were seen at baseline and after one, two and three years. Whenever a child had indicated that the voices had disappeared, no attempts were made to re-interview the child at the next follow-up so as to avoid focusing unnecessarily on the child's past, and often upsetting, experience. However, to estimate the rate of recurrence of voices after earlier discontinuation, an attempt was made to again interview all 80 children at the fourth interview occasion, regardless of whether they were hearing voices at that time or not.

\section{Research instruments and procedures}

The research team consisted of two fieldworkers who had extensive prior experience in interviewing individuals with hallucinations using a similar interview schedule. Nearly all the children were interviewed at home. The baseline interview was conducted in the presence of at least one parent or grandparent. All subjects and their parents (when appropriate) provided their written informed consent, to conform with local ethical committee guidelines.

During the interviews, care was taken to elicit and record the child's experiences rather than those of the parents. The researchers made no therapeutic statements or suggestions (although they would, of course, answer any questions to the best of their ability), and did not comment on any ongoing mental health care. At the end of each interview, the research staff prepared a report covering all the data collected. This was subsequently discussed with the research team (MR, SE and $\mathrm{AB})$ in order to discuss problems and ambiguities, and to create a consensus on how to rate the answers in a standardised way.

For each interview the same three instruments were used; however, two instruments were added in the first and the last year. The main instrument was the Maastricht Voices Interview for Children (MIK). This interview was adapted from the Maastricht Voices Interview for adults, with the aid of a clinical child psychologist. The interview is semi-structured and collects quantitative as well as qualitative data (Romme \& Escher, 2000).

The MIK focuses on the experience of hearing voices using questions generated by voice hearers during pilot interviews. It contains 12 items related to the voices: the nature of the experience; characteristics of the voices; the history of the voice hearing (the onset); current triggers in terms of time, place and/or emotions; the content of the voices; the influence of the voices in terms of their perceived power and the child's relationship to the voices in terms of perceived control over them; and lastly, the voice-hearers' own explanation for the voices and their means of coping defined in behavioural, cognitive and physiological approaches. In addition, there were questions relating to the experience of childhood adversity, and an assessment was made of the size of the child's social network. The interview subject's treatment history was ascertained by asking whether professional care was being received in relation to the voices. Differentiations were made of the help given by asking about what kind of care was involved, the professional background of the therapist, the content of the care and the perceived effect.

At each interview we assessed psychopathology using the Extended Brief Psychiatric Rating Scale (BPRS) (Lukoff, Neuchterlein \& Ventura, 1986; Overall \& Gorham, 1962) to assess specific symptom clusters as well as overall severity. Each year, the Youth Self Report/11-18 (YSR) (Achenbach, 1991) was used to measure problem behaviour.

During the first and last interviews, the children filled in the Dissociative Experience Scale (DES) (Bernstein \& Putnam, 1986) and the interviewer assessed the 


\section{Escher et al.}

Children's Global Assessment Scale (CGAS) (Shaffer, Gould, Brasic, Ambrosum \& Fisher, 1983).

\section{Analysis}

Children who ceased to hear voices at one screening point were excluded for incidence rate analyses at the next screening points. The STCOX command in STATA (Version 6 STATA, Stata Corporation, 1999) was used to estimate Cox maximum-likelihood proportional hazard models of discontinuation of hallucinations (Clayton \& Hills, 1993).

In order to examine whether the effect of predictors of voice discontinuation varied as a function of being in care or being a 'case' in terms of either high levels of psychopathology, or problem behaviour, or low levels of social functioning, we studied interactions between, on the one hand, predictors, and on the other hand, receipt of mental health care; 'case' level of psychopathology (defined as a score greater than 90th percentile on BPRS sum score); 'case' level of problem behaviour (score greater than 90th percentile on the YASR); and 'case' level of poor social functioning (score greater than 90th percentile on the CGAF). Interactions were assessed by likelihood ratio tests (LRS).

\section{Results}

\section{Voice discontinuation}

The overall rate of discontinuation was 60 per cent over the research period (Escher et al., 2002a). Higher severity ratings on the BPRS on the items anxiety, depression and hallucinations and a high frequency of voice-hearing predicted voice persistence. Voice persistence was also associated with a high score on the DES, older age and lack of clear triggers in time and place (Escher et al., 2002a). Developing delusional ideation had no influence on voice continuation/ discontinuation. Having professional mental health care did not in itself influence the probability of voice discontinuation (Escher et al., 2002a).

\section{Problems because of the voices}

The voices often had a major influence on daily life. In the first year most of the children reported problems at home (70 per cent) and problems at school (82 per cent) because of the voices (Escher \& Romme, 1998). Children reported that the voices evoked emotions such as anxiety ( 80 per cent) and confusion (68 per cent), or the voice-hearing resulted in aggression (54 per cent), sadness (50 per cent), feeling lonely (49 per cent) or uncertain (46 per cent). The influence of the voices resulted in such problems as difficulty paying attention in class at school (59 per cent); children reported problems at home that irritated the other family members, such as 'doing things they did not want to do themselves' (50 per cent), stealing, running up and down the staircase, touching tiles. Because of the voices, some children reported talking out loud in public, smashing things, being provoked into quarrels or being disturbed while doing homework. Many children also said that they were punished because of their behaviour connected with the voices (41 per cent).

In the second year fewer problems related to the voices were reported. Of the 57 children still hearing voices, 35 per cent reported voice-related problems at home and 42 per cent at school.

\section{Need for care}

Need for care was defined as having received professional mental health care because of hearing voices. Children who received professional mental health care generally had higher scores on social and psychopathological dysfunction than did the children who were not receiving care, i.e. at baseline they had a higher rating on the BPRS hallucinations item, higher YASR problem behaviour scores, lower CGAS scores and more BPRS anxiety/depression and negative symptoms. They also had a higher score on the DES. Children in care reported more emotional triggers to the voices and greater childhood adversity. Emotional appraisal of the voices was more often negative, and the voices influenced their emotions and behaviours more. Lastly, children in care used specific coping strategies (Escher et al., 2002a) such as passive problem-solving (see Table 2).

Being in care was further related to receipt of special education (of the 18 children placed in special schooling, 12 were in care). Children in care reported more traumatic events. Children who acted out aggressively, hit their siblings, broke things or shouted at their parents also ended up in care more often. Sometimes it was the child's behaviour at school that forced the parents to look for care, for example when a child started to talk out loud to the voices during class.

\section{Different kinds of care}

When exploring the treatment history, we looked at all the modalities of care that the youngsters had received, not only professional mental health care, but also 'supplementary care' (see Table 3 ). At the baseline interview, 44 (55 per cent) of the children were receiving professional mental health care from community mental health services, child psychiatric hospitals, psychiatric hospitals, private psychiatrists or school psychologists. When parents or children were dissatisfied with the care, they looked elsewhere. (Of the 44 children receiving professional mental health care, 12 children changed care modality. Among them 
Children hearing voices

Table 2. Baseline differences between children who did and those who did not receive professional help.

\begin{tabular}{|c|c|c|c|c|c|}
\hline Group & Variables (range) & $\begin{array}{l}\text { Professional } \\
\text { help } \\
\text { Mean (SD) or } \\
\text { percentage }\end{array}$ & $\begin{array}{l}\text { No prof. help } \\
\text { Mean (SD) or } \\
\text { percentage }\end{array}$ & $\begin{array}{l}\text { t-test or } \\
\text { chi-squared } \\
\text { est }\end{array}$ & $P$ \\
\hline \multirow[t]{4}{*}{ Demographic } & Age (years; 8, 19) & $13.5(0.5)$ & $12.2(0.4)$ & $\mathrm{t}_{78}=-1.9$ & 0.059 \\
\hline & Sex & & & & \\
\hline & Boys & 47.5 & 45.0 & $\chi_{1}^{2}=0.05$ & 0.82 \\
\hline & Girls & 52.5 & 55.0 & & \\
\hline \multirow[t]{17}{*}{ Voice characteristics } & Number of voices: & & & & \\
\hline & 1 & 12.8 & 27.5 & & \\
\hline & $2-5$ & 43.6 & 32.5 & & \\
\hline & $6-10$ & 18.0 & 15.0 & & \\
\hline & $>10$ & 25.6 & 20.0 & $\chi_{4}^{2}=5.1$ & 0.28 \\
\hline & Variable & 0.0 & 5.0 & & \\
\hline & BPRS rating hallucinations & & & & \\
\hline & Lowest & 27.5 & 50.0 & & \\
\hline & Middle & 32.5 & 27.5 & & \\
\hline & Highest & 40.0 & 22.5 & $\chi_{\text {trend }}^{2}=4.7$ & 0.033 \\
\hline & Frequency of voices & & & & \\
\hline & Continuous & 12.5 & 7.5 & & \\
\hline & Hourly & 20.0 & 7.5 & & \\
\hline & Daily & 35.0 & 32.5 & & \\
\hline & Weekly & 17.5 & 22.5 & & \\
\hline & Monthly & 2.5 & 7.5 & & \\
\hline & Variable & 12.5 & 22.5 & $\chi_{5}^{2}=5.2$ & 0.39 \\
\hline & Sees things & 57.5 & 67.1 & $\chi_{1}^{2}=1.6$ & 0.21 \\
\hline \multirow{7}{*}{ and dissociation } & $\begin{array}{l}\text { Total YASR problem behaviour } \\
(42,138)\end{array}$ & $92.3(23.9)$ & $74.2(20.7)$ & $t_{72}=-3.5$ & 0.0009 \\
\hline & Total DES score $(2,76)$ & $23.4(15.9)$ & $19.6(13.7)$ & $\mathrm{t}_{78}=-1.1$ & 0.26 \\
\hline & BPRS anxiety/depression $(4,23)$ & $10.0(5.2)$ & $6.4(2.3)$ & $t_{78}=-4.1$ & 0.0001 \\
\hline & BPRS positive symptoms $(5,15)$ & $9.9(2.5)$ & $9.6(2.4)$ & $t_{78}=-0.5$ & 0.65 \\
\hline & BPRS disorganisation $(3,7)$ & $3.2(0.7)$ & $3.1(0.5)$ & $\mathrm{t}_{78}=-0.7$ & 0.47 \\
\hline & BPRS negative symptoms $(4,8)$ & $4.3(0.9)$ & $4.0(0.0)$ & $\mathrm{t}_{78}=-2.2$ & 0.035 \\
\hline & BPRS mania $(4,10)$ & $5.2(1.5)$ & $5.2(1.6)$ & $t_{78}=0.1$ & 0.89 \\
\hline \multirow{6}{*}{$\begin{array}{l}\text { Triggers and } \\
\text { adversity }\end{array}$} & Presence emotional trigger & 95.0 & 77.5 & $\chi_{1}^{2}=5.2$ & 0.023 \\
\hline & Presence trigger in place & 42.5 & 62.5 & $\chi_{1}^{2}=3.2$ & 0.073 \\
\hline & Presence trigger in time & 42.5 & 35.0 & $\chi_{1}^{2}=0.5$ & 0.49 \\
\hline & Sleep related & 27.9 & 23.2 & $\chi_{1}^{2}=0.5$ & 0.50 \\
\hline & Total life event score $(0,3.2)$ & $0.9(0.8)$ & $0.7(0.8)$ & $\mathrm{t}_{77}=-0.9$ & 0.37 \\
\hline & Childhood adversity score $(0,8)$ & $2.0(1.9)$ & $1.1(1.3)$ & $t_{78}=-2.5$ & 0.016 \\
\hline \multirow[t]{7}{*}{ Attributions } & Secondary explanation & 57.5 & 65.0 & $\chi_{1}^{2}=0.5$ & 0.49 \\
\hline & Attribution past adversity & 25.0 & 26.3 & $\chi_{1}^{2}=0.02$ & 0.89 \\
\hline & Affective appraisal & & & & \\
\hline & Mainly positive & 7.5 & 27.5 & & \\
\hline & Mainly negative & 75.0 & 47.5 & & \\
\hline & Variable & 17.5 & 25.0 & $\chi_{2}^{2}=7.6$ & 0.023 \\
\hline & $\begin{array}{l}\text { Perceived influence on } \\
\text { emotions/behaviour }(0,8)\end{array}$ & $4.7(2.2)$ & $3.0(1.9)$ & $\mathrm{t}_{78}=-3.7$ & 0.0004 \\
\hline \multirow[t]{7}{*}{ Coping } & Total coping score $(0,9)$ & $4.1(2.3)$ & $4.7(2.6)$ & $t_{78}=1.1$ & 0.26 \\
\hline & Passive illness behaviour & $0.088(0.22)$ & $0.064(0.17)$ & $\mathrm{t}_{77}=-0.5$ & 0.60 \\
\hline & Active problem-solving & $0.26(0.20)$ & $0.33(0.26)$ & $t_{78}=1.5$ & 0.13 \\
\hline & Passive problem-solving & $0.29(0.26)$ & $0.44(0.36)$ & $\mathrm{t}_{78}=2.2$ & 0.035 \\
\hline & Active problem avoidant & $0.21(0.25)$ & $0.19(0.20)$ & $\mathrm{t}_{78}=-0.4$ & 0.69 \\
\hline & Symptomatic & $0.25(0.36)$ & $0.29(0.34)$ & $t_{78}=0.5$ & 0.63 \\
\hline & Other & $0.28(0.45)$ & $0.23(0.42)$ & $t_{78}=-0.5$ & 0.61 \\
\hline Global & Baseline CGAS & $57.0(17.1)$ & $67.7(11.2)$ & $\mathrm{t}_{77}=3.3$ & 0.0015 \\
\hline \multirow{2}{*}{ functioning } & Last follow-up CGAS & $67.8(18.2)$ & $76.9(16.0)$ & $t_{72}=2.3$ & 0.025 \\
\hline & $\begin{array}{l}\text { CGAS improvement baseline to last } \\
\text { follow-up }\end{array}$ & $10.1(11.1)$ & $8.7(11.5)$ & $t_{72}=-0.5$ & 0.60 \\
\hline \multirow[t]{2}{*}{ Help sought/received } & $\begin{array}{l}\text { Proportion in network discussed with } \\
(0,100)\end{array}$ & $40.3(24.0)$ & $35.2(23.6)$ & $\mathrm{t}_{78}=-1.0$ & 0.34 \\
\hline & Was admitted to hospital & 0.0 & 15.0 & $\chi_{1}^{2}=6.5$ & 0.011 \\
\hline
\end{tabular}


Table 3. Modalities of care received by children who hear voices.

\begin{tabular}{lll}
\hline & $\begin{array}{l}\text { Baseline } \\
n=80 \\
(\% \text { in parens) }\end{array}$ & $\begin{array}{l}\text { Whole research } \\
\text { period } \mathrm{n}=67 \\
\text { (\% in parens) }\end{array}$ \\
\hline $\begin{array}{l}\text { Care } \\
\text { Professional mental health } \\
\text { care only }\end{array}$ & $29(36)$ & $26(40)$ \\
$\begin{array}{c}\text { Professional mental health } \\
\text { care + Supplementary care }\end{array}$ & $15(19)$ & $12(18)$ \\
$\begin{array}{l}\text { Supplementary care only } \\
\text { No care }\end{array}$ & $16(20)$ & $12(18)$ \\
\hline
\end{tabular}

a total of 33 children visited different professional mental health care services).

Of the 44 children who sought professional care at baseline, 12 (33 per cent) received supplementary care including homeopathy; body-focused therapy such as bio-energetica and haptonomy; and therapy from paranormal healers who aim at restoring harmony between energies. These therapies acknowledge illness, but see it as a process of learning.

Of all respondents, 12 children (18 per cent) received supplementary care only. Taking all the different forms of care into account, we found that 75 per cent of the youngsters had received some form of care, while the remaining 25 per cent had received no care at all.

\section{Evaluation of received care}

In the evaluation of received care, we included only those children who participated throughout the whole research period. Dropout had no effect on the differentiation of respondents receiving different care modalities (Escher et al., 2002a).

To evaluate received care, we looked at both discontinuation of the voices and the development of the child. All kinds of variations were possible. Hospital care, for instance, might result in discontinuation of the voices, but also in discontinuation of the natural development of the child. On the other hand, supplementary care treatment might not be aimed primarily at a discontinuation of the voices, but rather at learning to cope with the voices so as to prevent their disrupting the child's functioning in daily life. Youngsters who did not receive any care at all might have actually needed care because they still had problems with their development, or they might actually not need care because they were developing in a positive way.

To explore the effect of the different treatment patterns on child development, we constructed an instrument of our own. To avoid stigmatising statements about development, we documented changes that had been discussed during the three-year follow-up. We did not originally hypothesise about the influence of possible treatments or about aspects of the children's development. These issues emerged during the followup period. In following the grounded theory approach (Glaser \& Strauss, 1967), we concluded that it would be sensible to include these issues in our report on promising kinds of treatment. Using grounded theory methodology was also appropriate because it prescribes taking a naive position in the search for knowledge in an otherwise meagrely researched field of enquiry.

Prior to analysing any data, we specified our criteria for development, based on discussions in the research team of what aspects of the developmental process were observable and measurable:

- acquiring more friends at peer-group level;

- knowing better what the child wanted to become in life;

- coping better with emotions;

- having fewer conflicts in the family and at school;

- a positive report on development reported by the child concerned and/or by the parents.

For each child a conclusion was reached in terms of one of three categories: a negative change; no change between base line and last interview; and a positive change. The conclusion was drawn in consensus by the whole team. When four of five elements were positive, a positive development was marked (see Table 4).

The column indicating discontinuation of the voices shows a high correlation between discontinuation and positive development. An interesting question arising from concerns the hierarchy of importance, i.e. does discontinuation of the voices promote positive development or does positive development promote discontinuation? Our view is that there is no 'either/or' answer to this question.

As Table 4 shows, discontinuation of the voices does not always result in a positive development. Of the 45 children whose voices were discontinued, a negative development was seen in six children who had received professional care, one child who was in supplementary care and one child who received professional care as well as supplementary care. A positive development was seen in 37 children ( 82 per cent).

Table 4 shows that the opposite situation does not always apply either. Continuation of the voices does not always result in a negative development. Of the 22 children who still heard voices, a negative development was seen in nine children who were in professional care, three children who received supplementary care and one child who received professional as well as supplementary care and two children who received no care at all. Of the 22 children who continued to hear voices, a negative development was seen in 15 (68 per cent). Continuation of the voices is combined with a negative development more often than discontinuation. Therefore, care might be best oriented to both development and to discontinuation. 
Table 4. Modalities of care, development and continuation or discontinuation of the voices.

\begin{tabular}{|c|c|c|c|c|c|}
\hline & \multirow[t]{2}{*}{ No } & \multicolumn{2}{|c|}{ Continuation of Hearing voices } & \multicolumn{2}{|c|}{ Discontinuation of Hearing voices } \\
\hline & & $\begin{array}{l}\text { Positive } \\
\text { development }\end{array}$ & $\begin{array}{l}\text { Negative } \\
\text { development }\end{array}$ & $\begin{array}{l}\text { Positive } \\
\text { development }\end{array}$ & $\begin{array}{l}\text { Negative } \\
\text { development }\end{array}$ \\
\hline No care & 17 & 1 & 2 & 14 & 0 \\
\hline Professional care only & 26 & 1 & 9 & 10 & 6 \\
\hline Supplementary care only & 12 & 3 & 3 & 5 & 1 \\
\hline $\begin{array}{l}\text { Professional care } \\
+ \text { Supplementary care }\end{array}$ & 12 & 2 & 1 & 8 & 1 \\
\hline Total & 67 & 7 & 15 & 37 & 8 \\
\hline
\end{tabular}

In analysing which form of care is most effective, Table 4 shows that receiving no care at all is the most successful and professional care the least successful. This is understandable for two reasons. First, in the group that received professional care, there are children whose voice-hearing was combined with learning disabilities associated with birth trauma or with ADHD, problems that could not really be solved. Second, we saw at the individual case level that illness-oriented care in this cohort was less effective in promoting development (see Table 6 later).

The second most effective form of care was the combination of professional and supplementary care. This is not surprising when we observe at an individual case level that therapists in supplementary care are more creative in guiding and supporting children to find ways to cope with the voices. In professional care we see that therapists have more knowledge about teaching children to cope with their emotions. We found that on an individual case level this combination of care is essential for success in promoting a positive development and the discontinuation of the voices. At an individual case level, we also observed that care orientated toward discontinuation of the voices by 'medication only' hampered the children's development. There seems to be a tendency for mental health professionals trained in psychotherapy to orient their therapy more towards coping with emotions, which seems to have a favourable effect on coping with voices. Mental health professionals trained in child clinical psychiatry and working in a clinical setting tend to accentuate diagnosis and use a 'medication only' approach.

So we can conclude that, despite the small number of cases in the study, treatment should be aimed at both positive development and discontinuation of the voices, not by suppressing them but by coping with them, giving all due attention to the emotions involved.

\section{Promising and rejected elements of care}

The persistence of voices is influenced by anxiety, depression and dissociation as well as by the frequency of the voices (Escher et al., 2002a, 2002b, 2003). This suggests
Table 5. Elements of care that were found helpful by children, parents and/or the research team.

\begin{tabular}{ll}
\hline $\begin{array}{l}\text { 1. Promoting the feeling of } \\
\text { safety }\end{array}$ & - Psycho-education \\
& - Accepting experiences \\
& - Anxiety-reducing techniques \\
& - Interventions focusing on problems \\
& resulting from the voices \\
2. Promoting support in the & - Interviews in the presents of the \\
environment & parents \\
3. Ego strengthening & - Psycho-education at school \\
& - Learning to make choices \\
& - Learning to express emotions \\
4. Working through problems & - Promoting an inner dialogue \\
& - Prief \\
& - Problems at school \\
& - Circumstances beyond own control
\end{tabular}

that the ability to cope with voices might be of crucial importance. Although statistically, professional mental health care did not influence the discontinuation of the voices, at case level children and parents reported that mental health care did influence the course of hearing voices. Table 5 gives an overview of those elements that were experienced as helpful by children and/or parents, or elements that the research team concluded to be promising given the positive course of the development of the child. These are: promoting the feeling of safety; promoting support in the environment; ego-strengthening; and working through problems that lay at the root of the voices. Several of these elements are described in more detail below.

\section{Promoting the feeling of safety}

The high level of anxiety about the voices ( 80 per cent at the first interview) suggests that the children felt stressed by them and might perceive them as omnipotent and overpowering (Birchwood, Meaden, Tower, Gilbert \& Murray, 2001; Chadwick \& Birchwood, 1994). Anxiety in connection with an experience does not make a person feel safe. Without a feeling of safety, 


\section{Escher et al.}

care is mostly ineffective because the child is not open to change. The following are some of the elements involved in promoting the feeling of safety.

\section{Psycho-education in which the experience is} normalised. Studies indicate that hearing voices occurs in the normal population (in 2 per cent of the adults and about 8 per cent of children). Voice-hearers often find it a relief to realise that they are not the only people who hear voices (Romme \& Escher, 1993) and that there are people who can cope with the voices. Psycho-education will allow parents and children to accept the voices.

Another element is to promote a more positive view concerning their experience, i.e. to accept the experience. Children who were in supplementary care reported having this more positive view. An example is the boy who reported in therapy that his voice had all the characteristics of his grandfather. His therapist replied: 'If it is your grandfather, then I think he doesn't want to leave you yet'. Most children do not relate the voices to illness (only two children in the study did); 39 per cent related it something positive, like a special gift. As one girl reported: 'I can tell this to my friends'.

Anxiety-reducing techniques: short-term interventions. Because of the high level of anxiety, attention should be given to anxiety-reducing techniques (Romme \& Escher, 2000). Examples are distraction, using a personal stereo, carrying a cuddly toy, sending the voices away, setting a specific time to talk to the voices etc. With adults, techniques applied in cognitive behavioural therapy are more well known; an example is focusing, a technique developed by Haddock, Bentall and Slade (1996). Focusing is an 18-session therapy in which questions are asked about specific elements of the voices such as their character, tone and content connecting them with triggers. Bentall and Haddock showed in their research that focusing on the voices reduces the anxiety as well as the frequency of the voices.

Anxiety problems might also be tackled in a practical way; for example by installing a nightlight in the child's bedroom, or by a family member checking the bedroom to assure the child that the bedroom is free of voices and ghosts. Some children find their own solution, such as one child who, because she was afraid to go out on the street, arranged for a friend to accompany her.

\section{Promoting support in the environment of the voice-hearer}

Promoting the feeling of safety is aimed at the individual level. However, children do not live in isolation, they live with other people and the voices might influence these relationships. In our own research we found that 70 per cent of the children had problems at home and 82 per cent had problems at school because of the voices.
During the three-year research period parents and children told the researchers that they found the interview in the family setting helpful, because parents thereby learnt much about the influence of the voices. Children could also use the opportunity to explain why they behaved in a certain way. For example, one child, when asked what the voices forbade her to do, addressed her reply to her father: 'That's why I couldn't play chess with you yesterday, the voices told me not to'. The parents were often not aware that the voices might resort to blackmail (in 39 per cent of cases).

By the second round of interviews, the problems resulting from the voices had diminished. Of the 57 children still hearing voices, 35 per cent reported having voice-related problems at home and 42 per cent at school. The researchers noticed that parents and children were more open to talking about the influence of the voices.

\section{Ego-strengthening}

As mentioned earlier, the voices had considerable influence on the behaviour of the children. The voices could be experienced as so powerful that the child felt overwhelmed. For most children (62 per cent), hearing voices was an involuntary experience and they felt that they could not summon the voices themselves. For most of the children (67 per cent), the voices seemed to 'pop up' from nowhere; the children were not aware of anything that might predict their arrival. Some of the children (12.5 per cent) became so afraid and overwhelmed that they could not listen to what the voices said; others (16 per cent) became so afraid that they could not move, talk or think. In the first year, 52 per cent of the children said that they could not refuse to do what the voices ordered them to do, and were either being blackmailed by them ( 39 per cent), or the voices interfered with their making their own choices (47 per cent). At times the child was even unable to decide what to eat or drink, what clothes to wear and what kind of shampoo to use.

These data suggest that learning to cope with the voices is related to the development of the child's own sense of power - to become more critical of the voices and to consider whether they actually agreed or disagreed with them.

Some of the children also learnt to use verbal powers to say what they wanted out loud. There was no specific question in the interview on this topic; it was something the researchers noticed at the case level. One example is the girl who was very shy during the first interview. In the last interview she reported that she openly disagreed with her psychiatrist and to the astonishment of her mother, had dismissed him. He did not give her the support she felt she needed during the period of her exams. Her voices were extremely negative, telling 
her that she would never succeed. She found a new therapist, who related the voices to her own feelings of insecurity, and she is now very satisfied with her helper.

As elements to empower the child we observed the following: developing one's own identity by learning to make choices; developing one's talents; learning to express emotion; and developing an inner dialogue.

Learning to make choices. Although we did not specifically ask about making choices in the first years, the researchers noticed that it was often difficult for the children to make decisions. In the last interview we introduced a specific question on this topic and 43 per cent of the children reported that they now felt more confident in making choices for everyday subjects than they had in the past; for 28 per cent it was still a problem. Only 10 per cent of the children reported that they still felt that they were unable to make choices. When asked how they had learned to make choices, several of the children said that they had developed a system in which they assigned numbers as a means to rank priorities; others said that they learned in therapy to use an imaginary scale to visualise which choice had a higher weight and could tip the scale.

Developing one's talents. Three of the children discovered that they had an exceptional talent. Training this talent helped them to feel stronger. One boy has since been invited to join the national Dutch youth football training group. One girl does high-diving and is on the national team. Another boy is currently in the national Dutch cycling team. This training helps the young people to become powerful in body and mind, as one of them phrased it; it is easier to say no to the voices. Two of the youths no longer heard voices and the third heard a positive voice that advised and stimulated her when the training became too difficult.

Learning to express emotions. The voice-hearers' ability to cope with emotions was very often weak. Instead of the child's feeling an emotion, the voices might speak. An example is the girl who said: 'I can never get angry, the voices get angry instead'.

In the last round of interviews, we asked about emotions that earlier had triggered the voices, such as anxiety, aggression, sadness, insecurity etc. Of the sixty-seven children, 62 per cent reported that they could now talk about these emotions, 59 per cent that they could feel them, 43 per cent that they could express them and 47 per cent that they could now control them. The children learned to cope with their emotions in several different ways. Some of the children reported that they learned to cope by themselves or that it happened spontaneously as they grew older; other children mentioned the support of their family; and still others said that they learned how to cope through professional help.

Developing an inner dialogue. In the last round of interviews, twenty-seven (40 per cent) of the children reported that they had developed an inner dialogue. Only one of the twenty-seven children still heard voices. An example of an inner voice is the boy who was afraid of his own feelings of aggression; he learned to cope with this emotion by discussing his conflict with a peer in the presence of the class teacher. He also developed an inner dialogue. When he gets angry he now says to himself: 'You better sit down, or else it will only get worse'. Another example is the girl who learned that the voices were her own thoughts: 'When I hear the voice I think: this is me and I realise that I have to listen to myself'.

\section{Working through problems that lay at the root of the voices}

In our studies with adults we found that in 70 per cent of the cases, the onset of the voices was related to some kind of trauma or to overpowering circumstances and conflicts. Having found this relationship in adults, we wondered whether it was also true for children. In about 75 per cent of the children we found that traumatic events or circumstances beyond their control had occurred at the onset of hearing voices.

Grief. For 18 of the children the onset of the voices was related to a period of grieving; for example, the death of a grandparent, the suicide of an uncle or the death of a friend or a classmate. When these deaths occurred parents often tried to protect the child from the ensuing emotions. An example is that of a four-yearold girl living next door to a grandmother who suddenly died. In the days that followed her mother, aunts and uncles were expressing their grief in the evenings at the home of the grandmother. As the girl was perceived to be too young to take part, she was put to bed instead. She subsequently began to hear voices.

In the last year of the study, 15 children reported that they had learned to cope with the emotion of grief and no longer heard voices.

Problems in the home. Nineteen of the children in the study related the voices to problems in the home situation, such as severe tension between the parents or problematic relations with their siblings (ten children). For example, for one boy in the study the voices disappeared when he got his own bedroom and no longer had to share it with his younger brother. Moving house was felt to be a threat by three of the children and brought on the voices; divorce was related to the onset of voice-hearing for six of the children. 


\section{Escher et al.}

Table 6. Elements in care that children and parents found not to be helpful.

\begin{tabular}{ll}
\hline Elements & Consequences for patients \\
\hline - Not accepting the voices as real for the child, calling it a fantasy & - Becomes too dependent on the treatment \\
or delusion & - Not given enough influence of his/her own \\
- Neuroleptics only therapy & - Often has to choose between two negative possibilities \\
- Constructing an illness instead of focusing on complaints & - Not enough attention is given to underlying problems in daily life \\
- Treating the illness instead of helping to solve the problem & - Reduces activities in order to adapt to illness \\
\hline
\end{tabular}

In the last year of the study, the situation at home and the relating emotions had changed for the better for 16 of the children, and the voices had disappeared. Three children, whose voices were related to the divorce of their parents, still heard the voices.

Problems at school. School could become problematic for many reasons - peer bullying, problems with teachers, learning ability problems. In total 19 children reported voices that related to problems of this kind. In the last year of the study, four children, whose problems at school had not been solved, still heard voices. When care was provided, it was not oriented towards these problems.

Circumstances beyond the child's control. There were ten children who related the onset of the voices to circumstances beyond their control, such as sexual abuse, birth trauma, long-term physical illness requiring hospitalisation and abortion. Four girls began to hear voices after they had been sexually abused, not by family members, but nevertheless by people they knew. Nowadays there is more literature about the relationship of sexual abuse and hearing voices (Ensink, 1994; Herman, 1992). This is a difficult problem and involves complex emotions. All four girls developed poorly. Three of them still hear voices and the fourth, who no longer hears voices, is under long-term medication, which also influences her development negatively.

The two children with birth traumas had difficulty accepting their handicap and acted with aggression. Both were given neuroleptic medication. In one child the voices disappeared and in the other, an adolescent, the voices moved to the background when he accepted his handicap and subsequently acquired a part-time job as a carpenter in his father and brother's firm.

Four of the children related the voices to physical illnesses and long stays in hospital. One boy stayed on a ward where other children had died. Another boy began to hear voices after he had been given anaesthesia in connection with an operation. In the last year of the study, five children in this group were still hearing voices.

\section{Elements of care that seemed unhelpful}

In Table 6 we categorised elements experienced by children and parents, respectively, as unhelpful and which they often rejected. The research team concluded that these elements were not helpful and even hampered the development of the children.

In fourteen children who sought psychiatric care, we observed that care was restricted to neuroleptic medication only. Furthermore, children and parents told us that no effort had been made to relate the voices to problems in daily life; instead, often they were forbidden to talk about the voices.

Of these fourteen children, nine discontinued the offered care and sought other kinds of care. Two children stayed in the same care programme and four children discontinued care without seeking an alternative.

The nine children who changed care found a care system that they believed helped them. All of these children subsequently stopped hearing voices and the research team found them to be developing in a positive manner. The two children who remained in care continued to hear voices and did not show a positive development. The four children who discontinued care and did not look for any other kind of care also continued to hear voices and did not show a positive development.

\section{Discussion}

Results from this study on children hearing voices are in agreement with contemporary epidemiological population surveys and with recent research into individual recovery. The results of this and similar studies should have consequences in three areas: hearing voices as a signal of serious problems in daily life; the construction of illness from the phenomenon of auditory hallucinations; and the kind of mental health care offered.

\section{Auditory hallucinations as a signal of serious problems in daily life}

In the last decade several population surveys (Bijl et al., 1998; Eaton et al., 1991; Tien, 1991; Van Os et al., 2001) have shown that, when measured with the CIDI (Robins et al., 1988), psychotic experiences such as hallucinations and delusions occur in the normal population without illness. These studies make it quite clear that there is no clear dichotomy between health and illness; illness/health is not an either/or situation. 
This is also in keeping with recent research on the recovery process of patients who have recovered from serious mental illness (Topor, 2001). These studies show that people who have recovered from mental illness often refer to the simultaneous existence of functional and dysfunctional elements, of being mad and rational at the same time. In the interviews conducted in these studies, recovery is described as the regaining of control over one's own life, and these results point towards a definition of pathology more in terms of a disturbed balance than of illness.

In our study of hearing voices among children, we found clear predictors that influence the continuation or discontinuation of the voice hearing experience as well as the need for care. These predictors are a high level of anxiety, a high level of depression, a high level of dissociation and a high frequency of time during which the voices are heard. This indicates that the person's appraisal of the voices has a greater influence on their continuation or discontinuation than does the phenomenon itself. This suggests that the voice-hearing phenomenon in itself need not be psychopathological, but that the inability to cope with voice-hearing might well lead to a dysfunction that can be interpreted as psychopathological and requiring care.

In the present study we found that in a high percentage of cases, hearing voices was associated with serious problems in daily life, within the family, at school etc. In many cases the voices disappeared when these problems were solved and the children's development took a positive turn.

For this reason, we suggest that it might be more adequate to interpret hearing voices as a reaction to serious life problems with which a child has difficulties coping; or, formulated differently, as a signal of serious life problems, instead of a symptom of a psychiatric illness in itself. Making a context analysis of cases of voice-hearing in which the situation of daily life, such as problems, trauma and adverse family circumstances are taken into account, seems to be more fruitful.

The fact that a number of children (20 per cent in our study) who did not receive care nevertheless developed in a positive way and mostly also stopped hearing voices indicates that quite a few of the children and their parents succeeded in creating a different relationship to their problems without resorting to mental health care. They either could solve the problem itself or the situation that caused the problem, for example by changes taking place in the school or by learning to express such emotions as grief and aggression.

In a number of cases we saw that the voices disappeared and the child developed positively, although there seemed to be no plausible explanation for the change. One factor that may be beneficial is time. The fact that 40 per cent of the children still heard voices at the end of the three-year period of the study might be explained partly in terms of the kind of care these children received and partly as being related to their inability to solve or change the threatening problems that existed at the onset of the voice-hearing. An example of such a problematic situation is divorce, in which the child felt unsafe or in which the child lost a figure with whom he or she identified. Another example is sexual abuse. As we last saw the children two years ago, it seemed fruitful to conduct another follow-up interview to obtain additional information about the course of their voice-hearing. We have now initiated these follow-up interviews, which we estimate will take about a year to complete.

\section{The illness construct and social values}

To associate auditory hallucinations with mental illness is a social construct that is restricted not to psychiatry alone but to society as well. Epidemiological population surveys have shown that this is a biased supposition, because it assumes that all voice-hearing is psychopathological. History shows that attitudes towards and explanations for voice-hearing change over time (Leuder \& Thomas, 2000; Slade \& Bentall, 1988; Thomas, 1997; Watkins, 1998). As science increased in importance, the focus shifted to the objective aspects of the voicehearers under study. Theories based on these objective aspects directed the development of care. In this process it seems that we have lost an important source of information - the experience of the voice-hearers themselves. By individualising voice-hearers and forbidding them to talk about their experiences, we alienate them from their own experiences and separate them from sources of help, the support of others, and we make it more difficult for them to understand how the voices influence their daily life. The literature shows that this view is more dominant in Western societies. In 'less rational' non-Western societies, hearing voices is regard in a different light. Voices are accepted, appreciated, even regarded as just as valuable as other life experiences, and the experience is shared with others (Bourguignon, 1970).

In our research we found that about 75 per cent of the children related the onset of the voices to circumstances and problems that made them feel powerless. More important than associating the voices with an illness seems to be the question of whether the voices are related to circumstances such as trauma. In these circumstances associated with the voices, we also saw a hierarchy. In the group of children where the onset of the voice-hearing was associated with grief, almost all the children stopped hearing voices and developed positively, while in the group of the children where the onset of the voices was related to divorce, physical illnesses or sexual abuse fewer children stopped hearing voices and more children showed negative 


\section{Escher et al.}

development. One might well ask how much this is influenced by our cultural values. Grief is generally socially accepted because we accept death. When the association is recognised between the voices and grief, the voice-hearer is not seen as deviant but as being in need of support. Divorce, victims of sexual abuse, mental and bodily handicaps are still not really accepted within our culture; nor have we developed rituals to support individuals who meet these circumstances.

\section{Promising and less promising kinds of mental health care}

During the three-year research programme, 60 per cent of the children stopped hearing voices. Statistically, professional mental health care had no relation to the continuation or discontinuation of the voices. The kinds of care that were experienced as helpful were mostly oriented to providing social support, promoting development and helping to work through social problems. In keeping with this finding are data that show that 20 per cent of the children who heard voices were not in need of care and seemed to be able to solve their problems within their family setting. This suggests that normalising the experience and supporting the natural resources of the child and the family might be important elements in the process of learning to cope. These elements are part of a process and require time rather than immediate professional action.

This raises the question of which elements of mental health care are effective or helpful. Parents and children mentioned the following as being effective and helpful:

- accepting the voices;

- recognising the experience;

- making the experience concrete;

- reducing anxiety;

- focusing on problems resulting from voices such as the problem of sleep deprivation;

- developing techniques for coping with the voices, techniques that promote coping with emotions and working through problems that trigger the voices.

Mental health care seemed more promising when it was oriented toward helping the person to feel safe, being supportive and was directed toward learning to cope with the voices; a very important element seemed to be working through the problems and emotions involved. This is logical when hearing voices is seen as a reaction to problems in daily life and not as an illness in itself. When hearing voices is interpreted only as part of an illness, diagnosing and treating that illness is the only consequence. In general, the subjects in the present study did not experience the kind of mental health care that follows from this perspective as being of much help. Parents and children mostly discontinued that kind of care and looked for other kinds of care such as those we have described here. The data show that those who sought care elsewhere did find helpful care, their voices disappeared and their development was positive. On the other hand, the data show that those children who stayed in the same kind of care continued to hear voices and did not develop well.

Our aim is to promote a more open view regarding the phenomenon of hearing voices. Voices are often messengers and relate to the individual's life history. By interpreting them in light of that history, the experience itself and the meaning of the experience for the voicehearer become of greater interest. It is our experience that this interest could stimulate the natural resources of the child and his/her family to successfully cope with the voice-hearing experience.

\section{References}

Achenbach TM (1991). Manual for the Child Behavior Checklist $(C B C L) / 4-18$ and 191 Profiles. University of Vermont, Department of Psychiatry.

Altman H, Collins M, Mundy P (1997). Subclinical hallucinations and delusions in nonpsychotic adolescents. Journal of Child Psychology and Psychiatry 38(4): 413-420.

Al-Issa I (1977). Social and cultural aspects of hallucinations. Psychological Bulletin 84(3): 570-587.

Barta PE, Pearlson GD, Powers RE (1990). Auditory hallucinations and smaller superior temporal gyral volume in schizophrenia. American Journal of Psychiatry 147: 14571462.

Barrett TR, Etheridge JB (1992). Verbal hallucinations in normals 1: People who hear 'voices'. Applied Cognitive Psychology 6: 379-387.

Bentall RP, Slade PD (1985). Reality testing in auditory hallucinations: a signal detection analysis. British Journal of Clinical Psychology 24: 159-169.

Bender L (1970). The maturation process and hallucinations in children. In: Kemp W, ed. Origin and Mechanisms of Hallucinations. New York, Plenum.

Bernstein EM, Putnam FW (1986). Development, reliability and validity of a dissociation scale (DES). Journal of Nervous and Mental Disease 174: 727-735.

Bettes BA, Walker E (1987). Positive and negative symptoms in psychotic and other psychiatrically disturbed children. Journal of Child Psychology and Psychiatry 28(4): 555568.

Birchwood M, Meaden A, Tower P, Gilbert P, Plaistow J (2000). The power and omnipotence of voices: subordination and entrapment by voices and significant others. Psychological Medicine 30: 337-344.

Bourguignon E (1970). Hallucinations and trance: an anthropologist's perspective. In: Kemp W, ed. Origin and Mechanisms of Hallucinations. New York, Plenum.

Bijl RV, Ravelli A, Van Zessen G (1998). Prevalence of psychotic disorder in the general population: results from the Netherlands mental health survey and incidence study. Social Psychiatry Epidemology 33: 587-596.

Chadwick P, Birchwood M (1994). The omnipotence of voices. Cognitive neuropsychiatric models of subordination and entrapment by voices and significant others. Psychological Medicine 30: 337-344.

Chambers WJ, Puig-Antich J, Tabrizi MA, Davies M (1982). Psychotic symptoms in prepuberal depressive disorder. Achives of General Psychiatry 39(8): 921-927. 
Clayton D, Hills M (1993). Cox's regression models. In: Statistical Methods in Epidemiology: 298-306. Oxford, Oxford University Press.

Cleghorn JM, Franco S, Szechtman B (1992). Towards a brain map of auditory hallucinations. American Journal of Psychiatry 149: 1062-1069.

Culberg J, Nybäck H (1992). Persistent auditory hallucinations correlate with the size of the third ventricle in schizophrenic patients. Acta Psychiatrica Scandinavia 86: 469-472.

Del Beccaro MA, Burke P, McCauley E (1988). Hallucinations in children: a follow-up study. Journal of the American Academy of Child and Adolescent Psychiatry 27: 462-465.

Eaton WW, Romanonski A, Anthony JC (1991). Screening for psychosis in the general population with a self-report interview. Journal of Nervous and Mental Disease 179: 689-693.

Ensink, BJ (1992). Confusing Realities. A Study on Child Sexual Abuse and Psychiatric Symptoms. Amsterdam, Free University Press.

Escher A, Romme M (1998). Small Talk: Voice-Hearing in Children. Open Mind July/August.

Escher A, Romme M, Buiks A, Delespaul P, Van Os J (2002a). Independent course of childhood auditory hallucinations: a sequential 3-year follow-up study. British Journal of Psychiatry 181, Suppl. 43: S10-S18.

Escher A, Romme M, Buiks A, Delespaul P, Van Os J (2002b). Formation of delusional ideation in adolescents hearing voices: a prospective study. American Journal of Medical Genetics 114: 913-920.

Escher A, Romme M, Buiks A, Delespaul P, Van Os J (2003). Coping defence and depression in adolescents hearing voices. Journal of Mental Health 12(1): 91-99.

Famularo R, Kinscherff R, Fenton T (1992). Psychiatric diagnoses of maltreated children: preliminary findings. Journal of American Academic Child Adolescents Psychiatry 31: 863-867.

Foster DA, Caplan RD (1994). Cognitive influences on perceived change in social support, motivation, and symptoms of depression. Applied Cognitive Psychology 8: 123-139.

Garralda ME (1984). Psychotic children with hallucinations. British Journal of Psychiatry 145: 74-77.

Galdos P, Van Os J ( 1995). Gender, psychopathology and development from puberty to early childhood. Schizophrenia Research 14: 105-112.

Galdos PM, Van Os J, Murray RM (1993). Puberty and the onset of psychosis. Schizophrenia Research 10: 7-14.

Glaser B, Strauss A (1967). The Discovery of Grounded Theory. Stategies for Qualitative Research. New York, Aldine de Gruyte.

Green EL (1973). Some methods of evaluating behavioral variations in children 6 to 18. Journal of the American Academy of Child Psychiatry 12(3): 531-553.

Green P, Preston M (1981). Reinforcement of vocal correlates of auditory hallucinations by auditory feedback: a case study. British Journal of Psychiatry 139: 204-208.

Green WH, Padron-Gayol M, Hardesty AS, Bassiri M (1992). Schizophrenia with childhood onset: a phenomenological study of 38 cases. Journal of American Academic Child and Adolescent Psychiatry 31(5): 968-976.

Haddock G, Bentall RP, Slade PD (1996). Treatment of auditory hallucinations. In: Haddock G, Slade PD, eds. Cognitive Behavioural Interventions with Psychotic Disorders. New York, Routledge.

Heilbrun AB, Blum N, Haas M (1983). Cognitive vulnerability to auditory hallucinations. British Journal of Psychiatry 143: 294-299.

Herman J (1992). Trauma and Recovery. London, Pandora.

Lukoff D, Neuchterlein KH, Ventura J (1986). Manual for Expanded Brief Psychiatric Rating Scale. Schizophrenia Bulletin 12: 594-602.

Leuder I, Thomas P (2000). Voices of Reason, Voices of Insanity. Studies of Verbal Hallucinations. London, Routledge.
McGee R, Williams S, Poulton R (2000). Hallucinations in nopsychotic children (letter, comments). Journal of American Academic Child and Adolescent Psychiatry 39(1): 12-13

Musalek M, Podreka L, Walter H (1989). Auditory hallucinations, tactile hallucinations and normal controls. Comprehensive Psychiatry 30(1): 99-108.

Overall JE, Gorham D (1962). The Brief Psychiatric Rating Scale. Psychologigal Reports 10: 799-812.

Poulton R, Caspi A, Moffit TE, Cannon M, Murray R, Harrington H (2000). Children's self-reported psychotic symptoms and adult schizophreniform disorder: a 15-year longitudinal study. Achives of General Psychiatry 1(11): $1053-1058$.

Posey TB (1986). Verbal hallucinations also occur in normals. The Behavioural and Brain Sciences 9: 530.

Posey TB, Losch ME (1983). Auditory hallucinations of hearing voices in 375 normal subjects. Imagination, Cognition and Personality 3(2): 99-113.

Putman FW, Peterson G (1994). Further validation of the child dissociative checklist. Dissociation 7: 204-220.

Pruett KD (1984). A chronology of defence adaptations to severe psychological trauma. Psychoanalytic Study of the Child, 39: 591-612.

Robins LN, Wing J, Wittchen HU, Helzer JE, Babor TF, Burke J, Farmer A, Jablenski A, Pickens R, Regier DA, Satorius N, Towle LH (1988). The Composite International Diagnostic Interview: an epidemiologic instrument suitable for use in cogjuntion with different diagnostic systems and in different cultures. Archives of General Psychiatry 45: 1069-1077.

Romme MAJ, Escher ADMAC (1989). Hearing voices. Schizophrenia Bulletin 15(2): 209-216.

Romme MAJ, Escher ADMAC eds. (1993). Accepting Voices. London, Mind Publications.

Romme MAJ, Escher ADMAC (1996). Empowering people who hear voices. In: Haddock G, Slade PD, eds. Cognitive Behavioral Interventions with Psychotic Disorders. London, Routledge.

Romme MAJ, Escher ADMAC (2000). Making Sense of Voices. London, Mind Publications.

Romme MAJ, Honig A, Noorthoorn O, Escher ADMAC (1992). Coping with voices: an emancipatory approach. British Journal of Psychiatry 161: 99-103.

Ryan ND, Puig-Antich J, Ambrosini H, Robbinson D, Nelson B, Lyengar S, Twomey J (1987). The clinical picture of major depression in children and adolescents. Archives of General Psychiatry 44(10): 854-861.

Sidgwick H, Sidgwick E, Johnson A (1894). Report of the census of hallucinations. Proceedings of the Society of Psychiatric Research 26: 259-394.

Schreier HA (1998). Auditory hallucinations in nonpsychotic children with affective syndroms and migraines: report of 13 cases (see comments). Journal of Child Neurology 13(8): 377-382.

Shaffer D, Gould MS, Brasic J, Ambrosini P, Fisher P, Bird H, Aluwahlie S (1983). A children's global assessment scale (CGAS). Archives of General Psychiatry 40(11): 12281231.

Stata Corporation (1999). STATA Statistical Software Release 6.0. College Station, TX: STATA Corporation.

Thomas P (1997). The Dialectics of Schizophrenia. London, Free Association Books.

Tien AY (1991). Distributions of hallucination in the population. Social Psychiatry and Psychiatric Epidemiology 26: 287-292.

Topor A (2001). Managing Contradictions. Recovery from Serious Mental Disorders. Doctoral dissertation, Stockholm University, Department of Social Work.

Van Os J (2000) [full details to follow]

Watkins J (1998). Hearing Voices: A Common Human Experience. Melbourne Australia, Hill of Content. 


\section{Escher et al.}

Wenar C (1994). Developmental Psychopathology: From Infancy through Adolescence (third edition). New York, McGraw-Hill.

West D (1948). A Mass Observation Questionnaire on Hallucinations. Journal of the Society for Psychical Research 34.
Winkler Prince (2000). Encyclopaedia. Basic edition. Microsoft Encarta.

Yates TT, Bernnard JR (1988). The 'haunted'child: Grief, hallucinations and family dynamics. Journal of the American Academy of Child and Adolescent Psychiatry 27(5): 573-581. 


\section{Chapter 8}

\section{Maastricht Interview with a children and adolescents hearing voices:}

Tijdschrift van de Vereniging voor kinder- en jeugd psychotherapie (2002) jaargang 29. tijdschrift 4.

A. Escher en M. Romme 


\title{
THE MAASTRICHT INTERVIEW for children and adolescents (MIK)
}

\author{
A. Escher and M.A.J. Romme
}

Hearing voices is a very intrusive experience that can have a strong influence on daily life. To begin with, the presence of the voices is often a confusing and distressing experience; for example, it is difficult to hold a conversation with people when other voices are talking to you at the same time. Dealing with the content of what the voices are saying presents a further difficulty. How do you evaluate this confusion? In 1989 based on the experience of adults who heard voices, we developed a structured interview with 11 topics, as a format for a dialogue about the experience of voice hearing. We used this interview both in our research and in therapeutic contacts. With the aid of a child psychoanalyst, Mrs. Gijssen-Pinckards we adapted it for children and adolescents and used this interview in our three-year follow-up study on 80 children between the age of 8yrs to 19yrs, who were hearing voices. We interviewed the children four times. In this article we will discuss the topics of the interview in detail, and use examples to allow some research finding to talk for themselves. Nearly all the interviews were conducted in the presence of at least one or both parents. Research proposal and conclusions are published in separate articles.

It was a patient who first challenged professionals to revise their attitude in relation to auditory hallucinations. The patient, Patsy Hage, heard voices that dominated her and made her feel powerless, she eventually became suicidal. It took her a year to convince her psychiatrist Marius Romme that the voices were real to her. The traditional opinion in psychiatry at that time was that to acknowledge peoples voices would be colluding with their delusions and it would confuse people more.

Marius Romme listened to Patsy and decided to test out her insistence that the voices were real to her. He arranged for Patsy to talk about her voices with other people who also heard voices. Comparing their experiences went well, but it soon became obvious that the other voice hearers, who were also patients, felt as powerless as Patsy did.

The conclusion was that someone who could cope with hearing voices must be found. Romme and Patsy participated in a very popular television program and asked people who heard voices to contact them. Of the 500 responses that followed there were about 173 people who could cope with hearing voices, functioned well in daily life and had never been psychiatric patients. In order to get more detailed information a questionnaire was designed and a pilot study conducted. The three most important findings of the study were that some people who heard voices, were able to cope with them, the onset of the voices is often related to a traumatic event or a situation in which a person is powerless and thirdly the voices are personal and they have a personal message.

These elements form four of the topics that are part of the Maastricht interview: the acceptance of the voices; to learn to talk about them; to learn to cope with them; to learn to understand their message. All these elements should be focused on in the therapeutic process.

\section{Dialogue}

The Maastricht interview is a tool that opens a dialogue and is means of encouraging talking about the voice hearing experience in which both the voice hearer and the interviewer gain knowledge. It is an open dialogue, during which experiences will be discussed and no conclusions will be made. Voice hearers often find that as soon as they start to talk about their voices people around them do not know how to react. In a therapeutic setting the value of the experience of the voice hearer is often not acknowledged or is viewed very negatively. This is understandable because therapist's ideas are based on the patients they meet. These are mainly voice hearers who cannot cope with their experience and are looking for psychiatric help. However it is only a certain group of people that look for psychiatric help, therapists mostly never meet the non-patients, people who cope with find hearing voices as part of there normal daily life.

Several studies on student populations and epidemiological studies found prevalence of voice hearing in the normal population of about $2 \%$. With children and adolescents, an even higher rating of about 8\% was found. (Sidgewick, 1894; West, 1948; Green, 1973; Posey en Losch, 1983; Bentall and Slade, 
1985; Young et al., 1986; Romme \& Escher 1989; Tien, 1991; Barrett e\& Etheridge, 1992; McGee, 2000, Bijl, Ravelli en Van Zessen, 1998). One might conclude that it is not the presence of the voices that is pathological, but the way in which people cope with them.

The lack of knowledge about the non-patient group is a consequence of the taboo surrounding hearing voices that prevents most people from talking freely about them. People who can cope with their voices prefer not to talk about them because within our western culture hearing voices is still frequently seen as a symptom of a mental illness.

The taboo and the association with an illness prevent people from learning about their experience. In order to start coping, one must be able to talk about voice hearing: to explore the experience, to look for a structure, to look for the message of the voices and to look for triggers that may induce the voices. The Maastricht interview attempts to make the experience into a personal study that allows this process. It can unfold a story that is understandable to both the voice hearer and other people.

The questions structure the experience and can give rise to new questions that the voice hearer has never previously thought about, for example: triggers and coping-mechanisms. For therapists the interviewer can give information about: the possible relationship with the voices and the life-history of the voice hearer, about underlying problems, the influence of the voices in daily life and the power structure between the voice hearer and the voice(s).

In this article quantitative and qualitative data will be used from the children's research to illustrate the kind of information that the 11 interview topics might give. The word 'children' will be used, meaning cover the whole population of children between 8 and 19 years of age.

\section{Nature of the experience}

Questions on the first topic are about the nature of the experience. Is the experience to be categorised as an auditory hallucination and, apart from hearing voices are other unusual experiences present? Under this heading the children were asked:

- do you hear the voices in the head or through the ears?

- do you think that the voices are 'not-me"'(ego-dystonic)?

- are the voices are sleep related (heard when falling asleep or waking up)?

- do you have other experiences like visions, auras, sounds or music?

- are you able to hold a dialogue with the voices?

All children participating in our research heard voices that were go-dystone. Most of them had an argument such as, 'it must be someone else, because I do not say such stupid things.' or 'I hear two voices, I cannot be two voices myself'. Most of the children believed that others could not hear their voices. Often they had checked it with the people around them. Only one child thought that another person might hear his voices, however he could not identify that person and has never met him.

Nature of the experience

- Hears voices in head only

$67 \%$

$33 \%$

- Hears voices through the ears

$27 \%$

- Hears voices during day time as well as sleep related voices

- Hwears voices during daytiem only

Other experiences:

- Has visions

$65 \%$

Visions: In this research, the emphasis is on hearing voices. We do not have quantitative figures about the interpretation of the visions, but there is an impression based on the interviews; $65 \%$ of the children saw visions. These varied from vague shadows to very clear images. Not all visions were described as frightening. During the interviews it became apparent that in most cases, it was the individual interpretation of the vision that produced fear and anxiety or otherwise in the children. Some children reported seeing coloured auras. They were initially afraid of these because they did not know what these colours meant. 
A good example of the relation between visions and anxiety is that of a child that told she was not afraid of the vision of deer ripped apart and bleeding. This vision would frighten everyone. Visions are not always associated with a voice or a sound: $39 \%$ of the children reported seeing a vision and hearing a voice or sound at the same time. About $50 \%$ of the children heard voices as well as sounds like the slamming of a door, or a garden gate or hearing music.

\section{Characteristics of the voices}

In this topic, extensive questions were asked about the characteristics of the five most important voices. The children were asked:

- The number of voices and the name of the five most important voice,

- The gender, age,

- Tone of the voice

- Frequency of the voice.

- Lastly, it asked whether the voices resemble someone known to the hearer.

These questions are asked because in our research on adults we found that:

- Voices with a clear identity might give an indication of past trauma or a situation that makes the voice hearer powerless.

- Characteristics of the voices like gender and age might give a direction about the identity of the person involved in the trauma;

- Voices might be positive and offer advice;

- A clear identity of the voice might offer more possibilities to develop a different (the voice hearer's own) opinion.

For therapists the characteristics might give direction about the kind of trauma and the people involved. For example, a male child reported that he heard the voice of his teacher. His problem appeared to be his related to this teacher. The boy's father was a soldier who was sent to Bosnia. The boy could not cope with it, after his father was sent abroad, the child never talked about him. However on one occasion at school, when he did try to speak about his father, the teacher ridiculed him about it. A short while later the boy started to hear the voice of the teacher who had ridiculed him.

In another case, it emerged that one girl who had been sexually abused by the boy next door and two of his friends, started to hear voices that had the same tone of voice, and were the same age and gender of the boys who had abused her.

The experience of using the interview showed that one should not make assumptions or jump to conclusions on the first information. It is better to finish the whole interview before attempting an analysis.

For example, an eleven-year-old boy heard a female and male voice, which quarrelled about him. When asked a question at school that he could not answer, the male voice gave him incorrect advice. Then the female voice told the boy this was not the right answer and both voices started to quarrel which confused the boy. During the interview the boy was asked whether the female voice was always right. He answered:' Mostly, she is. Not in traffic'. Within five minutes, his mother disclosed that she did not like driving, as she was not very skilful in traffic. On first impressions there seemed to be a connection between the parents and the voices the child heard, suggesting that there could be a problematic situation. However in the third year of the research it emerged that the child's IQ was 85, much to low for the school he was attending.

\section{Number of Voices}

Analysis showed that the number of voices each child heard had no influence on how they coped with the voices or on the continuation or discontinuation of the voices. We concluded that coping with hearing only one voice, was no easier to than coping with a small number of voices, or that hearing only one voice made it more likely that the voice would disappear. In the first interview, we found that most children heard less than five voices. 
Number of voices:

- One voice $\quad 21 \%$

- Between two and five voices $37 \%$

- Between six and ten voices $\quad 17 \%$

- More than ten voices $20 \%$

- Changing number of voices $\quad 5 \%$

The number of voices was asked as well as the characteristics of the five most important voices of most children was the same. These were mostly male voices; only $40 \%$ had a name.

- Between 60 and $70 \%$ of the most important voice was a male voice of someone 30 or 40 years of age (about the age of their father)

- Always the same voice $70 \%$

- $\quad 40 \%$

Identity of the most important voice, the children reported that:

\begin{tabular}{|c|c|c|c|}
\hline - Unknown & $65.4 \%$ & Decaesed person & $2.5 \%$ \\
\hline - $\quad$ Father & $2.5 \%$ & Themselves & $4.9 \%$ \\
\hline - Mother & $1.2 \%$ & Teacher & $1.2 \%$ \\
\hline - Sister/bother & $2.4 \%$ & Friend & $1.2 \%$ \\
\hline - Grandfather & $2.5 \%$ & Alien/computer & $3.7 \%$ \\
\hline - Grandmother & $2.5 \%$ & Different to above* & $9.9 \%$ \\
\hline
\end{tabular}

*(Robot, ghost, phantom, spook, beast)

Characteristics of the voices: tone: Overall tone of the voices:

- Friendly $25 \%$

- Agressieve or unpleasant $\quad 50 \%$

- Neutral (neither positive nor negative) $\quad 25 \%$

\section{Frequency:}

In the analysis, we found that the frequency was very important; a high frequency was a predictor on the continuation of the voices. The more often the voices were heard, the more the likelihood they would not disappear.

Frequency of the voices:

- Daily* $60 \%$

* Continuous $\quad 10 \%$

* Every hour $\quad 13 \%$

- $\quad$ Every week*

(Varying from onc to several times)

- $\quad$ Every months *

(Varying from once to several times)

- $\quad$ Changing frequnecy*

(voices might be heard sometimes, often and sometimes rarely) 


\section{Triggers}

Time place and activity related to voice hearing: In the interview, we distinguished two categories of triggers to hearing voices. The first category was related to the time, place and activity when the voices were heard. Generally, it was not difficult for the children to talk about these triggers.

Emotions related to voice hearing: The second category was related to emotions such as aggression, anger, sadness, being tired, anxiety, doubt, and jealousy, being happy. Talking about emotional triggers was more difficult. The structure of the interview enables talking about emotional triggers to build up. In the daily life of the children, we often saw a combination of both categories. For example, some children reported that they were afraid at night in their own bedroom, when it was dark. Or they were afraid to be walking in the streets on their own.

When a question in this topic was answered with 'yes', it might indicate that there was a problem in this specific area. In therapy, it is wise to check whether there is a relation between triggers and possible problems in this area. For example in our research, we found that quite a lot of children heard voices at school. These children experienced problems at school that people around them were not always aware of. For example they were bullied by their peers or dealt with unfairly by their teacher. For example, a teacher had put a girl who had a hearing impairment in the last row of the classroom. Not only was she unable to hear what he said, she also had too much time to spend with the voices.

A number of children were having capability problems. Their inability to cope with some subjects on the school curriculum could result in some children behaving aggressively. Their powerlessness and inability to cope with at school was an emotion that the voices continually intensified. The results of the research showed that sometimes, changes in the circumstances that triggered the voices, might make the voices disappear. For example, a number of children reported that the voices disappeared when they changed schools because of their capability problems or because they went from primary school to secondary school.

Because the children were interviewed four times they became more familiar with the interview topics. In the time in between the interviews, parents and children discussed them and some parents made their own conclusions. For one mother the connection between the problems her daughter experienced at school with her peers and the voices was so clear, that she told the interviewer: 'I would not be surprised if the voices are gone next year, when she will be changing school'. She proved to be right. More insight into what triggers the voices creates the possibility of organising support that is more efficient for the children. As in the case of the girl who saw visions and heard a voice in her bedroom. She became so afraid that she did not want to go to bed. Her family took her seriously and her father went to her bedroom every night to look in her closet and under her bed to see whether there was a voice or a vision. As he found none, he told the girl and she was satisfied and went to bed. However, a problem arose in the early darkness of winter. The girl liked to take long showers and insisted that a family member would wait outside the shower room in the cold corridor, so she would feel safe. No one wanted to do this. Eventually the mother offered a solution; she would call the girl for her daily shower at four o' clock when it was still daylight.

Support, such as this is important, as long as it is within reason. When limits are exceeded, other problems can arise. For example if parents allow their child to sleep in their bed when they are afraid of the voices. One father complained about his ten-year-old daughter, who slept between him and his wife for four years. As her size increased with age, she took up more and more space in the bed. The father eventually had to sleep on the edge of the bed. His daughter often could not bear heat and threw the duvet off the bed. She had become a child that dominated his marriage as well as his sleep and had not learned to cope with her voices independently of her parents.

\section{Emotional triggers}

The second category is emotional triggers. In the interview there is a whole list of them, corresponding with the emotions voice hearers mentioned in the pilot study. The list is always carried out systematically. This systematic approach has been found to help reveal unexpected factors that might explain certain behaviours of the children. 
First, we asked whether the voices came when the children felt particular emotions. Secondly, we asked, what the effects of emotions on the voice are on these occasions? Do the voices intensify the emotion in a positive or negative way? Or do they just come? Therefore, the questions obtain information about the presence of emotions in relation to the appearance of the voices, as well as the reaction of the child on the presence of emotion combined with the voices. Some children said that when they are angry the voices help them by saying: 'do you think this is wise? Do you have to be so angry?' Most children reported that when they are angry, the voices make them feel angrier. Sometimes voices can cause some children to exceed limits, for example, a very slim good-looking girl who said that she became so angry that she pulled a woman over her shopping trolley.

The emotional triggers often appear to have the same hold as the triggers of time place and activity. If the voices appear with particular emotions, there might well be problems with these feelings. For example, Max is eleven years old; he has never been in residential care because of hearing voices. In the first interview, Max said that he could become so angry, that he was afraid that he would start a fight. He knew that he was so strong that he would probably knock the person down. This reasoning put Max into an impossible position. Instead of becoming angry himself, he made other people angry. At the first interview a very angry mother aided, by an uncle was present.

In the third year of the research Max accidentally found a teacher who could help him. Max had explained that one of his classmates bullied him and this made him become so angry that he did not know what to do about his anger. He was afraid that if he started to fight with the boy he would knock him down. The teacher invited both Max and the classmate for a talk. In the presence of the teacher, the boys were forced to explain to each other what provoked their disagreements and they had to find a compromise. They had to make a deal and shake hands to show the other that they meant it seriously. This solution worked well, every time Max felt angry and he felt that he could not cope with this emotion, he consulted the teacher. When he became very angry at home he went voluntarily to his bedroom and stayed there until he calmed down. During the previous year, his parents sent him to his room as a punishment.

In the last interview, Max reported that he could cope better with aggression by carrying out an internal dialogue. When he became angry he would say to himself: 'do sit down, it can only become worse.' Some of the children in the study were unable to learn how to cope with emotion in the way Max had learned to. However, they learned to cope with the help of professional care. In Holland the ambulatory care unit, and some private therapist provide assertiveness training. Through this training, the children who frequently felt angry learned to express themselves in different ways. Consequently they did not explode with anger, but could talk about their feelings and express them safely.

It is striking that not only the presence of certain emotions, but their absence, can indicate certain problems. One girl reported that she was never angry. She said: ' whenever I start feeling angry, the voices come. I never get angry.' In group therapy, she learned to feel anger. She had to explain to other group members certain disturbing experiences. Why they had happened and why she could not react. The therapist would repeatedly say. 'I have not fully understood what you are explaining'. The child had to tell the story repeatedly until she felt the emotions connected to the incident that she was relating.

Two frequent triggers for voices were doubt and uncertainty. The voices repeatedly interfered with and ridiculed the children's decisions, sometimes with far reaching consequences. One girl reported that she only bought black clothes. 'The voices want me to buy them. I don't even like black!' she said. Another child, a boy, reported that the voices decided what he would put on his bread. It had begun with him asking for advice from his voices and it ended with the total dominance of the voices. The voices only allowed him to eat what they said he should eat. If he did not listen, they would punish him.

However, the opposite also happened, some children who began to ask their voices for advice found they could rely on it. Whenever they did not know what to choose, or for example what to wear, they asked the voices. One girl heard her voice say; 'I would rather put those red shoes on, they fit nicely with your frock'. She put frock and shoes together and agreed. Children who cope with the voices in this way often are not usually in residential care. They learned to be critical and discerning about what the voices said and decided whether they could use the advice or whether it would give them trouble. 
Place, time and activity as triggers.

The triggers, place, time and activity scored less often than the emotional triggers.

The voices appear:

- On a certain place: at home or at school $\quad 52 \%$

- With certain activities like doing homework or playing outside $44 \%$

- At a certain time like the weekend or in the evening going to bed $38 \%$

Although $50 \%$ of the children were not in psychiatric care, most children were afraid of the voices. The triggers anxiety, fear and sadness scored highly. Nearly $50 \%$ of the children mentioned being alone as a trigger. In the research, 'being alone' is not seen as part of the categories of place, activity or time, it was put under the topic emotional trigger. Some children reported that 'being alone' was positive while others felt it was negative.

Emotional triggers:

- Anxiety $70 \%$

- Anger $54 \%$

- Sadness $50 \%$

- Being alone $49 \%$

- Doubt $40 \%$

- Uncertainty $46 \%$

- Feeling unhappy $36 \%$

- Feeling quilty $35 \%$

- $\quad$ Being tired $29 \%$

\section{History of voice hearing}

In our research with adults hearing voices (Romme en Escher, 1989) we found that $70 \%$ of people started to hear voices in relation to a trauma or to an emotionally overpowering situation. One of the research questions in the children's research was therefore whether this was also the case with children. With adults, we saw that if they were able to see a relationship between the voices and a possible trauma, this had a positive influence on their way of coping with the voices. By relating the voices to their life history, the experience became more understandable and less alien.

Under the topic 'history of voice hearing' is a checklist with 18 life-events that could make a person powerless and could be experienced as traumatic; the death of a grandmother, grandfather or a friend, divorce of parents, moving house, changing schools etc. In the pilot study, many adults and children reported that events such as these preceded the onset of their voice hearing.

The checklist is systematic and the first question first asked is whether the child has experienced a particular event. The second question asked whether the particular event triggered the onset of the voices. In cases where the voice hearing preceded the trauma, we asked whether the event had changed the nature of the voices. Therapists who have used this method with a patient they thought they knew well, have been surprised to hear things many things they previously did not know about.

In the research setting, a girl had begun to hear a voice at the age of six at the time that her grandmother died. The voice was friendly and supportive. When she was eleven years old, the voice changed and she began to hear more voices. Gradually the voices became very negative and destructive. In the first interview, the girl said nothing traumatic had happened to her. However, before the second interview she had an informal discussion with the interviewer during which she tested the interviewer to see if she could trust her by asking her opinion about hallucinations and delusions. Later during the formal interview, talking about life-events, she told reported that when she was eleven she had had a boyfriend of nineteen, who gave her drugs and let his friends sexually abuse her. She had never told anyone about this incident because she felt that she was to blame. 
A boy, Wim, started to hear positive voices in a time that several things happened to him. His family moved to a temporary house. The school year ended and he expected to go to the same school as his brother, but was not admitted because of a clerical error made by his teacher. Six months before his first interview the voices had become negative. The boy became aggressive and was referred to the school GP. The doctor had heard about our research and advised Wim to participate in it. In the first interview, Wim told that us how unexpectedly the voices had suddenly become negative. The interviewer asked Wim and his mother, who was present; to return in their thoughts to the time this had happened. Suddenly they both knew what had happened.

One Saturday Wim had accompanied his mother, brother and his brother's friend to a football ground. His friend played of line keeper and tried to stop a ball, but missed it and fell into a window. Glass cut his arms, the boy got an arterial bleeding and nearly died. Wim's brother and mother offered first aid, while Wim went to the parking lot to clear it for the ambulance. In the following weeks Wim's mother and brother talked a lot about the event, never mentioning Wim's role. Remembering the event caused Wim and his mother to talk about it in detail. In this discussion, the mother admitted that it was strange that she had never involved Wim in previous discussions about the event. She realised she had paid enough attention to what Wim had done. She shared the new feelings with Wim and in the next year, both the voices and Wim's aggressive behaviour disappeared.

Of the 80 children participating in the research $62 \%$ reported that they recognised a relationship between the voices and at least one traumatic event. Some children reported more than one trauma. Statistically we saw that children who had experienced more than one trauma were more likely to look for psychiatric care.

Events precipitating the onset of voices, divided in four categories

- Confrontation with death

- Problems at home

- Serious tension with parents and or brothers/sisters

- Divorced parents

- Moving houses

- Problems in the schoolsituation

- Capacity problems

- Cahnging schools

- Being bullied

- Other kind of trauma/problem

- Sexual abuse

- Long time hospital stay because of health problems

- Birth trauma

- Seeing something wierd

- Being rejected in love

- Abortion

- Aneasthesia

- Brain damage caused by traffic accident

- No trauma

\section{Total}

19

10

10
3

19

17

$N$

18

Percentage

$\mathbf{2 2 . 5 \%}$

$23.7 \%$

3

11

9
7
3

9

3

$21.2 \%$

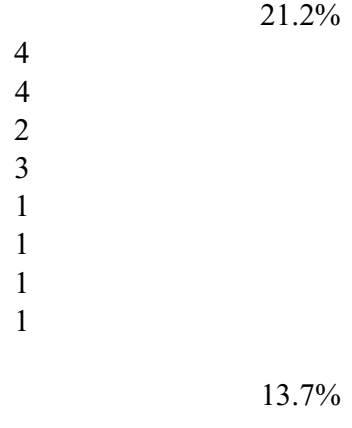

$23.7 \%$

Every item could be answered with 'yes'.

\section{Influence of the voices}

Which influence does hearing voices have in daily life? Do they only have influence at home, only at school, only in social contacts or do they influence all levels of daily life? This topic contains 13 items. From the interviews we know that the voices scare the children, cause them to pick quarrel and fights, to steal, to lie, disturb doing homework etc. Notwithstanding these negative consequences, the 
influence of voices might can also be positive. The voices can give support, advice and counsel. They might suggest for example, 'shouldn't you do your homework, because it is nearly bedtime'.

It is striking that about $50 \%$ of the children hear positive voices (as well as negative). In questioning the influence of voices, we had discussions with the children about the consequences on their own behaviour. Some children reported that the voices made them so angry that they started to quarrel with their siblings or withdraw to their bedroom.

Two examples show that this line of questioning might be more important for parents in explaining the child's behaviour than for the child itself. During an interview, one child, a girl ignored the interviewer but said directly to her father: 'that is why I could not play chess with you yesterday. The voices forbade me to'. On another occasion, a boy turned around to his mother and said, 'that is way I always wait to go to the toilet until you go to the kitchen at night. The voice might be in the corridor leading to the toilet.'

During the research period, it became clear that as the behaviour of the child became more understandable to the parents, they became more tolerant towards the children. The children began to feel less insecure and showed affection more openly. Some parents explained the changes between the child and themselves as: ' my child has become like one of the other children. They are no longer singled out as ' the voice-hearing child'. I also allow myself to become angry again when something is not right'.

Analyses of the first interviews showed that the voices considerably influenced all the children's daily life. Seventy $\%$ of the children experienced problems at home because of the voices. Eighty two \% experienced problems at school. Most of the children, $(80 \%)$ were afraid of the voices. Problems in the home included extremely aggressive behaviour. One boy threatened his brother with a knife, another boy hit a glass window so hard that it broke and cut into his wrist. At school problems that arose were mainly lack of concentration, and not paying attention to the teacher and getting confused by the voices who twisted answers or turned figures round. The voices distracted the children, demanded attention, some children responded by talking out loud to the voices

In the second year 57 children still heard voices, however the influence of the voices had diminished immensely. The children still experienced problems thought to be voice related at home, $33 \%$ and at school $42 \%$. In the following table, the data of the 57 children still hearing voices in the second year were compared with the first year.

Influence of the voices

\begin{tabular}{|c|c|c|}
\hline $\begin{array}{ll}\text { - } & \text { Frightening } \\
\text { - } & \text { Confusion } \\
\text { - } & \text { Concentration problems } \\
\text { - } & \text { Provoked quarrels } \\
\text { - } & \text { Disturbed while doing homework } \\
\text { - } & \text { Got punished (by following commands of the voices) } \\
\text { - } & \text { Made them do things they did not want to do }\end{array}$ & $\begin{array}{l}\text { First year } \\
78 \% \\
66 \% \\
63 \% \\
52 \% \\
38 \% \\
42 \% \\
54 \% \\
15 \%\end{array}$ & $\begin{array}{l}\text { Second year } \\
42 \% \\
54 \% \\
35 \% \\
32 \% \\
19 \% \\
21 \% \\
46 \% \\
7 \%\end{array}$ \\
\hline
\end{tabular}

Every item could be answered with 'yes'.

\section{Interpretation of the voices}

Our research with adults showed that most people looked for their own explanation, or cause for the voices. Their explanation was often different from that of their therapist. Hardly any voice hearer reported that they thought the voices were an illness. We also found that if a therapist rejected the explanation of the voice hearer, this influenced the therapeutic process, and it became more of a battlefield between the two parties. In adults, we saw that the personal explanation was important as it helped them to accept the voices and gave the experience a frame of reference or belief system, to fit into. Having found a belief system, they acquired the language to explain their experience; it became possible to discuss the experience with other people. The more socially acceptable the explanation, the easier it seemed to accept the voices. 
One of the present research questions was whether this was the case with children. From the interview, we saw that children were not as interested as adults in finding an explanation were. Parents appeared to find it more important, to many parents, to explain the voices as a 'gift' was more acceptable than to call it an illness. Most parents explained the voices as 'paranormal' or a 'special gift'. Some mothers even started training in the paranormal field in order to understand their child better.

Questions in this topic are important for the organisation of support, for example, $\mathrm{n}$ the first interview Eric reacted physically when he talked about the voices. He started to sweat and looked very pale. He could hardly talk about his experiences, and struggled to find words to describe them. During the interview, his mother said she believed that he was specially gifted. On hearing this the father, who had just entered the room said, 'Nonsense'. 'He is just a nerd. He hardly can ride his bicycle'. Perhaps fortunately for Eric, the mother did not accept his father's explanation. In the second year his mother thought that he needed care and consulted the family GP, who did not know a lot about hearing voices (which is normal practice for many GP's) and wanted to refer Eric to a psychiatrist. The mother did not agree to this and found a paranormal therapist who practised group therapy with children who hear voices. In the second year Eric showed no physical reactions and was able to talk clearly about his experiences. Throughout the research, Eric and his mother visited the therapist regularly, even thought they have to travel for hours to see her.

Although most of the children explained the voices as a paranormal gift, there were quite a number that related the voices to the 'other world' or ghosts. Only 3\% of the children thought it was an illness, all of these children were in psychiatric care.

Interpretation of the voices.

- It is a paranormal gift $\quad 39 \%$

- A ghost $20 \%$

- They come from the other world $18 \%$

- Religion 16\%

- An illness (all these children were in care) $\quad 3 \%$

- Other explanations (like a doll, robot etc) $20 \%$

Every item could be answered with 'yes'.

\section{Relation with the voices}

Questions in this topic are meant to make the child aware that he/she has a relationship with the voices. Having a relationship means that there are two parties which influence each other involved. As in every relationship, it is a question of action and reaction. In this case, for example if the voice hearer allows the voices to exceed small limits, the voices will expand their territory. If the voice hearer lets them know that she/he is not impressed by their punishment, the voices seem to know they do not have enough power. Because of the often-negative content of the messages of the voices, voice hearers do not like to think in terms of a relationship. They have not chosen this relationship; the voices have been imposed on them. However, to use an analogy, you may have unpleasant neighbours, but you also have to have a relationship with them whatever form it may take, from ignoring them to trying to get along with them. It is more a question of acknowledging the situation and trying to have as much as influence as possible to help the situation.

In our research with adults, we found that voice hearers who had never been in psychiatric care, described the voices as positive or as mostly positive. They had a relationship in which they felt as powerful as the voices. In most cases, they re able to summon the voices as well as to send them away. If the voices gave information they did not like, they sent the voices away, ignored the information or thought about it and only used it if it seemed relevant. In their relationship with the voices, they kept their own identity.

With the psychiatric patient groups, this was not the case. They perceived the voices as mostly negative. They were often so afraid of the voices that they did not dare to be critical about the content 
and did whatever the voices asked them to do. People who were made powerless by the voices often did not realise that they had a relationship in which their own action and reaction also determined the relationship.

The questions in this topic supply information about how active or passive the voices hearer is in their relationship with the voices. A relationship is subjective and will change as soon as the power relations change. During the children's research, we often saw it happen. In this topic to determine the level of the power relationship we ask: whether the voices listen to the child, agree with him/her, if the child is able to refuse a command of the voices, if they are able to call the voices or if the voices can make them so afraid that they feel totally powerless.

\section{Power relation with the voices:}

- Voice listens

- Child is able to refuse commands

- Child is able to call the voice

- Child is paralysed by fear of the voices

- Child Is more powerful than the voices

Every item could be answered with 'yes'.

Children who were able to summon the voices and could refuse commands of the voices were less hindered by the voices. The children that heard negative voices that also listened to them, perceived less hindrance from the voices than the children who felt overpowered by the voices did. From literature (Chadwick and Birchwood, 1994, Watkins, 1998) and from our own research (Escher and Romme, 2002) we saw that the power that the voice-hearer attributes to the voices has influence on the continuation or discontinuation of the voices.

We compared the children's opinion about the voices that they heard voices in the second year, with their opinion of the voices that they heard in the first year.

\section{Attribution of the voices:}

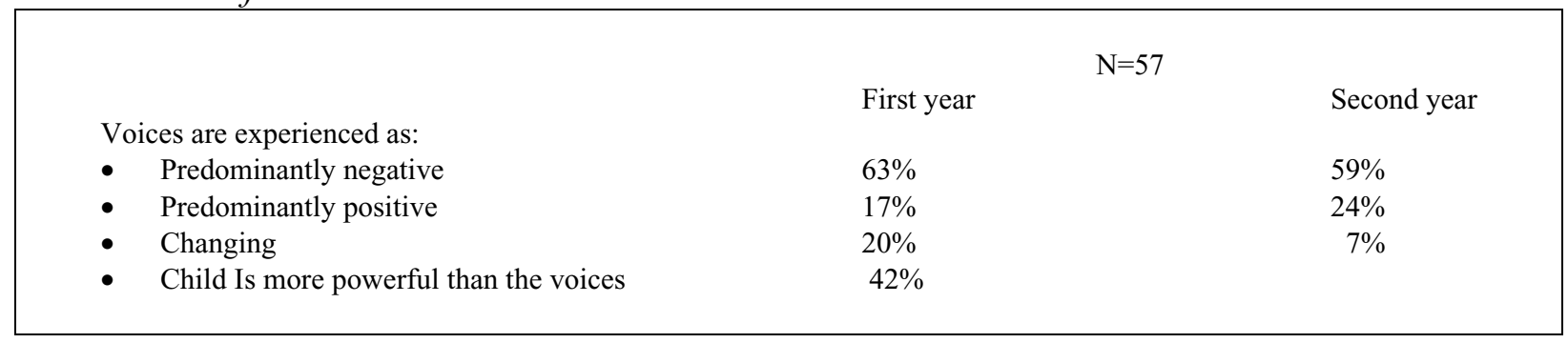

In the analysis, we see that about $50 \%$ of the children hear positive voices. There is no significant difference between the patients and the non-patient group. This confirms the finding that it is largely the attributes the voice hearer gives to the voices that dominate his/her behaviour towards the voices. For example, a child heard voices that commanded him to destroy the things he liked. Although he perceived the voice as negative, he was not afraid of the voice. Overall, he does not think the voices are negative.

\section{Coping}

Questions under this topic are meant to get more information about the way that the children cope with the voices. It is not only about how active or passive the voice hearer is, but also how many coping strategies the child uses. Voice hearers who are made powerless by the voices often used one, ineffective form of coping.

This topic can help the children to think about the way they cope. Are the strategies they use effective of ineffective? There are many coping strategies; maybe they would like to try another one?

We distinguished three categories: 
- $\quad$ Cognitive strategies such as sending the voices away or making a deal with the voices, listening selectively, thinking about something else, and scolding the voices.

- Behavioural strategies such as doing something, closing yourself off from the voices, distraction, or keeping a diary.

- $\quad$ Physiological strategies like medication, eating sweets or food.

Differentiation between active and passive coping is made.

- Active coping is sending the voices away, listen selectively, and make a deal with the voices, seeking distraction, keeping a diary.

- Passive coping is ignoring the voices, scolding the voices and carrying out rituals.

Some children became very creative and found their own ways of coping. For instance, one boy adapted a computer game. In a labyrinth, a round eating ball would chase an object. He imagined this object was his voice. As he played the game, the round ball ate his voice. Another boy heard two robots. He made a drawing of the robots and a big hypodermic syringe. In his fantasy he gave the metal men an injection and they disappeared. One girl was afraid of a vision of a huge black bear. Her mother, a voice hearer herself, advised the girl to wash the bear until he was white. The child did as her mother suggested and it helped, as she was not afraid of a white bear.

This topic should stimulate and encourage the children and the therapist to become creative. To look at which strategies work and which do not.

The first interview showed that the 80 children participating in the research used a total of 193 coping strategies between them, showing that most children used more than one.

\section{Most used coping strategies:}

\begin{tabular}{|ll|}
\hline & $\mathrm{N}=193$ \\
- & $\mathrm{N}=33$ \\
- & $\mathrm{N}=28$ \\
- Istraction & $\mathrm{N}=28$ \\
- Listening the voices away & $\mathrm{N}=25$ \\
- Started doing something (reading, watching television) & $\mathrm{N}=23$ \\
- Scoing to someone & $\mathrm{N}=20$ \\
- Thinking about something else & $\mathrm{N}=19$ \\
& $\mathrm{~N}=17$ \\
\hline
\end{tabular}

Every item could be answered with 'yes'.

\section{History of care}

In this topic, the history of care in relation to the voices is inventoried. We asked: what forms of care the children received? From which therapist and from which profession and whether the children were satisfied with the care they received. The data was quite revealing, this topic elicited too much data for discussion in this article.

Statistically we found that whether or not the children were receiving psychiatric care or not had no influence on the continuation or discontinuation of the voices. On a qualitative level, we found there were differences in the responses of the children, depending on the relationship between the child and the therapist. It appeared that the relationship with the therapist was more important than the technique the therapist used.

\section{Social Network}

The data from the adult research showed that voice hearers, who had never been in care, received more support at home. Moreover, the more people around them were aware that they heard voices. It was no secret and these people could talk openly about their experience with other people. Therefore, we wanted to know if the same happened to the children.

In this topic we make an inventory of the ten most important people, to the idea of the voice hearer, that know about the voices and with whom they dare to talk about the voices. Sometime there was surprising 
information. Like some children who did not find one or more siblings important, or a father that had to be left out. A detail, $28 \%$ of the children had one or more family members who heard voices as well.

Being able to talk about the voices is important in intimate relations. Some children told that they did not dare to tell their friend or lover about the voices. These relations mostly did not last.

\section{The art of interviewing}

The ground for the interview is set before it begins. The voice hearer must feel that he/she can trust the interviewer. Information must be given. Talking about the voices is talking about emotions; the interviewee's voices might react to this. However it is quite normal and should not be frightening. We always give a telephone number where the voice hearer can reach us in the first 24 hours in case he/she has become disturbed by the interview and wants to discuss anything about it. Sometimes a voice hearer, who has never had much opportunity to talk about their voices, opens up too much. He/she might give so much information that it is confusing for the interviewer. From experience we know that if the interviewer states before the interview that the interviewee will interrupted whenever the answers are too far away form the line of questioning, we have found that this does not interfere with the interview.

It is important to realise that during the interview, the interviewer should not make interpretations as this might disturb the process. The purpose of the interview is to collect information about the experience and to hold a dialogue in which the experience and opinion of the voice hearer is central. Interpretation might scare the voice hearer. Many voice hearers know from past experience that as soon as they talk about their voices, people react in a very negative way. They might not believe the voice hearer, or might see him/her as mentally ill. For a valuable interview, you need the trust of the voice hearer, without trust, they will with hold information.

It may sounds simple but for people with training in a therapeutic educational background, it seems to be very difficult not to interpret information and make into diagnosis or recommend therapy, for example in case of bereavement.

One more piece of advice, when interviewing a voice hearer, be clear about your own ideas on the subject. They are part of your personality that you cannot hide.

\section{From interview to report to construct (Romme en Escher, 2000)}

The length of the interview depends on the skill of the interviewer. A skilled interviewer will take about one-and a-half hour hours.

With all the information from the interview, one should make a report. (Romme en Escher, 1999, 2000). The report is a summary of about two 500 words in which all the topic are mentioned and together they are enough to make sense of voices in the voice hearers life. It should give enough information to make the influence of the voices on the interviewees' life understandable: the triggers to the voices and the relation with trauma or underlying problems. By building a rapport with the interviewee one can learn how much, and which information is important. In the beginning people tend to make the report too short or too long.

The report is talked through with the voice hearer, they begin to understand and accept their experience. We found that using quotes from the voice hearer helped to make a report that is accepted by the voice hearer as his or her story. It can be used as an example to show how this is helpful.

When the voice hearer agrees with the report, the therapist will use it as a construct and an intervention schedule. The construct is a kind of social diagnosis. If possible it makes the relationship between the voices and the life history understandable to the voice hearer. Information that is used is:

1. The identity of the voices,

2. The characteristics of the voices,

3. The triggers

4. The onset of the voices (or the change from positive to negative voices)

5. The youth history

Within the construct two questions are important. Firstly, whom do the voices represent?

Secondly, what problems do they indicate?

The identity and characteristics of the voices will answer the first question. The onset of the voices and the history of the child will answer the second question. 
The report, construct and intervention schedule and therapy phases are too complicated to explain in detail here, the book; 'Making Sense of Voice' published by Mind gives very detailed information.

\section{References}

Bentall and Slade (1985). Reality testing in auditory hallucinations: a signal detection analysis. British Journal of Clinical Psychology, 24, 159-169.

Barrett, T.R., and Etheridge, J.B. (1992). Verbal hallucinations in normal 1: people who hear 'voices'. Applied Cognitive Psychology, 6, 379-387.

Bijl.RV, Ravelli, A., Van Zessen. G., (1998). Prevalence of psychotic disorder in the general population: results from the Netherlands mental health survey and incidence study. Social Psychiatry Epidemology, 33, 587-596.

Chadwick, P., Birchwood, M. (1994). The omnipotence of voices: a cognitive approach to

auditory hallucinations, British Journal of Psychiatry, 164, 190-201.

Escher, A., Romme, M., Buiks, A., Delespaul, Ph., van Os, J. (2002). Independent course of childhood auditory hallucinations: a sequential 3-year follow-up study. British Journal of Psychiatry. 181 (suppl.43),s10-s18.

Green,E.L. et al. (1973). Some methods of evaluating behavioural variations in children 6 to 18. Journal of the American Academy of Child Psychiatry, vol. 12 (3), 531-553.

McGee, R., Williams, S., Poulton, R. ( 2000). Hallucinations in no psychotic children (letter, comments). Journal of American Academic Child and Adolescent Psychiatry 39 (1), 12-13.

Posey, T.B., \& Losch, M.E. (1983-84). Auditory hallucinations of hearing voices in 375 normal subjects. Imagination, Cognition and Personality, 3 (2), 99-113.

Young, H.F., Bentall, R.P., Slade, P.D., Dewey, Michael, E. (1986). Disposition towards hallucination, gender and EPQ score. A brief report. Personality and individual differences 7 (2), 247-249.

Romme, M.A.J. \& Escher, A.D.M.A.C. (1989). Hearing voices. Schizophrenia Bulletin, 15, (2), 209216.

Romme, M.A.J., Honig, A., Noorthoorn, O., Escher, A.D.M.A.C. (1992). Coping with voices: an emancipatory approach. British Journal of psychiatry 161, 99-103.

Romme, M.A.J. \& Escher, A.D.M.A.C. (1999). Werken met stemmenhoorders, in eigen beheer.

Romme, M.A.J. \& Escher, A.D.M.A.C. (2000). Stemmen horen accepteren, Tirion, Baarn

Romme, M.A.J. \& Escher, A.D.M.A.C. (2000). Making sense of voices. Mind Publications, London.

Sidgewick, H.A. et al (1894). Report of the census of hallucinations. Proceedings of the Society of Psychiatric Research 26, 259-394.

Tien, A.Y. (1991). Distributions of hallucination in the population. Social Psychiatry and Psychiatric Epidemiology 26, 287-2921 


\title{
Chapter 9
}

\section{Stimmenhören bei Kindern}

\author{
A., Escher and M.Romme
}

in

'Anstösze’Zu einer antropologischen Psychiatrie. Editors. Thomas Bock, Klaus Dörner and Dieter Naber (2004) p. 211-218. Psychiatrie Verlag, Bonn. Germany. 


\section{Stimmenhören bei Kindern und Jugendlichen Sandra Escher und Marius Romme}

Stimmenhören bei Kindern und Jugendlichen taucht in der Fachliteratur meist im Zusammenhang mit Störungen wie Schizophrenie, ( Bettes, 1987, Green, 1992, Galdos, 1993, 1995), Angst und Depression (Garralda, 1984, Ryan, 1987, Chambers, 1982) , Migräne (Schreier, 1998), Traumen, dissoziativen Prozessen und reaktiven psychotischen Episoden auf (Altman, 1997, Famularo, 1992, Putnam, 1994). Untersuchungen beziehen sich auf klinische Gruppen von geringer Größe. Die Langzeitstudien zeigen von einander abweichende Ergebnisse, die vermutlich auf die sehr unterschiedlichen Störungsbilder zurückzuführen sind, die in den verschiedenen Studien erfaßt wurden (Garralda, 1984, Del Beccaro, 1988). Eine neuere Untersuchung über den Verbreitungsgrad des Stimmenhörens in der Allgemeinbevölkerung fand eine Prävalenzrate von 8\% für Stimmenhören bei Kindern, nur ein Drittel von ihnen hatte eine psychiatrische Diagnose (McGee, 2000). Das heißt, Stimmenhören scheint bei dem größeren Teil der Kinder keine krankmachende Erfahrung darzustellen. Andere Arbeiten lassen vermuten, daß besonders andauerndes kindliches Stimmenhören das Risiko für eine spätere psychotische Erkrankung erhöhen kann (Fennig, 1997).

\section{Die kindliche Erfahrung des Stimmenhőrens}

Die bisherige Forschung zeigt also unterschiedliche mögliche Konsequenzen bei pathologischem und nicht-pathologischem kindlichem Stimmenhören und obgleich das Risiko, an einer Psychose zu erkranken, erhöht zu sein scheint, entwickelt tatsächlich nur ein sehr kleiner Teil dieser Kinder eine Psychose. Im Verlauf unserer Untersuchungen an erwachsenen Stimmenhörern wurde deutlich, daß Stimmenhören an sich keine Krankheit darstellt, aber daß Stimmenhören krank machen kann. Da bisher keine Langzeituntersuchungen über die Einflußfaktoren auf die Art des Stimmenhörens und auf den Verlauf des Stimmenhörens bei Kindern vorlagen, entschieden wir uns, Kinder zu untersuchen. Wir wollten 80 Stimmen hörende Kinder drei Jahre lang mit jährlichen Kontakten begleiten, um erst einmal zu erfassen, in welchem Umfang Stimmenhören bei Kindern schlicht irgendwann wieder aufhört. Darüber hinaus wollten wir herausfinden, welche Bedingungen es ermöglichen, daß die Stimmen wieder verstummen, d.h. welche Bedingungen könnten Prädiktoren sein?

Kriterien für eine Teilnahme waren:

- Stimmenhören, das den Kriterien des akustischen Halluzinierens entspricht, und das seit mindestens einem halben Jahr besteht.

- Teilnahme an schulischer Ausbildung (75\% der Kinder nahmen an einer normalen Beschulung, 25\% an einer Sonderbeschulung teil. Dieser Prozentsatz ist etwas höher als in der durchschnittlichen holländischen Bevölkerung.

- 50\% der erfaßten Kinder waren wegen des Stimmenhörens Patienten, die meisten auf ambulanter Basis, einige wenige waren in stationärer psychiatrischer Behandlung. Die anderen 50\% setzten sich aus Kindern und Jugendlichen zusammen, die niemals professionelle Hilfe aufgesucht hatten.

Im Verlauf eines Jahres wurden so 80 Kinder, die über die Niederlande verteilt wohnten, für die Untersuchung rekrutiert. Sie wurden in einer Voruntersuchung und anschließend in jährlichen Intervallen 3 Jahre lang gesehen, so daß insgesamt jedes Kind 4 mal interviewt werden konnte. Wenn ein Kind allerdings bei der ersten Nachfolgeuntersuchung mitteilte, daß seine Stimmen verschwunden waren, wurde die Nachfolgebefragung nicht durchgeführt, um 
eine unnötige Fokussierung auf zurückliegende - oft aufwühlende - Erfahrung zu vermeiden. Um aber ein eventuelles Wiederauftauchen von Stimmen zu erfassen, wurde der Versuch unternommen, alle 80 Kinder der Voruntersuchung bei der abschließenden Untersuchung nach 3 Jahren wieder zu befragen und zwar unabhängig davon, ob sie zu dem Zeitpunkt noch Stimmen hörten oder nicht.

Die ungefähr gleichmäßig auf beide Geschlechter verteilten (53\% Mädchen) 80 stimmenhörenden Kinder im Alter von 12-19 Jahren (Durchschnittsalter 12,9) wurden wiederholt mit folgenden 4 Testverfahren untersucht.

- Maastricht Interview für Kinder (MIC) $)^{i}$ von Escher \& Romme (1995), mit dem wir die Wahrnehmung und die Charakteristika der Stimmen, ihre Geschichte und Auslöser, ihren Einfluß sowie die Bewältigungsstrategien des stimmenhörenden Kindes sowie sein soziales Netzwerk erfassen wollen.

- Brief Psychiatric Rating Scale (BPRS) (zur Einschätzung von Angst/Depressivität, Vorhandensein positiver und negativer psychotischer Symptome, Disorganisation, Manie u.a.)

- Youth Self Report (YSR) von Achenbach (1982) (Lebensereignisse der Vergangenheit wie Tod, Krankheit, Unfälle, Umzug von Freunden, Schulwechsel, erste Menstruation, Schwangerschaft, unerwiderte Liebe, Scheidung der Eltern, Sitzenbleiben etc. wurden mit der Häufigkeit des Auftretens erfaßt).

- Ein Gesamtwert für das Ausmaß ungünstiger Kindheitserfahrungen wurden durch die Anoder Abwesenheit bestimmter Erfahrungen erfasst, zum Beispiel: fühlte sich nicht sicher zu Hause, auf der Straße, in der Schule, erfuhr absonderliche Strafmaßnahmen wurde regelmäßig geschlagen, fühlte sich ungewünscht, Zeuge körperlichen Mißbrauchs, Zeuge sexuellen Mißbrauchs, erfuhr selbst sexuelle Belästigung oder sexuellen Mißbrauch.

- Dissociative Experience Scale (DES) von Bernstein \& Puttman (1986) - nur im ersten und letzten Interview.

Außerdem wurde danach gefragt, ob die Erfahrung des Stimmenhörens zum Aufsuchen professioneller Hilfe geführt hatte und auch nach dem Vorhandensein von Personen des sozialen Netzwerks, mit denen das Kind über das Stimmenhören reden kann. Während der Interviews wurde Wert darauf gelegt, besonders die kindlichen Erfahrungen und weniger die Wahrnehmungen der Eltern zu erfassen. Es wurden keine therapeutischen Einschätzungen oder Deutungen gegeben.

\section{Eine befristete Erfahrung?}

Eine der Zentralen fragen, die uns beschäftigte, war: Wie häufig hört Stimmenhören einfach wieder auf? Im ersten Jahr der Untersuchung berichteten 19 Kinder, daß ihre Stimmen verschwunden waren, im zweiten Jahr kamen 13 Kinder dazu und im dritten Jahr hörten nachweislich insgesamt 48 Kinder $(=60 \%)$ keine Stimmen mehr (von den 13 Kindern, die im dritten Jahr nicht mehr erreicht werden konnten, ist nicht bekannt, bei wie vielen von ihnen die Stimmen verstummt sind, sie werden daher in der Statistik vorsichtshalber als weiterhin Stimmen hörende Kinder geführt). 18 von den Kindern, deren Stimmen verstummt waren, wurden ein Jahr nach dem Aufhören erneut befragt, nur bei vier von ihnen waren die Stimmen wieder aufgetaucht.

Die mächtigsten Prädiktoren für das Bestehenbleiben des Stimmenhörens waren

- Häufigkeit der Stimmen

- Angst

- Depressivität

- Ausmaß der Dissoziation 
Nicht die Anzahl der Stimmen sondern die Häufigkeit des Stimmenhörens erwies sich als bedeutsam für das Fortbestehen der Stimmen. Je höher die Werte der Angst- und der Depressivitäts- und der Dissoziationsmessungen waren, um so wahrscheinlicher blieben die Stimmen bestehen. Statistische Analysen zeigen, daß Angst, Depression und Dissoziation in enger Beziehung zueinander stehen und daß sie wahrscheinlich Reaktionen auf das Stimmenhören darstellen (Escher, 2002). Das hieße, je besser jemand lernt, mit Angst, Depressivität und Dissoziation klar zu kommen, um so besser wird er auch mit dem Stimmenhören klar kommen.

Ein Vergleich von Patienten mit Nicht-Patienten brachte folgende Ergebnisse

Im allgemeinen zeigten Kinder, die professionelle Hilfe aufsuchten, mehr soziale und psychopathologische Störungen als solche, die keine professionelle Hilfe aufsuchten. So erreichten die kindlichen Patienten höhere Werte bei der Messung von Angst und Depressivität, zeigten mehr negative Symptome, waren unangepaßter, berichteten von mehr unglücklichen Ereignissen in der Kindheit, erzählten häufiger von emotionalen Auslösern des Stimmenhörens, erlebten die Stimmen häufiger als „vorwiegend negativ“ und vor allem fühlten sie sich in ihrem Verhalten und ihren Gefühlen stärker unter der Kontrolle der Stimmen. In ihrem Problemlöseverhalten nutzten sie eher passive Strategien (Escher, 2002,2003).

\section{Was hilft? - Fallgeschichten}

$50 \%$ der von uns erfaßten Kinder befanden sich zu Beginn der Untersuchung in Psychiatrische Behandlung. Es wurde kein systematischer Zusammenhang zwischen Verschwinden der Stimmen und Behandlung gefunden. Dieses Ergebnis trifft nicht nur für psychosoziale Behandlungsformen sondern auch für medikamentöse Behandlungen zu.

Nur vier der Kinder und ihre Eltern waren mit den angebotenen Behandlungen zufrieden. Wir vermuten, daß diese niedrige Quote etwas mit gängigen psychiatrischen Theorien zum Stimmenhören zu tun hat, die sich nicht ausreichend mit den Erfahrungen der stimmenhörenden Menschen bzw. was man aus diesen Erfahrungen lernen kann, befassen. Eines unserer Ergebnisse, das in diese Richtung zeigt, widerlegt die Annahme, daß Wahn sich auf das Stimmenhören auswirkt. Wir konnten keinen signifikanten Zusammenhang zwischen Wahn und dem Fortbestehen von Stimmenhören finden.

Das führt uns zu der Frage, was hilft, welche Form der Betreuung ist effektiv? Wir wollen hier vier Fallvignetten vorstellen und anschließend einige Schlußfolgerungen kurz zusammenfassen.

\section{Marten, 11 Jahre}

Marten kann sich an kein auslösendes Ereignis erinnern, er meint, Stimmen zuhören, seitdem er auf der Welt sei. Er hört eine ganze Reihe von Stimmen aber die beiden vorherrschenden Stimmen sind männlich und ärgern ihn ständig, sie quälen ihn und geben ihm Befehle. Dadurch beeinflussen sie sein Verhalten und er bekommt Probleme zu Hause und in der Schule.

Aufgrund der Schulprobleme wird er an den kinderpsychiatrischen Dienst überwiesen, von dem er über ein Jahr lang behandelt wird. Er bekommt Medikamente. Als er dem Psychiater erklärt, daß er Angst vor den Stimmen hat, erklärt der ihm, daß er sich die Stimmen immer dann, wenn er ängstlich würde, einbilde. Marten und seine Eltern sind mit dieser Erklärung nicht zufrieden. Sie beenden die Behandlung und vertrauen auf die Behandlung des Großvaters von Marten, einem Homöopathen.

Der Großvater sagt Marten, er solle die Stimmen weg schicken und Marten lernt, sich den Stimmen gegenüber bei Bedarf zu verschließen. Wenn er das nicht schafft, kann er seinen Großvater rufen, der ihn dabei unterstützt. Der Großvater verschreibt Marten darüber hinaus die Abwehrkräfte stärkende homöopathische Medikamente, die ihm ein größeres Gefühl der 
Sicherheit vermitteln. Im zweiten Jahr der Untersuchung besucht Marten einen Kurs für Selbstsicherheit, durch den er lernt, seine Aggressivität zu kontrollieren. Außerdem lernt er, über seine Gefühle zu reden. Im 3. Jahr der Untersuchung verschwinden die Stimmen.

\section{Karen, 9 Jahre}

Karens Stimmen fingen in derselben Woche an, als ein Freund ihres einzigen Bruders im Bett tot aufgefunden wurde. Da erst keine Todesursache gefunden werden konnte, wurde das Kind nicht begraben. In derselben Zeit entstanden starke familiäre Spannungen, da der Vater seine Arbeit verloren hatte und die Mutter massive Herzprobleme entwickelte. Karen konnte die Krankheit ihrer Mutter nicht akzeptieren. Mit dem Stimmen tauchten auch optische Halluzinationen auf, sie sah Skelette, die ihren Kopf unter dem Arm trugen. Vor lauter Angst traute sie sich nicht, ins Bett zu gehen.

Der Vater entwickelte ein Ritual, indem er jeden Abend vor ihr in ihr Schlafzimmer ging, um zu überprüfen, ob Stimmen da sind. Wenn er keine fand, sagte er Karen, daß sie sicher ins Bett gehen könne.

In der Schule kam es wegen der Stimmen zu anderen Problemen. Karen konnte sich nicht auf den Unterricht konzentrieren und fing manchmal an, laut mit den Stimmen zu reden. Karen suchte einen niedergelassenen Psychiater auf, der ihr Medikamente gegen die Angst verschrieb und ihr den Zusammenhang zwischen dem Tod des Freundes und den Stimmen erklärte. Als Karens Vater wieder Arbeit fand, fühlte sich die Familie wieder sicherer. Karens Stimmen verschwanden im vierten Jahr der Untersuchung.

\section{July, 18 Jahre}

July fing im Alter von 6 Jahren an, freundliche, positive Stimmen zu hören. In der Zeit starb ihre Großmutter aber July kann darin keinen Zusammenhang zu ihren Stimmen erkennen. Als sie 12 Jahre alt ist, werden die Stimmen unangenehm. Nichts ist passiert. Sie hört mehrere Stimmen und sieht getötete Tiere und als sie in ein Kaffee geht, öffnet sich der Boden. Sie fühlt sich so, als ob sie in einer anderen Welt sei. Als sie 16 Jahre alt ist, beginnt sie, sich selbst zu verletzen. Zum Zeitpunkt der ersten Untersuchung wartet sie auf einen Therapieplatz in einer psychiatrischen Klinik. Ihr Dissoziationsscore ist extrem hoch.

Zum Zeitpunkt des 2. Interviews befindet sich July in einer psychiatrischen Klinik. Während des Interviews testet mich July mehrfach, ob ich ihr ehrlich antworte, bevor sie mir mitteilt, daß sie als 12-Jährige von ihrem 19 Jahre alten Freund sexuell mißbraucht worden sei. Er gab ihr Drogen und brachte sie dazu, mit mehreren seiner Freunde zu schlafen. Damals schuf sie sich ihre eigene Welt. July wird von einem Psychiater, den sie nicht mag, und von einer Psychologin, die sie mag, behandelt. Keinem von beiden erzählt sie von dem sexuellen Mißbrauch, da sie meint, selber Schuld daran zu sein. Sie spricht auch mit niemandem in ihrer Familie darüber.

Während des 3. Interviews lebt sie zu Hause, da das psychiatrische Krankenhaus geschlossen wurde und sie vor die Wahl gestellt wurde, entweder auf eine geschlossenen Station in einer anderen Klinik oder nach Hause zu gehen. Sie hat sich für die zweite Lösung entschieden, obwohl die Mutter nicht glücklich darüber ist, da es in letzter Zeit zu vielen Aggressionen und starken Selbstverletzungen gekommen ist. Unter der Bedingung, daß sie ihre Medikamente einnimmt, durfte July nach Hause kommen. Die Eltern haben ihr ein Pferd zur Pflege übergeben, damit sie ihren Tag strukturiert. Sie arbeitet freiwillig als Stallhilfe in einem Pferdestall, deren Besitzerin July sehr wohlwollend begegnet. Julys Mutter muß sie täglich zum Stall bringen, da sie außerhalb des Hauses alleine zu viele Ängste entwickelt.

Zum Zeitpunkt des vierten Interviews arbeitet July mehrere Stunden pro Tag in dem Stall, reitet mehrere Pferde und ist mit dieser Arbeit sehr zufrieden.. Gelegentlich sieht sie wegen ihrer Medikamente einen Psychiater, zu dem sie sonst keine Beziehung hat. Alle 14 Tage sieht sie eine psychiatrische Pflegekraft, mit der sie über ihre Gefühle spricht. Mit 
diesem Arrangement ist sie zufrieden. Sie hat einen Freund. Ihre Stimmen sind verschwunden aber sie hat immer noch die andere Welt, in die sie entkommen kann. Sie fühlt sich durch die Medikation beeinträchtigt und ist weiterhin nicht imstande, sich mit dem Trauma auseinanderzusetzen. Sie erlaubt mir nicht, mit ihren Eltern darüber zu reden. Sie hat bisher kein Lebensziele entwickelt und sie weiß nicht, was sie sich von der Zukunft wünschen soll.

\section{Eric, 16 Jahre}

Eric fing ohne besonderen Anlaß sehr früh an, Stimmen zu hören. Mit 15 Jahren wurde er wegen der Musik und wegen der Kleidung Mitglied in einem Satanskult. Er begann „grenzenlos“ zu denken und ein halbes Jahr vor dem ersten Interview machte er einen Suicidversuch in betrunkenem Zustand. Er wurde in ein psychiatrisches Krankenhaus eingewiesen und die Stimmen wurden bösartig.

Einige Monate später entschied der Vater, daß Eric nicht richtig behandelt werde, er ginge ein, wie eine Blume ohne Wasser, und nahm Kontakt zu unserem Forschungsprogramm auf, obwohl das keine Therapie anbietet. Das Einverständnis von Eric vorausgesetzt, erklärten wir uns bereit, Eric in unser Projekt aufzunehmen, und die Auswertung seiner Interviews an das behandelnde Krankenhaus zu senden. Ich interviewte Eric in der Gegenwart seiner Eltern. Angeregt durch die Fragen, konnte er eine Hierarchie seiner Stimmen erstellen. Es gab einen Anführer, der versuchte, Eric zu beschützen. Er war ein freundlicher Lehrer, Eric nannte die Stimme eine paranormale Stimme. Allerdings war diese Stimme nicht imstande, die bösen Stimmen zu kontrollieren. Der Vater war von Erics Schilderungen sehr beeindruckt und bestand darauf, daß die Auswertung des Interviews für die weitere Therapie nutzbar gemacht würde.

Beim zweiten Interview hatte Eric das Krankenhaus verlassen. Die bösen Stimmen waren verschwunden und der Therapeut sagte, daß er die paranormale Stimme nicht behandeln kann. Eric nimmt keine Medikamente mehr und hat mit Hilfe seiner Mutter Kontakt zu einem Para-Psychologen (paranor-malen Heiler) aufgenommen, der ihn lehrt, sich zu verschließen und die paranormale Stimme zum Schutz gegen die bösen Stimmen einzusetzen. Dieser Mann organisiert auch wöchentliche Gruppentreffen zur Diskussion der Schriften eines Philosophen namens Bruno, die von guten und von bösen Mächten in der Welt handeln.

Zum Zeitpunkt des vierten Interviews hört Eric keine Stimmen mehr, er fühlt aber den Schutz von Bruno. Er hat eine Berufsausbildung zum psychiatrischen Pfleger angefangen

\section{Akzeptanz, Kontrolle, und Behutsamkeit}

Wenn wir die Berichte der von uns befragten Kinder überprüfen, können wir folgende Erkenntnisse daraus gewinnen (Escher, in press) . Hilfe wird dann effektiv, wenn

1. eine vertrauensvolle Beziehung erstellt werden kann, in der

- die Stimmen akzeptiert werden

- ehrliche Reaktionen und Antworten gegeben werden

- Interesse an den Erfahrungen gezeigt wird, ohne daß Bewertungen genutzt werden

- Grenzen respektiert werden

2. eine zielorientierte Behandlung angeboten wird, d.h.

- mehr Kontrolle über die Stimmen anstreben

- Beziehung zu den Stimmen auf der Ebene des Problems und der Ebene der Gefühle aufnehmen

- Unterstützung bei der Ausweitung des sozialen Netzwerks anbieten

3. sie je früher, desto vorsichtiger Angeboten wird, d.h. 
- das Umfeld einbezogen

- $\quad$ Ort und Art der Interventionen möglichst wenig stigmatisieren

- Die Diagnostik behutsam und problemzentriert erfolgt

\section{Literatur}

Achenbach, T.M. (1991). Manual for the Child Behavior Checklist (CBCL)/4-18 and 1991 profiles. University of Vermont, Department of Psychiatry.

Altman, H. Collins, M., Mundy,P. (1997). Subclinical hallucinations and delusions in nonpsychotic adolescents. Journal of Child Psychology and Psychiatry 38,(4),413-420.

Bernstein, E.M. \& Putman, F.W. (1986) Development, reliability and validity of a dissociation scale (DES). Journal of nervous and Mental Disease, 727-735.

Bettes, B.A., Walker, E. (1987). Positive and negative symptoms in psychotic and other psychiatrically disturbed children. Journal of Child Psychology and psychiatry 28 (4), 555-568.

Chambers, W.J., Puig-Antich, J. Tabrizi, M.A., Davies, M. (1982). Psychotic symptoms in prepuberal depressive disorder. Archieves of General Psychiatry 39 (8), 921-927.

Del Beccaro, M.A., Burke, P.\& McCauley, E. (1988). Hallucinations in children: a follow-up study. Journal of the American Academy of Child and Adolescent Psychiatry, 27. 462-465.

Escher, A., Romme, M., Buiks, A., Delespaul, Ph., Van Os, J., (2002) Independent course of childhood auditory hallucinations: a sequential 3-year follow-up study. British Journal of Psychiatry . 181 (suppl. 43), s10-s18.

Escher, A., Romme, M., Buiks, A., Delespaul, Ph., Van Os, J., (2002).Formation of delusional ideation in adolescents hearing voices: a prospective study. American Journal of Medical Genetics. 114:913-920.

Escher,Sandra, Delespaul,Philippe, Romme,Marius, Buiks,Alex, Van Os. Jim (2003). Coping defence and depression in adolescents hearing voices. Journal of Mental Health. 12,1,91-99.

Escher, A., Morris, M., Buiks, A., Delespaul, Ph., Van Os, J., Romme, M.(2004) Determinants of outcome in the pathways through care for children hearing voices. International Journal of social Welfare (In press).

Famularo, R. Kinscherff, R. Fenton, T. (1992). Psychiatric diagnoses of maltreated children: preliminary findings. Journal of American Academic Child Adolescents Psychiatry 31, 863-867.

Fennig,S.,Susser,E.S.,Pilowsky,D.J., et al (1997). Childhood hallucinations preceding the first psychotic episode. Journal of Nervous and Mental Disease, 185. 115-117.

Garralda, M.E. (1984). Psychotic children with hallucinations. British Journal of Psychiatry, $145,74-77$.

Garralda, M.E.(1984). Hallucinations in children with conduct and emotional disorder: In: The clinical phenomena. Psychological Medicine, 14, 589-596.

Galdos, P., Van Os, J. ( 1995). Gender, psychopathology and development from puberty to early childhood, Schizofrenia RES 14 (2) 105-112.

Galdos, P.M., Van Os, J.J., Murray, R.M. (1993). Puberty and the onset of psychosis. Schizophrenia Res 10 (1), 7-14.

Green, W.H., Padron-Gayol, M. Hardesty, A.S., Bassiri, M. (1992). Schizophrenia with childhood onset, a phenomenological study of 38 cases. Journal of American Academic Child and Adolescent Psychiatry 31 (5), 968-976.

McGee, R., Williams, S., Poulton, R. ( 2000). Hallucinations in non-psychotic children (letter). Journal of American Academic Child and Adolescent Psychiatry 39 (1), 12-13.

Putman, F.W., Peterson, G. (1994). Further validation of the child dissociative checklist. Dissociation (7) 204220.

Romme, M.A.J., Escher, A.D.M.(2000) Making sense of voices. Mind publications, London.

Ryan, N.D., Puig-Antich,J., Ambrosini. H., Robbinson, D., Nelson, B., Lyengar, S., Twomey,J. (1987). The clinical picture of major depression in children and adolescents. Archives of General Psychiatry 44 (10), 854-861.

Schreier, H.A., (1998). Auditory hallucinations in nonpsychotic children with affective syndroms and migraines: report of 13 cases (see comments). Journal of Child Neurology 13 (8), 377382 


\section{Chapter 10}

\section{Trauma and hearing voices}

Romme, M.A.J., Escher, A.D.M.A.C. in print.

in

'Understanding Trauma and Psychosis': New Horizons for Theory and Therapy. Editors: Warren Larkin \& Tony Morrison Publisher: Brunner-Routledge, Hove. 


\section{Trauma and hearing voices}

M.A.J.Romme and A.D.M. Escher

It is a very good initiative of Dr. Morrison and Dr. Larkin to compose a book about the relationship between trauma and psychosis. We feel honoured to be invited to present a contribution.

Over the last twenty years there has been a growing body of research showing that many people with psychosis have suffered from traumatic experiences. Mueser (1998) reported that in a population of psychotic patients, nearly everybody (98\%) had experienced trauma, while in the case history, only seldom (2\%) was this acknowledged and reported. It does seem that trauma does not get enough attention as an aetiological factor in the development of psychotic illnesses. This is also the case with people hearing voices. In psychiatry this experience is called 'Auditory Hallucinations' and is interpreted as a psychotic experience.

In this chapter we will show from our own research and that of others, that hearing voices is not only apparent in psychotic patients, but it is also common in the general population, in people without formal psychiatric diagnosis. There are many people who can cope well with their voices and use them to their advantage. However, in both the patient and the non-patient group, voices are frequently related to traumatic experiences. It is not specifically the kind of trauma, but rather the consequences of the trauma that influence the outcome. We found that the non-patients could overcome them, while in the patient group, the trauma had detrimental consequences that were harder to manage. We found that this applied to children hearing voices as well as adults.

In this chapter we will describe:

1. The current tradition in the diagnosis and treatment of psychosis, highlighting some reasons why traumatic experiences are neglected.

2. Research that demonstrates the relationship between trauma and hearing voices.

3. Characteristics of the trauma history.

4. Possible pathways from trauma to psychosis.

5. Several theories which we have found to be helpful in the analysis and therapy of people hearing voices and/or experiencing psychosis.

6. Important elements in treatment.

\section{The Current Tradition.}

There are a number of reasons why, in clinical psychiatry, traumatic experiences are not seen as influential in the development of psychosis. One of these reasons is the reductionist way trauma is defined within the diagnostic system. The Diagnostic and Statistical Manual (DSM IV; A.P.A., 1994) defines trauma only in the context of posttraumatic stress disorder (PTSD). To qualify for this diagnosis one must have experienced an event defined by the following criteria:

"The person has been exposed to a traumatic event in which both of the following are present.

1. The person experienced, witnessed, or was confronted with an event or events that involved actual or threatened death, serious injury, or a threat to the physical integrity of self or others.

2. The person's response involved intense fear, helplessness or horror (p. 427-428)."

The greatest problem with this definition is that it requires a threat to the physical integrity of the individual. This exclusive focus on physical integrity is too narrow and might well have been the consequence of a political influence. If you look at this definition, it fits very well 
the experience of war, and that is also it's origin. The PTSD concept in the DSM is strongly influenced by the Veterans Administration, an association of war veterans in the USA. They wanted a clear diagnosis for their members and were not happy with the existing DSM psychosis categories. Contemporary research has indeed shown that so-called chronic PTSD has many diagnostic similarities to the diagnosis of schizophrenia. In chronic PTSD, negative symptoms are common, as are delusions and hallucinations (Hammer et al., 2000). The relationship between trauma arising from war and the existing psychosis categories in the DSM are politically very sensitive. It is very unpleasant, when as a result of traumatic war experiences, you come to suffer from something that is diagnosed as schizophrenia. Neither would it be politically attractive to identify schizophrenia as a traumatic reaction pattern. This would show the weaknesses in our society, but it could also harm the image of the profession as medical specialists, treating biological illnesses.

A second reason why the influence of trauma is neglected in the development of psychosis, is the way the DSM system works. A diagnosis in the DSM is based on the observable behaviour and mental experience of the person, in which all elements are seen as a consequence, or symptoms of an illness. There is no differentiation into primary or secondary reactions. However, when one studies a person's reactions to traumatic experiences, there is indeed a differentiation. For example, if a person reacts to an overwhelming trauma, by hearing voices, because of the inability to cope with this trauma, the voices might be seen as a primary reaction. When the signal function of the voices is not perceived, the voices might become the main problem. However the inability to cope with the voices might result in a number of secondary reactions; like concentration difficulties (because of the disturbing influence of the voices), delusions (as an attempt to explain this strange experience), inappropriate affect (laughing because the voices say something funny while they are involved in a serious discussion) and negative symptoms (they might isolate themselves or stay in bed to prevent to perform the aggressive acts the voices commands them to do). These secondary reactions can mimic a full picture of the schizophrenia spectrum (Coleman, 1999, Bock, 2000). As there is no differentiation in the DSM between primary and secondary reactions, all elements in behaviour and experience are seen as the direct consequence of the illness. In this way, the reaction pattern quality of such diagnosis is denied. As a consequence, the influence of trauma is often denied.

A third reason for neglecting the influence of trauma in the development of psychosis is that dissociative experiences are not measured in most diagnostic instruments. An example is the often used, Brief Psychiatric Rating Scale (BPRS; Overall, 1962; Lukoff, 1986) where these experiences are not taken into account. A second example we find in the DSM. Even though dissociative experiences are one of the most frequent reactions to trauma, they are not listed within the symptoms of psychotic diagnoses in the DSM. Research has shown that many schizophrenic patients also experience dissociative symptoms (Spitzer, 1997).

There is an other problem. Although there are quite a number of people $(42 \%)$ with dissociative disorders who hear voices (Ensink 1992), this phenomenon is not listed within the DSM category of dissociative disorders. Neither is dissociation listed within the symptoms of schizophrenia or other psychosis categories. These factors mystify the relationship between trauma, hearing voices and psychosis.

Researchers have been peculiarly faithful to the diagnostic categories within the DSM. This faithfulness we meet in research on trauma and psychosis, when they refer to the posttraumatic stress disorder category. They suggest that there could be a double disorder of schizophrenia and PTSD (Mueser, 1998, Morrison et al., 2003), instead of suggesting the possibility that trauma may lead to a reaction pattern that is called schizophrenia in the DSM. 
In studying the relationship between trauma and psychosis we should not become prisoners of the DSM diagnostic system, but openly evaluate the reaction pattern people show as a consequence of their experienced trauma. We should then also study all the experiences people report to us as consequences of their experienced trauma. Secondly, we should use a less narrow and more generally accepted definition of trauma, as we might find in encyclopaedia or dictionaries. For example, the Oxford English dictionary (Brown, 1993 p. 3377), where trauma is defined as:

"a psychic injury, caused by emotional shock, the memory of which may be either repressed and unresolved, or disturbingly persistent: a state or condition resulting from this".

\section{Research exploring the relationship between trauma and hearing voices.}

In psychiatry, a high percentage of voice hearers are placed within the diagnostic category of schizophrenia. It is, therefore, commonly identified with this diagnosis and not with trauma. Research that shows a relationship between trauma and schizophrenia could be seen as evidence of the relationship between trauma and psychosis. It is a first indication of the possible relationship with hearing voices. We will present a selection of such studies also focussing on populations of patients diagnosed with schizophrenia. Table 1 gives such a selection.

Table 1. Studies of trauma and psychosis

Author N. Population Frequency

\begin{tabular}{|c|c|c|c|c|}
\hline Mueser (1998) & 275 & \multicolumn{2}{|c|}{ Serious Mental Illness (+Schizo + Man.depr.) } & $98 \%$ \\
\hline Drayer (1999) & 135 & psych. hosp. patients & & $95 \%$ \\
\hline Jacobson $(1987$ & 100 & psych. hosp. & (29\% Psychotic) & $87 \%$ \\
\hline Goodman (1995) & 99 & Homeless women & (59\% Schizo.) & $97 \%)$ \\
\hline Muenzenmaier(1993) & 78 & Outpatients Women & (57\% Schizo.) & $74 \%$ \\
\hline Davies (1996) & 105 & Homeless women & (47\% Schizo.) & $77 \%$ \\
\hline Craine (1988) & 105 & Inpatients state hosp. & ( $41 \%$ Schizo.) & $51 \%$ \\
\hline Carmen (1984) & 122 & psychiatric hosp. & (18\% psychotic) & $53 \%$ \\
\hline Romme (1996) & 50 & voice hearers & ( $36 \%$ Schizo.) & $77 \%$ \\
\hline
\end{tabular}

In this table, there is a diminishing percentage of trauma in the chosen order. This is the result of the kind of trauma included in the research. The first 4 studies used the DSM definition, while 5 and 6 included only sexual abuse, while 7 and 8 looked only at sexual abuse in childhood. In our own research we looked for the frequency of trauma related to the onset of hearing voices. We did this in 3 different studies; two with adults and one with children hearing voices. In all three studies we found a relationship between the experienced trauma and the voice hearing. In the first study we did not use a psychiatric diagnostic instrument, in 
the second study we used the DSM diagnosis, assessed with the CIDI (Robison, 19..?). In the children's study we used the BPRS (Overall, 1962; Lukoff, 1986). We will first report the adult studies, and describe the study focussing on children separately.

The first study was an experiment, (Romme \& Escher, 1989, Romme et al., 1992) in which our aim was to get in touch with voice hearers who could cope with their voices. All the patients we knew in our community mental health centre were not able to cope with them. We looked for help from the media. In a popular TV talk show, one of my (MR) patients told how much she was hindered and overpowered by her voices and that she felt unable to resist their demands. As a psychiatrist, I explained on the talk show that psychiatry did not have much to offer, and therefore, we asked people who heard voices and could cope with them, to react by telephone after the broadcast. We also invited them to the first congress for voice hearers. About 750 people reacted and 540 said they heard voices. There were more reactions than we could handle. We than sent out a questionnaire, with 30 questions in 10 sections, about all kinds of aspects derived from the spontaneous information given by telephone. We sent out 450 questionnaires and received back 178 suitable for analysis. One of the sections in the questionnaire was about the personal history of hearing voices and we asked about what had happened to them when the voices started. From the answers it became clear that about $70 \%$ indicated a relationship between their voices and traumatic events they had experienced.

We also invited those individuals who clearly explained their experiences, to become speakers at the congress (Romme \& Escher, 1989). To our astonishment, a number of those voice hearers could cope well with their voices and functioned well socially, but could not be given a diagnosis and did not need any help with their voices. At that time (1987) we were more impressed by the fact that we met people hearing voices without involvement with psychiatric services, than the fact that $70 \%$ told us about a relationship with a traumatic event. Like most people working in mental healthcare, we were convinced that hearing voices (auditory hallucinations) were a sign of psychopathology and most probably a symptom of a psychiatric disorder. Meeting many people with whom this was not the case, motivated us to start reading more differentiated literature and this informed our next study.

\section{Second study}

In the second study (Romme, 1996, Pennings et al, 1996, Honig et al, 1998) we compared people hearing voices, whobecome psychiatric patients, and people who had not become psychiatric patients. We selected voice hearers from two diagnostic categories; one group diagnosed with schizophrenia and one group diagnosed with a dissociative disorder. The third group were the non-patient voice hearers we had met. We assessed them all with a psychiatric diagnostic instrument (CIDI).

In this second study we were interested in the differences and similarities in the characteristics of the voice hearing experience between patients and non-patients. Psychiatry has for a long time tried to differentiate real and pseudo-hallucinations. Real hallucinations were seen as a symptom of schizophrenia. They were characterised by: being experienced as 'not-me'; heard from outside their head ( by the ears); speaking to them in the $3^{\text {rd }}$ person, giving comments on their thoughts and behaviour and they would not be able to talk to their voices ( Schneider, 1959). From our second study, it became evident, that the nature of the experience did not significantly differ between the two patient groups as well as between the patients and the non-patients group. In the three groups all individuals experienced their voices as 'not-me'. In all three groups there were people hearing their voices as coming from outside themselves, as well as hearing voices inside their head. All three groups could have a dialogue with them; 
were spoken to in the second and in the third person, and heard commenting voices. The only difference was that in the patient group diagnosed with schizophrenia, voices speaking to them in the third person were more frequent

Table 2. Characteristics of voices in the groups.

Characteristics of voices*

$\begin{array}{lll}\text { Schizophrenia } & \text { dissociative } & \text { non-patients } \\ \mathrm{N}=18 & \mathrm{~N}=15 & \mathrm{~N}=15\end{array}$

By the ears

$13(72 \%)$

$9(60 \%)$

$7(50 \%)$

In the head

$9(50 \%)$

$11(73 \%)$

$10(67 \%)$

Voices are me

$2(11 \%)$

$1(7 \%)$

$3(20 \%)$

Voices are not me

$18(100 \%)$

$14(93 \%)$

$14(93 \%)$

Can talk with voices

$12(67 \%)$

$5(33 \%)$

$10(67 \%)$

Cannot talk with voices

$6(33 \%)$

$10(67 \%)$

$5(33 \%)$

Spoken to in 2nd pers.

$17(94 \%)$

$14(93 \%)$

$15(100 \%)$

Spoken to in 3rd.pers.

$7(39 \%)$

$3(23 \%)$

$4(27 \%)$

Commenting voices

$13(72 \%)$

$12(80 \%)$

$7(47 \%)$

* the characteristics can be different for each voice.

An important difference between the patients and the non-patients concerned the attributions and the influence of the voices on the voice hearer. This is also accentuated by Chadwick and Birchwood (Chadwick \& Birchwood, 1994). All groups heard positive as well as negative voices. However, the patient groups experienced the voices as predominantly negative, while the overall experience of the non-patient group was predominantly positive. The most important difference was that nearly all the patients were afraid of their voices, while no one in the non-patient group were afraid of them. This possibly explains why cognitive therapy has a positive effect. It has an anxiety reducing result (Bentall, Haddock\& Slade, 1994). The anxiety might be one of the main reasons why people are hindered by the voices in daily life. From this study it shows that patient groups were more hindered by their voices.

\section{Personal history}

We interviewed all respondents with an interview developed from the questionnaire we used in the first study. One of the 10 sections of this interview is about the personal history. To explore the personal history we focus on the onset of voice hearing, starting with the question "how old were you when you first heard voices?". To stimulate them to focus on that time we would say: 'let us return to the time you first heard voices. Where did you live? What did you do? Did anything happened to you at that time?'. In this section we have added life events; a 
list of 25 stressful situations categorised into 4 categories: "stressful changes"; "confrontations with illness and death"; "troubles with love and sexuality"; "religion, spirituality, mystic or cosmic experiences". We first ask if this has happened to them independent of the voices in order to differentiate what is related to the voices and what is not related. We do this because everybody, also voice hearers have experienced stressful situations. We then ask if these experiences had anything to do with the onset or change in their voices.

The results showed that $70 \%$ of voice hearers related their voices to traumatic events $(77 \%$ in the schizophrenia patients: $100 \%$ in the dissociative disorder patients and $53 \%$ in the nonpatients). This last group showed more people hearing voices from childhood onwards, which might have influenced their memory about the events that triggered their voices (see table 3 ). As far as the history of lifetime abuse is concerned, some differentiations are reported in table 3.

Table 3

\begin{tabular}{lcccccc}
\hline & \multicolumn{2}{c}{ Schizophr. } & \multicolumn{2}{c}{ Dissociat. } & \multicolumn{2}{c}{ Non-Pat. } \\
& $\mathrm{N}$ & $\%$ & $\mathrm{~N}$ & $\%$ & $\mathrm{~N}$ & $\%$ \\
Emotional neglect & 12 & $67 \%$ & 13 & $87 \%$ & 10 & $67 \%$ \\
Physical abuse & 11 & $61 \%$ & 10 & $67 \%$ & 7 & $47 \%$ \\
Sexual abuse & 3 & $17 \%$ & 8 & $57 \%$ & 5 & $33 \%$ \\
No abuse & 3 & $17 \%$ & 2 & $14 \%$ & 4 & $27 \%$
\end{tabular}

It looks like there are some discrepancies between the information about the frequency of trauma at the onset of the voices and the information about the experienced neglect or abuse. We have to keep in mind that abuse and neglect were not always the trigger at onset, and that other trauma may have triggered the voices. We also have to acknowledge that there are other kinds of trauma that might be of importance in the relationship with the voice hearing experience.

\section{The history of trauma}

In our studies patients as well as non-patients experienced trauma in relation to the onset of the voices. Similarities between the patients and the non-patients are the traumatic events that evoked the onset of the voices. They are perceived as threatening because the event is:

1. Physically threatening to themselves, as in severe illness with the threat of dying.

2. Socially threatening because it threatens the continuity of ones' expectations of the future; in case of losing ones' job, a divorce or the death of a loved one.

3. Emotionally threatening, because of an overwhelming emotional confrontation, like that of the death of a father by whom the person was abused, or the confrontation of a confused sexual identity in case of sexual abuse.

However, there are differences as well. The differences between patients and the non-patients are as follows:

1. The difference in the consequences the traumatic event has on ones' life for instance, one can be cured from a life threatening illness, but can also remain seriously handicapped. 
2. The difference in the number of traumata. We explored this with children and saw that the cumulative trauma score was higher in patients, than in non-patients. This was also highlighted by Ensink (1992) in her research about the consequences of sexual abuse in childhood.

3. The differences in defensibility and identity formation build-up during upbringing, before the voice-triggering trauma happened. In the second study this difference between patients and non-patients seemed to be important in overcoming trauma. One might say the difference in vulnerability originates from the life history. This is understandable from the research of Bowlby (1951) where he states that feeling unsafe and experiencing broken relationships in childhood are harmful for the capacity to cope with stress later in life.

4. There seem to be differences in coping, with traumatic events, between patients and non-patients. We saw that non-patients do not deny the traumatic events and have been able to resolve them, or have changed their lives in such a way that the consequences did not harm them any longer. Patient voice hearers more often deny the events or the problems resulting from them. They often stick to a victim role, not being able to put the events in the past and take up their lives again. Neither are they supported with solving their problems, because the trauma is often denied by others. They are seen as a patient with an illness, instead of the victim of a trauma inflicted by others. The aggressor might even blackmail the voice hearer; threaten with punishment or put all the guilt with the victim. Like the priest who raped an 11 year old boy and accused the boy of seducing him.

In a recent fourth study we have started to explore the anthology in relation to the trauma history in patients who recovered from their psychotic experiences. We found a number of similarities:

1. Their traumatisation concerned a number of traumatic events or a long period.

2. There is a second generation problem. One example, is a woman who told us that her grandfather lost a leg in the second world war. He thereafter fully changed in his character and started to beat up members of the family like his son, who later became the father of the woman who told us the story. She was physically abused by her father over a longer period of time. She also told us that since she knew the history of her father and grandfather, she is better able to forgive his aggression towards her and her mother.

3. Unsafe social situation in youth in which the trauma was often inflicted by a very aggressive male (father, uncle, brother, priest, boyfriend). This was not compensated by a supportive party (mother, friend or family member). They were isolated and powerless with their problem.

4. Toxic factors. In the trauma history we saw a number of elements that complicated working through the trauma. One of these factors is the early age of the traumatic experience. Ensink (1992) finds in her study, that the age of 7 is a turning point in people's coping possibilities. Another factor is the threat and aggression connected with the trauma and the blackmail associated with the trauma.

5. In the children's study we found four factors that predicted the continuation of the voice hearing experience: A high score on depression and anxiety on the BPRS as well as a high score of dissociation on the DES and a high frequency of the voices. These factors seem to make it more difficult to cope with the experience as well as with the underlying traumatic events. 


\section{Pathways from trauma to psychosis.}

From the trauma history it becomes understandable that in certain conditions traumatic experiences may lead to a psychosis for which the person feels a need for care. We have met quite a number of people with different psychoses who told us about the same traumatic events that ultimately led to the onset of psychosis and we also had met people with similar psychotic reactions as a result of very different traumatic experiences. Therefore it is clear that there is no simple connection between cause and effect in the relationship between trauma and psychosis. From our comparison of voice hearers who became patients suffering from psychosis and those who heard voices but did not become patients, we had learned that the vulnerability to developing psychosis was related to the influences of the trauma on their defensibility (Romme 1996; Pennings et al. 1996). We saw that in patients this defensibility was much more harmed than in non patients. This depended on the kind of trauma and the support experienced. This is in line with the stress-unreality model for psychosis (Zubin \& Spring1977). Vulnerability does not have to be biological, but can also originate from traumatic experiences. Our comparative study made us curious to explore the different pathways that were taken by different individuals, who suffered from psychosis. We therefore invited a few people who had suffered psychotic episodes and also had suffered from serious trauma, to describe their pathway from trauma to psychosis. They had more or less completely recovered and were able to look back at their experiences and were willing to do so.

From these descriptions we would like to present six pathways and these are partly also described in literature. The basic principle with psychosis is the impossibility for the person to accept the reality of the trauma and the involved emotions. Individuals differ in the kind of solutions they attempt. The kind of solution influences the persons development. Denial (see pathway 5) does block the development more intensely than an active fantasy (delusion, see pathway 4 ).

1. The dissociative pathway. One of the dissociative pathways is to create a substitute. Another is the realisation of partial splits. For example, during the trauma of sexual abuse, the person is emotionally and psychically setting her/himself apart, and looks from a distance at what is going on. Alternatively, another person might take his/her place. This other person might become a voice that reminds the voice hearer what has happened. In this way, emotions are kept at bay or literally at a distance. This is often combined with an effort to deny what has happened. Mostly this dissociation is a survival strategy.

Psychosis develops when the dissociation fails and the memory becomes intrusive with anxiety provoking images. A psychosis, for example, might develop when there is a emotional reliving of the trauma following a reminder like the death of the perpetrator; the loss of protective life circumstances; anxiety provoking circumstances; conditions that lower the self-esteem; stress or emotions that diminish the defence function of dissociation. This process of dissociation is very well described by Judith L. Herman (1992). Many others have studied dissociation, but few describe the relationship with psychotic disintegration.

2. Turning the suffered powerlessness and aggression towards oneself. Although this pathway is described in psychodynamic and psychoanalytic literature, it can be experienced differently by patients. For example, an aggressive father who had great difficulty managing his firm, acted out his distress on his son, who had to work in the business from the age of six. The father beat his son often. Over the years the son became deaf, quite possibly from being beaten up. When he was 15 years old, the son hit back at his father. The father reacted extremely badly to this 
event, walked away and threatened to kill himself. This provoked the family to react in a way that made the son feel guilty for his fathers' state of mind. This did not change when the father returned a few hours later unharmed. From that moment on, the son told us that he did not feel any anger anymore. He was convinced that he, himself, was the source of the problem, and not the abusing father. His first mental health problems began when he left home and started living on his own. He was not used to making any kind of decisions and in this new situation he lacked sufficient emotional orientation. This situation led to psychotic episodes and delusions of guilt. He let voices make his decisions and had delusions centred around being worthless. One could say that he lacked a self-identity.

Physical abuse and intense verbal aggression over longer periods, we observed, can often result in an abolition of emotions of aggression. People don't feel those emotions anymore or mix them up with other emotions. When this is combined with a negative self-image and guilt feelings, psychosis develops when the defence is attacked by circumstances like in example 1. Aggression turns into negative hallucinations or delusions combined with anxiety- provoking intrusive images, and then guilt, which can result in suicidal ideation.

3. The abolition of all emotions or becoming like a robot. We observed this reaction a few times in individuals after being rejected in love; after suicide of a loved one, or confrontation of unresolved issues of sexual identity. Psychotic reactions can be postponed as long as there are compensatory possibilities in work or sport. Activities that take all the persons energy and promote the self-esteem. When the compensation fails, the lost lover might start speaking as a voice, or a compensatory delusion like a Christ delusion might develop. When the person is not able to interpret the experience as a signal of an existing emotional problem, coping with these experiences is more difficult. Secondary reactions can mimic a full picture of schizophrenia as described earlier.

4. A flight reaction from the existing problems into a fantasy solution. When reality is too difficult to accept people can try to prevent what is happening by doing their utmost best in all kind of activities. Because what is going to happen does not so much depend on their own decisions (like in case of divorce; a friend dying from cancer; a critical attitude of some one else etc), these activities are doomed to fail. When this occurs, or just before or after, the mind snaps and finds a mental way out in a delusional solution. This combined with exhaustion because of all the activities done for the prevention of what was feared, a Manic reaction pattern can be the result. An example is someone whose marital relationship was near divorce at the time her mother died. She also had difficulties at work because she worked at the same office as her husband. When it became clear that divorce could not be prevented, she heard the voice of her mother telling her that she should take an airplane to Iswahan, because she would find a new husband there. Another example is of a woman whose best friend had cancer and was near to death. This was problematic because she could not accept the loss of this friend, who had helped her so much in difficult situations. She spent all her energy trying to care for her, but at the same time also had her own job. In her mind she could not accept the death and was afraid of being swept back into difficult living conditions she had experienced once before. She became rather exhausted from all her activities. Then her mind snapped, and she developed a delusion in which the world all of a sudden turned backwards. And as a consequence, time also ran backward. So everybody became younger, and her friend was not ill anymore. These examples are both from psychotic episodes diagnosed as bi-polar psychosis 
in the manic phase. Exhaustion is part of the process that leads to the snapping of the mind into a psychotic experience that produces a magical solution for an unacceptable reality.

5. Trying to fulfil impossible expectations. This is also a pathway that might lead to manic-depressive episodes. There are examples in literature described by Thomas Bock (2000). In these examples he accentuated the influence of the context as a pressure on the persons behaviour. Thomas Bock describes a woman who annually developed a manic episode around her birthday. She was participating in a self-help group and together they analysed what happened in the time before she compensated. It became clear that in preparing her birthday party, she had to fulfil the expectations of her mother who would come to the party and would have all kinds of critical comments. Every year she tried to prove that she could organise her party so well that her mother would find no reason for comment. But each year, just before the party, she would snap into a manic episode. Together, in the self-help group, they came up with the idea that she would organise her party this year separately for friends, and for her parents. This appeared to help, because, and that year she did not have a manic episode.

6 Denial or transforming what has happened. The pathway of denial means that a person cannot accept what has happened We saw this with being rejected in a love relationship or being misused in a love relationship and also in case of a person struggling with an unacceptable sexual identity, like homosexuality. The denial of a sexual identity is very difficult because one is reminded often by the nature of ones'? biology and the constant meeting of people. Isolation is only partly a solution. Another solution is the projection in the outer world of a critical? voice talking about homosexuality. Creating conflict between you and the voice, also functions as prevention for acceptance. This reaction pattern will be easily seen as a condition of schizophrenia, because of the voices and the avoidance, delusions of being followed etc. The stress of accepting a different sexual identity or being rejected in love is seldom, thus will not commonly be a reason for a psychotic reaction but that depends on the vulnerability. We saw this in case of a family background in which a father, who was very critical on all activities of the children and belittled them and the mother was highly idealistic. Therefore it was hardly ever good enough. This resulted in constant efforts to satisfy the parents and in avoiding failure. With this kind of vulnerability for failure, being rejected in love or coming to term with homosexuallity takes on a different emotional value.

7 To surrender to a higher power. For this pathway a spiritual solution is sought to cope with an unsolvable contradiction. This might lead to a positive as well as a negative outcome. We observed this pathway in many healthy voice hearers. They see their voice as a higher power and use it as an advisor in making difficult choices. This has similarities perhaps, with how many people in the general population use their religious beliefs in prayer. However, they do not deny their problems or conflicts. It works out negatively, however, when at the same time the original conflict is denied or transformed. Then the voices are no longer experienced as a helping power, but as threatening. Consequently the behavioural problems might expand because of the secondary reactions as described in the first paragraph and also referred to in example 3.

These great differences in the pathways people might take; indicate that a personal approach is necessary to understand the psychotic experiences in relation to the trauma and context. Every time one has to explore the reaction a person develops, in relation to 
his/her psychosis, in coping with their life experiences. This is often a time consuming procedure, because the person themselves have immersed themselves in their coping strategies. Denial and deformation of their reality takes place in the context of aggression, blackmail, induced guilt and broken down self-esteem. These elements hinder coping and working through the problems.

Psychological theories needed in understanding the process.

Most research in psychology leads to, or is derived from theories, that only explain a small part of the process in the development of psychosis. We will highlight some important theories to clarify this issue. Knowledge needed:

1. Psychoanalytic theory developed the idea of a defence mechanism. We learned from this, that an emotion is replaced by what we call a symptom. This means that the symptom has to be translated back into the involved emotion(s).

2. Psycho-trauma theory. When a trauma is not emotionally worked through, all kinds of symptoms show up also on the level of psychotic symptoms. The first research we know of is the Lindeman study (1946). Lindeman conducted a followup about grief within the family or partners who lost somebody in the fire in a discotheque in New York. He shows the development of a paranoid psychosis that resulted for one of the victims when they could not grieve. Worth reading is also Ensink (1992) who wrote about the psychiatric symptoms women developed after being sexually abused in childhood. In this book John Read highlights this process. Furthermore Judith L. Herman (1992) wrote a very detailed account of the process of trauma and their consequences, as well as how to treat these problems.

3. Attachment theory. From the research of Bowlby $(1951,1952)$ and others, it becomes clear that feeling unsafe and experiencing broken relationships in childhood are also harmful for the capacity to cope with stress later in life (psychological vulnerability).

4. Cognitive behavioural theory. Cognitive behavioural theory is concerned with how individuals acquire and apply knowledge about the world (cognition = knowledge). Psychologists world-wide, but mainly in England have done much research into psychotic phenomenon. They have developed interventions that teach patients to cope with those phenomena, and specifically to get more control over them. (Haddock et all., 1996).

5. Epidemiology. Contemporary research (Tien, 1991, Eaton, 1991, Romme, 1996, Bijl, 1998, Van Os et al, 2001) shows that in the general population it is common for people to experience auditory hallucinations and delusions without involvement with psychiatric servies. The studies referred to, used a psychiatric diagnostic instrument. The consequence of these studies is that these phenomenons cannot be interpreted as psychopathology or a symptom of a psychotic illness. This indicates that we might have to change our ideas profoundly. Mental health professionals tend to interpret these experiences as indicators of potential latent problems. By doing this they deny the implications of these epidemiological studies and base their ideas on research on a relatively small group of persons A step forwards would be the emancipation of these experiences like in the fifties and sixties of the last century with homosexuality. This would free the individual and help would be oriented toward accepting and coping instead of treating an 'illness'.

6. Context analysis. There is now a small but growing body of knowledge relating psychosis and the context in which they develop. Examples are books of Thomas Bock (2000); Bracken \& Thomas (2004), Michael White, (1996), Watkins, (1998); Romme \& Escher, (1993, 1996, 2000). These texts and studies suggest a mostly 
differentiated but sometimes simple relationship between the so-called psychotic phenomenon and the context of people's lives who experience them.

7. Spirituality. Theories in this area concern themselves with the latest step in evolution, when out of life arose consciousness. They recognise the differences between matter, life and mind. Many individuals with spiritual experiences, and also those with psychotic experiences, relate them to a higher level of consciousness and to relationships between living humans and the deceased. In order to understand those ways of thinking and the experiences associated with it, some knowledge and openness to these concepts are necessary. A kind of bible in this field is Ken Wilber's (1995) book 'sex, ecology, spirituality'. There are less complex readings, and one way for therapists to inform themselves is to ask patients who share spiritual believes to bring with them some texts that particularly inspire them. Another way would be to befriend themselves with non-patients, who use spiritual explanations to cope with their voices.

8. Normalising. In the area of hearing voices, Kingdon and Turkington (1994) have studied those situations in life that trigger the onset of hearing voices. Situations like isolation, long-term threats, life threatening stress, torture etc. It is part of the context analysis to see if the conditions a patient actually lives in, or has lived in, might have characteristics of those situations that might give rise to hearing voices.

9. User literature. There is a growing body of knowledge from people who have experienced psychosis as well as the traditional treatment for it. They give very worthwhile insights in the way they have developed their psychosis and also give advice about interventions that are helpful. They generally accentuate the importance of the relationship in treatment, the support, the respect, the search together for coping strategies and solutions of problems, and the importance of safety in daily life etc. They also describe how they support each other. Worthwhile reading is Coleman's book, 'Recovery, an alien concept", Judy Chamberline's "On our own", Read and Reynolds', "Speaking our Mind" and furthermore; articles by Wilma Bouvink (2001), Pat Deegan (1994), Peter Cambell (1989) and Bock et al. (2002). Research accounts worth reading are from Topor (2001) and Tooth (1997).

\section{Important elements in treatment}

From these important fields of knowledge, there are also interventions for treatment that have been developed. From our experience with voice hearers, we learned that interventions should follow a certain system or order. When, for example, a person who feels very unsafe because of her voices is not able to cope with them: In that phase, that person is not open for working through the experienced trauma. The person then needs to have more control over their voices first. The interventions used to get more control however, are again secondary to a relationship of trust and acceptance. Therefore we propose the following order in the therapeutic process:

1. One of the first steps is to accept the reality of the experience for the voice hearer. This means not going into a debate about the existence of hearing voices and surely not about the explanation of the voice hearer could you exlain alittle further?. Personal explanations might offer support and understanding for the voice hearer.

2. Secondly, it is important to build up a relationship in which the person feels safe. This means being accepted, respected and the feeling of genuine interest from the therapist in the experience of the person as an expert on their voices. The therapist should also show his/her experience or he/she should acknowledge that he does not know much about the voice hearing experience. A genuine interest can be 
expressed with a systematic interview, like the Maastricht Interview with voice hearers (Escher et. al. 2000).

3. Exchanging well organised information, in order to exclude misunderstandings. This can be reached by making a report from the interview and discussing this report with the voice hearer.

4. Inform oneself about general issues in the person's daily life concerning safety in the actual context of his/her life, and realistically help and support the person in making social conditions better see also Kingdon \& Turkington (1994). This should have priority above starting technical interventions aimed at reducing preoccupation with the voices.

5. Discuss coping strategies that the voice hearer has used and those others have used in order to get more control over the voices. Better control enables the person to spend his or her time better, and get more social control over his or her own life. Then start training sessions and accentuate the use of these strategies in a systematic way.

6. Support the voice hearer with the influences of the voices that are hindering them in daily life. This concerns family relationships, social interactions and triggers that provoke the voices. This is part of the exploration of existing problems (see Alanen 1997). It also might concern sleeping, medication, or encouraging the person to talk about the voices.

7. More specific cognitive interventions aimed at helping the individual to cope with the voices. For example, "focussing", a method developed by Haddock and Bentall(1996), coping enhancement (Tarrier et al.,1996), or influencing the beliefe system (Chadwick and Birchwood, 1996). For this part of the process, there is extensive literature (Litt at choice of editors).

8. Working through the traumatic experiences with their emotional and social consequences; such as guilt and aggression problems, or shame and lack of support. In more classical ways this is described by Gail Hornstein (2000) in her biography on Frieda Fromm-Reichmann and more recently in a less theoretical way by Judith.L. Hermann (1992) in her book 'Trauma and recovery'. Might be worth mentioning Paul Gilbert's work on Shame?

9. Social rehabilitation and recovery oriented interventions in order to compensate for the serious problems and realise dreams and capacities. This is about taking up ones' own life again and trying out choices, fulfilling roles in a wider society in concordance with ambitions, and overcoming discrimination by self and others. Literature on this subject is quite extensive, but is based on very different ideas about mental health difficulties. Worth reading are: Liz Sayce (2000); Alanen 1997) Coleman (1999) Bouvink (2002) Deagen (1994)

\section{Children, hearing voices and trauma}

Our interest in children hearing voices was stimulated by our studies on adults, where we found that about $10 \%$ started to hear voices in childhood. In our studies on adults we also found in $70 \%$ of cases, a relationship between trauma and the onset of hallucinations. This made us wonder about the course of experience in children.

We conducted a three year follow-up study for which 80 children were recruited between 8 and 18 years of age. Around half (53.8\%) were female. About 50\% of the children were in professional mental health care because of the voices. The other half were not receiving mental health care, which did not mend that the experience was unproblematic (Escher, 1998). 
For this follow-up study the children were interviewed four times, with about one year in between the interviews.

In this research five research instruments were used. The main instrument was the Maastricht Voices Interview for Children (MIC) a version of our in adult interview (Romme, 1996;

Romme \& Escher, 1996) which we adapted for children with the aid of a clinical child psychologist. The MIC explores many elements of the experience of hearing voices, but does not measure psychopathology. To measure general and specific psychopathology, the Extended Brief Psychiatric Rating Scale (BPRS; Overall \& Gorham, 1962; Lukoff et al., 1986) was used. As dissociation might be a reaction to trauma, we also used the Dissociative Experience Scale (DES; Bernstein \& Putman, 1986). With the Youth Self Report / 11-18 (YSR) we measured general problem behaviour expressed as the total score (Verhulst et al., 1996), and for the global level of functioning, the Children's Global Assessment Scale (CGAS; Shaffer et al., 1983) was used. For extended information about this research we refer to our articles Escher \& Romme (1989) Escher et al. (2002, 2003, 2004) and Escher (2004).

Nearly all the children were interviewed at home. The baseline interview was conducted in the presence of at least one parent or grandparent. During the interviews, care was taken to elicit and record the child's experiences, rather than those of their parents.

One of the sections of the MIC concerns a total score of life events that might be related to the onset of the voices. In a structured way, about 22 childhood events/trauma, that in the pilot study children related to the onset of voice hearing, were scored "present" or "absent" (e.g. death, illness, accidents, friends moving away, changing school, first menstruation, pregnancy, unanswered love, arguments, parental divorce, repeating a school year and other life events.). The last question being; if the child thought there was a relationship between the onset of the voices and the life-event mentioned.

One other topic in the MIC concerned the possible presents of childhood adversities. The child was also asked if the childhood was pleasant or unpleasant, if the child was not feeling safe or unsafe at home, if the child was feeling safe or unsafe on the street, whether the child was feeling safe or unsafe at school, if the child was being punished in strange ways, being beaten regularly, being scolded regularly, feeling unwanted, witness of physical abuse, witness of sexual abuse, molested or abused sexually (Escher et al., 2002, Escher, 2004).

\section{The course of voice hearing}

From our study it became clear that hearing voices in children is not a continuous phenomenon. Over the three-year period $60 \%$ of the children lost their voices. However, in $13 \%$ of children ( 4 ? ) whose voices disappeared on one occasion, the experience recurred at another time. Looking for factors that might influence the persistence of voice hearing, four predictors were found: a high level of anxiety, a high level of depression, a high frequency of the voices and a high level of dissociation (Escher et al. 2002, 2003, 2004). Professional health care was not related to the discontinuation of the voices (Escher et al. 2004).

Severity of voices assessed by the BPRS, as well as associated with anxiety and depression influenced both receipt of care and voice persistence, confirming the possible role of cognitive processes regulating appraisals and frequency of experience of voices and the ensuing affective response (Escher et al. 2002, 2003).

The favourable course associated with the child being able to identify triggers in time and place (for example, only hearing voices at school or when alone in ones bedroom at night) suggests that individuals, whose voices are not omnipresent, but instead limited to a 
circumscribed situation, are more likely to overcome the experience (Escher et al. 2002, 2003).

Higher scores on the DES were associated with increased likelihood of voice persistence (Escher et al. 2003). High levels of dissociation measured with the DES are associated with higher levels of psychosis proneness, and the current findings suggest that the DES may be identifying those individuals who are most liable to develop enduring psychotic symptoms (Allen, 1995; Spitzer, 1997; Pope, 2000). High scores on the DES in the context of psychosis may be associated with childhood adversity (Goff, 1991) and although reported childhood adversity did not predict voice persistence, it may be that part of the effect of the DES is mediated through its association with childhood adversity, individuals with high DES scores representing the group most prone to enduring experiences of voices given exposure to early adversity.

\section{Trauma}

Childhood adversity was found in a small group of children, while in the whole group high scores on life events relating to the onset of the voice hearing were found. Of the children $86.3 \%$ reported one or more trauma around the time of the onset of the voices. Most children experienced one trauma (48\%); two traumas were reported by $15.9 \%$ and three by $7.3 \%$. We distinguished six groups of trauma: confrontation with death; problems in and around home; problems in and around school; physical condition interfering with development; trauma's in relation to sexuality and a group of trauma that did not fit into the other groups. Children who experienced more trauma, more often looked for care.

Table 1; trauma reported in or around the onset of the voice hearing

\begin{tabular}{|c|c|c|c|}
\hline & Total & $N$ & $\%$ \\
\hline Confrontation with death & 18 & & $22.5 \%$ \\
\hline Problems at home & 19 & & $23.7 \%$ \\
\hline Serious tension with parents and or brothers/sisters & & 10 & \\
\hline Divorced parents & & 6 & \\
\hline Moving house & & 3 & \\
\hline Problems around the school situation & 19 & & $23.7 \%$ \\
\hline Capability problems & & 9 & \\
\hline Changing schools & & 7 & \\
\hline Being bullied & & 3 & \\
\hline
\end{tabular}


Physical condition interfering with development

Brain damage caused by traffic accident

A physical health problem with long term hospital admission

Birth trauma

In relation to sexuality

Sexual abuse *

Rejection in love

Abortion

Other kinds of trauma/problems

Seeing something weird

Anaesthesia

No trauma

* The small percentage of reported sexual abuse, might be related to the research context. Most children and adolescence came to participate in this research through their parents. The four girls who reported sexual abuse, were not abused by parents or siblings, but by people they knew, like the boy next door, classmates, a boyfriend and an uncle.

\section{Trauma and discontinuation of the voices}

In the last year (of the study?) we discussed with the child the trauma at the onset of the voices in relation to the emotions concerned. In the six distinguished groups we saw:

Confrontation with death. For eighteen of the children the onset of the voices was related to a period of grieving; for example, the death of a grandparent, the suicide of an uncle or the death of a friend or a classmate. When these deaths occurred parents often tried to protect the child from the ensuing emotions. An example is that of a four-year-old girl living next door to a grandmother who suddenly died. In the following days her mother, aunts and uncles were expressing their grief in the evenings at the house of the grandmother. As the girl was perceived to be too young to take part, she was put in bed instead. She started to hear voices. In the last year of the study, fifteen out of eighteen children reported that they had learned to cope with the emotion of grief and no longer heard voices.

Problems in the home: Nineteen of the children in the study related the voices to problems in the home situation, such as severe tension between the parents or problematic relations with their siblings ( 10 children). For example, for one boy in the study the voices disappeared when he got his own bedroom and no longer had to share it with his younger brother. Moving house was felt to be a threat by three of the children and brought on the voices; also divorce was related to the onset of voice hearing for six of the children. 
In the last year of the study, the situation at home and the relating emotions had changed for the better for sixteen of the children and the voices had disappeared. Three children whose voices were related to the divorce of their parents still heard voices

Problems at school: School could become problematic for many reasons: peer bullying, problems with teachers, learning capacity problems. In total nineteen children reported voices that related to these problems of this kind. In the last year of the study, four children, whose problems at school had not been solved, still heard voices. When care was provided, it was not oriented towards these problems.

Powerless-making circumstances that cannot be changed: There were ten children who related the onset of the voices to powerless-making circumstances, such as sexual abuse, birth trauma, long-term physical illness requiring hospitalisation and abortion. Four girls began to hear voices after they had been sexually abused, not by family members, but nevertheless by people they knew. Nowadays there is more literature about the relationship of sexual abuse and hearing voices (Ensink, 1994; Herman, 1992) This is a difficult problem and involves complex emotions. All four girls developed poorly. Three still hear voices and the one who does not, receives long-term medication, which unfortunately also influences her development negatively.

The two children with birth traumas had difficulty accepting their handicap and acted out with aggressiveness. Both were given neuroleptic medication. In one child the voices disappeared and in the other, an adolescent, the voices moved to the background when he accepted his handicap and subsequently acquired a part-time job as a carpenter in the firm of his father and brother.

Four of the children related the voices to physical illnesses and long stays in hospital. One boy stayed on a ward where other children had died. Another boy started to hear voices after he had been operated on and had been given anaesthetics. In the last year of the study, all four children in this group still heard voices.

\section{Relationship to problems}

Although one or more traumatic experiences might have happened around the time of the onset, for most children (and parents) a possible relationship between the onset and their voices was not clear. Interviewers did not push a relationship, but followed a list and asked the children if events had happened and then if the event had evoked or changed the voices. Most children $(62.6 \%)$ had never thought about a relationship with the voices (no one ever mentioned it) and did not connect the voices to a any traumatic experience, for $11.2 \%$ of the children it was clear that there was no relationship at all and $26.2 \%$ reported a possible relationship. It was striking that two girls who had been sexually abused said there was no relationship while the voice had all the characteristics of the abusers.

During the research period we noticed that parents and children started to talk about possible problems at the time the voices started, especially when the characteristics of the voices were indicative of the problems that lay at the root. For example, the boy who heard the voice of his teacher, who he found very abusive, but he never dared to tell his mother about it, or children that heard the voice of their grandparent who had died. Voices could be metaphorical in cases of capacity problems at school. In these cases we noticed that when the voices mixed up numbers, the child already had problems in following the educational level and the voices made it worse. When the children changed schools and the voices disappeared, parents and children then discussed the relationship between the voices and problems at school.

Some of the traumas were related to school or situations at home in which the child was not seen as a person with his/her own emotions and therefore not talked about openly like in 
divorce, grieving, school bullying or sexual abuse. It might also be that the onset of the voices was not seen related to the trauma, because what had happened was seen as a secret or shameful experience is and therefore not talked about and recognised as relating to the onset of voice hearing. Like in the following example.

Some children did not mention any kind of trauma in the first interview, but disclosed in the second or third. For example, a girl of 18 had a total DES score of 60 at the first interview, but reported no trauma. At the second interview, after being admitted to a psychiatric hospital and diagnosed as schizophrenic, this girl told interviewer about the sexual abuse she experienced when she was 12. At this point she had a boyfriend of 19. The boyfriend gave her drugs and let his friends sexually abuse her in this condition. She did not tell anyone and asked the interviewer not to tell her parents or therapist, as she felt ashamed and guilty about what had happened.

\section{Voices and development}

During the interviews, it became evident that quite a few children had experienced all kinds of changes. Their social network grew, they got more friends and life seemed to be broader than just the voices. As some children stated, 'there is more to life than my voices'. With other children, the initial problems often relating to the onset of the voices were not resolved and continued to influence their lives.

The changes we noticed seemed to concern the development of the children. It looked as if development had a positive influence on the discontinuation of the voices. We therefore became interested in development and the relationship between discontinuation, or continuation of voices. To assess the importance of child development on voice hearing, we developed our own instrument (Escher et al. 2004). To avoid stigmatising statements about development, we documented changes that had been discussed during the three-year follow-up. We did not originally hypothesise the issues that might arise, they emerged during the follow-up period.

Prior to analysing any data, and blind to possible relationships, we specified our criteria for undisturbed development, based on discussion within the research team regarding what was observable and measurable in the developmental process:

1. Acquiring more friends at the peer group level;

2. Knowing better what they wanted to become in life;

3. Learning to cope better with emotions;

4. Having fewer conflicts within the family and at school.

5. A positive report on development reported by the child concerned and/or by the parents.

For each child an assessment was made in terms of: a negative change; undisturbed development/ disturbed development or no change between base-line and last interview. When four out of five elements were positive, the positive development was marked.

In the analysis, we included only the 67 children who participated throughout the whole research period. Outcome factors were the discontinuation of the voices as well as the development of the child.

There was a significant association between discontinuation of the voices and positive development $\left(\chi_{(1)}^{2}=18.56, \mathrm{P}<.001\right)$. However, discontinuation of the voices does not always result in a positive development. From the 45 children with discontinuation, 38 (84\%) had a positive and seven had a negative development. 
Equally so, continuation of the voices does not always result in a negative development. Of the 22 children who continued to hear voices, a negative development was seen in $15(68 \%)$ (Escher et al. 2004).

Table 2. continuation or discontinuation of the voices, development and received care

\begin{tabular}{|c|c|c|c|c|c|}
\hline & & Continuation & of hearing voic & $\begin{array}{l}\text { Discontinuat } \\
\text { voices }\end{array}$ & of hearing \\
\hline & $\mathrm{N}$ & $\begin{array}{l}\text { Positive } \\
\text { development }\end{array}$ & $\begin{array}{l}\text { Negative } \\
\text { development }\end{array}$ & $\begin{array}{l}\text { Positive } \\
\text { development }\end{array}$ & $\begin{array}{l}\text { Negative } \\
\text { development }\end{array}$ \\
\hline Professional care & 38 & 3 & 10 & 19 & 6 \\
\hline No care & 29 & 4 & 5 & 19 & 1 \\
\hline Total & 67 & 7 & 15 & 38 & 7 \\
\hline
\end{tabular}

\section{Conclusions}

The traditional psychiatric system of categorising psychotic disorders does not take into account the factors that lead to the disorder. It only promotes attention toward the behaviour and experiences of the person and neglects the individual variation. It denies the interaction between the symptoms and interprets all the symptoms as a consequence of the disorder. It thereby neglects the relationship of the different symptoms with the life history. In this way it mystifies the causes and thereby does not take into account the experienced traumatic events. From our research it became clear that in about $70 \%$ of the people hearing voices with a diagnosis of schizophrenia, hearing voices was triggered by traumatic events and a psychological vulnerability was present from childhood adversity. From our research and from epidemiological studies (Tien 1991; Eaton 1991 Bijl at al 2001), we learned that in itself hearing voices is not a psychopathological phenomenon. However it leads to dysfunctioning and being diagnosed with an 'illness' when the person is not able to cope with their voices and the problems in life that lay at the roots of their voice hearing experience. In these cases we see a variation of secondary reactions that can mimic the full picture of a schizophrenia disorder but can also lead to other mental health disorders like dissociative disorders. The pathways to psychosis are showing a great variation.

The traumatic background of psychotic disorders means there is a great urgency to ensure that the treatment should not be based on a traditional psychiatric diagnosis but on a thorough analyses of the life history in relation to the different complaints (symptoms). The traumatic experiences at the onset of the voices are not indicators for the continuation of hearing them. In adults and in children we saw that voices might disappear when the trauma is worked through or the powerless situation has changed. However some conditions handicap this process. In our research we were able to identify a number of factors that influence the coping possibilities. This became most clear in the children's study. In this study $60 \%$ of the children lost their voices during the three-year research follow up period. The factors related to continuation were 1) high level of anxiety; 2) high level of depression; 3) high level of dissociation and 4) a high frequency of hearing them. These factors all indicate that the 
attributions associated with the voices are of more importance for the difficulties associated with them and the need for help because of them, than the experience of hearing voices itself. From the analysis of the effectiveness or ineffectiveness of treatment, it is to be concluded that giving attention to the development of the person who hears voices might well be of greater importance for recovery than a reduction in preoccupation with the phenomenon it self (Escher et al. 2004).

\section{References}

Alanen Yrjo. (1997) Schizophrenia. Its Origin and Need-Adapted Treatment. Karnac Books London.U.K.

Allan, J.G.,\& Goyne, L. (1995) Dissociation and vulnerability to psychotic experiences. The Dissociative Experience Scale and the MMP1-2. Journal of Nervous and Mental Disease, 183, 615-622.

Altmann, H. Collins, M., Mundy,P. (1997) Subclinical hallucinations and delusions in non psychotic adolescents. Journal of Child Psychology and Psychiatry 38,(4),413-420. A.P.A.: American Psychiatric Association (1994) Diagnostic and Statistical Manual of Mental Disorders, (4th ed.) Washington, DC.

Bernstein, E.M. \& Putman, F.W. (1986) Development, reliability and validity of a dissociation scale (DES). Journal of nervous and Mental Disease, 727-735.

Bock, Th. (2000) Lichtjahre, Psychose ohne Psychiatrie (Psychosis without Psychiatry) Psychiatrie Verlag, Bonn, Germany

Bock, Th.; Dorner,K1.; Heim S.; Kotulla,J.; Schafer, C.; Schmitt,E.; Stolz,P.; (2002) It is normal to be different; University of Hamburg dep. of psychiatry

Boevink W. (2002) Monsters from the past in Peter Lehmann; Coming of Psychiatric Drugs. Shrewsburry, Shropshire, U.K.

Bolwby, J. (1951) Maternal Care and Mental Health; W.H.O.Monogr.Ser.,Geneve

Bowlby.J.; Robertson, J.; Rosenbluth, A.; (1952) A Two-Year-Old goes to Hospital, The Psycho analytic Study of the Child No 7 London.

Bracken,P. and Thomas,P. (2004). Postpsychiatry: a new direction for mental health. British Medical Journal.322,724-727.

Bijl R.V.; Ravelli A.; van Zessen, G.,(1998) Prevalence of psychiatric disorder in the general population: results from the Netherlands mental health survey and incidence study. Social Psychiatry, Psychiatric Epidemiol. 33. 587596

Chadwick, P.; Birchwood M.; Cognitive Therapy For Voices, page 7186 in Haddock G. and Slade P. Behavioural Interventions with Psychotic Disorders. Routledge London. U.K in Haddock G. and Slade P. Behavioural Interventions with Psychotic Disorders. Routledge London. U.K

Campbell J.; Schraiber, R. (1989) The Well-Being project, Mental Health Clients Speak for Themselves. California Dep. Of Mental Health. ( www. Pie.org/mimhweb/

database/getarticle.asp?value $=1601)$

Carmen E.;Rieker P.P.; Mills T.; (1984) Victims of violence and psychiatric illness. American Journal of Psychiatry 141(3):378-383

Chamberlaine Judi (1978) On Our Own. Patient controlled alternativesd to the mental health system. McGraw-Hill paperback edition 1979 New York U.S.A.

Coleman Ron (1999). Recovery an alien concept; Handsell Publishing Gloucester.U.K. Craine, L.S.; Henson, C.E.; Colliver, J.A.; Mac Lean, D.G. (1988) Prevalence of a history of sexual abuse among female psychiatric patients in a State Hospital system. Hospital and Community Psychiatry 39 (3) 300-304. 
Davies-Netzley, S.; Hurlburt, M.S.; Hough, R. (1996) Childhood abuse as a precursor to homelessnessfor homeless women with severe mental illness. Violence and Victims, 11(2) 129-142.

Deegan P. (1996) Recovering Our Sense of Value After Being Labelled. Journal of Psychosocial Nursing 31 (4)

Drayer, N.; Langeland, M.A. (1999) Childhood trauma and perceived parental dysfunction in the etiology of dissociative symptoms in Psychiatric Inpatients. American Journal of Psychiatry 156(3) 379-385

Eaton,W.;Romanosky, A.; Anthony, J.C. et all(1991) Screening for psychosis in the general population with a self report interview. Journal of Nervous and Mental Disease 179, 689-693 Ensink Bernardine (1992). Confusing Realities A study on child sexual abuse and psychiatric symptoms. Free University Press. Amsterdam Holland.

Escher, A., Romme, M. (1998) Small talk: voice-hearing in Children. Open Mind July/August.

Escher, S. Hage, P. ,Romme, M. (2000) Interview with a Person, who Hears Voices in Romme M.; Escher, S. Making Sense of Voices. Mind, London.

Escher, A., Romme, M., Buiks, A., Delespaul, Ph., Van Os, J., (2002 a) Independent course of childhood auditory hallucinations: a sequential 3-year follow-up study. British Journal of Psychiatry . 181 (suppl. 43), s10-s18

Escher, A., Romme, M., Buiks, A., Delespaul, Ph., Van Os, J., (2002 b) Formation of delusional ideation in adolescents hearing voices: a prospective study. American Journal of Medical Genetics. 114:913-920

Escher, A, Delespaul, Ph, Romme, M., Buiks, A, Van Os. J. (2003) Coping defence and depression in adolescents hearing voices. Journal of Mental Health. 12,1,91-99

Escher, A., Morris, M., Buiks, A., Delespaul, Ph., Van Os, J., Romme, M. (2004)

Determinants of outcome in the pathways through care for children hearing voices.

International Journal of social Welfare.

Escher, A., An exploration of auditory hallucinations in children and adolescents (2004).

M.Phil. UCE. Birmingham.

Fowler D.; Garety Ph.; Kuipers E. (1995) Cognitive Behavior Therapy for Psychosis. John Wiley Chicester U.K.

Galdos, P.M., Van Os, J.J., Murray, R.M. (1993). Puberty and the onset of psychosis.

Schizophrenia Res 10 (1), 7-14.

Goodman L.A.; Dutton M.A.; Harris M.; (1995)Physical and sexual assault prevalence among episodically homeless, women with serious mental illness. American Journal of Orthopsychiatry, 65(4): 468-478.

Greenberg Joanne. (1964) I Never Promised You a Rose Garden. New American Library New York U.S.A.

Goff,D.C.,Brotman,A.W.,Kindlon,D. et al. (1991). Self-reports of childhood abuse in chronically psychotic patients. Psychiatry Research, 37. 73-80.

Haddock, G.; Bentall R.; Slade P. (1996). Treatment of Auditory Hallucinations in Haddock G. and Slade P. Behavioural Interventions with Psychotic Disorders. Routledge London. U.K p 45-71

Hamner M.B.; Frueh B.C.; Ulmer H.G.; Huber M.G.; Twomey T.J.; Tyson C.; Arana G.W. (2000) Psychotic features in Chronic Posttraumatic Stress Disorder and Schizophrenia. The Journal of Nervous and Mental Disease 188, (4) 217 - 221.

Herman Judith L. (1992) Trauma and Recovery. Pandorra, London, U.K.

Honig A.; Romme M.; Ensink B.; Escher S.; Pennings M.; de Vries M.; (1998). Auditory hallucinations, a comparison between Patients and Non-Patients. Journal of Nervous and Mental Disease 186(10) 646-651. 
Hornstein Gail. (2000) To Redeem One Person is to Redeem the World. The life of Frieda Fromm - Reichmann. The Free Press London ;New York.

Jacobson A.; Richardson B. (1987) Assault Experience of 100 Psychiatric Inpatients: evidence of need for routine inquiry. American Journal of Psychiatry 144(7) 908-913. Janssen I, Krabbendam L, Bak M, Hanssen M, Vollebergh W, de Graaf R, et al. Childhood abuse as a risk factor for psychotic experiences. Acta Psychiatr Scand 2004; 109:38-45. Kingdon, D.G. ; Turkington, D. (1994) Cognitive Behavioural Therapy of Schizophrenia. Guilford Press, New York/London.

Lindemann, E.;(1944). Symptomatology and management of acute grief. American Journal of Psychiatry 101

Lukoff, D. Neuchterlein, K.H., Ventura, J. (1986) Manual for expanded Brief Psychiatric Rating Scale. Schizophrenia Bulletin, 12, 594-602.

May, Rufus. (2000) Routes to Recovery From Psychosis. The Roots of a Clinical Psychologist. Clinical Psychology Forum, 146, 6-10

May Rufus, (2002) Understanding Psychotic Experience and Working Towards Recovery. Paper read at "Beyond Belief" congres on Hearing Voices 10 April 2002 Senate House London.

Morrison, A.P., Frame. L., \& Larkin, W., (2003). Relation ships between trauma and psychosis: a review and integration. British Journal of Clinical Psychology. 42,331-353. Mueser K.T.; Goodman L.B.; Trumbetta S.L.; Rosenberg S.D.; Osher F.C.; Vidaver R.; Auciello P.; Foy D.W. (1998) Trauma and Posttraumatic Stress Disorder in Severe Mental Illness. Journal of Consulting and Clinical Psychology 66(3) 493-499.

Muenzenmaier K.; Meyer I.; Struening E.; Ferber J.; (1993) Chilhood abuse and neglect among women outpatients with chronic mental illness. Hospital and Community Psychiatry, 44(7) 666-670.

Os J. van; Mc.Kenna (2003) Does Schizophrenics exists? Maudsley discussion paper no 12. Os J. van; Hanssen M.; Bijl R.V.; Vollebergh W.; (2001). Prevalence of psychotic disorder and community level of psychotic symptoms. Archives of General Psychiatry 58 663-668 Overall, J.E., Gorham, D. (1962) The Brief Psychiatric Rating Scale. Psychological reports, 10, 799-812.

Pennings M.; Romme M.; Buiks A.;(1996) Auditieve hallucinaties bij patienten en nietpatienten. Tijdschrift voor Psychiatrie 38 (9) 648-660

Pope,C.A.\&Kwapil,T.R. (2000). Dissociative experiences in hypothetically psychosis-prone college students. Journal of nervous and Mental Disease, 188, 530-536.

Putman, F.W., Peterson, G. (1994) Further validation of the child dissociative checklist. Dissociation (7) 204-220.

Read J.;Reynolds J.; (1996) Speaking our Minds an Anthology. MacMillan Press.Ltd London Tien, A.Y. (1991) Distributions of hallucination in the population. Social Psychiatry and Psychiatric Epidemiology 26, 287-292

Romme M.; Escher S.;(1989) Hearing Voices. Schizophrenia Bulletin 15(2) 209-216.

Romme M.; Honig A.; Noordhoorn, O.; Escher A.; (1992). Coping with Voices, an emancipatory approach. British Journal of Psychiatry 161, 99-103

Romme M.; Escher S.; (1993). Accepting voices. Mind. London.

Romme, M.; Escher, S.; (1996). Empowering people who hear voices page 137-151 in Haddock and Slade Cognitive Behavioural Interventions with Psychotic Disorders Routledge, London.

Romme M. (1996). Understanding voices. Handsell Publications, Gloucester.

Romme M.; Escher S.; (2000) Making Sense of Voices. Mind. London.

Sayce Liz (2000) From psychiatric patient to Citizen Palgrave Hampshire. RG 21 6XS. U.K. Schneider, K. (1959) Clinical Psychopathology (5th edition) Grune and Stratton, New York. 
Shaffer, D., Gould, M.S., Brasic, J., Ambrosini, P., Fisher, P., Bird, H., Aluwahlie, S. (1983). A children's global assessment scale (CGAS). Archives of General Psychiatry 40 (11) 12281231.

Spitzer,C.,Haug,H.J.\& Freyberger,H.J. (1977). Dissociative symptoms in schizophrenic patients with positive and negative symptoms. Psychopathology, 30.67-75.

Tarrier et all (1996). Coping Enchancement in Haddock,G.\& Slade P. eds. Behavioral interventions with Psychotic Disorder. Routlkedge. London.

Topor Alain (2001) Managing the contradictions; Recovery from serious Mental Disorders Stockholm University Departmenty of Social Work

Tooth, B. et all (1997) Recovery from Schizophrenia; A Consumer Perspective. Final Report to Health and Humanm Sevices Research Australia. Unpublished.

Verhulst, F.C., Van der Ende,J. \& Koot,H.M.H. et al (1996) Handleiding voor de CBCL 4-18: Sopia Kinderziekenhuis/Academisch Ziekenhuis, Erasmus Universiteit.

Watkins John (1998) Hearing Voices A common human experience. Hill of Content

Publishing Melbourne, Australia

White, Michael (1996) Power to our Journeys. American Family Therapy Academy

Newsletter Summer Edition, 11-6

Wilber Ken (1995) Sex; Ecology; Spirituality, The spirit of evolution. Shambhala Boston \& London

Yusupoff, Y.; Tarrier, N.; (1996). Coping Strategy Enhancement For Persistent

Hallucinations and Delusions in Haddock and Slade Cognitive Behavioural Interventions with Psychotic Disorders Routledge, London. p 86-103

Zubin, J.; Spring,B. (1977)Vulnerability: a new view of Schizophrenia. Journal of Abnormal Psychology 86, 103-126 
Chapter 11

\section{Epilogue}




\section{Epilogue}

Three months ago I received an e-mail from a voice hearer in which she asked my advice. She wrote that during her psychology study she had become psychotic and because she kept on hearing voices, she was given the diagnosis of schizophrenia with the message: 'you have to take medication for the rest of your life and you will never get better". She describes: 'I had a very clear part in me that thought 'Do I have to stop my future, is my future drinking coffee all day?'. 'No' she decided, and she started to fight, finished her study and is now faced with the fact the society does not allow her a job because of the diagnosis of schizophrenia.

This e-mail does not stand on its own. In the 17 years that I worked with voice hearers I met many voice hearers with similar stories. The findings of the children's research are no different. Children who received traditional clinical care were not helped in preparing for their future in society. By traditional clinical care, I mean care that identifies hearing voices as a symptom of an illness, such as schizophrenia or borderline personality, treatment with medication, and forbidding the voice hearer to discuss the experience because it reinforces their delusions. This approach is only interested in those characteristics of voices necessary to categorise an illness. There is virtually no interest in the relationship between voices and the person's life history. The treatment strategy is limited to medication in order to suppress the experience, rather than accepting the voices and learning the voice hearer to cope with them. Traditional clinical psychiatry overlooks the fact that voices can occur in response to trauma or situations in which the individual is rendered powerless. This impairs personal development.

Our research on adults, like that on children, strongly suggests a relationship between past or recent traumatic events and the onset of the voice hearing ( $70 \%$ in adults, $85 \%$ in children ). In the children's research we found that children were most helped by therapy aimed at helping:

- the child to accept the experience,

- not alienating the child from it,

- supporting the child to feel less afraid for it,

- enabling it to learn to cope with the voices and with emotions relating to the voices and the life problems.

This is consistent with the finding that a high level of anxiety, depression, dissociation or a high frequency of the voices predict the persistence of voices. 
Traditional clinical psychiatric treatment sees the voices as the target of care. This approach overlooks the fundamental problems in the person's life. We found that these problems are difficult to talk about. Traumatic events, especially sexual abuse, are shameful and kept secret. Interventions that mystify the voices by interpreting them as illness reduce the voice hearers' resources, and impede recovery.

In the last 110 years several population surveys have shown that hearing voices is apparent in $2 \%$ to $4 \%$ of the normal adult population (Sidgewick et al., 1894, Tien, 1991, Eaton et al., 1991, Bijl et al., 1998) Tien (1991) found 2\%. The same percentage as Sidgewick et al. in 1894. Tien (1991) looked for need of mental health care and found that from the group of people hearing voices, only a third asked for help. Eaton (1991) found 4\% people with auditory hallucinations and from this group only $16 \%$ met the criteria for the diagnosis of schizophrenia. The results of these epidemiological studies show that it is wrong to identify voices with illness (chapter 3). The experience is apparent in the general population also in those with no need of mental health care. This challenges the idea that we should see the phenomenon as a sign of mental illness. In addition scientific research failed to yield evidence of a biological basis for schizophrenia (Bentall, 1991, Boyle, 1991, Thomas, 1997, Blom, 2003). This has made the interpretation of hearing voices a matter of debate. In a Social Psychiatric approach one can demonstrate that voices make sense in relation to the individual life history.

If one accepts that voice hearing is apparent in the normal population what might we learn from the way the non-patient voice hearers cope with their experiences? In our research we found differences between patients and non-patients in coping styles and appraisal of the voices (see chapter 2,3,6). However, the most important difference was that patients seemed to lose awareness of the problems or trauma they could not cope with, and than fully focuses on their voices they also cannot cope with. Non-patients, however, did not deny problems but accepted their voices as sources of help in solving their problems, or they saw their voices as indicative of problems to be dealt with. If the health care system colludes with and amplifies voice hearers' anxiety about their voices then problems of living become mental health problems; social problems become medical problems.

I have talked about the voice hearers' perspectives but what about the therapist's. In reflecting on my work with adults who hear voices and the children's research, I wondered why psychiatry, a profession that offers help to people who feel in need of care, is so dominated by 
false believes. Diagnosis and treatment protocols, limited time, whose interests do they serve? Certainly not those of voice hearers. It is the therapeutic relationship that matters most, the techniques are only a tool. In maximising service efficiency we have lost the target: the patient as a person.

Listening to voice hearers' stories makes me wonder how psychiatry came to such a negative view of voice hearing. Why is it not possible to instil hope? Why can't people be given hope ? A lot of people do recover or find a much more positive way to live with extraordinary experiences. Why can't people be helped to make the most of their own strengths? Why can't people be helped on their own terms, instead of being controlled and alienated from themselves through professional languages, scientific objectivity, diagnosis and statistics in support of evidence-based medicine? Hearing voices should be seen from a broader perspective, and in a way that invokes hope for the future. Why don't we reflect on the course of hearing voices throughout the history of mankind and look from there into the future, instead of locating its origins in the birth of psychiatry.

Hearing voices must be seen from a wider perspective, and not restricted to the clinical psychiatric frame of reference. We argue for a change of attitude; the epidemiological evidence, our own research and many report of recovered patients (Deegan, 1990; Coleman, 1996; Topor, 2001) support this. From all the interviews we have conducted over the last 17 years it became apparent that voice hearing is a very personal experience. We also became aware that the voices could often be seen as messengers, telling stories of trauma or problems people could not cope with. Voices hearer are not helped to develop their own strengths and to recover. As long as clinical approaches focus on the eradication of voices rather than understanding them in terms of the person's life story, voice hearers will be barred from recovery.

The results of epidemiological studies should be accepted by psychiatry. As a consequence, the knowledge and experience of non-patients should be integrated into psychiatric training and practice, and used therapeutically with voice hearers.

The traumatic background of psychotic disorders means there is a great urgency to ensure that the treatment should not be based on a traditional psychiatric diagnosis but on a thorough analyses of the life history in relation to the different complaints (symptoms). In adults and in 
children we saw that voices might disappear when the trauma is worked through or the powerless situation has changed.

There is an urgent need for an action research program in which a media offensive is combined with an intervention program. The media should advocate for the importance of accepting the voices as a non pathological phenomenon, to free people from the anxiety invoked by illness interpretations, which hampers personal development. The media offensive should coincide with the launch of three centres across Holland, in which people with psychotic experiences such as hearing voices are given mental health education. In these centres, voice hearers who have learned to cope with their experiences have an important role helping those who can't cope to accept their voices, reduce their anxiety, to regain control over the voices, in short to help them recover. These interventions should be evaluated and voice hearers encouraged to participate in a three year follow-up program, in comparison with a group of patients in traditional services. The outcome should be in terms of improvements in social functioning, not psychopathology.

\section{References}

Bentall, R.P. (ed) (1990) Reconstructing Schizophrenia (Routledge, London/New York).

Bijl, R.V., Ravelli, A., Van Zessen. G.,(1998) Prevalence of psychotic disorder in the general population: results from the Netherlands mental health survey and incidence study. Social Psychiatry Epidemiology, 33, 587-596

Boyle, M. (1990) Schizophrenia - A.Scientific Delusion? London/New York: Routledge

Blom, J.D. (2003) Deconstructing schizophrenia; an analysis of the epistemic and nonepistemic values that govern the biomedical schizophrenia concept. Boom, Amsterdam.

Coleman, R. (1996) Recovery - an alien concept. Gloucester: Handsell Publishing

Deegan. P (1990). Spirit breaking; when the helping professions hurt. The humanistic Psychologist, 18 (3), 301-313.

Eaton, W.W., Romanonski, A., Anthony, J.C. (1991) Screening for psychosis in the general population with a self-report interview. Journal of nervous and mental Disease 179, 689-693

Sidgewick, H., Johnson, A, Myers, FWH et al (1894) Report on the census of hallucinations. Proceedings of the Society for Psychical Research, 34, 25-394

Tien, A.Y. (1991) Distributions of hallucination in the population. Social Psychiatry and

Psychiatric Epidemiology 26, 287-292

Thomas, P. (1997) The Dialectics of Schizophrenia. London/ New York: Free Association Books

Topor, A. (2001) Managing contradictions. Recovery from Severe Mental Disorders, Akademitryck AB, Edsbruk, Sweden 
Chapter 12

Summary 


\section{Summary}

The study that is presented in this thesis is part of a scientific journey of discovery into the experience of hearing voices or as traditional psychiatry calls it 'auditory hallucinations'. The aim of this journey is to try to make sense of psychotic experience.

From 1987 onward several studies were conducted on adults hearing voices which were focussed on the experience of hearing voices, particularly comparing the experience of patients and non-patients (Romme \& Escher, 1989, 1993, 1996; Romme, 1996; Pennings \& Romme. 1996; Honig et al. 1998). These studies have led to the exploration of the experience of children who hear voices. This thesis is centred on a study of 80 children who participated in a 3 year follow-up study, aged between 8 and 19 years and all hearing voices with the characteristics of auditory hallucinations. About $50 \%$ of the children were in regular mental health care (in this research referred to as patients) because of the voices; the others were not in regular care (in this research referred to as non-patients).

The study had two aims. Firstly to explore the nature of the experience of voice hearing in children and adolescents, to determine whether hearing voices is as suggested by Green et al. (1973) a 'continuous phenomenon'. A logical consequence of this aim was to explore the differences between the children who continue to hear voices and those whose voices stopped. In order to explore the experience a semi-structured interview was used (see Appendix) with questions were asked about the characteristics of the voices, the content, the influence, the history of the onset of the voices and what methods of coping the children used. Psychopathology, dissociation, social functioning and problem behaviour were measured respectively by the Extended Brief Psychiatric Rating Scale (BPRS; Overall \& Gorham, 1962; Lukoff et al., 1986); the Youth Self Report / 11-18 (YSR) (Verhulst et al., 1996); the Children's Global Assessment Scale (CGAS; Shaffer et al., 1983) and the Dissociative Experience Scale (DES; Bernstein \& Putman, 1986).

The second aim was to investigate what factors might influence the need for mental health care and, if these factors were present, to identify whether there are differences between patients and non-patients. During the study attention was also given to explore those elements in mental health care that seemed to be experienced as helpful. The social-emotional development of the children was categorised and the children were divided in one of 3 categories: children with a positive development, or a negative development or children that 
did not show any development. These 3 categories were further related to the continuation or discontinuation of the voices.

\section{Background}

In the introduction to the thesis (Escher 2004) the background of our studies into hearing voices is explained. From the beginning the experiences of patients and non-patient voice hearers were compared. By studying patients and non-patients we found that by comparison the non-patients were not afraid of the voices, felt stronger than the voices; were able to cope with the voices; felt that the voices mostly did not disturb their daily life; and the non-patients experienced more social support from those around them. The hearing voices project did not restrict its focus to research but was extended to organising annual congresses at which voice hearers, therapists and family members would meet. The basis idea behind meeting each other was the social psychiatry perspective of influencing social factors. We aimed at breaking down the isolation of voice hearers, and creating the possibility of gaining more support. Each congress was attended by around 350 people, and provided a strong confrontation with the problem of social taboo that surrounds voice hearers in our society, raising the need for creating a more open attitude.

The first initiative for this study of children stems from 1993. Research findings from the adult studies identified that about $10 \%$ of voice hearers report the onset of this experience in their childhood, stimulating a curiosity about the course of voice hearing in children. Was hearing voices a continuous phenomenon or was it something that changed over time? In order to see whether a research study would be possible with children the same format as in the adult approach was used. Marius Romme and a young boy, who was hearing voices, asked in a popular t.v. talk show people to react and 150 people reacted. About half of them were in the age group that we looked for: between 8 and 19 years of age. We than conducted a pilot study and I organised a congress for children hearing voices in Amsterdam, followed by the quest for funding for a research proposal, and thereafter the search for the research population.

In 1993 still little was known about children who hear voices. There was neither an extensive overview of the content of the voices, nor an understanding of the possible relationship with the social context, nor any of the positive health care factors that are reported by the children themselves. 


\section{Hearing voices and its course through history}

Supported by literature about the attitude towards voice hearing through history, results of epidemiological studies and the findings in our own adult studies, the starting point of this study on children was that hearing voices is in itself not an illness, but one might become ill because of the way one copes with the voices and with problems in the life situation. In order to understand this line of reasoning I will first revisit the arguments about why this position was adopted.

In chapter 1 (Escher, 2004) a brief historical overview is given of the attitude of society toward hearing voices. This provides an outline how the current dominant psychiatric frame of reference developed over time. I am aware that my outline is a reduction of selected facts. This subject should be given more attention, however there are several well known scientists who have written whole books about this development like Slade and Bentall (1988), Thomas (1997), Watson (1998) and very recent Blom (2003).

In contemporary psychiatry hearing voices (auditory hallucinations) is mostly related to a severe illness such as schizophrenia. However contemporary epidemiological research (Sidgewick et al., 1894, Romme \& Escher, 1989; Tien, 1991, Eaton et al., 1991, Van Os et al. 2000) as well as human history does not support this view. The psychiatric idea is relative young. Throughout history there has been previously a much more positive attitude towards this experience. Hearing voices was reported from the earliest civilisations of Egypt, Rome, Babylon, Tibet and Greece. Voice hearers are found in the earliest writings such as the Bible, including Jesus, Moses and Maria, and also more recently Jeanne d'Arc, Swedenbourgh, Ghandi, Churchill, Jung and Freud. However through time opinions about hearing voices have changed and the psychiatric construct developed and became dominant, and it is this more restricted view of the experience as an illness that has become a handicap (Thomas, 1997).

Chapter 2 contains the article Romme \& Escher (1987) 'Hearing Voices' (Schizophrenia Bulletin, 15, (2), 209-216), describing the 1987 experiment of bringing voices hearers into contact with each other. In 1987 social psychiatrist Marius Romme and his patient Patsy Hage appeared in a popular television talk show to ask people who hear voices to get in touch with them and told that a congress for people hearing voices was going to be organised.

About 700 people reacted. This number of people is regarded as an extremely high response for the Netherlands (Langelaan, 1987). Of the 700 reactions 450 of them were voice hearers, 
300 of the respondents reported not being able to cope with their voices, the other 150 told they could handle their voices. The confrontation with a large number of non-patients was influential in the research line taken by the hearing voices project.

People who telephoned gave very diverse information. To obtain more homogeneous information a questionnaire was sent to the voice hearers. From those who returned the questionnaire 20 people were selected to give a talk about their experience at the first congress organised for voice hearers only. In preparing the talks of speakers for the congress, we encountered voice hearers that were not only functioning well in daily life but also had never looked for mental health care.

The data from the questionnaire were used to systemise the experience. Three possible phases of coping with the voices were distinguished:

- the 'startling phase', the usually sudden onset and primarily a frightening experience;

- the 'organisation phase', the process of selecting how to cope with the voices, communication about the meaning of the voices and the relation to the live history;

- the 'stabilization phase', the period in which a more continuous way of handling the voices is acquired and the voice hearer is concentrating on issues in daily live as well.

Furthermore in the data of the questionnaire a differentiation was made between people who could cope and people who could not cope with their voices. In this article the emphasis is on successful coping, frames of references and coping strategies.

One hypothesis that might be generated from this congress for voice hearers is that the reduction of 'hearing voices' to a view of being a pathological phenomenon is not very fruitful in helping patients to deal with these experiences.

Chapter 3 contains the article Romme, M.A.J., Honig, A., Noorthoorn, O., Escher, A.D.M.A.C. (1992). 'Coping with Hearing Voices; An Emancipatory Approach' (British Journal of Psychiatry, 161,99-103). In the Schizophrenia Bulletin article (chapter 2) the accent lies on describing the experiment of bringing voice hearers together and distinguishing three phases in coping with voices. This article reports in detail the information gathered from the questionnaire that was sent to the 450 people who had reacted to the television broadcast. Of these questionnaires 186 could be used for the research as they contained all the information. In them a small number (13) of voice hearers reported that they did not experience disruption of social contacts by the voices nor any other formal psychiatric symptoms. They experienced the voices as stimulant, as a friend or as a tutor. In this group seven felt themselves to be paranormally gifted and described themselves as 'clairaudient'. These subjects were excluded 
from further evaluation as one might question whether these experiences were true hallucinations. After this deduction we had 173 samples that could be used for our research. Most of these respondents heard the voices five years or more, with the onset peaking between 15 and 30 year of age.

We than divided the sample (173) into a coping and a non-coping group, according to their own statements in answer to the question 'are you able to cope with the voices or not?' Of the 173 respondents $66 \%$ reported that they could not cope with the voices. The non-copers felt significantly less in control of their voices and experienced the voices more negatively. The copers reported to be able to set more limits to the voices and to listen selectively. Copers were significantly less often in psychiatric care (24\%) than the non-copers (49\%).

Respondents in psychiatric care (patients) compared with the others (non-patients) perceived significantly less support from others. These data also indicate the importance of the communication between staff of the psychiatric wards and chronic psychiatric patients about their experience.

Thus far the articles concerned the research on adults hearing voices. The following articles report the main focus of this thesis, the study of children who hear voices.

Chapter 4 contains the article Escher, A., Romme, M., Buiks, A., Delespaul, Ph., Van Os, J., (2002). 'Independent course of childhood auditory hallucinations: a sequential 3-year followup study' (British Journal of Psychiatry, 181 (suppl. 43), s10-18.). Over a three-year period the cumulative rate of discontinuation of voice hearing in the 80 children was $60 \%$. However in $13 \%$ of children $(n=4)$ whose voices had disappeared on one occasion, the experience then recurred at later time. Looking for factors that might influence the persistence of voice hearing, four predictors were identified:

- a high level of anxiety;

- a high level of depression;

- a high frequency of the voices;

- a high level of dissociation.

The four predictors for the voice persistence only partially discriminated between those children who did and those who did not receive mental health care. Severity of voices assessed by the BPRS, as well as the level of anxiety and depression, influenced both receipt of care and voice persistence, confirming the possible role of cognitive processes in regulating appraisal of volume and frequency of the experience of voices, and the ensuing affective 
response. We saw that children with a higher score on the DES were associated with increased likelihood of voice persistence. The favourable course associated with the child being able to identify triggers in time and place (for example, only hearing voices at school or when alone in ones bedroom at night), suggests that individuals whose voices are not omnipresent (and therefore not "omnipotent") but instead limited to a circumscribed situation, are more likely to overcome the experience.

Chapter 5 contains the article Escher, A., Romme, M., Buiks, A., Delespaul, Ph., Van Os, J., (2002). 'Formation of Delusional Ideation in Adolescents Hearing Voices: A Prospective Study '(American Journal of medical Genetics, 2002, 114:913-920). Recent population-based work suggests that among children the prevalence of hallucinatory phenomena is around $8 \%$ (McGee et al., 2000). From this group around a third present with a DSM-III diagnosis, a number low enough to suggest that for the majority of hallucinating children in the general population, these experiences are non-pathological.

In patients with a diagnosis of psychotic disorder, the positive symptoms of hallucinations and delusions typically occur together (Bilder et al., 1985;Liddle, 1987; Peralta et al., 1992). Observational studies suggest that also in non-clinical samples experience of hallucinations is strongly associated with delusional ideation (Van Os et al., 2001). These observations are compatible with theories that some delusions arise secondarily in an attempt to explain abnormal perceptual experiences (De Clérambault, 1942; Maher, 1974, 1988), and that biased conscious appraisal processes are critical in the voice hearer judging that these confusing experiences are in fact externally caused (Garety et al., 2001).

Prospectively we examined what factors may influence the formation of delusions given the presence of hallucinatory experiences. We found that delusion formation over the follow-up period was associated with baseline voice appraisals and attributions such as the tone of the voices, perceived location of the voices and whether the voices resembled that of a parent. Other predictors were baseline BPRS anxiety/depression, baseline BPRS disorganisation and the baseline amount of reported recent life events. In addition in older children, the perceived influence of the voices on emotions and behaviour was strongly associated with delusion formation.

Chapter 6 contains the article Escher, Sandra., Delespaul, Philippe., Romme, Marius., Buiks, Alex., Van Os, Jim (2003). 'Coping defence and depression in adolescents hearing voices' 
(Journal of mental Health, 2003, 12 .91-99). The level of self-initiated coping defences in the face of auditory hallucinations reflects the degree to which the psychotic experiences are exceeding the person's resources (Lazarus \& Folkman, 1984). Findings in this children's study show also that the baseline level of self-initiated coping was strongly associated with baseline severity of positive symptoms of psychosis, suggesting that coping is indeed a valid measure for the degree to which individuals attempt to "defend" themselves from the experience of being overwhelmed by their psychotic experiences. In this study we found that higher levels of coping defences at baseline were strongly predictive of depression at followup, and that this association was independent of severity of baseline psychopathology dimensions, including depression. Higher levels of coping defences was also found to be independent of demographic characteristics, help-seeking and voice characteristics such as frequency, emotional tone and attributions about their origin. The findings therefore suggest that the pathway from coping defence to depression is one related to a characteristic of the person rather than a characteristic of the psychotic experience itself. It has been proposed that the individual's underlying schema of social subordination and, by implication, the tendency to feel overwhelmed by the psychotic experiences, fuels feelings of distress associated with the experiences (Birchwood et al., 2000;Romme \& Escher, 2000;Romme \& Escher, 1989). The current results therefore agree with these theories.

Chapter 7 contains the article Escher, A., Morris, M., Buiks, A., Delespaul, Ph., Van Os, J., Romme, M. (2004) 'Determinants of outcome in the pathway through care for children hearing voices'. (International Journal of social Welfare, 2004, 13, 208-222). The children's study included children who were currently receiving regular mental health care, or had been in mental health care, because of the voices. In the study these children were defined as patients. However we found that a group of the children looked for care outside the regular mental health care system. They were defined as non-patients while the children who were using mental health as well and complementary care were defined as patients. Receipt of professional help cannot be equated with the need for care or the absence of the need of care. Statistically being in care had no influence on discontinuation of the voices. However during the research period we saw substantial changes within the children that were associated with the personal development. We than developed an instrument from which 5 aspects of the developmental process could be measured:

- increase of their social network;

- awareness of a goal in life; 
- learning to cope better with emotions;

- reduction of conflicts within the family and/or at school;

- self report of positive development (which might also be confirmed by parents).

For each child a conclusion was reached in terms of one of three categories: a positive development (when four of the elements were positive); a negative development (when less than four elements were positive) or no development (no substantial change was found). The conclusion was reached by consensus of the whole team. A high correlation between discontinuation and positive development was found.

The Maastricht interview gave room for comments by the parents and children on the elements of care they thought were helpful or were not helpful. In analysing the elements 4 categories were detected that were helpful: promoting the feeling of safety; promoting support in the environment; ego-strengthening and working through problems.

When related to care, parents and children reported that care was effective and helpful when the voices were accepted, so that the therapist: recognised the experience; could make the experience more concrete; was able to help to reduce the anxiety by anxiety reducing techniques giving more control over the voices; focussed on the problems resulting from the voices such as sleep deprivation and; taught the children techniques to cope with the voices.

Overall this suggests that when voices were interpreted as a reaction to problems and not as an isolated illness, children and parents were supported to develop their own resources. The assumption that voices must be seen in association with schizophrenia made them powerless and frightened them, and the parents found it difficult to overcome their own fear in order to support their child.

Chapter 8 contains a translated version of the Dutch article, Escher \& Romme 'Het Maastrichts Interview voor Kinderen en Jeugdigen' (Tijdschrift van de vereniging voor kinder en jeugd psychotherapie, 2002, jaargang 29, nummer 4). This article gives an overview of the data from each of the items from the Maastricht Interview.

Statistically no separate element in the interview has a significant relationship with any outcome variables, supporting the idea that hearing voices is a very individual experience. However the 13 categories distinguished in the pilot study to focus on the experience itself were recognisable for the children. The interview was done mostly in the presence of their parents and the parents often expressed their surprise at the large number of questions that 
could be asked, and the fact that the children recognised and could answer these questions. During the follow-up period parents and children made comments or asked questions that suggested that they had started to think about the experience. Data from the interview could also be used to reduce the anxiety. The children were mostly unaware that other children heard voices. We also found that whilst their experiences were not exactly the same as others, more general ideas of the experience might reduce the anxiety.

In chapter 9 contains the paper Escher\& Romme, 'Stimmenhören bei Kindern. This work is published in a text edited by Thomas Bock, Klaus Dörner and Dieter Naber 'Anstősze' Zu einer antropologischen Psychiatrie. (2004) p. 211-218. Psychiatrie Verlag, Bonn. Germany. In this article the coping processes of four children from the follow-up study is reported, where during this time the voices had disappeared for all of them. Three of them reported a positive development, and all three found that they had a future and were on the road again. The fourth was a young woman, who at the start of the research was 18 years of age. She was sexually abused when she was 11 years old, and was not able to work through her traumatic experiences, having also kept them secret from her parents and her therapists. One could say that her development had stopped at the age of 15 when she stopped going to school. She has no professional education and she does not know what she wants from life. She is now 22 years of age now and still living at home.

Chapter 10 contains, Romme \& Escher, 'Trauma and hearing voices' which is accepted and going to be published in the book Understanding Trauma and Psychosis: New Horizons for Theory and Therapy. Editors: Warren Larkin \& Tony Morrison Publisher: BrunnerRoutledge, Hove.

In psychiatry, a high percentage of voice hearers are placed within the diagnostic category of schizophrenia. It is, therefore, commonly identified with this diagnosis and not with trauma.

The traditional psychiatric system of categorising psychotic disorders does not take into account the factors that lead to the disorder. It neither takes into account the relationship between the different symptoms. It denies the interaction between the symptoms and interprets all the symptoms as a consequence of the disorder. It thereby neglects the relationship of the different symptoms with the life history. In this way it mystifies the causes and thereby does not take into account the experienced traumatic events. 
From our research it became clear that in about $70 \%$ of the people hearing voices with a diagnosis of schizophrenia, hearing voices was triggered by traumatic events and a psychological vulnerability was present from childhood adversity. From our research and from epidemiological studies (Tien 1991; Eaton et al., 1991 Bijl at al., 1998), we learned that in itself hearing voices is not a psychopathological phenomenon. However it might lead to dysfunctioning and being diagnosed with an 'illness' when the person is not able to cope with their voices and with the problems in life, that lay at the roots of their voice hearing experience. In these cases we see a variation of secondary reactions that can mimic the full picture of a schizophrenia disorder but can also lead to other mental health disorders like dissociative disorders. The pathways to psychosis are showing a great variation.

\section{Conclusion}

The findings of the 3-year follow-up study of 80 children hearing voices suggest that hearing voices changes over time. The chance that the voices might disappear is quite high. The incidence of trauma found at the onset of voice hearing suggests a relation with the life history, especially trauma or problems in daily life that make the child powerless. The findings also support the literature and research that suggests that people can learn to cope with their voices. Anxiety and depression, dissociation and a high frequency of the voices are factors that influence the power relationship with the voices. Coping means that the voice hearer themselves must find ways to do it, as mental health care cannot take over this process. From this perspective it is then logical to suggest that therapy should aim at supporting the power of the voice hearer, and not by focussing only on reducing the power of the voice by medication, or by forbidding the voice hearer to talk about their experience. Voice hearing has a lot to do with a power relationship in which therapy can help to switch the power from voices to voice hearer.

\section{References}

Bernstein, E. M., Putman, F.W. (1986). 'Development,reliability and validity of a dissociation scale'. Journal of Nervous and mental Disease 174, 727-35

Bilder,R.M.,Mukherjee,S., Reider,R.O., Pandurangi,A.K. (1985). Symptomatic and neuropsychological components of defect states. Schizophrenia Bulletin, 11:409-419.

Bijl, R.V., Ravelli, A., Van Zessen. G.,(1998) Prevalence of psychotic disorder in the general population: results from the Netherlands mental health survey and incidence study. Social Psychiatry Epidemiology, 33, 587-596

Birchwood, M., Meaden, A. Tower, P., et al (2000) The power and omnipotence of voices: subordination and entrapment by voices and significant others. Psychological Medicine, 30, 337-344

De Clèrambault,G.(1942) Oevre Psychiatric. In: PUF.p.457-46. .

Eaton, W.W., Romanonski, A., Anthony, J.C. (1991) Screening for psychosis in the 
general population with a self-report interview. Journal of nervous and mental Disease 179, 689-693

Escher, A., Romme, M., Buiks, A., Delespaul, Ph., Van Os, J., (2002a) Independent course of childhood auditory hallucinations: a sequential 3-year follow-up study. British Journal of Psychiatry . 181 (suppl. 43), s10-s18

Escher, A., Romme, M., Buiks, A., Delespaul, Ph., Van Os, J., (2002b) Formation of delusional ideation in adolescents hearing voices: a prospective study. American Journal of Medical Genetics. 114: 913-920

Escher, A., Delespaul, P., Romme, M., Buiks, A., Van Os. J. (2003) Coping defence and depression in adolescents hearing voices. Journal of Mental Health. 12,1,91-99

Escher, A., Morris, M., Buiks, A., Delespaul, Ph., Van Os, J., Romme, M. (2004) Determinants of outcome in the pathways through care for children hearing voices. International Journal of social Welfare. 13, 208-222

Escher, A.D.M., Romme, M.A.J., (2004) 'Stimmenhören bei Kindern' in 'Anstösze'Zu einer antropologischen Psychiatrie. Editors. Thomas Bock, Klaus Dőrner and Dieter Naber. p. 211218. Psychiatrie Verlag, Bonn. Germany.

Escher, A.D.M.A.C. (2004) Hearing voices and its historical course, in 'an exploration of auditory hallucinations in children and adolescents'. University of Central England.

Garety, P.A., Kuipers,E., Fowler,D., Freeman,D., Beddington,P.E. (2001). A cognitive model of the positive symptoms of psychosis. Psychol. Med. 31:189-195.

Green, E.L. (1973) Some methods of evaluating behavioral variations in children age 6 to 18. Journal of the American Academy of Child Psychiatry, vol. 12 (3), 531-553

Honig, A., Romme, M.A.J., Ensink, B. Escher, S., Pennings, M., de Vries,M. (1998) Auditory Hallucinations: a comparison between patients and nonpatients. Journal of Nervous and Mental disease 186: 646-651

Lazarus, R.S., \&Folkman, S. (1984). Stress, Appraisal and Coping. New York: Springer Verlag.

Little, P.F. (1987). The symptoms of chronic schizophrenia. A re-examination of the positive-negative dichotomy. British Journal of Psychiatry. 151:145-151.

Lukoff, D., Neuchterlein, K.H., Ventura, J. (1986) Manual for expanded Brief Psychiatric Rating Scale. Schizophrenia Bulletin 12, 594-602.

Maher, B.A., (1974). Delusional thinking and perceptual disorder. Journal. Ind. Psychology. 30:98113.

Maher, B.a., (1988). Anomalous experience and delusional thinking: the logic of explanations. In: Oltmans, T.f., Maher, B.A. eds. Delusional beliefs. New York: Wiley.p.15-33

McGee, R., Williams, S., Poulton, R. (2000) Hallucinations in non-psychotic children (letter). Journal of American Academic Child and Adolescent Psychiatry 39 (1), 12-13. Overall,J.E.\&Gorham,D.R. (1962). The Brief Psychiatric Rating Scale. Psychological Report, 10,799-812.

Peralta,v., de Leon, J., Cuesta, M.J. (1992). Are there more than two syndromes in Schizophrenia? A critique of the positive-negative dichotomy. British Journal of Psychiatry. 161;335-343.

Pennings, M., Romme,M. (1996) Stemmen horen bij schizofrene patienten, patienten met een dissociatieve stoornis en niet-patienten, in: Zin in waanzin. (eds. De hert,M.,Thys,E. Peusekens., Petry, D, van Raay,B. )Babylon-de Geus, Amsterdam. P. 127-140

Romme, M.A.J. \& Escher, A.D.M.A.C. (1989) Hearing voices. Schizophrenia Bulletin, 15, (2), 209-216.

Romme, M.A.J., Honig, A., Noorthoorn, O., Escher, A.D.M.A.C. (1992) Coping with voices: an emancipatory approach. British Journal of psychiatry 161, 99-103. Romme, M.A.J., Escher, A.D.M.A.C (1993) Accepting voices. London: Mind.

Romme. M.A.J. (1996) Understanding voices. Handsell publications. Gloucester

Romme, M.A.J., Escher, A.D.M.A.C (2000). Making Sense of voices. London: Mind

Shaffer, D. Gould, M.S., Brasic, J., at al. (1983).A Children's global assessment scale (CGas). Archives of General Psychiatry,40.1228-1231.

Sidgewick, H., Johnson, A, Myers, FWH et al (1894) Report on the census of hallucinations. Proceedings of the Society for Psychical Research, 34, 25-394

Thomas, P. (1997) The Dialectics of Schizophrenia. London/ New York: Free Association Books 
Tien, A.Y. (1991) Distributions of hallucination in the population. Social Psychiatry and Psychiatric Epidemiology 26, 287-292

Van Os, J., Hanssen, M., Bijl, R.V., Ravelli, A. (2000) Strauss (1969) revisited: A psychosis continuum in the general population? Schizophrenia Research, 45, 11-20

Van Os,J,Hanssen,M,Bijl,R.v.,Vollebergh,W. (2001). Prevalence of psychotic disorder and community level of psychotic symptoms: an urban-rural comparison. Archives General Psychiatry. 58:663-668.

Verhulst, F.C., Van der Ende,J., Koot, H.M.H. et al (1996) Handleiding voor de CBCL 4-18: Sophia Kinderziekenhuis/Academisch Ziekenhuis, Erasmus Universiteit. 
Samenvatting 


\section{Samenvatting}

De onderzoeksresultaten in dit proefschrift vormen een onderdeel van een wetenschappelijke ontdekkingsreis naar de ervaring van het horen van stemmen of zoals dat in de traditionele psychiatrie genoemd wordt: 'auditieve hallucinaties'. Vanaf 1987 zijn er vanuit de vakgroep sociale psychiatrie te Maastricht verschillende studies bij volwassenen die stemmen horen gedaan; 'het stemmen horen project' (Romme \& Escher, 1989, 1993, 1996; Romme, 1996; Pennings \& Romme, 1996; Honig et al. 1998). Het uitzonderlijke aan deze studies was dat de ervaringsdeskundigheid van de stemmenhoorder centraal stond. Deze studies waren aanleiding om de ervaringen van kinderen te exploreren. In dit proefschrift staat de studie van 80 kinderen die deelnamen aan een 3-jarige vervolgstudie, centraal. De kinderen waren tussen de 8 en 19 jaar. Ze hoorden allen stemmen met de karakteristieken van een auditieve hallucinatie. Ongeveer de helft van de kinderen was in behandeling bij de reguliere gezondheidszorginstellingen vanwege het horen van stemmen (in deze studie gedefinieerd als patiënten); de overigen waren niet in reguliere behandeling (in deze studie de niet-patiënten). De studie had twee doelen. Het eerste doel was de ervaring van het stemmen horen te exploreren om te kijken of stemmen horen zoals Green et al (1993) suggereren een fenomeen is dat niet verdwijnt. We keken dan ook naar de verschillen tussen de kinderen, waarbij de stemmen verdwenen en de kinderen die de stemmen behielden. Om de ervaring in kaart te brengen hebben we een semi-gestructureerd interview (zie appendix) gebruikt waarin vragen werden gesteld over de karakteristieken van de stemmen, de inhoud van hun tekst, hun invloed, onder welke omstandigheden de stemmen kwamen en op welke manier de kinderen met de stemmen omgingen. Psychopathologie, dissociatie, sociaal functioneren en problematisch gedrag werden gemeten met andere instrumenten met respectievelijk de BPRS (Brief Psychiatric Rating Scale), de DES (Dissosiative Experience Scale), de CGas (Children's Global Assesement Scale) en de YSR (Youth Self Report).

Het tweede doel was om te kijken welke factoren van invloed zouden kunnen zijn op een hulpvraag en indien er factoren bleken te zijn, welke verschillen er zouden zijn tussen de patiënten en de niet-patiënten. Tijdens de studie werd eveneens geëxploreerd, welke elementen in de hulpverlening als behulpzaam werden ervaren en welke niet. De sociaal emotionele ontwikkeling van kinderen werd eveneens in kaart gebracht en de kinderen werden in drie categorieën ingedeeld: kinderen met een 'positieve ontwikkeling, een negatieve ontwikkeling of een ontwikkeling die gelijk gebleven was. Deze ontwikkeling werd vervolgens afgezet tegenover het aanblijven of verdwijnen van de stemmen. 


\section{Achtergrond}

In het hoofdstuk 'Introduction' wordt uiteengezet vanuit welke achtergrond we onze studies hebben gedaan. Vanaf het begin werden de ervaringen van patiënten en niet patiënten (mensen die nooit vanwege de stemmen in de reguliere hulpverlening waren geweest) met elkaar vergeleken. Er werden diverse verschillen gevonden. Zo bleken de niet-patiënten niet bang voor de stemmen te zijn, zich sterker te voelen dan de stemmen, met de stemmen overweg te kunnen en de niet-patiënten vonden dat de stemmen over het algemeen hun dagelijks leven niet of nauwelijks verstoorden. De niet-patiënten kregen eveneens meer steun vanuit hun directe omgeving.

Het stemmen horen project richtte zich niet alleen op onderzoek, maar verlegde haar grenzen naar maatschappelijke activiteiten. Er werden jaarlijkse congressen georganiseerd, waarbij stemmenhoorders, therapeuten en familieleden elkaar konden ontmoeten. Voor dit sociale aspect was bewust gekozen vanwege de sociaal psychiatrische optiek, die er vanuit gaat dat de sociale omgeving grote invloed heeft op de geestelijke gezondheid van het individu en daarom ook meegenomen moet worden. In het geval van stemmen horen houdt de invloed onder andere in, om de ervaring in een bredere context te plaatsen (te normaliseren) en het taboe er omheen te doorbreken, de stemmenhoorders hierdoor uit hun isolement te halen en hen op die manier de mogelijkheid te bieden om openlijk meer support te krijgen.

De jaarlijkse congressen werden door ongeveer 350 mensen bezocht. De vele persoonlijke reacties van stemmenhoorders en van familieleden en de aandacht die in de media aan deze congressen werd gegeven, leverden een duidelijke aanwijzing voor de noodzaak om dit probleem publiekelijk meer bespreekbaar te maken.

Het eerste initiatief voor de kinderstudie ligt in 1993. Uit het onderzoek bij volwassenen was onder meer naar voren gekomen dat 10\% van hen al stemmen hoorde in hun vroege jeugd. Dit gegeven was aanleiding om nieuwsgierig te worden naar het verloop van het stemmen horen. Was stemmen horen iets dat door de tijd heen bleef bestaan of kon het weer verdwijnen? Om te kijken of het mogelijk was om met kinderen die stemmen horen in contact te komen werd dezelfde procedure gevolgd als bij de werving van volwassenen. Romme en een kind dat stemmen hoorde deden via het populaire tv-programma van Sonja Barends, een oproep aan kinderen met een gelijke ervaring om te reageren via de stichting Correlatie. Van de 150 reacties waren er 70 van kinderen in de leeftijdsgroep die werd gezocht; kinderen van tussen de 8 en 19 jaar. Er werd een congres georganiseerd in de dierentuin Artis in Amsterdam waaraan 40 kinderen en hun ouders deelnamen. Er werd een pilotstudy gedaan en er werden 
onderzoeksgelden aangevraagd en gekregen van Zon. Daarna begon de werving. Vooral dankzij de hulp van de media slaagde ik erin om binnen een jaar 80 kinderen te werven.

In 1993 was er nog relatief weinig bekend over kinderen die stemmen horen. Er was nog geen kwalitatieve inventarisatie van de ervaring, noch was er veel kennis voorhanden over de mogelijke relatie tussen de stemmen en de sociale context. Evenmin waren er positieve factoren bekend die een invloed zouden kunnen hebben op het verloop van het horen van stemmen, door de kinderen en hun ouders zelf benoemd.

\section{De geschiedenis van het stemmen horen}

De geschiedschrijving, bevindingen van epidemiologische onderzoeken en ook ons eigen onderzoek bij volwassen stemmenhoorders waren aanleiding om ervan uit te gaan dat stemmen horen op zichzelf geen ziekte is. Echter, men kan er wel ziek van worden als men niet leert omgaan met de stemmen en met problemen of trauma in de levensgeschiedenis, die aanleiding waren tot de aanvang van het stemmen. Om dit uitgangspunt te kunnen begrijpen zal ik eerst argumenten aandragen waarom dit uitgangspunt werd gekozen.

Hoofdstuk 1 (Escher, 2004). Hierin wordt een kort overzicht gegeven over de attitude binnen de samenleving ten aanzien van het stemmen horen. Er wordt beschreven hoe de hedendaagse dominante opvatting, die gebaseerd is op het psychiatrisch model, zich door de tijd heen heeft ontwikkeld. Ik ben me ervan bewust dat het overzicht een reductie en een selectie van feiten is. Het onderwerp vraagt eigenlijk om meer aandacht. Er zijn echter al diverse wetenschappers die er een doorwrocht boek of een gedegen hoofdstuk van een boek aan hebben gewijd, zoals Slade en Bentall (1988), Thomas (1997), Watson (1998) en heel recent Blom (2003).

Binnen de psychiatrie wordt stemmen horen, auditieve hallucinaties genoemd, meestal toegeschreven aan de ziekte schizofrenie. Epidemiologische onderzoeken (Sidgewick, 1894, Romme \& Escher, 1989, Tien, 1991, Eaton, 1991, Van Os et al. 2001) alsmede de geschiedenis van de mensheid ondersteunen dit standpunt niet. Het recente negatieve beeld van stemmen horen is historisch gezien relatief jong. Aanvankelijk was er een veel positievere houding ten aanzien van deze ervaringen. In de geschiedenisboeken zijn er al beschrijvingen te vinden vanaf de vroege beschavingsvormen zoals in Babylon, Egypte, Griekenland, Rome en Tibet. Vanuit die tijd zijn er ook individuen bekend die stemmen horen zoals Socrates en figuren uit de bijbel Jezus, Mozes, Abraham, Maria en uit latere tijden Jeanne d'Arc, 
Swedenbourgh, Ghandi, Churchill, Jung en zelfs Freud. Door de tijd heen verschoof de mening ten aanzien van deze ervaring en werd het huidige dominante psychiatrische construct ontwikkeld met als gevolg dat dit eenzijdige uitgangspunt, gebaseerd op het ziektebegrip voor stemmenhoorders, een handicap is geworden (Thomas, 1997).

Hoofdstuk 2 bevat het artikel 'Hearing Voices' (Schizophrenia Bulletin, 15, (2), 209-216). Hierin wordt het experiment beschreven dat in 1987 plaatsvond en waarbij stemmenhoorders met elkaar in contact werden gebracht. Het experiment werd mogelijk nadat Professor Romme en zijn patiënt Patsy Hage, in het populaire praatprogramma 'Sonja Barend op Maandag' geïnterviewd werden. Patsy vertelde over haar eigen ervaringen met haar stemmen en Romme over het onvermogen van de psychiatrie om hier adequaat mee om te gaan. Ze deden een oproep aan stemmenhoorders om contact op te nemen via de Stichting Correlatie en kondigden eveneens aan dat er een congres voor stemmenhoorders georganiseerd zou worden.

Ongeveer 700 mensen reageerden, waarvan er 450 stemmen hoorden en 300 aan gaven dat ze niet in staat waren met de stemmen om te gaan; 150 mensen gaven aan er wel mee overweg te kunnen. Volgens de Stichting Correlatie, een organisatie die telefonische opvang doet na afloop van emotie oproepende tv-uitzendingen, was het aantal reacties extreem hoog (Langelaan, 1987). Voor Romme was de confrontatie met de grote groep niet-patiënten van veel invloed op het uitzetten van de onderzoekslijn van het project Stemmen Horen.

Mensen die de stichting Correlatie opbelden vertelden medewerkers heel verschillende aspecten over het horen van stemmen. Om meer homogene informatie te krijgen werd aan alle mensen die hadden gereageerd een vragenlijst gestuurd. Informatie die over de telefoon gegeven was, werd gebruikt en omgezet in vragen van de vragenlijst (deze vragenlijst werd later nog verder bewerkt tot het Maastrichtse interview voor stemmenhoorders).

Van de mensen die een volledig ingevulde vragenlijst terugstuurden werden er 20 geselecteerd om tijdens het congres over hun ervaringen te spreken. We hielpen (M.R., S.E.) de sprekers hun lezingen voor te bereiden en kwamen op die manier in direct contact met stemmenhoorders die nooit enige vorm van hulp voor hun stemmen hadden gezocht, zeker niet in de reguliere zorg (de groep niet-patiënten). Zij functioneerden heel goed in hun dagelijks leven.

Aan de hand van de informatie uit de vragenlijst bleken er drie fases te onderscheiden;

- de verwarringsfase; met het meestal plotselinge begin van het stemmen horen dat vaak aanvankelijk veel angst oproept; 
- de organisatiefase, met het proces van selectie van omgang, communicatie over de betekenis van de stemmen en de relatie met de levensgeschiedenis;

- de stabilisatiefase met de tijd waarin een meer uitgebalanceerde manier van omgang met de stemmen is gevonden en de stemmenhoorder zich ook meer richt op elementen in het dagelijkse leven.

In het artikel 'Hearing Voices' ligt de nadruk op effectieve en niet effectieve manieren van het omgaan met de stemmen en op de verklaringen die stemmenhoorders voor de stemmen hebben.

Eén van de hypothesen die vanuit dit eerste congres voor stemmenhoorders kon worden afgeleid is, dat de reductionistische opvatting, dat het horen van stemmen een pathologisch fenomeen is, niet erg vruchtbaar is om mensen die stemmen horen te helpen met hun ervaring om te gaan.

Hoofdstuk 3 bevat het artikel 'Coping with Hearing Voices; An Emancipatory Approach' (British Journal of Psychiatry, 1992, 161, 99-103). Het artikel in dit hoofdstuk geeft gedetailleerd informatie uit de vragenlijst die aan 450 mensen werd gestuurd, die hadden gereageerd op de tv-uitzending. Van deze mensen stuurden 186 een volledig ingevulde vragenlijst terug. Een kleine groep mensen (13) gaf aan helemaal geen hinder van de stemmen te ondervinden. Ze ervoeren de stemmen als stimulerend, als een vriend of als een raadgever. Deze respondenten werden buiten de analyses gehouden, omdat wij twijfelden of er hier sprake was van zoals de psychiatrie ze definieert, auditieve hallucinaties. Op grond van hun eigen verklaring werden de overigen respondenten (173) in twee groepen gedeeld: mensen die met de stemmen overweg konden (copers) en mensen die er niet mee overweg konden (nietcopers). De meeste respondenten hoorden langer dan 5 jaar stemmen en deze waren gekomen tussen hun $15^{\mathrm{e}}$ en $30^{\text {ste }}$ jaar. Van de 173 respondenten gaf $66 \%$ aan niet met de stemmen om te kunnen gaan. De mensen die niet met de stemmen overweg konden voelden zich beduidend minder vaak de baas over de stemmen en ervoeren de stemmen negatiever dan de copers. Mensen die met de stemmen overweg konden stelden meer grenzen en luisterden selectiever naar de stemmen. De niet-copers zochten beduidend meer afleiding als ze stemmen hoorden en stelden slechts zelden grenzen. Mensen die met de stemmen overweg konden, waren minder vaak in psychiatrische behandeling. Deze groep kreeg ook significant minder sociaal support dan de copers.

De gegevens uit het onderzoek zijn aanleiding om epidemiologische literatuur over het stemmen horen te verzamelen. Ze laten ook zien dat praten over de ervaring met de omgeving 
een belangrijk element voor support is. Communicatie tussen de chronisch psychiatrische patiënten en de stafmedewerkers van de psychiatrische afdelingen over het stemmen horen zou dan ook eerder gestimuleerd moeten worden dan verboden.

In de voorgaande hoofdstukken gingen de artikelen over het onderzoek bij volwassen. De volgende artikelen gaan over het recente onderzoek bij kinderen die stemmen horen.

Hoofdstuk 4 bevat het artikel 'Independent course of childhood auditory hallucinations: a sequential 3-year follow-up study' (British Journal of Psychiatry, 2002, 181 (suppl. 43, s1018). In deze driejarige vervolgstudie bij 80 kinderen die stemmen hoorden verdween bij $60 \%$ van de jongeren de stemmen. Interessant is dat er vier predictoren blijken te zijn voor het aanblijven van de stemmen:

- een hoog angst niveau,

- een hoge mate van depressiviteit,

- een hoge frequentie van de stemmen en

- een hoge mate van dissociëren.

Een hoge frequentie van de stemmen, een hoge mate van angst en van depressie waren zowel van invloed op het zorgpatroon als op het aanblijven van de stemmen. Deze bevindingen laten zien dat cognitieve processen een rol spelen bij de affectieve betekenis die aan de stemmen wordt gegeven. Zij zouden ook invloed kunnen hebben op de frequentie van de stemmen. Een ongunstig verloop was er te zien bij kinderen met een hogere DES-score. Deze kinderen hebben een grotere kans dat ze stemmen blijven horen.

Verder vonden we dat een gunstig verloop van het stemmen horen geassocieerd was met het vermogen van het kind om de triggers tijd en plaats te identificeren (bijvoorbeeld kind hoort alleen stemmen op school of alleen stemmen wanneer het 's nachts alleen in de eigen slaapkamer is). Dit zou kunnen betekenen dat kinderen wiens stemmen gelimiteerd aanwezig zijn in bepaalde situaties (en daardoor ook niet almachtig) een grotere kans maken om over de ervaring heen te groeien.

Hoofdstuk 5 bevat het artikel: 'Formation of Delusional Ideation in Adolescents Hearing Voices: A Prospective Study '(American Journal of medical Genetics, 2002, 114:913-920). Recent epidemiologisch onderzoek laat zien dat ongeveer 8\% van de kinderen hallucinatoire ervaringen heeft (MCGee et al. 2000). Ongeveer een derde van deze groep krijgt een DSM-III diagnose. Dit percentage is laag genoeg om te veronderstellen dat voor de meerderheid van de 
hallucinerende kinderen deze ervaringen niet pathologisch zijn. We vroegen ons af of de ontwikkeling van een waan van invloed zou kunnen zijn op het verloop van het stemmen horen.

Bij patiënten met de diagnose psychose komen positieve symptomen zoals hallucinaties en wanen gelijktijdig voor (Bilder et al., 1985; Liddle, 1987, Peralta et al, 1992). Observerende studies geven de indruk dat ook bij niet-klinische samples er een relatie is tussen hallucinaties en de ontwikkeling van wanen (van Os. et al., 1992). Deze klinische observaties komen overeen met theorieën waarin wordt verondersteld dat sommige wanen ontstaan als secondaire reactie in een poging om abnormale perceptuele ervaringen te verklaren (De Clérambault, 1942; Maher, 1974, 1988) en dat er een bias is door de kritische, bewuste waarnemingen van de stemmenhoorder zelf bij de beoordeling van die waarneming, waardoor de stemmenhoorder veronderstelt, dat zijn verwarrende ervaringen in feite veroorzaakt worden door externe factoren (Garety et al., 2001).

We hebben prospectief onderzocht welke factoren bij hallucinatoire ervaringen van invloed zouden kunnen zijn op de ontwikkeling van wanen. Over de follow-up periode troffen we aan dat de ontwikkeling van wanen geassocieerd was met baseline verklaring voor de stemmen en kenmerken van de stemmen zoals de toon, de locatie van de stemmen en of de stemmen leken op die van een ouder. Andere predictoren die we vonden, waren baseline angst/depressie, baseline verwarring en baseline gerapporteerde aantal recente life events. Bovendien bleek dat bij oudere kinderen de invloed van de stemmen op emoties en gedrag een significante relatie had met de ontwikkeling van wanen.

Hoofdstuk 6 bevat het artikel 'Coping defence and depression in adolescents hearing voices' (Journal of mental Health, 2003, 12,1.91-99). Bij auditieve hallucinaties reflecteert zelf geïnitieerde afweer door coping, de mate waarin psychotische ervaringen de individuele hulpbronnen te buiten gaan (Lazarus \& Folkman, 1984). Resultaten bij de kinderstudie laten zien dat zelf geïnitieerde coping bij baseline, geassocieerd was met baseline ernst van positieve symptomen van een psychose. Deze bevindingen laten zien dat zelf geïnitieerde coping inderdaad een valide maatstaf is voor de mate waarin individuen zich trachten te verdedigen als ze overweldigd worden door hun psychotische ervaringen.

In de kinderstudie vonden we dat coping's score bij baseline een grote voorspellende waarde had op de ontwikkeling van depressie in de drie opvolgende jaren en dit verband onafhankelijk was van de ernst van baseline psychopathologie dimensies, inclusief depressie. 
Een hogere coping's score werd eveneens gevonden, onafhankelijk van demografische kenmerken, hulpvraag, verklaringen voor de oorsprong van de stemmen en karakteristieken van de stemmen zoals frequentie en de emotionele toon. Deze bevindingen suggereren daarom dat het pad van afweer door coping naar depressie eerder gerelateerd is aan individuele kenmerken dan aan kenmerken van een psychose. In de literatuur wordt verondersteld (Birchwood, 2000; Romme \& Escher, 2000; Romme \& Escher, 1989), dat onderliggende individuele schemata van sociale ondergeschiktheid en daarmee samenhangend de neiging om zich overweldigd te voelen door psychotische ervaringen, gevoelens van angst aanwakkeren die geassocieerd zijn met deze ervaringen. De bevingen uit het kinderonderzoek komen overeen met deze veronderstellingen.

In hoofdstuk 7 staat het artikel 'Determinants of outcome in the pathway through care for children hearing voices'. (International Journal of social Welfare, 2004, 13, 208-222). In de kinderstudie kreeg ongeveer de helft van de kinderen hulp of had hulp gezocht binnen de reguliere zorg vanwege de stemmen. In de studie werden deze kinderen gedefinieerd als 'patiënten'. We vonden echter ook kinderen die geen hulp zochten en een groep kinderen die hulp zochten buiten de reguliere zorg. Deze kinderen werden gedefinieerd als 'niet-patiënten'. Dan was er ook nog een groep kinderen die zowel binnen als buiten de reguliere zorg hulp zochten. Deze kinderen werden tot de groep patiënten gerekend omdat ze in aanraking kwamen met de reguliere zorg.. We moeten ons echter bedenken dat een hulpvraag binnen de reguliere zorg niet gelijk gesteld worden met de noodzaak van zorg of geen zorg nodig hebben.

Uit de analyses bleek dat het in zorg zijn geen invloed had op het al of niet verdwijnen van de stemmen. Gedurende de onderzoeksjaren zagen we echter opmerkelijke individuele veranderingen bij kinderen die gelieerd waren aan de voortgang van hun ontwikkeling. We ontwikkelden een instrument waarmee vijf aspecten van de ontwikkeling konden worden gemeten: toename van het sociale netwerk, bewustwording van een levensdoel; beter leren omgaan met emoties; afname van conflicten thuis en/of op school; de eigen mening van het kind en/of ouders over de eigen ontwikkeling. De kinderen werden aan het eind van het onderzoek in drie categorieën ingedeeld: positieve ontwikkeling indien vier van de vijf factoren positief waren; een negatieve ontwikkeling wanneer er minder dan vier factoren positief waren en de derde categorie was geen ontwikkeling indien er geen duidelijke veranderingen waren. De conclusie over ieder kind werd gemaakt met consensus van het hele onderzoeksteam. Er was sprake van een hoge correlatie tussen het verdwijnen van de stemmen en een positieve ontwikkeling. 
Het Maastrichtse interview voor kinderen gaf aan ouders en kinderen ruimte om commentaar te geven op de elementen die ze wel of niet behulpzaam vonden. Bij de analyses van hun commentaar werden er vier elementen gevonden die als behulpzaam werden ervaren: het bevorderen van het gevoel van veiligheid; bevorderen van support in de omgeving; ego ontwikkeling en het doorwerken van problemen.

In directe relatie tot de hulpverlening rapporteerden kinderen en ouders dat het behulpzaam was als in de hulpverlening de stemmen werden geaccepteerd, sterker nog indien de therapeut de ervaring herkende (of uit eigen ervaring of omdat er ervaringskennis was met andere stemmenhoorders); indien de ervaring meer concreet gemaakt werd; indien de hulpverlener in staat was om te helpen de angst voor de stemmen te verminderen door middel van technieken die meer controle over de stemmen gaven; indien de hulpverlening aandacht gaf aan problemen die door de stemmen ontstonden zoals als gebrek aan slaap en als de kinderen technieken werden geleerd om met de stemmen om te gaan. In grote lijnen betekent dit, dat indien de stemmen werden geïnterpreteerd als een reactie op problemen en niet als een geïsoleerde ziekte, zowel kinderen als ouders aangemoedigd werden om hun eigen hulpbronnen te leren aanspreken in plaats van afhankelijk te worden van een dokter en medicatie. De veronderstelling dat de stemmen voornamelijk gezien moeten worden als symptoom van schizofrenie, maakt machteloos en makt mensen bang. Voor ouders was het dan ook moeilijker hun eigen angst te overwinnen waardoor ze niet goed in staat waren hun kind te ondersteunen.

In hoofdstuk 8 staat de vertaalde versie van het Nederlandse artikel: 'Het Maastrichts Interview voor Kinderen en Jeugdigen' (Tijdschrift van de vereniging voor Kinder- en Jeugd Psychotherapie, 2002, jaargang 29, nummer 4). Dit artikel geeft een overzicht van de data die verkregen werden bij ieder van de items uit het Maastrichtse interview.

In het interview is geen significant element te onderscheiden dat indicatief is voor het omgaan met de stemmen. Dit gegeven steunt de veronderstelling dat stemmen horen een heel individuele ervaring is. Aan de ander kant was het wel zo dat de kinderen de dertien items uit het interview en de vragen uit de items herkenden. Er is dus wel degelijk ook sprake van een gemeenschappelijkheid in meer algemene zin.

Het interview werd meestal afgenomen in het bijzijn van één van de ouders en deze waren vaak verbaasd over het grote aantal vragen die gesteld konden worden en het feit dat de kinderen de vragen herkenden en konden beantwoorden. Gedurende de drie onderzoeksjaren 
merkten onderzoekers uit vragen en commentaar dat kinderen en ouders over de ervaringen durfden te gaan nadenken. Bovendien bleek over de ervaringen te kunnen praten en aan de omgeving uit te kunnen leggen, bijvoorbeeld over de chantage van de stemmen, de angst ervoor te verminderen. Vaak waren de kinderen zich ook niet bewust dat er andere kinderen waren die ook stemmen hoorden. Kennis over de ervaringen van anderen gaf ook vermindering van angst.

In hoofdstuk 9 staat 'Stimmenhören bei Kindern'. Dit werk is gepubliceerd in het boek dat is samengesteld door Thomas Bock, Klaus Dőrner en Dieter Naber 'Anstősze Zu einer antropologischen Psychiatrie', (2004) p. 211-218. Psychiatrie Verlag, Bonn. Duitsland In dit hoofdstuk worden kwalitatieve voorbeelden gegeven van de verschillende manieren waarop vier van de kinderen die betrokken waren bij het onderzoek omgaan met hun stemmen. Bij alle vier de kinderen verdwenen de stemmen, maar het verdwijnen van de stemmen bleek niet per definitie een gunstige ontwikkeling te voorspellen. Bij de drie van de vier kinderen is er sprake van een positieve ontwikkeling. Alle drie hebben weer een toekomstperspectief en zijn terug op een levenspad dat vergeleken kan worden met hun leeftijdsgenoten. De vierde is een jonge vrouw die bij de aanvang van het onderzoek 18 jaar was. Ze was met zijn toestemming, door vrienden van haar eigen vriend, meerdere malen aangerand toen ze 11 jaar was. Ze is ervan overtuigd dat het haar eigen schuld is en blijkt niet in staat haar traumatische ervaringen te verwerken. Ze hield het trauma geheim en vertelde het noch aan haar ouders noch aan haar therapeuten. Als je naar haar ervaringen luistert dan lijkt het erop of haar ontwikkeling na haar $15^{\mathrm{e}}$ stil bleef staan, toen ze stopte met naar school gaan en begon zichzelf te beschadigen. Ze is nu 22 jaar, heeft geen enkele opleiding afgemaakt en heeft geen idee wat ze met haar leven nog wil doen.

In hoofdstuk 10 is het hoofdstuk 'Trauma and hearing voices' opgenomen. Deze bijdrage werd geaccepteerd, nog niet gepubliceerd, en is opgenomen in het boek 'Understanding Trauma and Psychosis: New Horizons for Theory and Therapy. Editors: Warren Larkin \& Tony Morrison Publisher: Brunner- Routledge, Hove.

In de psychiatrie krijgen mensen die stemmen horen vaak de diagnose schizofrenie. Hierdoor wordt stemmen horen dan ook meestal geïdentificeerd met deze diagnose en niet met trauma. Door de manier waarop de traditionele psychiatrie psychotische symptomen categoriseert, wordt er geen rekening gehouden met factoren die aanleiding zouden kunnen zijn bij het ontstaan ervan. Er wordt evenmin rekening gehouden met een relatie tussen de verschillende 
symptomen. De interactie tussen symptomen wordt ontkent en alle symptomen worden als de consequenties van een aandoening gezien. Hierdoor wordt de relatie tussen de verschillende symptomen en de levensgeschiedenis verwaarloosd Op deze manier wordt de oorzaak gemystificeerd en worden meegemaakte traumatische gebeurtenissen buiten de diagnostiek gehouden.

In ons onderzoek kwam naar voren dat bij ongeveer $70 \%$ van de mensen die stemmen hoorden en de diagnose schizofrenie gekregen hadden, het stemmen horen begonnen was naar aanleiding van een traumatische gebeurtenis en er bovendien sprake was van psychologische vulnerabiliteit vanwege traumatische ervaringen in de kindertijd. Uit ons eigen onderzoek en uit epidemiologische studies (Tien 1991; Eaton 1991 Bijl at al 2001) kwam naar voren dat stemmen horen op zichzelf geen pathologisch fenomeen is. Het kan echter wel aanleiding zijn tot disfunctioneren en daardoor gediagnosticeerd worden als 'ziekte' wanneer de persoon niet in staat is met de stemmen en met de levens problemen, die aan het stemmen horen ten grondslag liggen, om te gaan. In dergelijke gevallen zien we een variatie van secondaire reacties die het volledige ziektebeeld van de schizofrenie kunnen nabootsen en die ook aanleiding kunnen zijn voor andere geestelijke gezondheids stoornissen of andere psychiatrische ziektebeelden zoals dissociatie. De manier waarop psychosen zich ontwikkelen vertonen een grote variatie.

Omdat psychotische aandoeningen een traumatische achtergrond kunnen hebben, is de noodzaak ontstaan ervoor te zorgen dat de behandeling niet gebaseerd wordt op de traditionele psychiatrische diagnose, maar dat in de analyse van de levensgeschiedenis de relatie tussen de verschillende klachten (symptomen) naar voren komt. Bij volwassenen en bij kinderen zagen we dat de stemmen konden verdwijnen als het trauma verwerkt was of de machteloos makende situatie veranderde.

\section{Conclusie}

De resultaten van de driejarige vervolgstudie bij 80 kinderen die stemmen horen laten zien dat het stemmen horen door de tijd heen verandert. Het is zelfs zo dat het erop lijkt dat de kans dat de stemmen verdwijnen vrij groot is. De grote hoeveelheid kinderen die een trauma of machteloos makende situatie in het dagelijkse leven vermelden bij het begin van het stemmen horen, suggereert dat er een relatie is tussen het horen van stemmen en de levensgeschiedenis. Deze bevindingen, namelijk dat de omgang met de stemmen veranderen kan en dat mensen met hun stemmen kunnen leren omgaan, worden ondersteund door literatuur en onderzoek. Er zijn echter factoren die van invloed zijn op de relatie met de stemmen: een hoge mate van 
angst, depressie, dissociatie en een hoge frequentie van de stemmen. Omgaan met de stemmen betekent dat de stemmenhoorder zelf moet uitzoeken wat hem/haar past. De hulpverlening kan dit proces niet van de stemmenhoorder overnemen, hooguit ondersteunen. Vanuit dit perspectief lijkt het alleszins redelijk te suggereren dat therapie gericht moet zijn op de kracht en de hulpbronnen van de stemmenhoorder zelf. Stemmen horen heeft alles te maken met een machtsrelatie, waarbij therapie ten doel moet stellen behulpzaam te zijn om de macht te verschuiven van de stemmen naar de stemmenhoorder.

\section{References}

Bernstein, E. M., Putman, F.W. (1986). 'Development,reliability and validity of a dissociation scale'. Journal of Nervous and mental Disease 174, 727-35

Bilder,R.M.,Mukherjee,S., Reider,R.O., Pandurangi,A.K. (1985). Symptomatic and neuropsychological components of defect states. Schizophrenia Bulletin, 11:409-419.

Bijl, R.V., Ravelli, A., Van Zessen. G.,(1998) Prevalence of psychotic disorder in the general population: results from the Netherlands mental health survey and incidence study. Social Psychiatry Epidemiology, 33, 587-596

Birchwood, M., Meaden, A. Tower, P., et al (2000) The power and omnipotence of voices: subordination and entrapment by voices and significant others. Psychological Medicine, 30, 337-344

De Clèrambault,G.(1942) Oevre Psychiatric. In: PUF.p.457-46. .

Eaton, W.W., Romanonski, A., Anthony, J.C. (1991) Screening for psychosis in the general population with a self-report interview. Journal of nervous and mental Disease 179, 689-693

Escher, A., Romme, M., Buiks, A., Delespaul, Ph., Van Os, J., (2002a) Independent course of childhood auditory hallucinations: a sequential 3-year follow-up study. British Journal of Psychiatry . 181 (suppl. 43), s10-s18

Escher, A., Romme, M., Buiks, A., Delespaul, Ph., Van Os, J., (2002b) Formation of delusional ideation in adolescents hearing voices: a prospective study. American Journal of Medical Genetics. 114: 913-920

Escher, A., Delespaul, P., Romme, M., Buiks, A., Van Os. J. (2003) Coping defence and depression in adolescents hearing voices. Journal of Mental Health. 12,1,91-99

Escher, A., Morris, M., Buiks, A., Delespaul, Ph., Van Os, J., Romme, M. (2004) Determinants of outcome in the pathways through care for children hearing voices. International Journal of social Welfare. 13, 208-222

Escher, A.D.M., Romme, M.A.J., (2004) 'Stimmenhören bei Kindern' in 'Anstősze'Zu einer antropologischen Psychiatrie. Editors. Thomas Bock, Klaus Dőrner and Dieter Naber. p. 211-218. Psychiatrie Verlag, Bonn. Germany.

Escher ,A.D.M.A.C. (2004) Hearing voices and its historical course, in 'an exploration of auditory hallucinations in children and adolescents'. University of Central England.

Garety, P.A., Kuipers,E., Fowler,D., Freeman,D., Beddington,P.E. (2001). A cognitive model of the positive symptoms of psychosis. Psychol. Med. 31:189-195.

Green, E.L. (1973) Some methods of evaluating behavioral variations in children age 6 to 18. Journal of the American Academy of Child Psychiatry, vol. 12 (3), 531-553

Honig, A., Romme, M.A.J., Ensink, B. Escher, S., Pennings, M., de Vries,M. (1998) Auditory Hallucinations: a comparison between patients and nonpatients. Journal of Nervous and Mental disease 186: 646-651 
Lazarus, R.S., \&Folkman, S. (1984). Stress, Appraisal and Coping. New York: Springer Verlag.

Little, P.F. (1987). The symptoms of chronic schizophrenia. A re-examination of the positivenegative dichotomy. British Journal of Psychiatry. 151:145-151.

Lukoff, D., Neuchterlein, K.H., Ventura, J. (1986) Manual for expanded Brief Psychiatric Rating Scale. Schizophrenia Bulletin 12, 594-602.

Maher, B.A., (1974). Delusional thinking and perceptual disorder. Journal. Ind. Psychology. 30:98-113.

Maher, B.a., (1988). Anomalous experience and delusional thinking: the logic of explanations. In: Oltmans, T.f., Maher, B.A. eds. Delusional beliefs. New York: Wiley.p.15-33

McGee, R., Williams, S., Poulton, R. (2000) Hallucinations in non-psychotic children (letter). Journal of American Academic Child and Adolescent Psychiatry 39 (1), 12-13. Overall,J.E.\&Gorham,D.R. (1962). The Brief Psychiatric Rating Scale. Psychological Report, 10,799-812.

Peralta,v., de Leon, J., Cuesta, M.J. (1992). Are there more than two syndromes in Schizophrenia? A critique of the positive-negative dichotomy. British Journal of Psychiatry. 161;335-343.

Pennings, M., Romme,M. (1996) Stemmen horen bij schizofrene patienten, patienten met een dissociatieve stoornis en niet-patienten, in: Zin in waanzin. (eds. De hert,M.,Thys,E. Peusekens., Petry, D, van Raay,B. )Babylon-de Geus, Amsterdam. P. 127-140

Romme, M.A.J. \& Escher, A.D.M.A.C. (1989) Hearing voices. Schizophrenia Bulletin, 15, (2), 209-216.

Romme, M.A.J., Honig, A., Noorthoorn, O., Escher, A.D.M.A.C. (1992) Coping with voices: an emancipatory approach. British Journal of psychiatry 161, 99-103. Romme, M.A.J., Escher, A.D.M.A.C (1993) Accepting voices. London: Mind.

Romme. M.A.J. (1996) Understanding voices. Handsell publications. Gloucester

Romme, M.A.J., Escher, A.D.M.A.C (2000). Making Sense of voices. London: Mind

Shaffer, D. Gould, M.S., Brasic, J., at al. (1983).A Children's global assessment scale (CGas). Archives of General Psychiatry,40.1228-1231.

Sidgewick, H., Johnson, A, Myers, FWH et al (1894) Report on the census of hallucinations. Proceedings of the Society for Psychical Research, 34, 25-394

Thomas, P. (1997) The Dialectics of Schizophrenia. London/ New York: Free Association Books

Tien, A.Y. (1991) Distributions of hallucination in the population. Social Psychiatry and Psychiatric Epidemiology 26, 287-292

Van Os, J., Hanssen, M., Bijl, R.V., Ravelli, A. (2000) Strauss (1969) revisited: A psychosis continuum in the general population? Schizophrenia Research, 45, 11-20

Van Os,J,Hanssen,M,Bijl,R.v.,Vollebergh,W. (2001). Prevalence of psychotic disorder and community level of psychotic symptoms: an urban-rural comparison. Archives General Psychiatry. 58:663-668.

Verhulst, F.C., Van der Ende,J., Koot, H.M.H. et al (1996) Handleiding voor de CBCL 4-18: Sophia Kinderziekenhuis/Academisch Ziekenhuis, Erasmus Universiteit. 
Chapter 13

\section{Dankwoord}




\section{Dankwoord}

Dit proefschrift is het resultaat van 17 jaar arbeid met stemmenhoorders en professionelen. Ik wil dan ook veel mensen vanuit de verschillende invalshoeken bedanken voor hun medewerking, hun steun en de kennis die ze me toevertrouwden. Zonder hen had ik de moed niet gehad om me als een terriër in dit onderwerp vast te bijten.

Als eerste dank ik Marius Romme. We delen heel veel in dit leven; werk, privé en onze passie voor paardrijden. Marius is mijn soulmate. Hij was vanaf de eerste ontmoeting geïnteresseerd in mijn denken. Mijn argumenten spraken hem aan en zo stimuleerde hij me tot een uitwisseling van gedachten die de uitdaging van mijn leven werd. Dat was niet altijd even makkelijk. Bij de doop van ons eerste boek 'stemmen horen accepteren' zei hij voor een groot publiek: "Ze is de meest eigenwijze werknemer die ik ooit gehad heb, maar wel de meest creatieve." Het is ook niet voor iedere man weggelegd om een relatie met een ambitieuze vrouw in stand te houden. Ambities zijn een autonoom proces waar anderen geen controle over kunnen hebben; hoe graag ze dat ook zouden willen. Geen controle, maar wel veel invloed.

Heel belangrijk voor mij is Jim van Os. Hij vond gewoon dat ik moest promoveren. Ik ben ambitieus, maar aan promoveren had ik niet gedacht. Jim is een duizendpoot. Hij is een heel prettige, stimulerende baas. Het is niet zozeer zijn kritiek op je werk, maar zijn hoge werktempo dat je de das om kan doen. Toch heb ik niet te klagen, want hij was mild voor mij. Ik voel me door hem gewaard ook als ik plannen heb die niet helemaal in het reguliere straatje passen.

Dan was er altijd wanneer ik hem nodig dacht te hebben Philippe Delespaul. Philippe wil ik danken voor de kritische hulp bij artikelen en zijn onnoemelijk geduld. Alex Buiks en ik deden samen het kinderonderzoek. Het is altijd in prettige samenwerking verlopen. Ik zou het zo met hem over willen doen. Lydia Krabbedam bedank ook voor haar medewerking bij een extra psychologische test die we in het tweede jaar van het kinderonderzoek invoerden.

Deze mensen zijn verbonden aan mijn werklek Maastricht. Toch moet ik voor dank als eerste naar Den Haag kijken en Joop van London noemen. Zijn vertrouwen in ons werk zorgde ervoor dat we twee maal financiering kregen voor het stemmen horen project. Net als John 
Strauss, die ons eerste artikel in het Schizophrenia Bulletin mogelijk maakte, zal ook Joop misschien nooit beseffen hoe belangrijk zijn steun voor zoveel mensen is geweest.

Vanaf het eerste uur kon ik rekenen op de steun van stemmenhoorders. Voor mij was het altijd een samenwerkingsrelatie. Ik heb enorm veel van hen geleerd. Ze stonden open voor mijn vragen en gaven me vertouwen in wat ik deed. De stemmenhoordster die als eerste genoemd moet worden is Patsy Hage. Ze was aanleiding tot de andere aanpak. Marius was haar psychiater, maar in onze contacten legde ze nooit een claim op hem.

$\mathrm{Er}$ is een lange rij mensen die $\mathrm{ik}$ ontmoette als $\mathrm{ik}$ de congressen organiseerde en met wie ik lezingen maakte, of stemmenhoorders die ik ontmoette als ik me voor Weerklank inzette. Ik noem als eerste de voorzitters van Weerklank: Ans Streefland, we gaven samen nog eens lezingen in Engeland; Mieke Simons, die meer dan tien jaar het 'Weerklank' schip laveerde en Jeanette Woolthuis met wie ik de liefde voor de kinderen die stemmen horen deel. Dan ben ik dank verschuldigd aan Resi Malecki, die zo ontzettend trouw jaren lang de zuidelijke motor van Weerklank was en aan Jolanda van Hoeij voor haar vriendschap en vertrouwen. Er zijn mensen van het eerste uur die ik niet vergeten wil zoals Cobie Cramer, Minon Luursema, Anna Hofkamp, Marga Croon, Lisette de Klerk, Carla Nijnens, Rinke Riemersma, Rina Nijman en Roy Mackeloni.

Marlieke de Jonge is bijna te creatief voor de gezondheidszorg en voor zichzelf. Ze is een bron van inspiratie voor me. Dan zijn er nog de mensen van het huidige uur die stimuleren en uitdagen: Ellen Jacobson, Josien ten Dijk en Frans Wever. Dan zijn er de niet-stemmen horende bestuursleden van Weerklank die ik wil danken, Ben Steultjes en Huub Beijers ondersteunen me trouw als ik weer eens met een energie vretend voorstel kom, zoals het organiseren van een congres. Op een zelfde manier wordt ik ondersteund en gesteund in vriendschap door Maria Mens (psychologe in Oestgeest) die technieken voor groepstherapie met stemmenhoorders ontwikkelde. Ook haar dank ik Buiten Weerklank, maar wel in Maastricht zijn er Jan Verhaegh, Marietje Lemmens en Floor Brummans die ik mijn dank niet wil onthouden..

In de loop der jaren ontmoette ik 'alternatief therapeuten'. Mensen die buiten de reguliere zorg, meer vanuit hun intuïtie en vanuit hun eigen ervaringen stemmenhoorders hulp geven. Van hen leerde ik onder andere een open oor te hebben voor de grote variatie van verhalen die 
voor mij, als niet stemmenhoorder, soms vreemd of angstaanjagend waren. Ginny van Landewijk vind ik heel bijzonder en van haar kreeg ik door de jaren heen ook veel steun. In het Maastrichtse was het Lea Helledoorn die me aan kinderen voor het onderzoek hielp en ook nooit iets vroeg, alleen maar gaf.

Dan zijn er Amsterdammers waarmee ik op verschillende manieren samenwerkte: Harry van Haastert, Saskia van Dorp, Wouter de Graaf, Hans van der Wilk en Mark Jansen. Al deze mensen gaven me vriendschap en deelden informatie die ik in de loop der jaren kon gebruiken als inbreng in het project stemmen horen.

Een beetje een zijsprong bij het stemmen horen was het project rond zelfbeschadiging. Ik vond het geweldig dat Wilma Boevink me uitnodigde om samen dit taboe onderwerp meer sociaal geaccepteerd te krijgen of in ieder geval ter discussie te stellen. We organiseerden een congres en stelden een boek samen. Met behulp van ervaringsdeskundigheid van Antoinette, Anna, Marietje, Irene en vanuit een andere invalshoek van Marius Romme en Dirk Corstens was ik in staat het interview dat we voor stemmenhoorders ontwikkelden aan te passen voor zelfbeschadiging. Wilma heeft veel geduld met me gehad. Het boek kwam een jaar te laat uit, maar haar wachten is beloond want het boek is bijna voor de $2^{\text {de }}$ maal uitverkocht.

Mijn werkzaamheden bleven vanaf het begin niet tot de vakgroep en tot Nederland beperkt, maar speelden zich voor een belangrijk deel daarbuiten af. In de loop der jaren werd Engeland mijn tweede basis. Ik ken inmiddels alle uithoeken van het grote prachtige land. In het Verenigd Koninkrijk, want niet iedereen wil van Engeland weten, moet ik vele mensen danken. Ik begin bij Paul Baker, een community mental health worker, toen uit Manchester. Hij was de eerste die ons uitnodigde en die ons werk promootte. Ik ben veel dank verschuldigd aan Richard Bentall. Hij was de eerste universitaire medewerker die ons uitnodigde in Liverpool in 1990, Anny Braxcks, publishing director van Mind en een Belgische van origine, kon ons eerste boek Stemmen horen accepteren lezen en besloot het uit te geven. Dankzij deze engelse versie kwam stemmen horen accepteren de wereld over. Mind nodigt ons nog jaarlijks uit om lezingen over het boek te geven.

Als ik iemand moet bedanken dan is het Ron Coleman. Hij is denk ik, werelds meest bekende stemmenhoorder. We werkten regelmatig samen om over de omgang en acceptatie van stemmen horen te vertellen. Hij leerde me niet alleen veel, organiseerde niet alleen veel congressen samen met zijn vrouw Karen, maar gaf ook vriendschap. Ron is een netwerker. 
Hij bracht ons in contact met Mervyn Morris van de University of Central England. Mervyn ben ik heel dankbaar voor al het werk dat hij deed zodat ik mijn M.Phil kon halen. Hij heeft mijn werk gecorrigeerd en gestroomlijnd. Zonder hem was het niet mogelijk geweest mijn M.Phil te halen. Bij Ron en Mervyn hoort ook Mike Smith. Mike gaf samen met Ron, Marius en mijzelf het stemmen horen vorm binnen een module in de post graduate opleiding voor verpleegkundigen aan de Universiteit van central England in Birmingham. Mike en ik voelden een verwantschap omdat we beiden onze plaats moesten veroveren naast zeer vaardige sprekers. Hij naast Ron en ik naast Marius.

Veel steun en vriendschap ondervond ik van psychiater Phil Thomas en zijn vrouw Stella. Phil is binnen de psychiatrie in Engeland actief om ook daar een attitude verandering in gang te zetten. Ik wil Terry MacGlocglin bedanken en July Downs. Ze gaven vorm aan ons werk in Manchester, waar het Nationale Hearing Voices Netwerk huist. In Schotland wil Pat Webster bedanken en Maria Griffin en Audry Reid voor hun commentaar op ons werk. Ze zijn uniek. Louise Pembroke wil ik beslist niet vergeten. We delen de liefde voor mijn honden. Louise leerde me hoe het is om geconfronteerd te worden met zelfverwonding. Sharon Lefevere blijft in mijn herinnering zoals we wandelden met de paarden terwijl ze me vertelde over haar verleden. Alan Leader bedank ik; hij organiseerde het eerste congres in Hackeny, maar verdween daarna meer naar de achtergrond. Op dat congres was Roddy Gordon aanwezig en hij kwam jaren later weer bij ons aankloppen om meer informatie. Babs Johnston probeert haar ervaringen samen te brengen in haar werk en onderzoek. Toch heeft ze nog tijd om ons te stimuleren met haar vragen. Howell Davies uit Wales gaf ons steun en vriendschap. Een bijzonder mens die ons pad kruiste was ook Rufus May.

In Duitsland zijn er vooral de mensen in Berlijn die actief zich inzetten en ons uitnodigen. We zijn er meerdere malen geweest. Monika Hoffmann nodigde niet alleen uit, maar vertaalde ook mijn lezingen in het Duits. Zij is niet weg te denken uit het Duitse netwerk. Ik dank haar voor de warme contacten en de vriendschap die ze bood. Hannelore Klafski is een felle gesprekspartner. Haar stemmen verdwenen. Antje Muller is nu de steun en toeverlaat van het netwerk. Ook haar bedank ik voor de rijke contacten.

In Oostenrijk is er ook een groepje mensen die ons enthousiast uitnodigen en ondersteunen: Chuck Schneider, Micheala Amering, Marlene Weiterschein, en Heinz Katchnick. Ieder van hen ben ik dank verschuldigd. 
In Zwitserland is er Teresia Krummenacher. $\mathrm{Ze}$ is ervaringsdeskundige. Met veel doorzettingsvermogen kreeg ze het al twee maal voor elkaar een cursus voor professionelen te organiseren en dat is uniek. Toch zijn hierbij twee psychiaters niet weg te denken: dr. Jacob uit Basel en dr. Marlo uit Geneve.

In Zweden organiseert de psycholoog Alain Topor een jaarlijkse cursus voor een klein publiek van therapeuten en hun patiënten. Ons boek werd in het Zweeds vertaald. Een van de mensen van het eerst Zweedse uur was Lis Bodil. Noella Bickham heeft ons met veel inzet geholpen met de publicatie van het artikel in het International Journal of Social Welfare. Een van de mensen die nog steeds actief is de therapeute Siv Wetterberg die onvermoeid onze bijeenkomsten blijft bezoeken waar ze ook zijn. Ik heb veel bewondering voor de Zweedse stemmenhoordster Ami Rothnitz die met haar meereist of alleen opererend aan professionelen laat zien dat je met de stemmen om kunt leren gaan. Maths Jesperoson ben ik veel dank verschuldigd. Door de jaren heen bleef hij een heel trouwe supporter. Hij mag dan geen stemmenhoorder zijn, maar met zijn psychiatrische verleden is hij een voorvechter van de emancipatie van patiënten.

In Noorwegen werden we uitgenodigd door Geir Fredrikson en later in Oslo door Marit Borg en het daarop volgende jaar door Siri Blesvik, hoogleraar verpleegkunde. Allen waren ze actief om onze benaderingswijze voor stemmenhoorders toegankelijk te maken.

In Denemarken kwamen we op uitnodiging van Karl Bach, later volgden er congressen en cursussen in georganiseerd door Inger Mosbaek-Greve in Arhus, Nina Stenshøj in Herning en Jorn Erickson in Lungby.

In Finland werden onze ideeën ondersteund door Marja Vuorinnen. We werden er meerdere keren uitgenodigd.

In Italië is de psychiater Pino Pini samen met Donnatella Miccineci actief om het stemmen horen een andere plaats in de hulpverlening te geven.

Dan is er nog Japan waar Prof. Wakio Sato twee maal congressen organiseerde en ons bezoek onvergetelijk maakte.

In Amerika werden we uitgenodigd door Loren Mosher in Washington, Ron Diamond In Denver en door Peter Stasney in New York. De Amerikaan die ik grote dank verschuldigd ben en blijf, is John Strauss. Hij was op uitnodiging van Marten de Vries op het eerste congres voor stemmenhoorders aanwezig en fatsoeneerde ons artikel Hearing Voices voor publicatie in het Schizophrenia Bulletin. Later ontmoetten we hem weer bij Alain Topor en zetten onze discussies voort bij een glas wijn. Hij is een heel bijzonder mens. 
In eigen land is het heel moeilijk om in te schatten hoe er met de kennis die we hebben geprobeerd door te geven, wordt omgegaan. Veranderingen komen langzaam, zeker in eigen tuin, maar ze komen er wel. Dat zie ik aan het werk binnen de vakgroep en bij de RIAGG. Omdat het zo weinig zichtbaar is, is het ook moeilijker de steun te voelen. Professionelen die ik wil bedanken wonen vooral in Maastricht.

Ik werk sinds 1987 in een combinatie tussen vakgroep sociale psychiatrie en RIAGG. Voor beide ben ik een vreemde eend in de bijt. Ik was aanvankelijk geen wetenschapper, ik ben nog steeds geen therapeut. Toch hield ik het 17 jaar vol in deze ondefinieerbare plaats. Mensen die me daarbij steunden waren Harry Pommerants, die me aanstelde; Frans Metsemakers, Elisa Carter, toenmalige directeur RIAGG, die me de vrijheid gaf om door te gaan waarmee ik bezig was. Hoewel ik een vreemde eend in de bijt was, heb ik altijd veel warmte en ondersteuning ondervonden van de medewerkers van de SPD. Ik werd betrokken bij hun jaarlijkse uitjes en uitgenodigd om over mijn werk te vertellen. Het begon met Aad van Marrello, Jo Maes en nu is er Leny Vallenga. Dirk Corstens is al jaren lang degene die in de RIAGG zorgt dat de hulpverlening aan stemmenhoorders niet vergeten wordt. Dirk geeft samen met Marius en mij regelmatig lezingen, workshops, radio- en tv-uitzendingen. Hij is een fijn maatje.

In de vakgroep sociale psychiatrie is er Marten de Vries, we denken hetzelfde en doen te weinig samen.

De vakgroep is inmiddels bevolkt met veel wetenschappelijk georiënteerde jonge vrouwen, voor wie ik, doordat ik veel thuis werk of op één van onze vele reizen ben, alleen een gezicht heb. Ze vergeten me niet uit te nodigen op vakgroep uitjes en dat is heel fijn, want ik mis toch regelmatig directe collega's.

Ik heb ze wel gehad, maar die zijn inmiddels elders gaan werken of werken net als ik meer thuis. Mensen uit de eerste jaren die ik voor hun steun wil danken zijn Herman Baars, Hub Hamers, Hans Uffing, Jan Scholten, Herro Kraan en Egbert van de Poel,.

Monique Pennings werkte meer met Marius samen dan met mij. Ze is geweldig secuur en kan goed lezingen geven. Ik was best jaloers op haar. Dan waren er korte tijd Adriaan Honig, Eric Noorthoorn en Bernadinne Ensink.Colette Gijssen-Pinckaers wil ik bedanken voor haar adviezen bij het op kindermaat maken van ons onderzoeks interview. 
Bij het organiseren van de congressen kreeg ik van allerlei mensen ondersteuning zoals van Maria van Laake die hielp bij de logistiek van één van de congressen en een cursus in Cadier en Keer. Ze heeft haar eigen lijn gevonden en is deze maand zelf ook gepromoveerd. Haar dochter Goedele studeerde af onder andere met een vervolg onderzoekje bij de kinderen die in het laatste jaar nog stemmen hoorden en bij een controlegroep van kinderen die geen stemmen meer hoorden.

De secretaressen wil ik niet vergeten. Gina Habets die het eerste congres organiseerde en die bij de publicatie van het eerste boek betrokken was. Pas nadat ze weg was en ik het volgende congres zelf organiseerde, werd ik met mijn neus op de feiten gedrukt dat ze zoveel zo perfect had gedaan. Het duurde meerdere congressen voordat ik alle details door had. Thea Gorissen die haar opvolgde had er jaren later nog last van, omdat ik dan weer in een onvoorzien probleem stapte.

Dan zijn er de secretaressen die niet direct bij het project werkten maar er wel indirect mee te maken kregen. Trees Soute zwaait al jaren de scepter over een deel van de vakgroep dat op de Parallelweg is gehuisd. Ze had jaren lang last van de vele telefoontjes en berichtjes die ze voor me aan moest nemen, omdat ik weer eens niet achter mijn bureau zat. Jocelyn de Monchy heeft me bij meerdere congressen met raad en veel daden bijgestaan. Jocelyn en ook Elly Mey hebben op het secretariaat van de SPD de nodige telefoontjes verwerkt. Oud secretaresse Tiny Lucassen kwam van pensioen terug om me een hele dag te helpen de telefoon te beantwoorden die maar bleef rinkelen naar aanleiding van één van de vele tvuitzendingen. Ook het secretariaat aan de RIAGG-voordeur heeft jaren lang last gehad van het telefoongeweld dat ik over hen afriep. Hartelijk dank aan Sabine Kuypers en Annemie Cappetti.

Onmisbaar was de ondersteuning door de jaren heen van de systeembeheerders van zowel Universiteit als Riagg: Guido Frings en Ron Mengelers. Heel veel dank voor het begrip dat jullie opbrachten voor mijn gatenkaas kennis van deze hedendaagse vorm van communicatie. Ik heb genoten van de correcties die Tineke Jansse in mijn Nederlandse teksten heeft aangebracht. Ik ben dyslectisch en hoewel dat met het ouder worden beter gaat, blijf ik nog steeds met het grootste gemak taalfouten maken en ze niet herkennen. Tineke daarentegen bezit het vermogen tot taalkundige perfectie.

Ik zal ongetwijfeld nog mensen vergeten zijn. Het waren er in al die jaren ook zoveel.

Als laatste wil ik mijn moeder bedanken. Ze is al jaren lang mijn trouwste fan. Ze is inmiddels 88 en als ik haar zie dan denk ik dat ik zo wel oud wil worden. 
Tenslotte: Dit proefschrift gaat vooral over kinderen en jeugdigen die stemmen horen. Ik wil alle jongeren die aan het onderzoek hebben meegewerkt bedanken voor hun inzet en vertrouwen. Hun bijdrage was van groter belang dan ze zich hebben kunnen realiseren.

\begin{tabular}{|c|c|c|}
\hline Bernadette & Jeltje & Coen \\
\hline Bjarne & Maikel & Natasja \\
\hline Micheal & Dirk-Jan & Tamara \\
\hline Wendy & Rebecca & Kim \\
\hline Niels & Wendy & Bart \\
\hline Janneke & Christa & Karlijn \\
\hline Gijs & Sanne & Johan \\
\hline Remco & Solange & Egid \\
\hline Judith & Roy-Peter & Robbert \\
\hline Denise & Patty & Roxanne \\
\hline Mandy & Ester & Johan \\
\hline Peter & Nadia & Maarten \\
\hline Naomi & Sander & Naoimi \\
\hline Jelmer & Germaine & Nicole \\
\hline Susanne & Maarten & Jeroen \\
\hline Robert-John & Lenny & Marjanneke \\
\hline Lieke & Tijs & Joyce \\
\hline Marieke & Rolie & Joris \\
\hline Sandy & Kevin & Boeis \\
\hline Micheal & Marjolein & Pauline \\
\hline Marieke & Piko & Richard \\
\hline Mireille & Ellis & Noortje \\
\hline Dorien & Peter & Laura \\
\hline Tim & Tom & Mart \\
\hline Chantal & Hidde & Roy \\
\hline Jeroen & & \\
\hline
\end{tabular}


Curriculum Vitae 


\section{Curriculum Vitae}

Met vele voornamen in het hoofd van haar ouders werd Alexandre, Dorotheé, Marie, Adrienne, Charlotte Escher op 14-06-1945 in Den Haag geboren. In deze stad groeide ze op, evenals in Wassenaar. Na 5 jaar kostschool in Amersfoort begon ze haar opleiding tot verpleegster in Den Haag. In 1965 trouwde ze met Gerhard Blaauw, neurochirurg in opleiding. Ze stopte met werken en kreeg twee zonen: Diederik in 1968 en Rutger in 1969. Na 23 jaar kwam er een einde aan haar huwelijk.

In 1976 besloot Sandra na een depressie haar huisvrouwen bestaan uit te breiden. Ze had de tijd mee; het feminisme en de emancipatie van vrouwen was een maatschappelijk geaccepteerd fenomeen geworden. In 1977 ging in Rotterdam de 'moeder Havo' van start, een dagopleiding voor volwassenen en Sandra was één van de 26 vrouwen die in dat eerste jaar deze opleiding ging volgen. Na haar eindexamen werd ze uitgeloot voor de school van de Journalistiek in Utrecht. Ze deed colloquium doctum, studeerde een jaar sociologie in Rotterdam en begon het daarop volgende jaar, nadat ze wel was ingeloot, aan haar journalistieke opleiding. Ze deed twee stages: bij het maandblad 'Opzij' en bij de vakgroep sociale psychiatrie waar ze medewerkers hielp met het schrijven van artikelen. Na haar opleiding bleef ze werkzaam bij deze vakgroep in een samenwerkingsverband tussen Universiteit en RIAGG. Dit werkverband is blijven bestaan en van belang gebleven.

$\mathrm{Na}$ een overweldigende publieke response naar aanleiding van het televisieoptreden van Prof. dr. M. Romme en Patsy Hage in 1987, richtten Sandra haar werkzaamheden zich op onderzoek met stemmenhoorders. Het was het begin van de ontwikkeling van een attitude die erop gericht was de ervaring van stemmenhoorders in de hulpverlening te gaan gebruiken.

In 1989 werd, dankzij de financiering van het Preventiefonds, een vierjarig project stemmen horen begonnen. Sandra interviewde vanuit haar journalistieke achtergrond, stemmenhoorders over hun ervaringen, hielp hen met lezingen maken en organiseerde 7 jaarlijkse congressen voor stemmenhoorders, therapeuten en familieleden. Rond de druk bezochte congressen was er meestal nogal wat mediabelangstelling die voor veel werk zorgde. Iedere tv-uitzending werd gevolgd door een storm van telefoontjes van mensen die hulp zochten. Buitenlandse media maakten een documentaire over het project stemmen horen, zoals de BBC en de Duitse televisiezenders Nord-West Rundfunk en Süd-West Rundfunk.

De werkzaamheden uit deze projectfase resulteerden in de ontwikkeling van een benaderingswijze voor de hulpverlening en leverden publicaties op die aanvankelijk in het Engels en vervolgens in meerdere talen vertaald werden, zoals Fins, Italiaans Portugees, Duits, Zweeds, Russisch, Deens, Tsjechisch en binnenkort in het Spaans.

In 1996 financierde Zon het kinderonderzoek, het onderwerp van deze dissertatie. In 1999 ging Marius Romme met pensioen. Het huidige hoofd van de vakgroep Psychiatrie en Neuropsychologie Prof. dr. Jim van Os stimuleerde Sandra om dit onderzoek te bewerken in een proefschrift. Als basis hiervoor haalde ze eerst in 2004 haar M.Phil in Birmingham.

Behalve congressen over stemmen horen organiseerde Sandra nog samen met Wilma Boevink (Trimbosinstituut) een congres over zelfbeschadiging. Ervaringsverhalen werden samen met de lezingen van hulpverleners gepubliceerd in het congresboek 'Zelfbeschadiging begrijpelijk maken'. Sandra was jaren lang een actief lid van de Stichting Weerklank, zat in de redactie van de Klankspiegel. Momenteel lid van de Raad van Advies van de cliëntenbond in Utrecht. $\mathrm{Ze}$ is sinds 1999 'honorary research fellow' aan de University of Central England in Birmingham.

Sandra Escher is in 1996 gehuwd met Marius Romme. Ze is oma van Stan, Fleur, Arlen en sinds februari van Bobette. 
Chapter 14

\section{Publications}




\section{Publications}

\section{Articles}

Butenaerts, J.L.M.G., Romme, M.A.J. \& Escher, A.D.M.A.C. (1999).Cognitieve therapie bij psychose en stemmen horen. Tijdschrift voor Psychiatrie.p.277-284

Escher,A.D.M.A.C., Romme, M.A.J.,Breuls,M.,Driessen,G., (1987).Maatschappelijk kwetsbaar en langdurig psychiatrisch ziek zijn. Tijdschrift voor Psychiatrie, 29:5,266281.

Escher, A.D.M.A.C.,Romme, M.A.J.(1989).Stemmen horen. Positieve effecten van leren omgaan met stemmen. Tijdschrift voor Ziekenverpleging 24, p. 784-788,

Escher, A.D.M.A.C.,Romme, M.A.J.(1991).Het dagboek als communicatiemiddel bij auditieve hallucinaties. Tijdschrift voor Ziekenverpleging (TVZ) 15 augustus 1991 543547

Escher., A.D.M.A.C. (1993)Stemmen horen: ziekte, gave, topervaring of fase in een groeiproces? Klankspiegel, maart 1993

Escher, A., Romme, M. (1998) Small talk: voice-hearing in Children. Open Mind July/August.

Escher, A., Romme, M., Buiks, A., Delespaul, Ph., Van Os, J., (2002a) Independent course of childhood auditory hallucinations: a sequential 3-year follow-up study. British Journal of Psychiatry . 181 (suppl. 43), s10-s18

Escher, A., Romme, M., Buiks, A., Delespaul, Ph., Van Os, J., (2002b) Formation of delusional ideation in adolescents hearing voices: a prospective study. American Journal of Medical Genetics. 114: 913-920

Escher, A.D.M., Romme,M.A.J., Buiks, A., Delespaul, Ph., Van Os, J., (2002) Kinderen en jeugdigen die stemmen horen: een prospectief driejarig onderzoek. Tijdschrift van de Vereniging voor kinder en jeugdpsychotherapie. Jaargang 29, nr. 4. blz. 4-21.

Escher, A., Romme, M., (2002). Het Maastrichts Interview voor kinderen en Jeugdigen (MIK). Tijdschrift van de Vereniging voor kinder en jeugdpsychotherapie. Jaargang 29, nr. 4. blz. 22-45.

Escher, A., Delespaul, P., Romme, M., Buiks, A., Van Os. J. (2003) Coping defence and depression in adolescents hearing voices. Journal of Mental Health. 12,1,91-99

Escher, A. D., Romme, M. A., et al. (2003). Formación de la ideación delirante en adolescentes con alucinaciones auditivas: un estudio prospectivo. Intervención en crisis y tratamiento agudo de los trastornos psiquiátricos graves. P. Pichot, J. Ezcurra, A. González-Pinto and M. Gutiérrz Fraile. Madrid, Aula Médica Ediciones: 185-208.

Escher, A., Morris, M., Buiks, A., Delespaul, Ph., Van Os, J., Romme, M. (2004) Determinants of outcome in the pathways through care for children hearing voices. International Journal of social Welfare. 13, 208-222

Noorthoorn, E.,Dijkman,C., Escher,A., Romme,M. (1988) Resultaten van de enquête, in Omgaan met stemmen horen. Blz. 199-214. Uitgever; Vakgroep Sociale psychiatrie, Rijksuniversiteit Limburg.

Noorthoorn,O., Romme,M.A.J.,Escher A.D.M.A.C. (1990). Wat kunnen mensen die stemmen horen de psychiatrie leren?. Sociale Dienstverlening in Nederland. Analyse en evaluatie (Red. E.K. Hicks) p. 60-70

Romme, M.A.J.,Escher,A.,Radstake,D.,Breuls,M(1987). Een indeling in groepen van patiënten met een langdurige psychiatrische patiëntencarrière. Tijdschrift voor Psychiatrie, 29,4,197-211.

Romme, M.A.J. \& Escher, A.D.M.A.C. (1987) Leren omgaan met het horen van stemmen. Maandblad Geestelijk Volksgezondheid 718, p 825-831. 
Romme, M.A.J. \& Escher, A.D.M.A.C. (1989) Hearing Voices. Schizophrenia Bulletin, 15, (2), 209-216.

Romme, M.A.J. \& Escher, A.D.M.A.C. (1989). Effects of mutual contacts from people with auditory hallucinations. Perspectief no 3, 37-43, juli 1989

Romme, M.A.J. \& Escher, A.D.M.A.C. (1989). Stimmen hören in Kontakt, Zeitschrift der HPE Österreich nr 116, Oktober 1989

Romme, M.A.J., Escher,A.D.M.A.C. (1990) Effecten van het onderlinge contact tussen mensen die stemmen horen. Oostland no 2, 8-14,

Romme, M.A.J. \& Escher, A.D.M.A.C. (1990). Heard but not seen. Open Mind No 49, 16-18,

Romme, M.A.J. \& Escher, A.D.M.A.C. (1991). Sense in voices. Open Mind 53, The mental health magazine, 9 November

Romme, M.A.J. \& Escher, A.D.M.A.C. (1991).Undire le Voci. Spazi della Menten nr. 8, december 1991 p 3-9

Romme, M.A.J., Honig, A., Noorthoorn, O., Escher, A.D.M.A.C. (1992) Coping with voices: an emancipatory approach. British Journal of psychiatry 161, 99-103.

Romme, M.A.J. \& Escher, A.D.M.A.C. (1993).Hearing Voices (Vertaling artikel uit Schizophrenia Bulletin 15-1, 1989). The Japanese Journal of Clinical Psychology, October 1993, Vo 31, no 2, 65-76

Romme,M., \& Escher,A. (2002). Effectieve en minder effectieve behandelingen van stemmen horen bij kinderen en jeugdigen. Tijdschrift van de Vereniging voor kinder en jeugdpsychotherapie. Jaargang 29, nr. 4. blz. 46-66. .

Romme \& Escher (2005). Managing Distressing Voice Hearing Experiences In Wellness Recovery Action Plan. Mary Ellen Copeland edited by Piers Allott. P.Sefton Recovery Group, Liverpool, UK. P. 114-118.

\section{Chapters}

Escher,A.D.M.A.C, van Laarhoven,J., (1988) Stemmen horen in de ambulante psychiatrische praktijk, in Omgaan met stemmen horen blz. 156-161.

Escher,A.,Hage,P.,Romme.M., (1998). Maastricht interview with a voice hearer, in Understanding voices, coping with auditory hallucinations and confusing realities. Romme, M. ed. Handsell Publications.Gloucester. UK. p. 57-57.

Escher,A.D.M.C., Romme,M.A.J., Breuls, M.G.G.J.,Driessen,G. (1988). Social vulnerability and prolonged psychiatric illness in Research to practice in community Psychiatry. Romme \& Escher eds. van Gorkum, Maastricht/Assen p. 12-24..

Escher,A. (1999) 'Dagboek; eigen ervaringen leren begrijpen en herkennen' in Romme \& Escher eds. Stemmen horen accepteren'Tirion, Baarn blz. 201-216.

Escher,A.D.M.,Romme,M.A.J., (2004) 'Stimmenhören bei Kindern' in 'Anstősze'Zu einer antropologischen Psychiatrie. Editors. Thomas Bock, Klaus Dőrner and Dieter Naber. p. 211218. Psychiatrie Verlag, Bonn. Duitsland.

Romme,M.A.J., Escher,A.D.M.C., Radstake,D.W.S.,Breuls, M.G.G.J. (1988).Group differentiation of chronically mentally ill in the community. An instrument for adequate treatment planning in Research to practice in community Psychiatry. Romme \& Escher eds. van Gorkum, Maastricht/Assen. p. 25-35.

Uffing,J.T.F., de Vries, E.A.A.M., Rotteveel,R.J., Escher,A.D.M.A.C. (1988). Do chronic mental patients get the appropriate ambulatory treatment? in Research to practice in community Psychiatry. Romme \& Escher eds. van Gorkum, Maastricht/Assen. p. 44-50.

Romme,M.A.J., Escher,A.D.M.A.C. (1988) Hearing Voices in Research to practice in community Psychiatry. Romme \& Escher eds. van Gorkum, Maastricht/Assen. p. 85-92. 
Romme, M.A.J.\& ,Escher, A.D.M.A.C (1996) Empowering people who hear voices. in Hadock \& Slade (eds.) Cognitive Behavioural Interventions with Psychotic Disorders'. Routledge, London UK. Chapter 8, page 137-150.

Romme,M.A.J., Escher,A.D.M.A.C. (1998) Understanding voices in psicologia e Sociedade.

Ciclo de Conferěncias. Duarte Gomes,A., e Pires Valentim (orgs.). Universitade de

Coimbra.

Romme,M., \& Escher,A. (2005) Trauma and Hearing voices in Understanding Trauma and Psychosis: New Horizons for Theory and Therapy. Editors: Warren Larkin \& Tony Morrison Publisher: Brunner- Routledge, Hove. (in press).

\section{Books}

Boevink, W., Escher, S. (eds.). (2001) Zelfverwonding begrijpelijk maken. St. Positieve Gezondheidzorg. Bemelen: Netherlands

Sandra Blaauw-Escher (1987). 150 jaar Rotterdamse Manege. Stichting tot Instandhouding van de Rotterdamsche Manège.

Sandra Escher \& Boudewijn Commandeur (1999). 70 jaar NRSV. Nederlandse Ruiter Sport Vereniging.

Romme,M.A.J., Escher,A.D.M.A.C. (1988).eds. Research to practice in Community Psychiatry. van Gorkum, Maastricht/Assen.

Romme, M.A.J., Escher,A.D.M.A.C., Habets, V.P.M.J.H.(1988). Omgaan met stemmen horen. (red). Universiteit Maastricht, vakgroep sociale Psychiatrie.

Romme, M.A.J., Escher, A.D.M.A.C (1993) Eds. Accepting voices. London: Mind.

Romme, M.A.J., Escher, A.D.M.A.C (1997) Stimmen hören akzeptieren. Psychiatrie-Verlag. Bonn.

Romme, M.A.J., Escher, A.D.M.A.C (1997) Acceptare le voice. Giuffrè editore. Milano

Romme, M.A.J., Escher, A.D.M.A.C (1997) Na compananhia das voces. Editorial Estampa, Lda., Lisboa Portugal

Romme, M.A.J., Escher, A.D.M.A.C (1997) Moniääniset. Printway Oy, Vantaa.Finland.

Romme, M.A.J., Escher, A.D.M.A.C. (1998) Призиание Годосов. Geneva Initiative on Psychiatrie, Zwitserland.

Romme, M.A.J., Escher, A.D.M.A.C. (1999). Omgaan met stemmen horen. Stichting Positieve Gezondheidszorg. Bemelen.

Romme, M.A.J., Escher, A.D.M.A.C. (1999) Stemmen horen accepteren. Tirion, Baarn.

Romme, M.A.J., Escher, A.D.M.A.C. (1999) Stimmenhören Akzeptieren, Neunplus 1 Berlin. Duitsland.

Romme, M.A.J., Escher, A.D.M.A.C (2000). Making Sense of voices. London: Mind

Romme, M.A.J., Escher, A.D.M.A.C (2003) Förstå och hantera roster. RSNH. Riksförbundet för Social och Mental Hälsa.Stockholm. Sweden

Romme, M.A.J., Escher, A.D.M.A.C (2003) Giv stemmerne mening. Systime Academic. Århus, Denmark. 


\section{Appendix}

\section{Maastricht Interview for children and adolescents who hear voices}




\section{MAASTRICHT INTERVIEW WITH A CHILD OR ADELSCENT WHO HEARS VOICES (MIC)}

Name voice hearer:

Name interviewer:

Address:

Telephone number:

Age:

Gender

Living situation

Kind of school

Class/group?

or

do you work or follow a study?.

Date interview:

year.

Case nummer:

(C) A.D.M. Escher, M.Phil \& Prof.Dr. M.A.J. Romme, social psychiatrist

Maastricht Universiteit, Postbus 616, 6200 MD Maastricht

e-mail: a.escher@skynet.be 
1. I would like you to tell me about your experience.

Do you hear voices?

1.2 Do you hear sounds or music? Can de sounds/voices you hear also be heard by other people? Can you explain why?

1.3 Do you have other perceptions? Do you see visions or colours?

If yes, could you describe them?

1.4 Where do the voice(s)/sounds come from (where are they located)? Your head, your ears (left/right/both), or somewhere else within your body?

1.5 Concerning the voices you hear, are these voices coming from your own person or are they from somebody or something else? Can you explain why?

1.6 Do you hear the voices in your bed only, or do you hear them during daytime?

Or both? 
To be concluded by the interviewer: does the voices-hearing possess the same or similar characteristics as an auditory hallucination

(as it is understood within psychiatry)

1. The respondent can hear voices that others cannot hear yes/no

2. The respondent hears voices through the ears

yes/no

3 . The respondent hears voices in his/her head

yes/no

4. The respondent is able to maintain a dialogue

yes/no

or other method of communication

5. The voices are experienced as me (1) or not-me (2)

$1 / 2$

6 . The voices are only sleep related

yes/no

\section{CHARACTERISTICS OF THE VOICES}

2.1 Do you hear one or more voices? How many? Are the voices always the same voices? Has it always been like this? Or has the number of voices ever changed?

2.2 I want to talk about the five most important voices. We start with the first voice and than I will ask the same questions about the other voices. Does your most important voice has a name? An age? What gender does the voice have? In what kind of tone do the voices talk to you? Are they kind or aggressive? How frequently do you hear this voice?

\begin{tabular}{|l|l|l|l|l|l|}
\hline No & name & age & gender & contents/tone & frequency \\
\hline 1 & & & & & \\
\hline 2 & & & & & \\
\hline 3 & & & & & \\
\hline 4 & & & & & \\
\hline 5 & & & & & \\
\hline
\end{tabular}

2.3 Does the manner or tone of the voices remind you of someone one you know or used to know? If yes, who? 
2.4 Have the voices ever disappeared and returned?

Did anything change in your live when they disappeared and when they came back?

If yes, can you tell what changed?

\section{HISTORY OF VOICE HEARING}

3.1 I would like you to remember the moment you started to hear voices for the first time. Could you tell me how old you were? How you lived? Had anything happened to you? Let us follow the list. I will first ask you if the event/circumstances happened in your live. Than I will ask you if it was the start of the voice hearing or whether the voices changed.

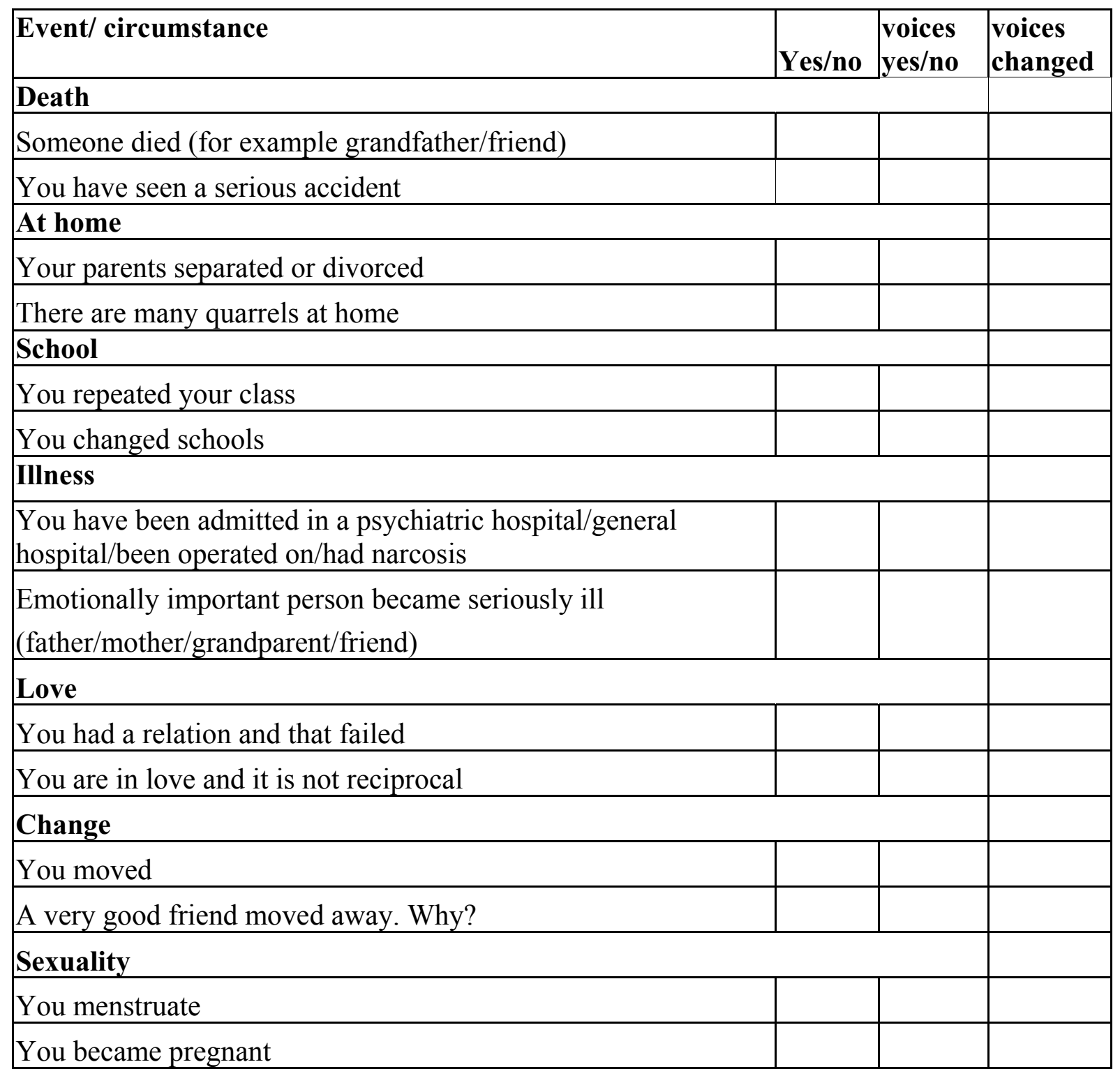




\begin{tabular}{|l|l|l|l|}
\hline You had an abortion & & & \\
\hline You were sexually abused? You saw others sexually abused? & & & \\
\hline You feel attracted by someone of the same sex? & & & \\
\hline We left out something that you felt was traumatic. What & & & \\
\hline
\end{tabular}

[ ] Have you ever tried to talk with other about the trauma/circumstances?

[ ] do you still want to talk about it?

[ ] do you feel you want revenge?

[ ] Do you feel powerless because of it?

[ ] Do you feel guilty?

What do the voices say about the event/trauma?

Suppose that you started to hear voices after some kind of trauma, for example when you failt an important test paper, do the voices react when you have to do an other test paper ?

Please tell me more about it.

yes/no

4 TRIGGERS

4.1 Do the voice come at a specific time (for example in the evening), at specific places (for example in your bedroom or in the class), at specific activities (for example playing outside, making homework)?

Yes/no

4.2.1 Have you ever noticed whether the voices are present when you feel certain emotions? Let us check this list. And can you describe how the voices react? For instance are they comforting, helpful or frightening and unhelpful

emotion

reaction of the voices

[]when you are angry

[] when you are afraid

[] when you are sad

[] when you are tired

[] when you doubt what to do....

[] when you feel guilty

[] when you feel lonely

[] when you are glad/in love

How do you normally cope with these emotions that trigger the voices. Are you able to

[] feel them 
[] express them,

[] controle them

[] talk about them

If not, could you explain why not?

\section{CONTENT OF THE VOICES}

5.2 the voices, are they friendly? $\quad$ Yes/no

Are they nasty? $\quad$ Yes/no

Do the voices command you?

Yes/no

Do you do what they command and if yes, why?

yes/no

Do the voice blackmail you?

Yes/no

Can you give an example?

Some children tell that the voices took over choosing thing. Does this happen with you? Yes/no

Are you able to make your own choices? Do you have a system for it? Yes/no

I would like to ask what kind of impact the voices have on your way of life.

6.1 Do the voices make you sad? Yes/no

Angry?

Yes/no

Do they frighten you?

Yes/no

Can they make you happy?

Yes/no

Do the voices confuse you?

Yes/no

Do the voices influence your mood at home

Yes/no

Do the voices influence your mood at school

Yes/no

Do the voices influence your mood in social contacts

Yes/no 
6.2 do the voices make that

you are unable to make your homework $\quad$ Yes/no

$\begin{array}{ll}\text { you start to quarrel with others } & \text { Yes/no }\end{array}$

you do something you will be punished over $\quad$ Yes/no

you run away $\quad$ Yes/no

you do something that you actually don't want to do Yes/no

do the voice make that

$\begin{array}{ll}\text { you feel not alone } & \text { Yes/no }\end{array}$

do they help you (give a solution to a problem or help with a choice) Yes/no

$\begin{array}{ll}\text { gives you advice } & \text { Yes/no }\end{array}$

Does the influence of the voices has consequences

for your behaviour at home? Yes/no

you behaviour at school? Yes/no

$\begin{array}{ll}\text { your behaviour in social contacts } & \text { Yes/no }\end{array}$

6.3 How do you feel about the voices ?How do you experience the voices as:

$\begin{array}{llr} & \text { now } & \text { in the past } \\ \text { predominately positive voices } & \text { yes/no } & \text { yes/no } \\ \text { predominately negative voices } & \text { yes/no } & \text { yes/no } \\ \text { neutral } & \text { yes/no } & \text { yes/no } \\ \text { negative as well as positive } & \text { yes/no } & \text { yes/no }\end{array}$

\section{INTERPRETATION OF THE VOICES}

7.1 For example if you hear the voice of you deceased grandfather do you might think the origin of the voices is related to an other world. Or if you hear the voice of the holy mother Marie you might think that the voice is related to religion. Or you voice might be related to telepathy. What do you think is the origin of your voices? Do all your voices have the same origin?.

Religion (devil, God, Maria, Jesus, angles) $\quad$ Yes/no

$\begin{array}{ll}\text { Ghosts or phantoms } & \text { Yes/no }\end{array}$

A (exceptional) gift (predicting the future or

$\begin{array}{ll}\text { thoughts of reading other peoples mind) } & \text { Yes/no }\end{array}$ 
A disease

An other world? (fantasy, different hemisphere)?

Yes/no

Different explanation

Are you able to talk to the voice?

Yes/no

Do the voices listen to you as well?

Yes/no

Do they respect you?

Yes/no

Do they agree with you?

Yes/no

Are you able to call the voices?

Yes/no

Do they come?

Yes/no

Are you able to shut yourself off from the voices?

Yes/no

Who is the boss?

you:

Yes/no

the voices

Yes/no

both

Yes/no

\section{COPING}

I would like to know what you do, how you cope with the voices. How active or passive you are.

\section{Cognitieve strategieën}

\begin{tabular}{|c|c|c|c|}
\hline nr. & strategy & Yes/no & Does it work \\
\hline 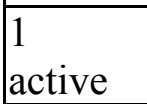 & Send the voices away & & \\
\hline $\begin{array}{l}2 \\
\text { active }\end{array}$ & Make a deal with the voices & & \\
\hline $\begin{array}{l}3 \\
\text { active }\end{array}$ & Listen to the nice things only & & \\
\hline \begin{tabular}{|l|}
4 \\
passive
\end{tabular} & Ignore the voices & & \\
\hline $\begin{array}{l}5 \\
\text { passive }\end{array}$ & Think about something else & & \\
\hline \begin{tabular}{|l|}
6 \\
passive
\end{tabular} & Concentrate on the voices & & \\
\hline $\begin{array}{l}7 \\
\text { passive }\end{array}$ & Scold to the voices & & \\
\hline
\end{tabular}




Behavioural strategy
\begin{tabular}{|l|l|l|l|}
\hline $\mathrm{nr}$ & strategy & Yes/no & Does it work \\
\hline $\begin{array}{l}8 \\
\text { active }\end{array}$ & $\begin{array}{l}\text { Do something (go shopping, take } \\
\text { shower) }\end{array}$ & & \\
\hline $\begin{array}{l}9 \\
\text { active }\end{array}$ & Close yourself off from the voices & & \\
\hline $\begin{array}{l}10 \\
\text { active }\end{array}$ & Distraction (TV, reading) & & \\
\hline $\begin{array}{l}11 \\
\text { active }\end{array}$ & Write about the voices (diary) & & \\
\hline $\begin{array}{l}12 \\
\text { passive }\end{array}$ & Telephone/visit someone & & \\
\hline $\begin{array}{l}13 \\
\text { passive }\end{array}$ & Run away for the voices & & \\
\hline $\begin{array}{l}14 \\
\text { passive }\end{array}$ & Perform rituals & & \\
\hline
\end{tabular}

\section{Physiological strategy}

\begin{tabular}{|l|l|l|l|}
\hline $\mathrm{nr}$ & strategy & Yes/no & Does it work \\
\hline $\begin{array}{l}15 \\
\text { active }\end{array}$ & Make a drawing of the voices & & \\
\hline $\begin{array}{l}16 \\
\text { passive }\end{array}$ & Take medication & & \\
\hline $\begin{array}{l}17 \\
\text { passive }\end{array}$ & Use alcohol or drugs & \\
\hline $\begin{array}{l}18 \\
\text { passive }\end{array}$ & Eat food or sweets & & \\
\hline
\end{tabular}

9.19 Do you feel you are in control?

Yes/no

9.20 Has this changed over time?

Yes/no

9.21 Do you still use your first coping strategy?

Yes/no

\section{MEDICAL HISTORY}

10.1 Did you ever got therapy ? Did you ever got therapy because of the voices? Which kind of therapist?

\begin{tabular}{|l|l|l|l|l|}
\hline year & clinic/ambulant & kind of therapist & lengths & $\begin{array}{l}\text { indication for } \\
\text { treatment }\end{array}$ \\
\hline & & & & \\
\hline & & & & \\
\hline & & & & \\
\hline & & & & \\
\hline & & & & \\
\hline & & & & \\
\hline
\end{tabular}

10.2 What did the therapist do in relation to the voices? 
10.3 With which therapist did you talk about the voices ?

Do you want me to send a report of this interview to your therapist/G.P. ?

Name en address to the person I have to send it to.

\section{SOCIAL NETWORK}

Contact with others is an important part of life. First, I would like to ask you to tell me about the person with whom you have a personal relationship and other persons that are important to you. The order is not important and you are not required to give complete names. Initials or something like Grandmother or friend is sufficient.

RESPONSE FILE SOCIAL NETWORK

\begin{tabular}{|c|c|l|l|}
\hline NO & NAME & $\begin{array}{l}\text { knows about the } \\
\text { voices yes/no }\end{array}$ & $\begin{array}{l}\text { talks about the voices } \\
\text { yes/no }\end{array}$ \\
\hline 01 & & & \\
\hline 02 & & & \\
\hline 03 & & & \\
\hline 04 & & & \\
\hline 05 & & & \\
\hline 06 & & & \\
\hline 07 & & & \\
\hline 08 & & & \\
\hline
\end{tabular}

Does hearing voices occur within the family?

Yes/no 
To be conducted by interviewer. To the judgement of the interviewer do the voices have a relation with the life history ? ( also to be discussed with the child/adolescent to see if there is consensus)

\begin{tabular}{|c|c|c|}
\hline Relation with the life history & Interviewer & respondent \\
\hline $\begin{array}{l}\text { a traumatic } \\
\text { event/circumstances }\end{array}$ & 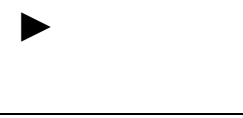 & 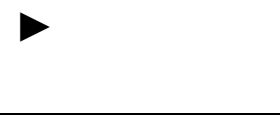 \\
\hline $\begin{array}{l}\text { too high expectations by social } \\
\text { environment (school/at home/self) }\end{array}$ & $\nabla$ & $>$ \\
\hline $\begin{array}{l}\text { Physical condition (birth } \\
\text { trauma) }\end{array}$ & $>$ & $>$ \\
\hline $\begin{array}{l}\text { a paranormal explanation } \\
\text { (acceptance from parents?) }\end{array}$ & $>$ & $>$ \\
\hline $\begin{array}{l}\text { exceptional position within } \\
\text { family or at school }\end{array}$ & $>$ & $>$ \\
\hline $\begin{array}{l}\text { not being able to express } \\
\text { emotion }\end{array}$ & $>$ & $>$ \\
\hline
\end{tabular}

For the report the most important information per interview item

\section{Nature of the experience.}

Is it a auditory hallucination?

Do the voice hearer has other perceptions like aura, hears music of hear voices?.

2 Characteristics of the voices

What is the age and gender

Do they resemble anyone?

Are the voices threatening?

How often are they heard?

\section{History of voice hearing}

Is there any trauma/powerless making situation. In what situation lives the child at the onset of the voice hearing.

Have the voices changed from positive to negative and at what age

\section{$4 \quad$ Triggers}

Are there triggers like time/place or activity 
Are there emotional triggers? Is the child able to talk about emotions, express them and control them,?

\section{Content of the voices}

Are the voices negative/positive? What issues do the voices talk about?

\section{Influence of the voices on:}

Emotions

Behaviour at home/school/social contacts

Consequences of the influence at the behaviour at home/at school/ in social contacts

How are the voices experienced?

\section{Origin}

Is the explanation for the origin making powerless?

\section{$8 \quad$ Relation with the voices}

Does the voice hearer has influence?

\section{$9 \quad$ Coping}

How active/passive is the voice hearer in coping with the voice?

\section{Social Network}

How many people know about the voices

11 Is there a relation between the voices and the life history?

Does the voice hearer agree?

\section{Does voice hearing occur within the family?}

13 Scores on the Brief Psychiatric Rating Scale (BPRS) and Dissociative Experience Scale (DES). High scores on anxiety, depression, frequency of the voices and dissociation are predictors for the ongoing of the voices. : 